NIST Special Publication 1600

\title{
Economics of Community Disaster Resilience Workshop Proceedings
}

Bilal M. Ayyub

Robert E. Chapman

Gerald E. Galloway

Richard N. Wright

This publication is available free of charge from:

http://dx.doi.org/10.6028/NIST.SP.1600
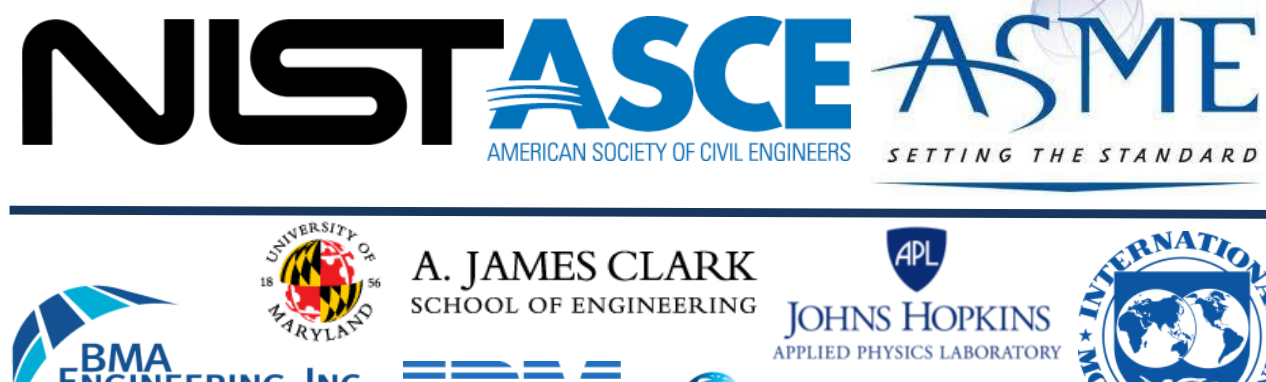

A. JAMES CLARK

SCHOOL OF ENGINEERING

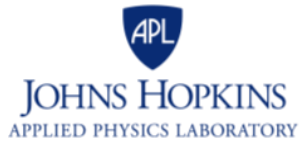

ENGINEERING, INC.

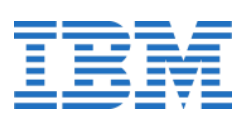

(4) WORLD BANKGROUP
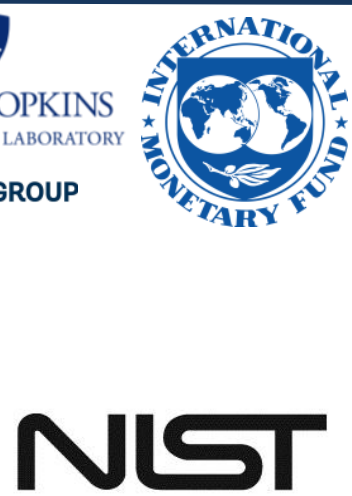

National Institute of Standards and Technology U.S. Department of Commerce 

NIST Special Publication 1600

\title{
Economics of Community Disaster Resilience Workshop Proceedings
}

\author{
Prepared for \\ U.S. Department of Commerce \\ Engineering Laboratory \\ National Institute of Standards and Technology \\ Gaithersburg, MD 20899-8600 \\ By \\ Bilal M. Ayyub \\ Robert E. Chapman \\ Gerald E. Galloway \\ Richard N. Wright
}

This publication is available free of charge from:

http://dx.doi.org/10.6028/NIST.SP.1600

February 2016

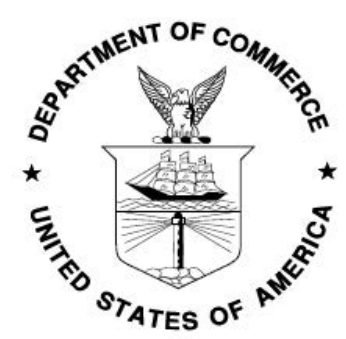

U.S. Department of Commerce

Penny Pritzker, Secretary

National Institute of Standards and Technology Willie May, Under Secretary of Commerce for Standards and Technology and Director 
Certain commercial entities, equipment, or materials may be identified in this document in order to describe an experimental procedure or concept adequately. Such identification is not intended to imply recommendation or endorsement by the National Institute of Standards and Technology, nor is it intended to imply that the entities, materials, or equipment are necessarily the best available for the purpose.

National Institute of Standards and Technology Special Publication 1600

Natl. Inst. Stand. Techno. Spec. Publ. 1600, 290 pages (February 2016) http://dx.doi.org/10.6028/NIST.SP.1600 CODEN: NSPUE2 


\section{Harary, Howard H., Director, Engineering Laboratory, National Institute of Standards and Technology}

\section{Foreword}

Communities in the United States experience natural and human-caused hazards every year. A disaster results when a hazard severely disrupts a community's ability to function. Severe storms, hurricanes, storm surge, tornados, wildfires, earthquakes, snow and ice, and humancaused disruptions lead to numerous Presidential disaster declarations and billions of dollars in losses every year. Despite significant progress in the application of science and technology to disaster reduction, communities are still challenged by disaster preparation, response, and recovery. The number of lives lost each year to natural and human-caused disasters is trending downward, but the costs following major disasters continue to rise, in part, due to the increasing value-at-risk of infrastructure. A reliance on response and rebuild-as-before strategies is impractical and inefficient when dealing with persistent hazards. Instead, communities must break that cycle by enhancing their disaster resilience. High-priority science and technology investments, coupled with sound decision-making at all levels—national, regional, and localwill enhance community resilience and reduce vulnerability.

The National Institute of Standards and Technology (NIST) develops unbiased, state-of-the-art measurement science that advances standards and technology in ways that enhance economic security and improves our quality of life. Community disaster resilience is recognized as a critical national priority - one that requires meaningful and rigorous measurement science to develop planning guidelines and tools, and to establish suitable performance metrics.

To support this need, NIST launched an effort to convene a workshop on the economics of community disaster resilience in order to guide the national agenda on economic considerations that might drive community investments in resilience. Led by NIST, the effort greatly benefitted from substantial collaboration with the American Society of Civil Engineers, the American Society of Mechanical Engineers, and BMA Engineering, Inc. Additional support was provided by the World Bank Group, the International Monetary Fund, IBM, the Johns Hopkins Applied Physics Laboratory, and the University of Maryland's A. James Clark School of Engineering Center for Technology and Systems Management. The workshop attendees comprised more than 70 participants, representing a wide variety of stakeholders, including academia, community planners, government executives, policy makers, and subject matter experts in economics, engineering, finance, and risk analysis.

The workshop was organized around three cross-cutting themes: (1) resilience planning and deployment; (2) dealing with uncertainty; and (3) the economics of recovery. Two keynote presentations explored the scope of the cross-cutting themes. The national perspective was presented by the Commerce Department's Chief Economist, and a "view from the trenches" was provided by the Chief Resilience Officer of the City of Norfolk. Plenary session presentations were commissioned covering each of the three cross-cutting themes, setting the stage for focused breakout sessions organized around the three cross-cutting themes. Workshop participants were assigned to the breakout sessions in a manner that made use of their expertise and personal 
experiences and facilitated discussions among the key stakeholder groups represented at the workshop. The breakout sessions were co-facilitated by each theme's plenary speakers, providing a firm base from which to develop a snapshot of the current state-of-the-art in that topic area, as well as identify gaps and research opportunities. Change agents were also identified for key stakeholder groups in industry, academia, government, standards development organizations, and hardware and software developers.

The results of the workshop breakout sessions presented herein provide a path forward for key stakeholders. These results are augmented and informed by: six cross-cutting theme papers, two for each of the three themes by recognized industry leaders; by a description of NIST's proposed Community Resilience Economic Decision Guide for Building and Infrastructure Systems; and by short, executive summary papers from workshop participants that lay out the challenges and opportunities associated with the three cross-cutting themes. This report provides the elements of a roadmap of national usefulness informing key stakeholders of potential opportunities for their resilience-related research, development, and deployment efforts.

Moreover, the workshop report provides many useful insights to the resilience stakeholder community. These include: the conflict between short-term priorities and long-term well-being; the concept of a "resilience dividend" where resilience is evaluated on a day-to-day co-benefit basis, rather than being justified on hypothetical disaster scenarios; the critical role of performance-based standards; the inequitable distribution of costs and benefits among stakeholders; the development of measures of economic resilience that are conceptually sound and empirically valid; and the promise that systems-based thinking has for increased resilience to natural and human-caused disasters.

The material contained in this report is intended to promote increased awareness of resiliencerelated issues - both challenges and opportunities. The report identifies definitional and methodological disconnects and analyzes them from a systems perspective. The report also identifies barriers to the adoption and use of resilience-enhancing products and practices and recommends an agenda for NIST and others to address these barriers. 
Ayyub, Bilal M., University of Maryland, College Park, and Robert E. Chapman, National Institute of Standards and Technology

\begin{abstract}
This report documents the effort launched by the National Institute of Standards and Technology (NIST) to develop, organize, and convene a workshop on the economics of community disaster resilience to promote the use of economics for system sustainment and guide NIST in developing a portfolio of programs that are focused on providing the enabling measurement science to key industry stakeholders. The workshop was organized around three cross-cutting themes: (1) resilience planning and deployment; (2) dealing with uncertainty; and (3) economics of recovery. Plenary session presentations were commissioned covering each of the three cross-cutting themes. The plenary session presentations set the stage for focused breakout sessions organized around the three cross-cutting themes. The breakout sessions were used to develop a snapshot of the current state-of-the-art in that topic area, as well as identify gaps and research opportunities. Change agents were also identified. The results of the workshop breakout sessions presented herein provide a path forward for key stakeholders. Thus, this report provides the elements of a roadmap useful not only for NIST but for other key industry stakeholders on potential opportunities for their resilience-related research, development, and deployment efforts. The workshop provided many useful insights for NIST as it moves forward with its portfolio of programs focused on resilience-related research. The material contained in this report is intended to promote an increased awareness of resilience-related issues. The report identifies definitional and methodological disconnects and analyzes them from a systems perspective. The report also identifies best practices and barriers to the increased use of resilience-related products and processes and recommends actions for NIST and others to address these barriers.
\end{abstract}

\title{
Keywords
}

Disaster, community, economics, life cycle assessment, metrics, resilience, standards, synergies and interdependencies, systems, uncertainty 


\section{Preface}

Community disaster resilience is recognized as a critical national priority —one that requires meaningful and rigorous measurement science to develop planning guidelines and tools, and to establish suitable performance metrics. To support this need, the National Institute of Standards and Technology (NIST) launched an effort to convene a workshop on the economics of community disaster resilience and produce this publication in order to guide the national agenda on economic considerations that might drive community investments in resilience. Led by NIST, the effort greatly benefitted from substantial collaboration with the American Society of Civil Engineers, the American Society of Mechanical Engineers, and BMA Engineering, Inc. Additional support was provided by the World Bank Group, the International Monetary Fund, IBM, the Johns Hopkins Applied Physics Laboratory, and the University of Maryland's A. James Clark School of Engineering Center for Technology and Systems Management. The organization of the workshop and the development of the first draft of this publication were produced as part of Contract SB1341-14-SU-1035 and its subsequent modifications issued by the National Institute of Standards and Technology to BMA Engineering, Inc.

\section{Organizing Committee}

Bilal M. Ayyub, Lead, University of Maryland, College Park

Robert E, Chapman, National Institute of Standards and Technology

Gerald E. Galloway, University of Maryland, College Park

Richard N. Wright, University of Maryland, College Park

\section{Sponsors}

National Institute of Standards and Technology (NIST)

American Society of Civil Engineers (ASCE)

American Society of Mechanical Engineers (ASME)

\section{Supporting Organizations}

BMA Engineering, Inc.

IBM

International Monetary Fund (IMF)

Johns Hopkins University, Applied Physics Laboratory

University of Maryland, College Park, A. James Clark School of Engineering

World Bank Group 


\section{Disclaimer and Limitations}

This report was prepared for the National Institute of Standards and Technology (hereafter referred to as NIST) as the primary sponsor, and the American Society of Civil Engineers (hereafter referred to as ASCE), and the American Society of Mechanical Engineers (hereafter referred to as ASME) by BMA Engineering, Inc. and its associates and subcontractors (hereafter referred to as the BMA). Although this product was prepared using the best available resources, NIST, ASCE, ASME and BMA do not make any warranty, expressed or implied, or assume any legal liability or responsibility for the accuracy, completeness, or usefulness of any information, apparatus, product or process disclosed, or represent that its uses would not infringe on privately owned rights. Reference herein to any specific commercial product, process, or service by trade name, trademark, manufacturer, or otherwise does not necessarily constitute or imply its endorsement, recommendation, or favoring by NIST, ASCE, ASME, and BMA. Opinions expressed in this report are personal opinions of the participants and do not reflect the opinions of the respective employers of the participants.

\section{Acknowledgments}

The editors would like to acknowledge the financial support of the sponsors, particularly the National Institute of Standards and Technology, and the help provided by Joseph Fiksel, Howard Kunreuther, Gene Feigel, Robert Prieto, Mark Ehlen, and Stephanie Chang as moderators; Doug Thomas, Anand Kandaswamy, David Butry, Jennifer Helgeson, Stanley Gilbert, and David Webb as co-facilitators; and Saurabh Mishra and Roy Emanuel.

\section{Recommended Citation}

Ayyub, B. M., Chapman, R. E., Galloway, G. E., and Wright, R. N. (editors), 2016, Economics of Community Disaster Resilience Workshop Proceedings, NIST Special Publication 1600, Gaithersburg, MD: National Institute of Standards and Technology. 


\section{Table of Contents}

[Papers of Section III are provided in alphabetical order of last name of first author.]

Harary, Howard H., Director, Engineering Laboratory, National Institute of Standards and

Technology

Foreword ii

Ayyub, Bilal M., University of Maryland, College Park, and Robert E. Chapman, National Institute of Standards and Technology .......................................................................... iv

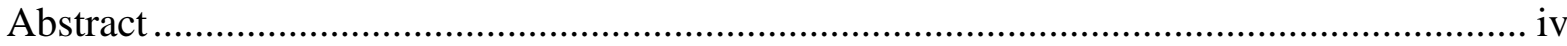

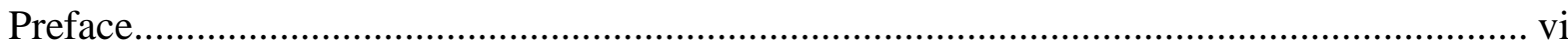

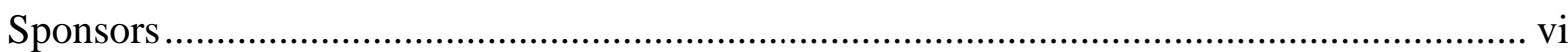

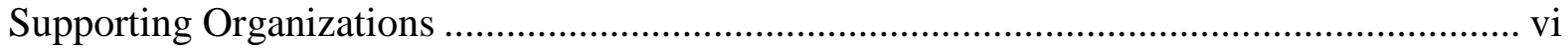

Disclaimer and Limitations ............................................................................................... vii

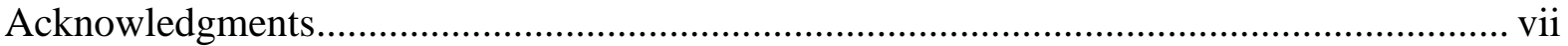

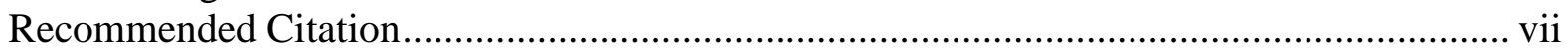

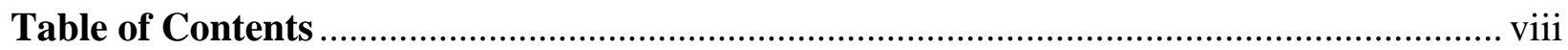

Ayyub, Bilal M., University of Maryland, College Park, and Robert E. Chapman, National Institute of Standards and Technology ......................................................................... xvi

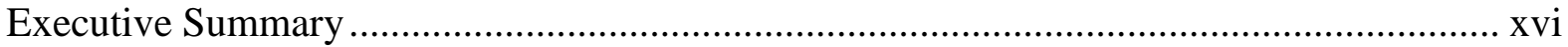

1. Community Resilience Economic Decision Guide for Buildings and Infrastructure Systems ........................................................................................................... xvi

2. Commissioned Papers Used to Develop the Cross-Cutting Themes Addressed in the

Breakout Sessions ............................................................................................... xvii

2.1. Resilience Planning and Deployment .............................................................. xvii

2.2. Dealing with Uncertainty .............................................................................. xviii

2.3. Economics of Recovery ...............................................................................................

3. Contributed Papers Documenting Stakeholder Perspectives .............................................. xix

3.1. Definitional and Methodological Issues ............................................................. xix

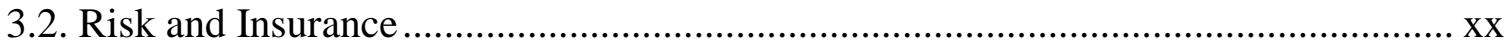

3.3. Mitigation and Recovery Strategies ...................................................................... xxi

3.4. Economic Impact Assessment ……………………….......................................... xxi

4. Findings and Recommendations from the Breakout Sessions .......................................... xxii

Harary, Howard, Director, Engineering Laboratory, National Institute of Standards and

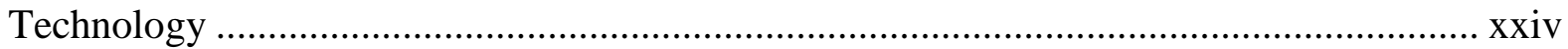

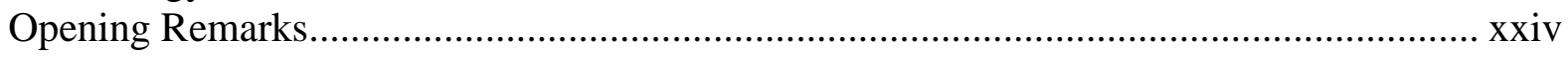

Helper, Sue, Chief Economist of the Department of Commerce, Washington, DC ................. xxviii

Perspectives on Resilience Economics for the Nation ......................................................... xxviii 
Morris, Christine, Chief Resilience Officer, City of Norfolk .................................................xxx

Community Resilience - A Chief Resilience Officer's Perspective ....................................xx

Ayyub, Bilal M., Gerald E. Galloway and Richard N. Wright, University of Maryland, and

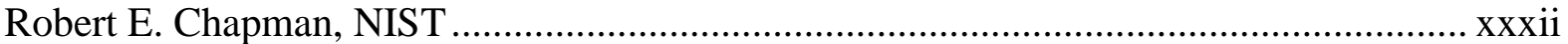

About the Workshop .............................................................................................. Xxii

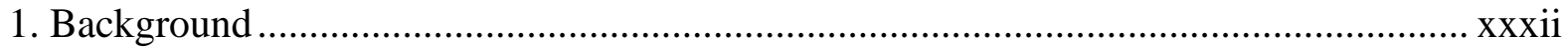

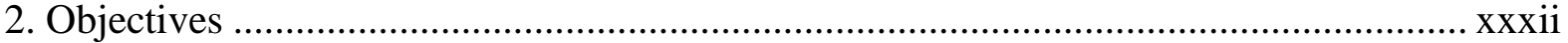

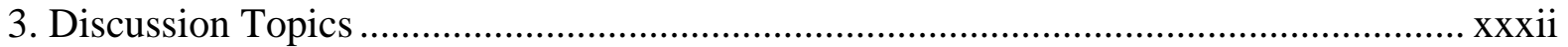

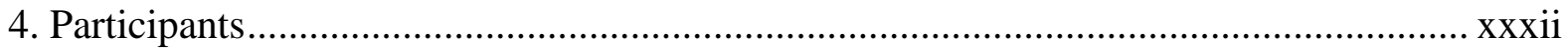

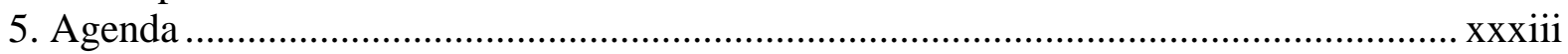

Ayyub, Bilal M., University of Maryland, and Robert E. Chapman, NIST ........................ xxxiv

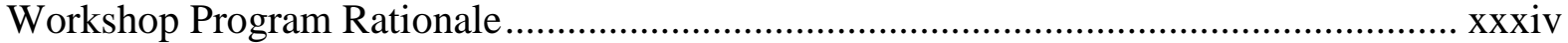

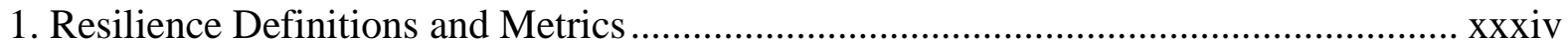

2. Resilience Economics: Breakout Sessions................................................................. xxxvii

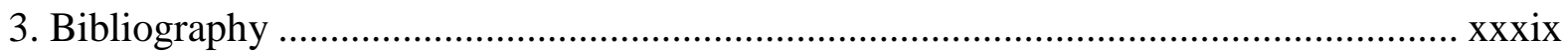

Section I. Community Resilience Economic Decision Guide for Buildings and

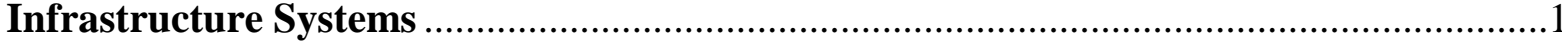

Chapman, Robert E., National Institute of Standards and Technology ....................................3

Community Resilience Economic Decision Guide for Buildings and Infrastructure

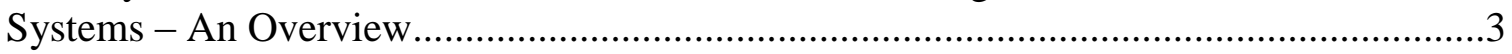

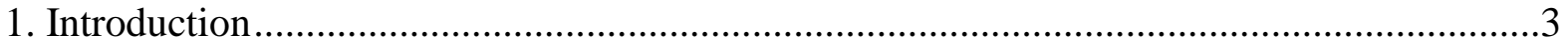

2. Relationship to the NIST Community Resilience Planning Guide for Buildings and

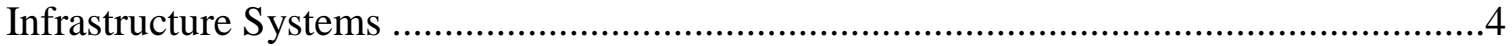

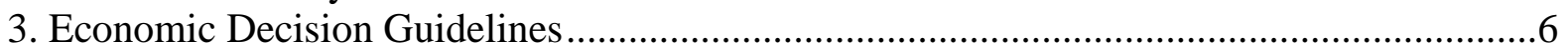

3.1. Select Candidate Strategies ............................................................................ 7

3.2. Define Investment Objectives and Scope ................................................... 8

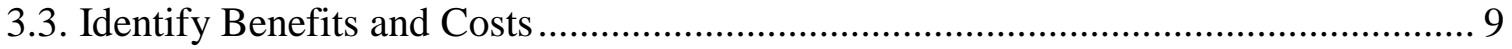

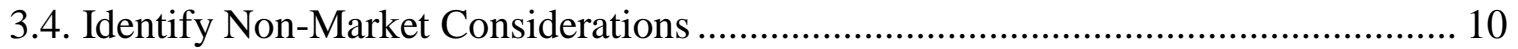

3.5. Define Analysis Parameters ............................................................................ 11

3.6. Perform Economic Evaluation ....................................................................... 12

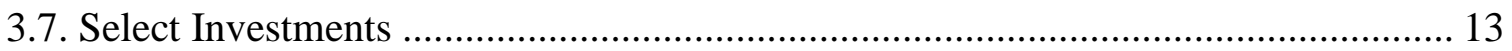

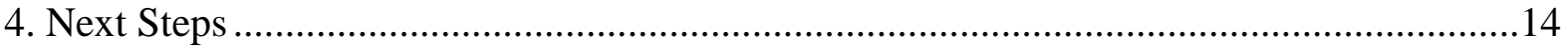

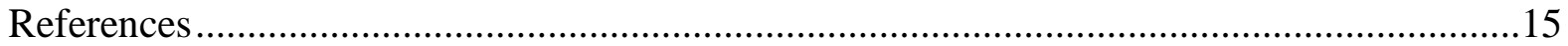

Section II. Papers by Moderators ....................................................................... 17

Fiksel, Joseph, Elena Irwin, and Matthew Gnagey..............................................................19

Resilience Economics: A Systems Approach .............................................................19

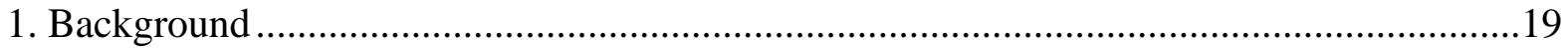

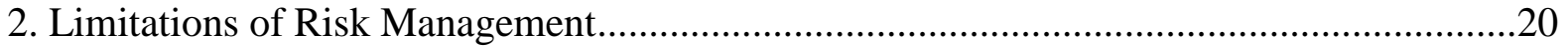

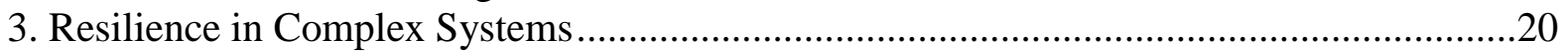

4. Taking a Systems Approach ...................................................................................22

4.1 Cost-Benefit Analysis in Managerial Accounting ....................................................23 


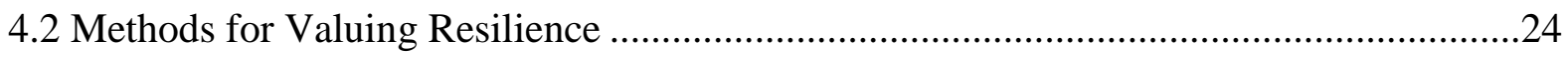

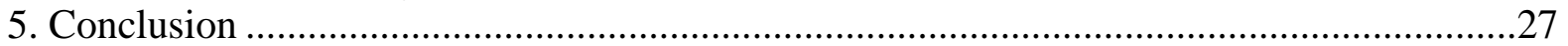

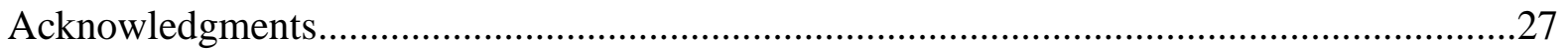

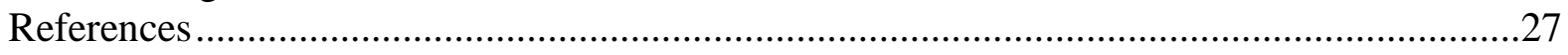

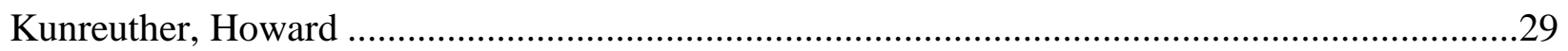

Community Resiliency and Planning for Natural Disasters: A Framework for

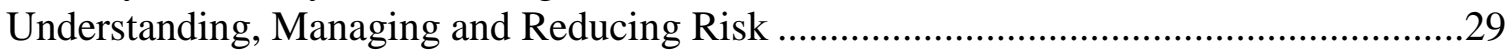

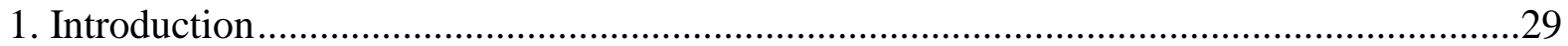

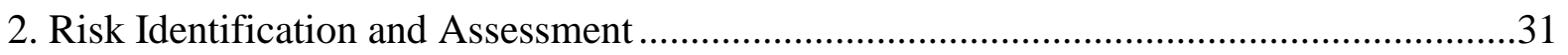

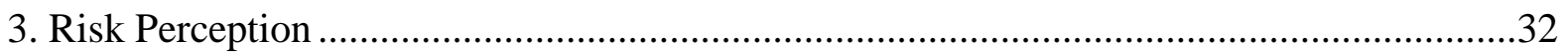

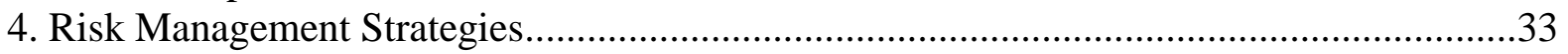

5. Modifying the National Flood Insurance Program ...........................................................36

6. Summary and Suggestions for Future Studies ………..........................................................

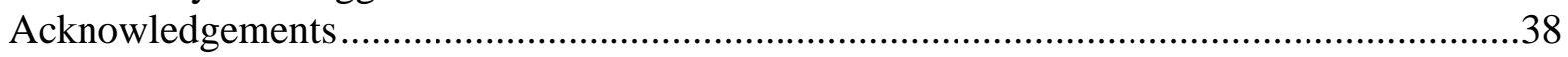

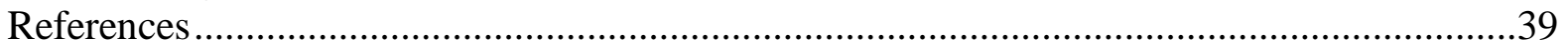

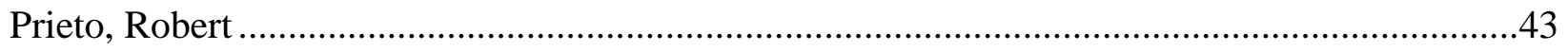

Economics of Community Disaster Resilience Dealing with Uncertainty ..............................43

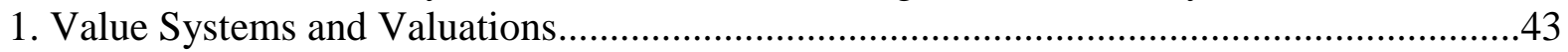

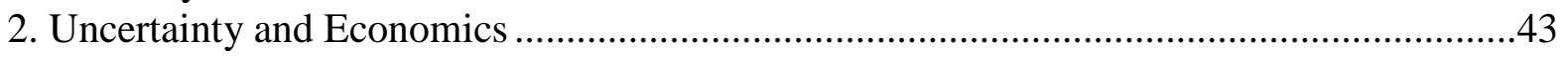

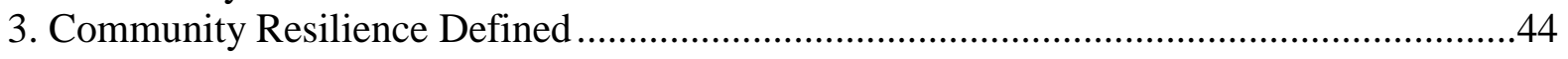

4. Resilience Outcome Defined ........................................................................................4

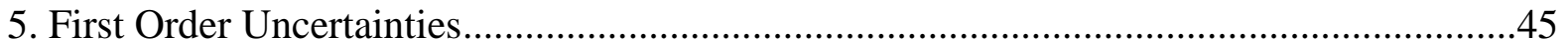

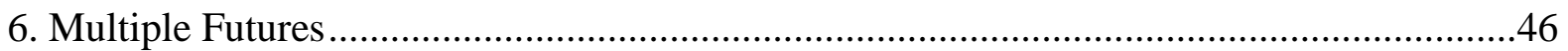

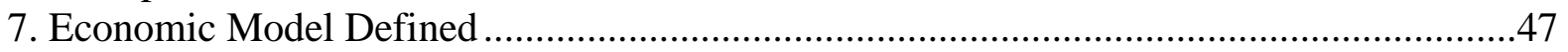

8. Community Resilience Lifecycle Model .......................................................................4

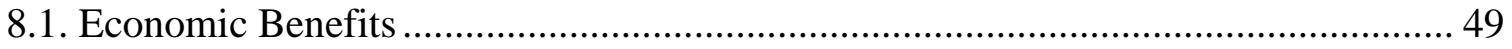

8.2. Asset Life Cycle Costs and Investments............................................................ 50

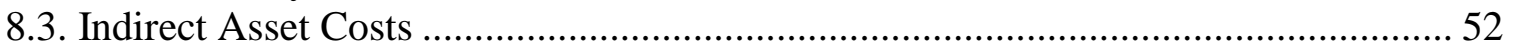

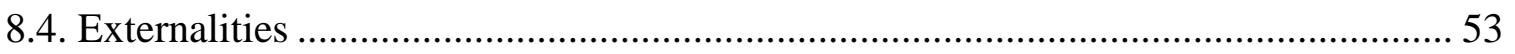

9. Modeling Risk, Uncertainty and Confidence Levels .......................................................53

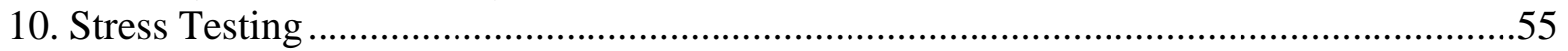

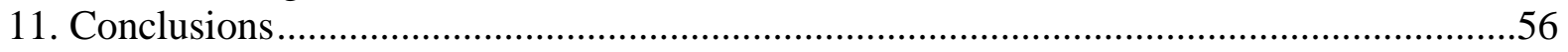

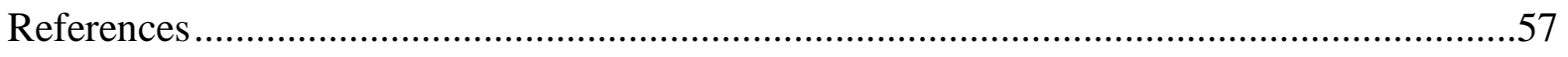

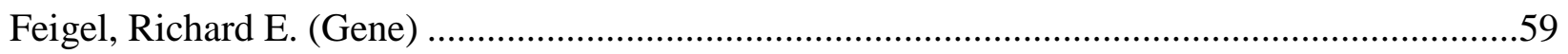

Economics of Community Disaster Resilience: Impact of Variability and Uncertainty ..........59

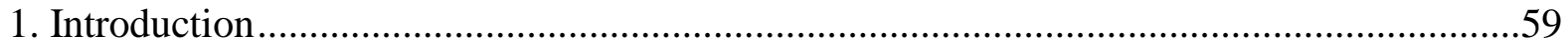

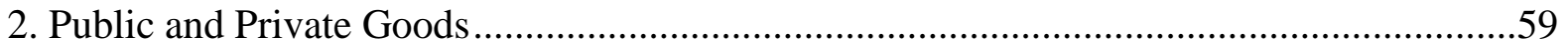

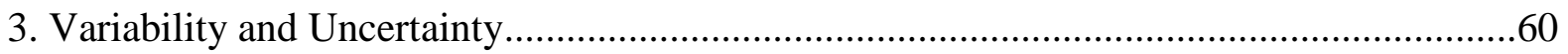

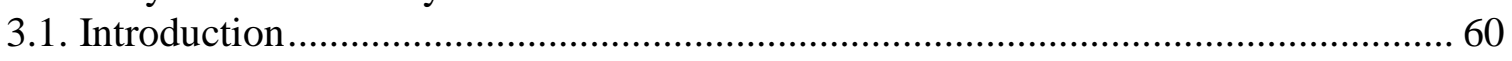

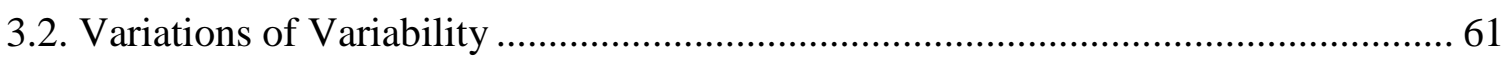

3.3. Secondary Uncertainty Correlation...............................................................................61

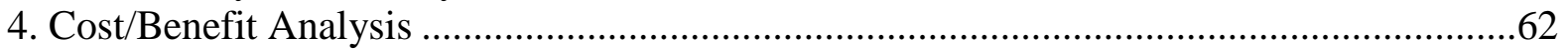

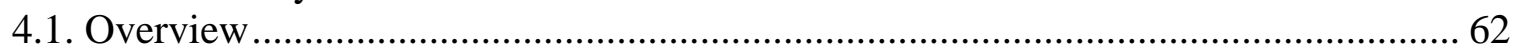

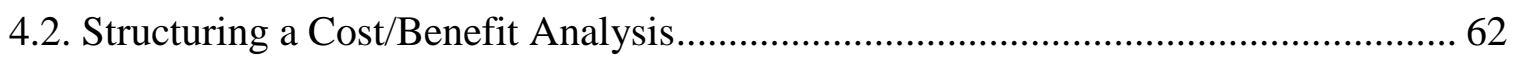




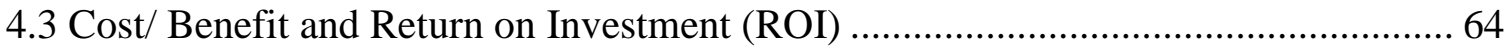

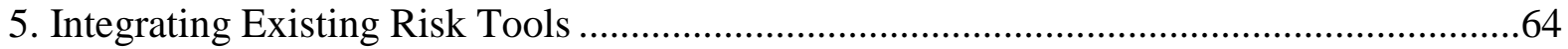

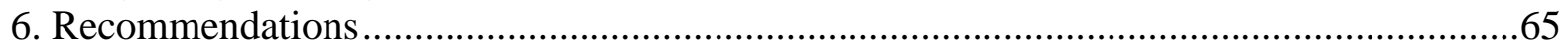

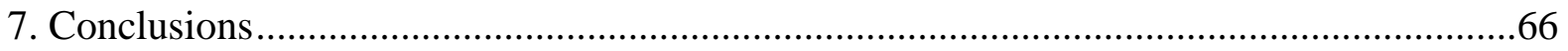

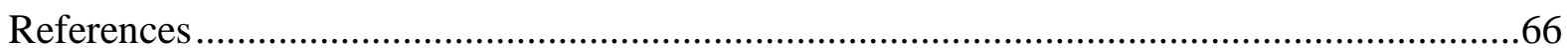

Ehlen, Mark A., Prabuddha Sanyal, and Mark A. Pepple .....................................................67

A Framework for Guiding Homeland Security Programs from Risk to Resilience ...............67

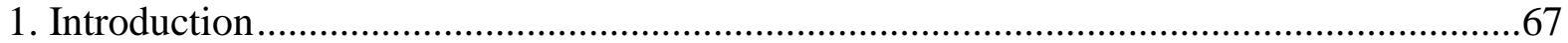

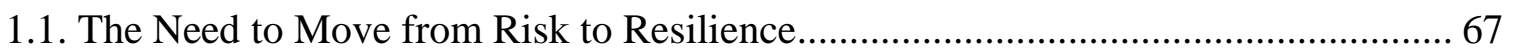

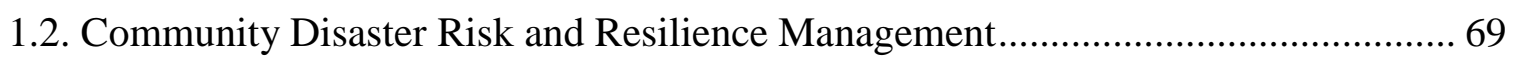

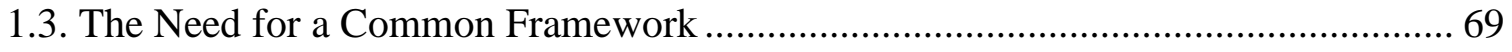

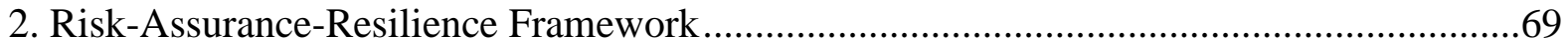

2.1. The General Duality Approach ........................................................................... 71

2.2. The Mission-Risk and Mission-Assurance Dual Problem ...................................... 73

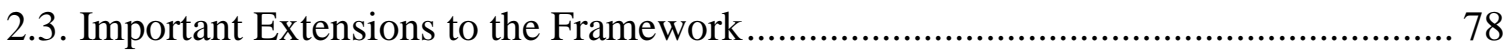

2.4. Application Example: the Pharmaceutical Industry ............................................... 80

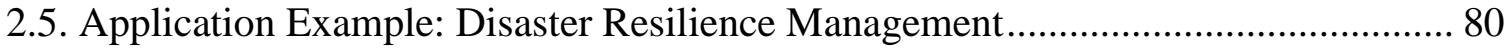

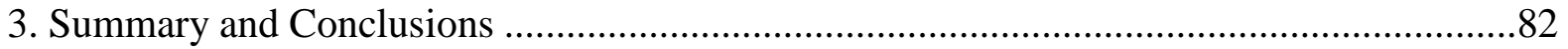

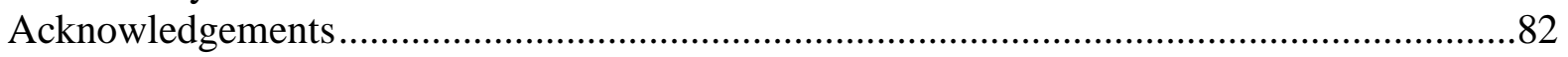

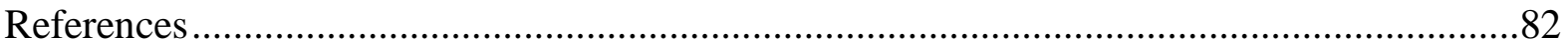

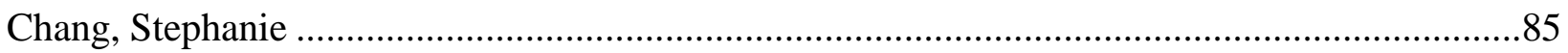

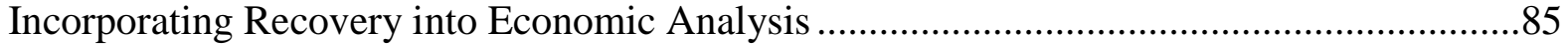

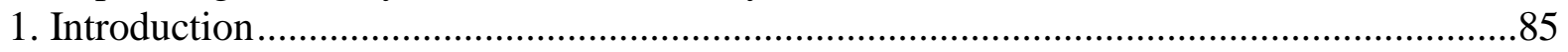

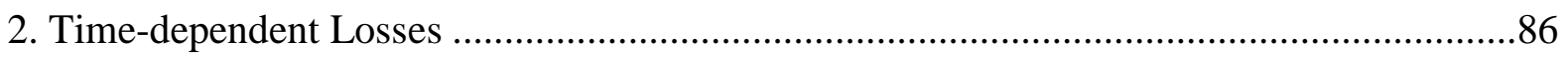

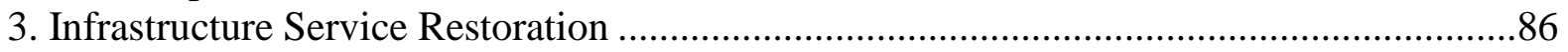

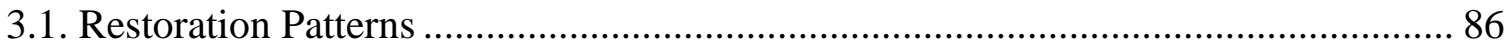

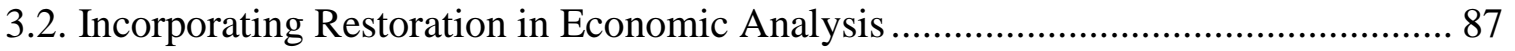

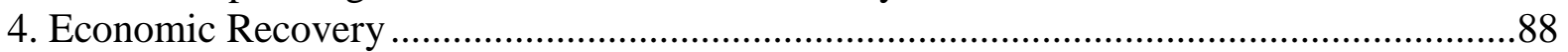

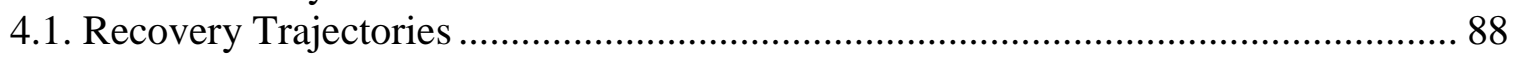

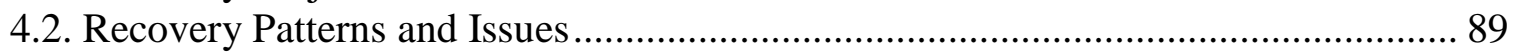

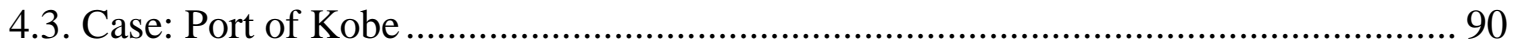

4.4. Case: Christchurch Central Business District .................................................... 91

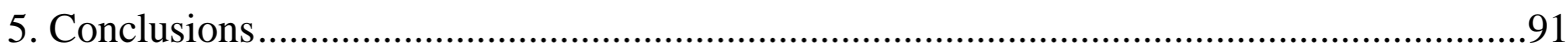

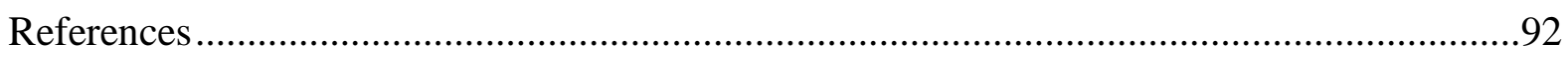

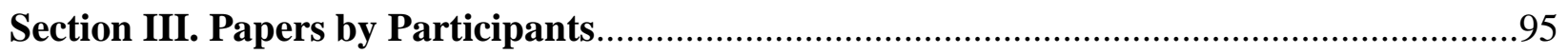

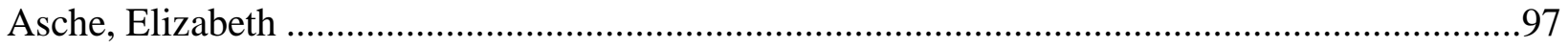

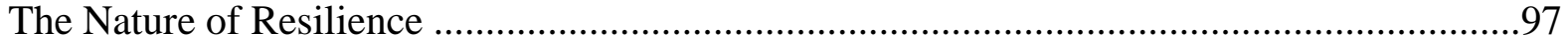

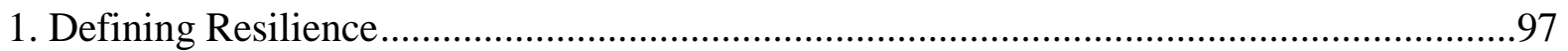

2. Defining Community Resilience ...................................................................................98

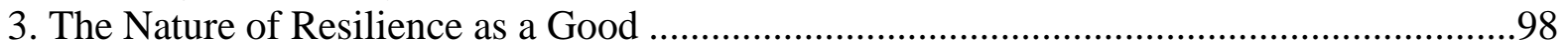

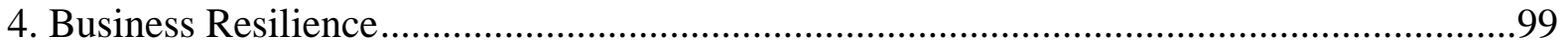

5. Whole Community Resilience: not just the sum of its parts......................................100

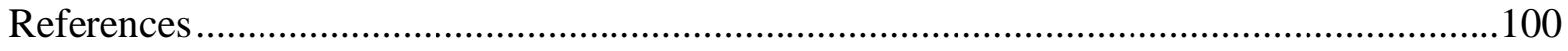


Ayyub, Bilal M., Athanasios A. Pantelous, and Jia Shao

Towards Resilience to Catastrophic Events: Financing Liabilities via Catastrophe Risk Bonds

Abstract

Keywords

1. Introduction: Catastrophic Risk

2. Liability Limitation Regimes

3. Catastrophe (CAT) Risk Bonds

4. Nuclear CAT Bonds

5. Two Coverage Type Trigger Nuclear CAT bond ......................................................109

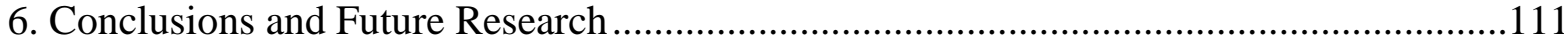

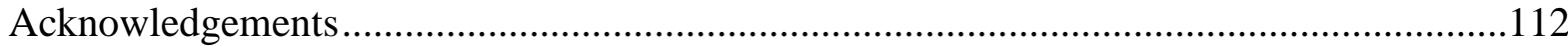

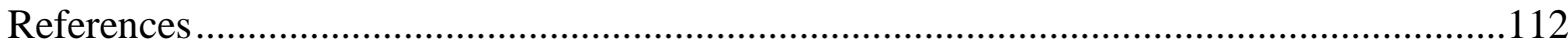

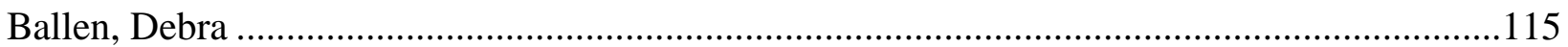

Economics of Community Disaster Resilience: An IBHS Perspective .............................115

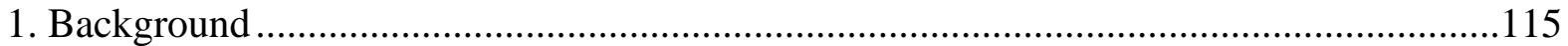

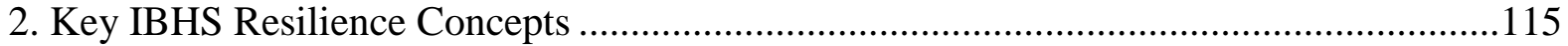

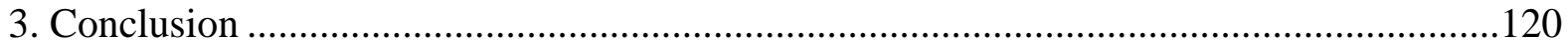

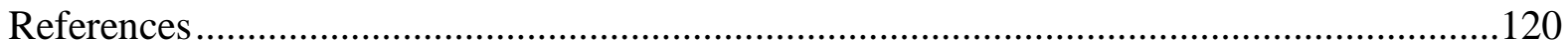

Bellomo, Doug, and J. Rolf Olsen .....................................................................................121

Economics of Community Disaster Resilience: Four Orders of Resilience Written in

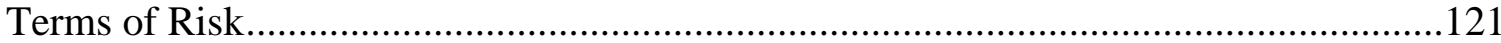

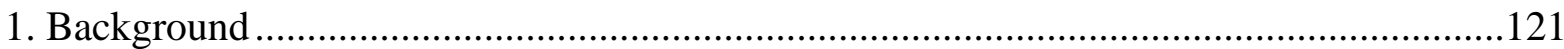

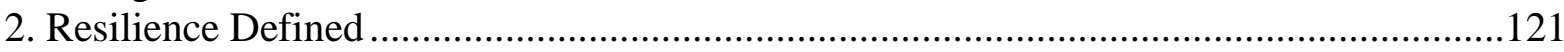

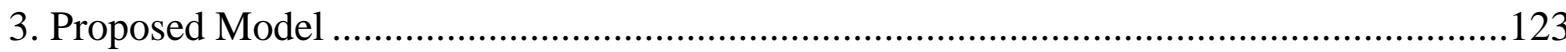

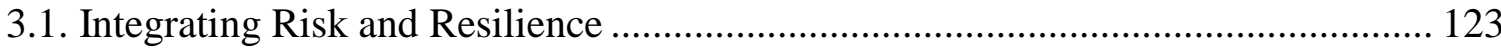

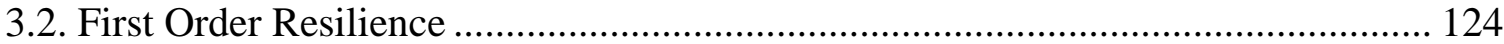

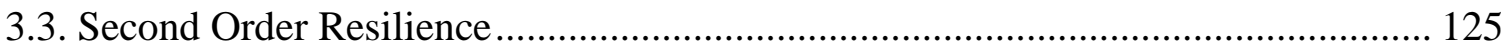

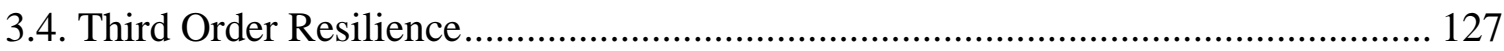

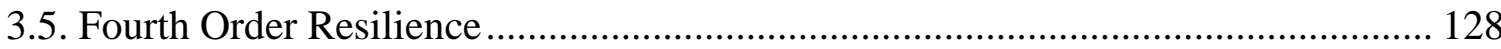

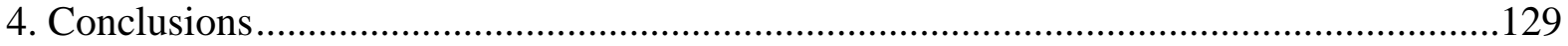

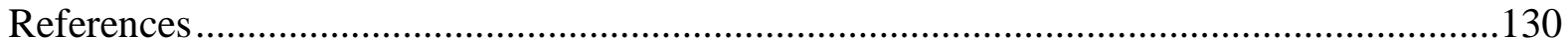

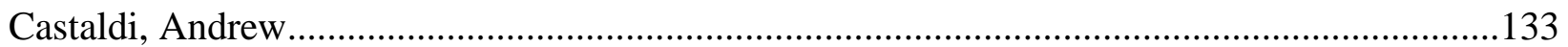

A Reinsurers Perspective of Why We Need to Improve the Economic Consequences

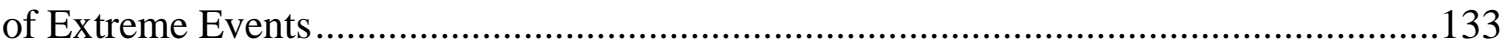

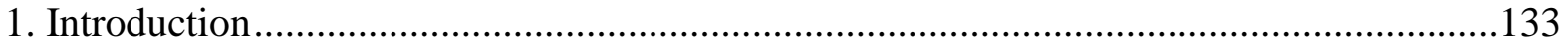

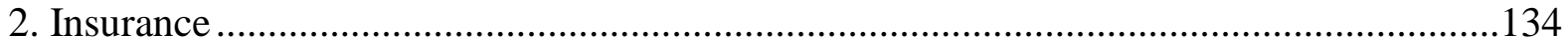

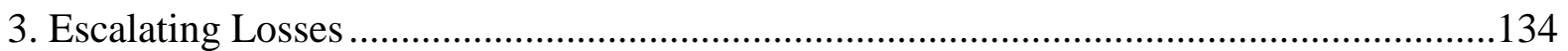

4. We Need to Change our Mindset and Act Quickly ......................................................135

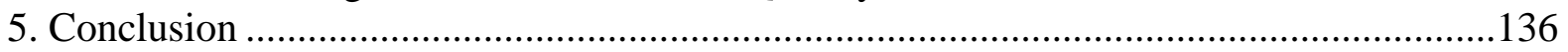

Chang, Wen-Huei, Dena Abou-El-Seoud, and Yue Cui......................................................139

An Introduction to the US Army Corps of Engineers Regional Economic System ..............139

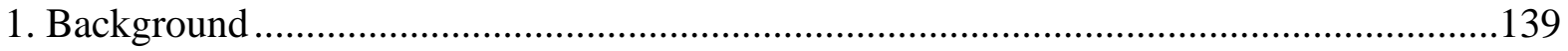




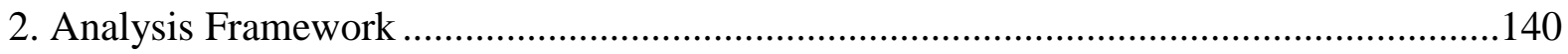

2.1. Economic Impact Analysis (EIA) ................................................................... 140

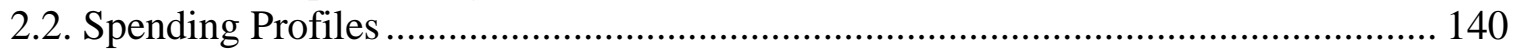

2.3. Study Area Identification: Functional Economic Areas ......................................... 140

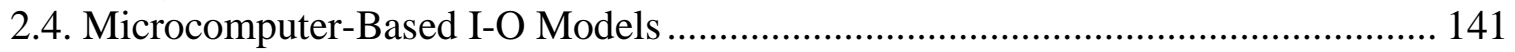

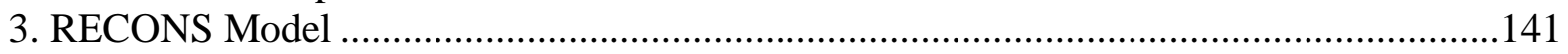

4. Illustration of the RECONS Model- Navigation Program ..............................................142

4.1. Identify Spending Associated with Navigation Program....................................... 142

4.2. Regional economic Impact Models ................................................................. 144

4.3. Carbon Emission Impacts. ................................................................................. 145

4.4. Demonstration of RECONS Functions and Capabilities ........................................ 145

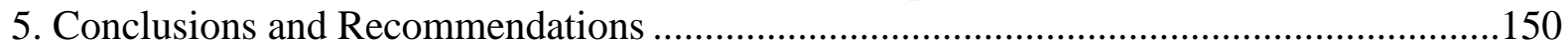

5.1. Institutionalizing the Economic Impact Analysis ............................................... 150

5.2. Additional Options for Estimating the Stemming from Effects ............................ 150

5.3. Trade-off Analysis for Greenhouse Gas Effects..................................................... 151

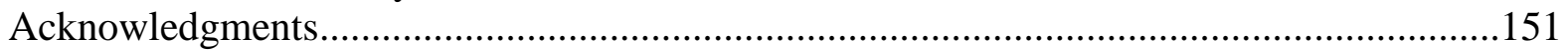

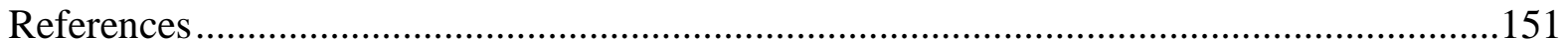

Cutler, Harvey, Martin Shields, Daniele Tavani, Sammy Zahran, and John W van de Lindt.....155 Computable General Equilibrium Models and Natural Disasters: A Note on

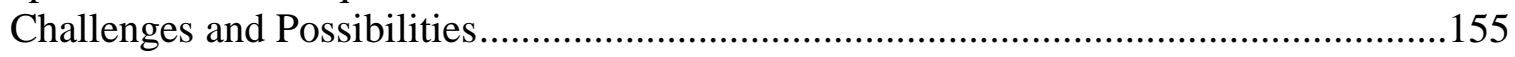

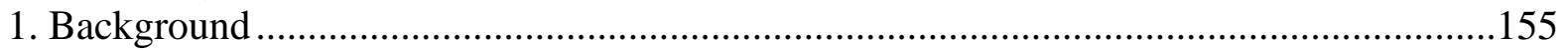

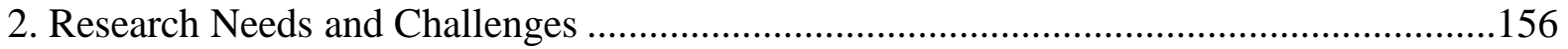

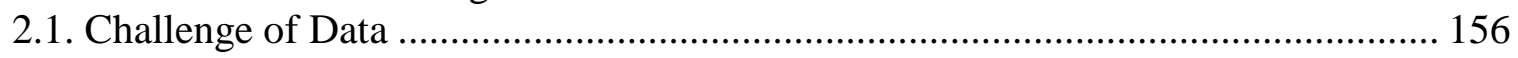

2.2. Challenge of Assumptions ................................................................................. 158

2.3. Challenge of Generalizability ............................................................................... 159

2.4. Challenge of Interdisciplinary Research............................................................ 160

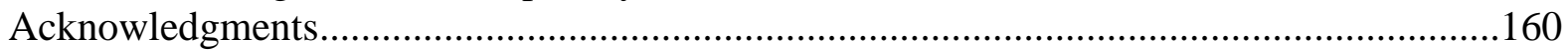

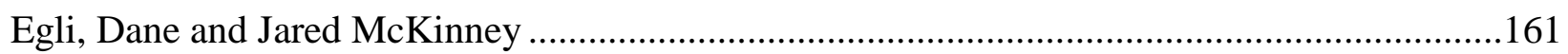

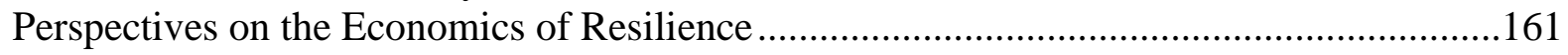

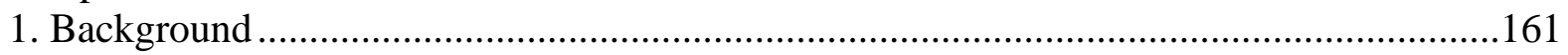

2. Connected world, Globalization and Technology .........................................................162

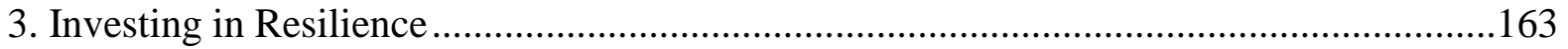

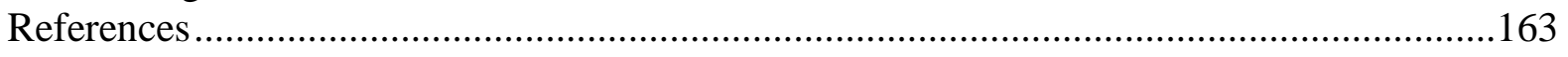

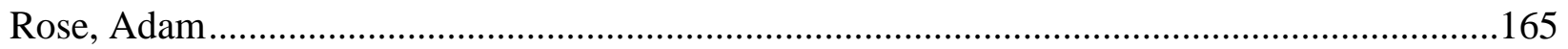

Measuring Economic Resilience to Disasters ...................................................................165

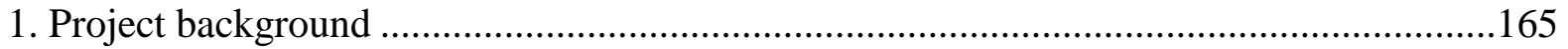

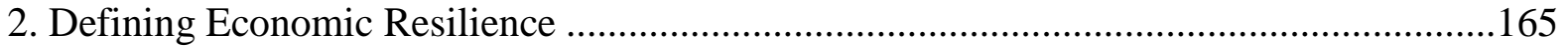

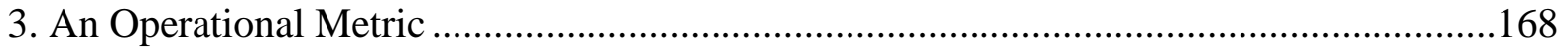

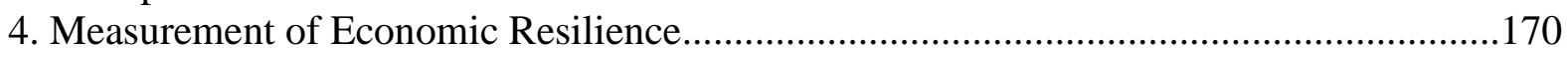

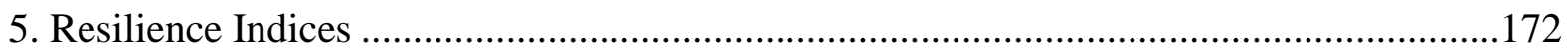

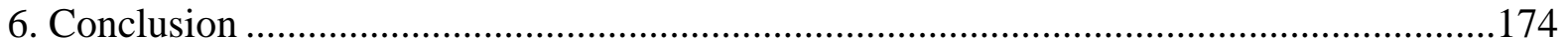

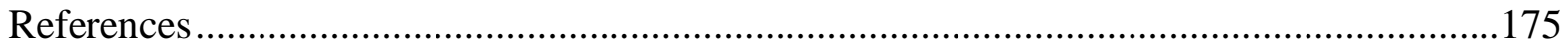

Seville, E., J.R. Stevenson, J. Vargo, C. Brown, and S. Giovinazzi.............................................177 
Resilience and Recovery: Business Behavior Following the Canterbury Earthquakes .........177

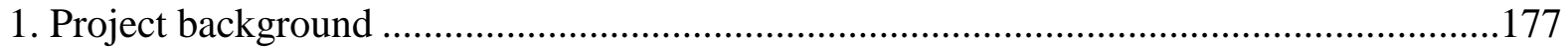

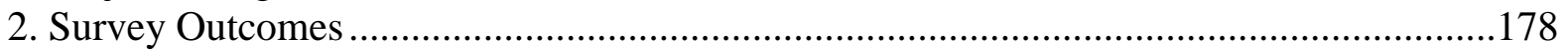

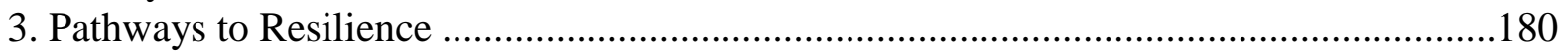

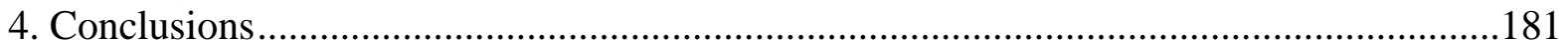

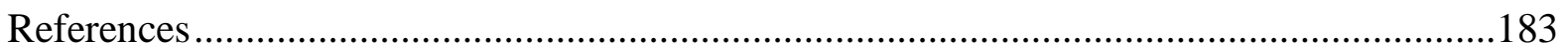

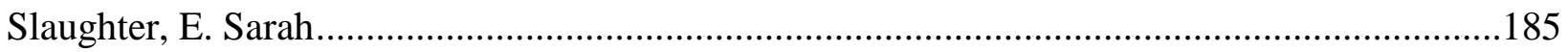

Economics of Investments for Resilient Communities: A Systems View..........................185

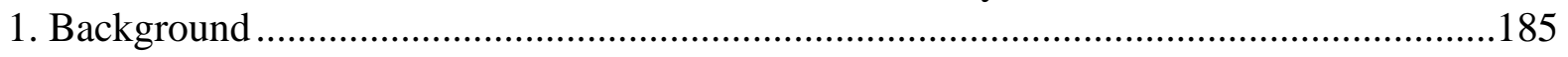

2. Building Community Resilience ...................................................................... 186

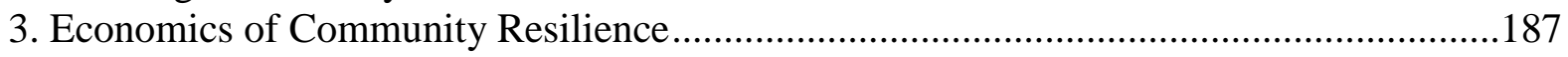

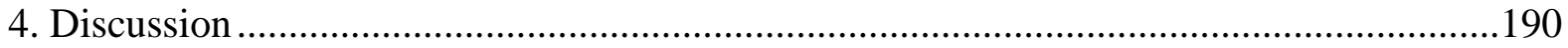

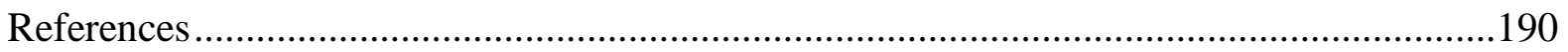

Section IV. Breakout Session Reports................................................................... 191

Co-Moderators: J. Fiksel and H. Kunreuther....................................................................193

Outcomes of Breakout Session 1 on Resilience Planning and Deployment........................193

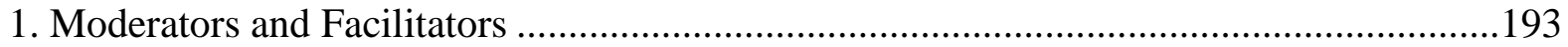

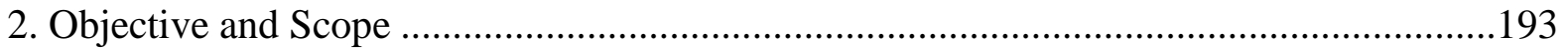

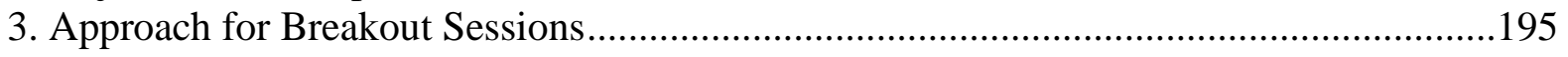

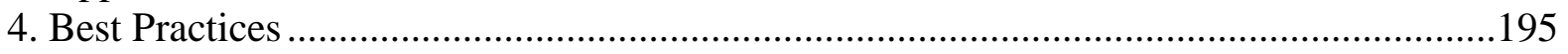

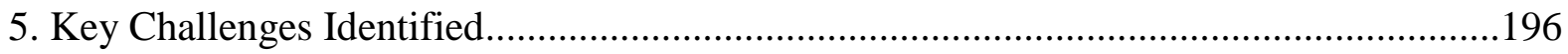

5.1. Challenge. Tension between Short-Term Returns and Long-Term Well-Being ..... 196

5.2. Challenge 2. Inequitable Distribution of Costs and Benefits among Stakeholders . 197

5.3. Challenge 3. Lack of Adequate Collaboration between Private and Public Sectors 198

5.4. Challenge 4. Lack of Motivation to Build Back Better Rather than Merely Recover

5.5. Challenge 5. Presence of Systematic Biases and Simplified Rules of Thumb Hinder

Resilience Efforts ...................................................................................... 200

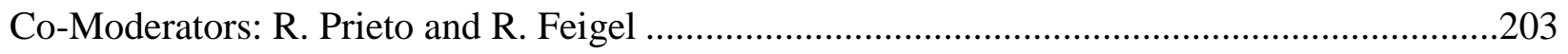

Outcomes of Breakout Session 2 on Dealing with Uncertainty ......................................203

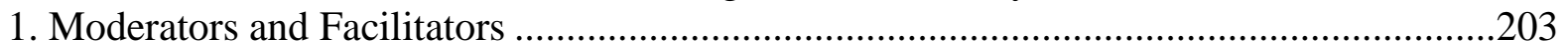

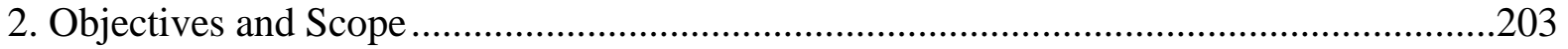

3. Approach for Breakout Sessions...........................................................................204

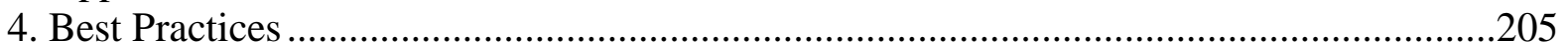

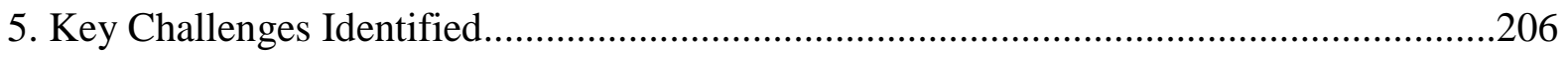

5.1. Challenge 1. Long Range Community Plans Addressing Resilience ..................... 207

5.2. Challenge 2. Performance-based Standards for Resilience .................................. 208

5.3. Challenge 3. Resilience for Socially Disadvantaged Groups ............................... 209

5.4. Challenge 4. Accounting for Temporal Uncertainties .......................................... 211

5.5. Challenge 5. Financial Products Supporting Resilience .................................... 212

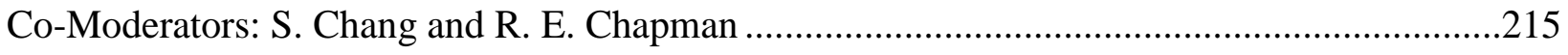

Outcomes of Breakout Session 3 on Economics of Recovery ….....................................215 


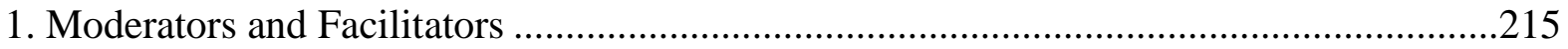

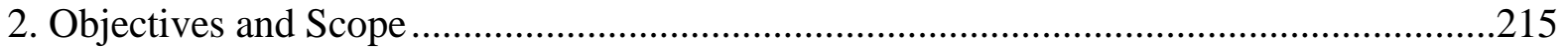

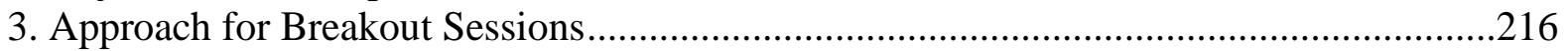

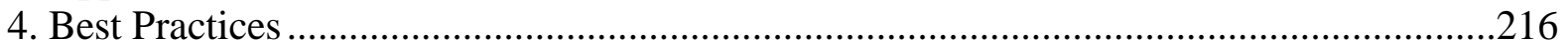

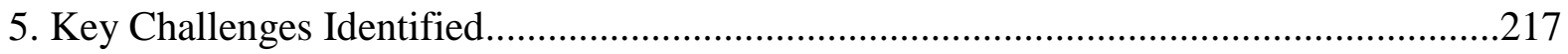

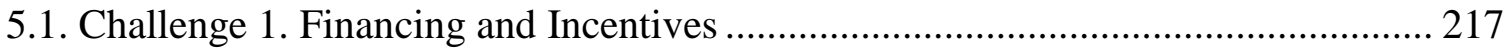

5.2. Challenge 2. Build Back Better vs. Build Back Quicker ...................................... 218

5.3. Challenge 3. Compiling an Economic Resilience Index ..................................... 220

5.4. Challenge 4. Capacity of the Community......................................................... 221

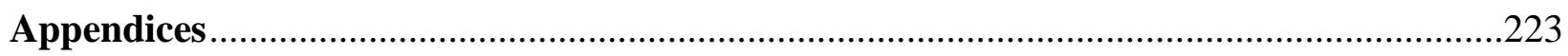

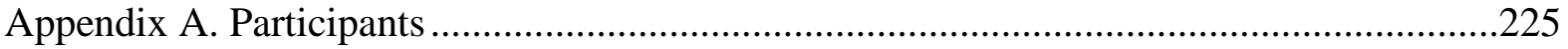

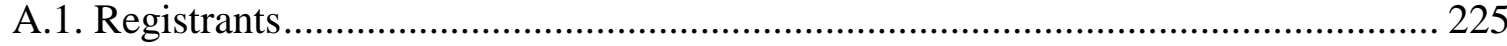

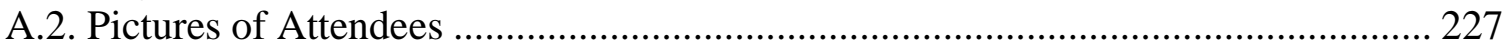

A.3. Breakout Session Attendees ........................................................................... 229

Appendix B. Biographical Information on Some Participants .......................................233 
Ayyub, Bilal M., University of Maryland, College Park, and Robert E. Chapman, National

Institute of Standards and Technology

\section{Executive Summary}

Community disaster resilience is recognized as a critical national priority —one that requires meaningful and rigorous measurement science to develop planning guidelines and tools, and to establish suitable performance metrics. To support this need, the National Institute of Standards and Technology (NIST) launched an effort to convene a workshop on the economics of community disaster resilience to help guide the national agenda on economic considerations that might drive community investments in resilience. The workshop attendees comprised more than 70 participants, representing a wide variety of stakeholders, including academia, community planners, government executives, policy makers, and subject matter experts in economics, engineering, finance, and risk analysis.

The workshop was organized around three cross-cutting themes: (1) resilience planning and deployment; (2) dealing with uncertainty; and (3) the economics of recovery. Two keynote presentations explored the scope of the cross-cutting themes. The national perspective was presented by Sue Helper, the Commerce Department's Chief Economist, and a local representative, a "view from the trenches" was provided by Christine Morris, the Chief Resilience Officer of the City of Norfolk.

Plenary session presentations were commissioned covering each of the three cross-cutting themes, setting the stage for focused breakout sessions organized around the three cross-cutting themes. Workshop participants were assigned to the breakout sessions in a manner that made use of their expertise and personal experiences and facilitated discussions among the key stakeholder groups represented at the workshop. The breakout sessions were co-facilitated by each theme's plenary speakers, providing a firm base from which to develop a snapshot of the current state-of-the-art in that topic area, as well as identify gaps and research opportunities. Change agents were also identified for key stakeholder groups in industry, academia, government, standards development organizations, and hardware and software developers.

The results of the workshop breakout sessions presented herein provide a path forward for key stakeholders. These results are augmented and informed by: six cross-cutting theme papers, two for each of the three themes by recognized industry leaders; by a description of NIST's proposed Community Resilience Economic Decision Guide for Building and Infrastructure Systems; and by short, executive summary papers from workshop participants that lay out the challenges and opportunities associated with the three cross-cutting themes.

\section{Community Resilience Economic Decision Guide for Buildings and Infrastructure Systems}

The Economic Guide builds on both economic concepts drawn from the literature (Gilbert, 2010) and first-hand experience by key stakeholders. An earlier draft of the Economic Guide in the form of a White Paper (Gilbert and Butry, 2015) was provided as part of the read-ahead materials to the 70 plus workshop registrants. Many workshop attendees provided comments on 
the earlier draft; several of whom provided extensive sets of comments which have been incorporated into the Economic Guide. The overview paper presented herein provides a concise and comprehensive summary of the standalone companion document, NIST Special Publication 1197, Community Resilience Economic Decision Guide for Buildings and Infrastructure Systems (Gilbert, Butry, Helgeson, and Chapman, 2015).

The Economic Guide provides a standard economic methodology for evaluating investment decisions aimed at improving the ability of communities to adapt to, withstand, and quickly recover from disasters. The Economic Guide is designed for use in conjunction with the NIST Community Resilience Planning Guide for Buildings and Infrastructure Systems (NIST, 2015), which provides a methodology for communities to develop long-term plans by engaging stakeholders, establishing performance goals for buildings and infrastructure systems, and developing an implementation strategy. The Economic Guide supports the NIST Planning Guide by providing a mechanism to determine the efficiency of resilience actions and prioritize them. Using the economic methodology frames the economic decision process by identifying and comparing the relevant present and future streams of costs and benefits - the latter realized through cost savings and damage loss avoidance-associated with new capital investment into resilience to those future streams generated by the status-quo. Topics related to non-market values and uncertainty are also explored. The Economic Guide provides context for increasing resilience capacity through focusing on those investments that target key social goals and objectives, and providing selection criteria that ensure reduction of risks as well as increases in resilience. Furthermore, the economic methodology aims to enable the built environment to be utilized more efficiently in terms of loss reduction during recovery and to enable faster and more efficient recovery in the face of future disasters.

\section{Commissioned Papers Used to Develop the Cross-Cutting Themes Addressed in the Breakout Sessions}

To promote a better understanding of the three cross-cutting themes, a series of papers documenting the key concepts associated with each cross-cutting theme was commissioned from industry thought leaders. Two papers for each cross-cutting theme were commissioned to allow for varying perspectives among the subject matter experts. The purpose of the papers was to inform workshop participants and assist them in selecting the breakout session that best fit their interest and area of expertise. The papers were sent to workshop registrants as read ahead materials, with the goal of enabling workshop participants to jump start their thought processes for the breakout sessions. The individual papers ae summarized briefly in the three sections that follow: Section 2.1 (Fiksel, Irwin and Gnagey, Resilience Economics: A Systems Approach; and Kunreuther, Community Resilience and Planning for Natural Disasters: A Framework for Understanding, Managing and Reducing Risk); Section 2.2 (Feigel, Economics of Community Disaster Resilience: Impact of Variability and Uncertainty; and Prieto, Economics of Community Disaster Resilience: Dealing with Uncertainty); and Section 2.3 (Chang, Incorporating Recovery into Economic Analysis; and Ehlen, Sanyal and Pepple, A Framework for Guiding Homeland Security Programs from Risk to Resilience).

\subsection{Resilience Planning and Deployment}

Natural disasters and other urban crises are becoming more frequent, while unsustainable development patterns place increasing pressures on natural resources and infrastructure. Communities are complex, adaptive systems, and traditional risk management approaches are 
not adequate for dealing with turbulent change and unforeseen disruptions. When crises occur, the responses are often driven by short-term priorities and may not consider longer term or systemic issues. Fiksel, Irwin and Gnagey argue that a comprehensive conceptual framework and new computational tools are needed to balance the immediate requirements for community resilience with the long-term goals of sustainability and well-being. There exists a broad range of methods for cost-benefit analysis of resilience investments, including managerial accounting approaches and economic valuation of non-monetary goods and services. By combining these methods with models of coupled human-natural systems, it is possible to develop an integrated approach based on an inclusive wealth framework that values economic, social, and natural capital. Although still in an early stage of development, these models can also be extended to account for the value of resilience improvement, which is critical for making investments and policy decisions that improve both the resilience and sustainability of a community.

Howard Kunreuther notes in his paper that individuals and communities often do not take steps prior to a disaster to undertake protective measures because they are prone to systematic biases with respect to their perception of the likelihood and outcomes from natural disaster when compared with expert risk assessments. They also tend to focus on the short-term and utilize simplified decision rules in determining whether to purchase insurance or invest in loss-reduction measures. Understanding how experts assess the likelihood and consequences of disasters as well as how individuals perceive these risks and make choices provide the ingredients for risk management strategies for communities to become more resilient with respect to hazards they face. Modifications to the National Flood Insurance Program, such as risk-based premiums and vouchers coupled with loans for flood mitigation measures could make individuals in floodprone communities more resilient.

\subsection{Dealing with Uncertainty}

Richard Feigel notes that crafting rational resiliency strategies underpinned by defensible technical and economic models is a daunting endeavor. Both ex ante and ex post facto uncertainty exacerbate the problem of developing models and communicating them to a wide variety of stakeholders. While there is no perfect bright line, distinguishing between variability and uncertainty is important, both for developing models which differentiate between data and parameter uncertainty and probably more importantly, to fashion credible risk communication. Developing resiliency protocols that deal with uncertainty is clearly a prerequisite for betterinformed public policy directives.

Robert Prieto's paper looks at uncertainty related to the economics of investments in community resilience and considers some of the unique characteristics of such investments. Uncertainty, as opposed to mathematical risk, is a pervasive fact of life and the paper explores first and higher order outcomes that impact our ability to achieve defined resilience objectives. A four part contextual definition of community is provided. Specific resilience outcome metrics, including Recovery Time Objective and Resilience Value at Risk, are suggested and a community resilience life cycle model outlined. Actionable recommendations for managing uncertainty in economic evaluations related to community resilience are provided.

\subsection{Economics of Recovery}

In current practice, economic analysis of disaster risk reduction often neglects time-dependent losses such as business interruption and income losses that accrue over time during post-disaster recovery. Stephanie Chang's paper argues that incorporating time-dependent losses is critical to 
making investment decisions that foster disaster resilience. Drawing from previous empirical and modeling work, the paper argues that incorporating economic impacts of short-term service outage and restoration is relatively straightforward and can be readily accomplished under certain assumptions -- most notably, assumptions of stable economic structure. Economic recovery is complex and highly context-dependent, however, and will remain very challenging to model, particularly for catastrophic events. To illustrate these points, examples are drawn from several cases in the U.S., Japan, and New Zealand.

Many government agencies are currently moving from risk-based to resilience-based policies; a good example is the current transition from community risk-based mitigation planning to resilience planning embodied in the NIST Economic Guide. What's not obvious to this transition is whether the new resilience plans will adequately address the existing risk needs, and whether the new resilience-based plans will be truly based on resilience and not just "resilience equals low risk." To help understand and reconcile these two concepts, Ehlen, Sanyal, and Pepple present a basic mathematical framework that can simultaneously achieve three important policy goals - minimized risks, ensured mission, and maximized resilience - by achieving any one of the three. Risk and resilience policies can then be developed and promulgated in an internally consistent, effective, and efficient manner.

\section{Contributed Papers Documenting Stakeholder Perspectives}

Workshop participants were given the opportunity to contribute short, executive summary papers that laid out their perspectives on the challenges and opportunities associated with their research, development and deployment activities associated with the three cross-cutting themes. The eleven contributed papers are presented in alphabetical order by first author name within Section III of the Proceedings. However, to provide a more compact summary of the eleven contributed papers presented herein, they have been grouped into four general subheadings: (1) definitional and methodological issues; (2) risk and insurance; (3) mitigation and recovery strategies; and (4) economic impact assessment.

\subsection{Definitional and Methodological Issues}

The concept of creating resilience is commonly thought of as beginning at the community level and building through the local, state, and federal levels. However, as Elizabeth Asche notes in her paper, it may be more beneficial to consider creating and understanding resilience from different perspectives, such as the business and individual perspectives within the community before aggregating at the community level. Asche's paper focuses on providing a clearer understanding of the terms that are generally used to define and talk about resilience at the community level and above.

In their paper, Bellomo and Olsen, propose a general framework for measuring resilience through the use of common definitions and a straight forward equation for risk. Building from these definitions and the risk equation, four orders of resilience are proposed. First order resilience is an object or system's ability to withstand a stress and by definition does not include any time for recovery. Second order resilience is a measure of both the systems deformation and its ability to recover to a pre-stress state. Third order resilience is an integration of different second order resilience values over a single threat of various magnitudes and fourth order resilience is a measure of the system or objects ability to withstand and recover from a variety of different threats. Use of a common framework for measuring resilience across a wide variety of 
fields will allow for meaningful comparisons, tracking over time, and ultimately aid in helping government officials, business owners, and the broader public make more informed risk management decisions.

The purpose of Adam Rose's paper is to explain static and dynamic economic resilience in relation to disasters. Rose begins with a rigorous definition of concepts at the micro, meso, and macroeconomic levels. It is extended to an operational metric and discussion of its successful application to measuring resilience in case studies of simulated and actual events. Rose then discusses the formulation of resilience indices. Rose emphasizes the importance of actionable variables that can lead to economic recovery and points out how to weight these variables in the overall index on the basis of studies of the effectiveness of individual resilience tactics.

In Sarah Slaughter's paper, she approached resilience from a systems view, in which a community is a set of people with shared values, norms and relationships that live in close proximity to each other in a specific place. The social system of a community has relationships with the other social systems in which it is nested, and also with the natural systems, both within that specific location and nested within the greater natural systems. Humans develop and build systems to provide critical services that enable civil society and commerce, and these built systems have relationships with both the social and natural aspects, and they with it. Resilience is defined as the "persistence of systems and their ability to absorb change and disturbance and still maintain the same relationships among populations or state variables." Enhancing resilience entails developing the community's long-term capacity to accommodate changes by effectively leveraging all of the assets and resources associated with its systems, relationships, and states.

\subsection{Risk and Insurance}

Catastrophic accidents include nuclear and chemical accidents, extreme storms, volcanic eruptions, pandemics, etc. For example, in light of the 2011 Fukushima disaster, recent discussion has focused on finding the best nuclear storage options, maximizing the oversight power of global institutions and strengthening safety measures. In addition to these, the development of dependable liability coverage that can be tapped in an emergency is also needed and should be considered thoughtfully. To succeed, financing is essential using special purpose instruments from the global bond market, which is as big as $\$ 175$ trillion. Thus, in their paper Ayyub, Pantelous and Shao present a two-coverage type trigger nuclear catastrophe (N-CAT) risk bond for potentially supplementing the covering of US commercial nuclear power plants beyond the coverage per the Price Anderson Act as amended. The N-CAT peril is categorized by three risk layers: incident, accident and major accident. The pricing formula is derived by using a semi-Markovian dependence structure in continuous time.

Castaldi notes in his paper that very few industries understand the risk that society faces due to extreme events as well as a reinsurer, whose core business model is to understand and quantify the impact of these events. Reinsurers build technologies to evaluate today's risk as well as tomorrows, such as the additional risk that society faces due to climate change. The potential losses due to natural events are growing at an alarming pace and we need to slow down that trend if not possibly reverse it. This is a problem that we all share and have to work together to reduce. 


\subsection{Mitigation and Recovery Strategies}

Debra Ballen notes that the Institute for Business and Home Safety has identified five concepts as central to the economics of community disaster resilience. These concepts are: (1) the importance of "going green and building strong"; (2) residential and commercial building performance; (3) emergency preparation and response as a shared responsibility; (4) building codes as a threshold, but not an end goal; and (5) the need for a variety of public and private sectors incentives.

Investing in resilience is a national imperative and increasingly considered a basic business practice. In addition to mitigating disaster-related damage by introducing new flexibility, it increases productivity, revenue, reputation, and shareholder value. Investing in resilience before disaster strikes is the smart choice for individuals, companies, and governments alike. In their paper Egli and McKinney offer perspectives on resilience related concerns.

Within an economy, businesses, governments and community service providers are the actorson-the-ground that experience the direct and indirect impacts of infrastructure failures. They are the actors whose responses, decisions, and adaptive behaviors collectively shape the path of economic recovery and patterns of growth and decline. In their paper, Seville et al present key findings from a study conducted with 541 public and private Canterbury regional organizations by Resilient Organizations as part of the Economics of Resilient Infrastructure project in New Zealand. The study was conducted following major disruptions in the aftermath of a complex earthquake sequence. Seville et al found how organizations mitigated those disruptions and recovered their productive capacity. Highlighted are the ways in which organizations adapted to facilitate continued or even improved functioning and discovered the impact of resilience on their ability to meet customer demand, productivity and cash-flow.

\subsection{Economic Impact Assessment}

The US Army Corps of Engineers (USACE) is one of the world's largest public engineering, design, construction and management agencies, and its civil works mission areas include navigation, flood risk management, hydropower, water supply, recreation, and environment with an annual budget of $\$ 5$ billion. To estimate total regional economic impacts of USACE's programs, a Regional Economic System (RECONS) model that includes more than 1,500 area specific input-output models was developed for all civil works project regions. In their paper, Chang et al describe the capabilities of RECONS, which allows the USACE to evaluate project and program expenditures associated with the annual civil works budgets of the eight business lines managed by the USACE. Chang et al illustrate how RECONS has incorporated the Environmental Extended Input-Output Model approach by augmenting the technical coefficients matrix to reflect energy consumption and greenhouse gas emissions. The total amount of carbon dioxide produced for each economic activity is available at the industry sector level in addition to jobs, income, sales and other economic effects.

Cutler et al describe Computable General Equilibrium (CGE) modeling, a quantitative methodology used to evaluate how a regional economy responds to changes in economic policy or other external factors. CGE models are particularly useful when the expected impacts of an external shock are complex and realized through multiple channels. While CGE models are typically used to estimate the impact of economic or policy shocks, Cutler et al intend to broaden the use of CGE analysis to examine the economic impacts of natural disasters toward the 
development of NIST-CORE (the NIST Community Resilience Modeling Environment) at the Center for Risk-Based Community Resilience Planning led by Colorado State University. Cutler et al highlight some of the key challenges associated with integrating a CGE model into NISTCORE. These challenges involve: (1) data and accounting matrices; (2) model assumptions; (3) city selection and generalizability of model findings; and (4) interdisciplinary collaboration across engineering, social and economic sciences.

\section{Findings and Recommendations from the Breakout Sessions}

Each of the breakout sessions was divided into three parts: (1) brainstorming; (2) challenge selection and prioritization; and (3) development of details. In the brainstorming part, the scope of the session was identified and challenges and best practices were identified. In the selection and prioritization part, a small set of challenges were selected for further development. In the third part, the selected challenges were developed for presentation to all workshop attendees in a final plenary session. Each selected challenge included a narrative description, its root causes, and an action plan through which key stakeholders could bring about change. It is important to note that the action plans presented in Section IV are aimed at advancing the state of resilience within the nation. Therefore, it is believed that many of the individual actions identified will help to guide the national agenda towards the selection of economic considerations that have the potential to drive community investments in resilience.

This Proceedings provides the elements of a roadmap of national usefulness informing key stakeholders of potential opportunities for their resilience-related research, development, and deployment efforts. Moreover, the Proceedings provides many useful considerations for the resilience stakeholders. These include: the conflict between short-term priorities and long-term well-being; the concept of a "resilience dividend" where resilience is evaluated on a day-to-day co-benefit basis, rather than being justified on hypothetical disaster scenarios; the critical role of performance-based standards; the inequitable distribution of costs and benefits among stakeholders; the development of measures of economic resilience that are conceptually sound and empirically valid; and the promise that systems-based thinking has for increased resilience to natural and human-caused disasters.

The material contained in this Proceedings is intended to promote increased awareness of resilience-related issues - both challenges and opportunities. The Proceedings identifies definitional and methodological disconnects and analyzes them from a systems perspective. The Proceedings also identifies barriers to the adoption and use of resilience-enhancing products and practices and recommends an agenda for NIST and others to address these barriers. 
xxiii 


\section{Harary, Howard, Director, Engineering Laboratory, National Institute of Standards and Technology}

\section{Opening Remarks}

Good morning and welcome to the Economics of Community Disaster Resilience Workshop. Thank you for taking the time out of your busy schedules to participate and provide your insights and experience to help make the business case for making investments in making a community more resilient.

You don't have to search far and wide for reasons to be here. Last year, wildfires scorched Southern California and Washington, and Napa was rocked by an earthquake. In fact, there were 45 major disaster declarations last year. And 2014 was a relatively quiet year -- at least in terms of raw numbers. In fact, the last time there were fewer than 50 major disaster declarations was 2002. And since 2002, the U.S. has endured seven of the 10 most costly disasters in its history, with Hurricane Katrina and Superstorm Sandy at the top of the list.

And as we look ahead, we know that the disaster risks will only increase. Recent studies have warned of increased coastal flooding, mega droughts, and Katrina-scale storms blasting the Northeast, just to name a few of the predicted impacts of climate change.

So, achieving disaster resilience should be a top priority for the Nation, states, businesses, citizens, and, especially, communities. Communities -- where we live, work, raise families -- are the necessary focal point. Communities are 'ground zero' when a hazard event strikes. And communities bear the brunt of recovery, which can span many years.

But communities also bear the responsibility to become more resilient so that random, yet almost inevitable hazards do not become disasters. They are challenged to be proactive -- to take steps so that they can better withstand, adapt, and recover quickly when nature throws a violent punch or when they are assailed by a human-caused catastrophe. But what steps? And how and when should communities take them? What are the priorities? What's the business case?

Well, that's why you're here -- and that's why the National Institute of Standards and Technology (NIST) has undertaken this collaborative, nationwide effort to develop a comprehensive, science-based approach to community disaster resilience. Communities want actionable information and guidance to support their decision-making and their investments in resilience. With reliable information, methods, and tools, communities can assess their strengths and their vulnerabilities. They can identify their blind spots. And they can develop an integrated view of what resilience looks like so that all the key players will be involved in helping to make it a reality.

Now nobody disagrees -- I hope -- that disaster resilience is important. In fact, resilience has become somewhat of a buzz word and catch-all term. In a recent letter to the journal Nature, which was prompted by an article on flood resilience, the writer claimed that there are over 70 different definitions of resilience in the scientific literature. While I agree that consistent 
terminology is important, I think we have a strong and building consensus on the key points to begin operationalizing the goal of community disaster resilience.

On April 27th, NIST released for public comment a draft of the Community Resilience Planning Guide for Buildings and Infrastructure Systems. The economic guidance document and decision support methodology being developed by our Applied Economics Office is designed to fit "hand-in-glove" with the planning guide. The planning guide is intended to be a customizable tool, one that a town or city can apply to better understand their own circumstances, define their particular risks, and set their own priorities and timetables for implementation.

Clearly, the time to plan for hazards is not after disaster strikes. Regrettably, that is still largely how we do it now -- during recovery. Sometimes, communities build back better, reduce their vulnerability, and improve their capacity to recover quickly and efficiently when the next hazard strikes. Communities are ready for a new approach that reduces damage levels and speeds recovery. Resilience planning and implementation really should be done proactively -- in anticipation of the next extreme event. After all, we live in what already is one of the most natural-disaster-prone regions in the world. And climate change will more than likely add to this worrisome distinction.

Our challenge is to clear and mark the path that leads to the goal of reducing the impacts of hazard events on our society and economy by enhancing the resilience of buildings and infrastructure systems in our communities. To do this, it is necessary to shift our thinking from the old way -- designing and operating buildings and infrastructure as independent systems -- to a new way -- as an integrated system-of-systems. We also must interweave resilience planning into a community's social and economic systems, since they are supported by the physical infrastructure and the vital services it enables.

Providing communities with guidance to avoid disastrous consequences can make a tremendously positive difference. Helping communities to make resilience an integral part of their long-term planning and development is an incredible two-for-one deal. It not only will increase resilience to disruptive events -- and reduce their enormous toll on people and the economy; it also will make our communities better places to live and more desirable locations for business and industry.

As many of you know, NIST's efforts are part of a much larger federal effort to enhance the resilience of our communities and by extension, the resilience of the Nation to the hazards we face. The Department of Commerce, of which NIST is a part, has made resilience a key element of its strategic plan. Many parts of the Department are engaged in efforts to improve the resilience of our communities and the Nation. The NIST resilience program is a part of -- and contributes to -- interagency efforts to prepare the Nation for the effects of a changing climate, as documented in the President's Climate Action Plan.

The efforts I have just described are only a part of NIST's commitment to improving the resilience of our Nation's communities. One important source of new knowledge and modeling capabilities will be the new NIST-funded Community Resilience Center of Excellence, based at Colorado State University. Working with NIST researchers and partners from 10 other 
universities, the center will develop models and computer tools to support community resilience efforts.

The objective of this workshop is to bring together decision makers, community planners, policy makers, and subject matter experts in economics, engineering, insurance, finance, and risk analysis to address the economics of community disaster resilience. My hope is that this workshop will go a long way towards enabling NIST -- and the Nation - to identify economicsbased opportunities, tools, and levers to support decision making in communities that will make them more disaster resilient.

So, thank you again for coming and for sharing your ideas. I look forward to a productive workshop. I greatly look forward to hearing about the outcomes of your work. 
xxvii 
Helper, Sue, Chief Economist of the Department of Commerce, Washington, DC

\section{Perspectives on Resilience Economics for the Nation}

Dr. Sue Helper, Chief Economist of the Department of Commerce, provided the keynote address to the NIST/ASCE/ASME (National Institute for Standards and Technology/American Society of Civil Engineers/ American Society of Mechanical Engineers) Workshop on the Economics of Community Resilience on April 30, 2015. She spoke about the imperative for incorporating resilience into community planning - the economic benefits realized by doing so and the potentially significant risks of not doing so, as demonstrated by relevant case studies. Dr. Helper's address was entitled "Perspectives on Resilience Economics for the Nation" and is responsive to Presidential Policy Directive 8, which calls for "strengthening the security and resilience of the United States through systematic preparation for the threats that pose the greatest risk to the security of the nation including acts of terrorism, cyberattacks, pandemics and catastrophic natural disasters." Dr. Helper spotlighted NIST's recent resilience efforts, both the workshop, "NIST's Community Resilience Planning Guide for Buildings and Infrastructure systems," and the NIST-funded Community Resilience Center of Excellence based at Colorado State University.

Dr. Helper noted that over $\$ 1$ trillion has been spent on 178 weather and climate disasters since 1980, per NOAA's National Climatic Data Center. But, she said, investments in resilience can reduce such costs. For example, she cited one store, IKEA, which invested in resilience prior to Superstorm Sandy and was able to function just after the storm passed through Brooklyn. Meanwhile, just blocks away, Fairway Market, which made no such investments in resilience, lost all of its inventory and was unable to function for a period of months. Dr. Helper said that modifications to enhance resilience for existing structures before disruptive events improve system performance and dramatically shorten time to full recovery.

Dr. Helper demonstrated how some communities undervalue and fail to invest in resilience since risks are often poorly understood and hard to monetize, choices are often collective and involve future generations, and risks are sometimes shifted to those least able to bear them. Dr. Helper emphasized the need to define the "risk correlation" or the "beta." Firms need to diversify their portfolio while reducing their high betas so that the community or firm can retain returns even after tough economic times or following a natural disaster.

The speech concluded with examples of Commerce data that have helped in responding to or evaluating the economic impacts of natural disasters. Dr. Helper pointed to the example of the U.S. Census Bureau's American Community Survey data. This information was used after the Hawaii Kilauea volcano eruption of 2014 to produce maps of vulnerable populations in the path of the Puma lava flows including locations of schools, students, households in poverty and the elderly. In another example, Dr. Helper highlighted the Bureau of Economic Analysis' Regional Input Output Modeling System multipliers, which were used by staff in her Office of the Chief Economist (OCE) to estimate the economic impact of Superstorm Sandy on New Jersey and New York - and in particular the projected economic and job impacts on travel and tourism in New Jersey. 
Finally, Dr. Helper noted an ongoing collaborative effort between OCE and NOAA's Office of the Chief Economist to develop a Departmental website to assist firms in incorporating natural capital in their business planning and operations. The year-long project includes a series of four business roundtable workshops - the Gulf of Mexico, the Great Lakes, the Northeast and Silicon Valley, culminating in an early 2016 event in Washington, D.C. 


\section{Morris, Christine, Chief Resilience Officer, City of Norfolk}

\section{Community Resilience-A Chief Resilience Officer's Perspective}

The city of Norfolk's natural and man-made assets are remarkable: 144 miles of coastline; 125 active and engaged civic leagues; the world's largest naval station; and the most multi-modal city in Virginia. But having been nearly destroyed during the American Revolution, burned down during the Civil War, and flooded repeatedly during the past century, Norfolk knows that resilience is key to its future.

In this city anchored by the Navy, and taking a whole-community approach focused on hazard mitigation, preparedness, response, and recovery, Norfolk has learned to "live with the water" as a coastal city; however, rising sea levels and recurrent flooding remain a major threat. Norfolk faces two overarching concerns. First, local transportation officials estimate thousands could be stranded if a major hurricane hits the region because the state's evacuation plan is inadequate. Second, energy security and redundancy remain a challenge, as power outages present safety and health hazards.

Norfolk's commitment to resilience was recognized through its selection as one of the 33 Wave 1 finalists in the Rockefeller Foundation's 100 Resilient Cities Centennial Challenge. Pioneered by the Rockefeller Foundation, 100 Resilient Cities (100RC) is dedicated to helping cities around the world become more resilient to the physical, social, and economic challenges that are a growing part of the 21 st century. 100RC supports the adoption and incorporation of a view of resilience that includes not just the shocks - earthquakes, fires, floods, etc. - but also the stresses that weaken the fabric of a city on a day-to-day or cyclical basis. These stresses include: high unemployment; an overtaxed or inefficient public transportation system; endemic violence; or chronic food and water shortages. By addressing both the shocks and the stresses, a city becomes more able to respond to adverse events, and is overall better able to deliver basic functions in both good times and bad to all populations.

Cities in the 100RC network are provided with the resources necessary to develop a roadmap to resilience along four major pathways: (1) financial and logistical guidance for establishing an innovative new position in city government, a Chief Resilience Officer (CRO), who will lead the city's resilience efforts; (2) expert support for development of a robust resilience strategy; (3) access to solutions, service providers, and partners from the private, public, and NGO sectors who can help them develop and implement their resilience strategies; and (4) membership in a global network of member cities who can learn from and help each other. Through these actions, 100RC aims not only to help individual cities become more resilient, but will facilitate the building of a global practice of resilience among governments, NGOs, the private sector, and individual citizens.

The city of Norfolk recognizes that resilience is the ability to withstand chronic stresses and acute shocks while still maintaining essential functions and recovering quickly and effectively. To meet that challenge, the Chief Resilience Officer will: (1) work across silos to create and implement a comprehensive resilience strategy; (2) serve as senior advisor to the city manager; 
(3) coordinate resilience efforts across government and multi-sector stakeholders; (4) promote resilience thinking and act as a global thought leader; and (5) liaise with other CROs, 100RC staff, and service providers via the 100RC network and platform. Through the CRO's efforts, the city of Norfolk has focused on three inter-related areas: (1) costal resilience; (2) economic resilience; and (3) neighborhood resilience. As part of its costal resilience effort, Norfolk is pioneering the first resilient land use code and is "re-imagining" structures and infrastructure in a rising sea environment. Economic resilience recognizes that a vibrant economy is a diverse economy and is working on creating an entrepreneurial ecosystem that can support business creation and business expansion. To improve residents understanding of risk and reduce repetitive loss flood insurance claims Norfolk is working to improve public awareness about flood risk. Neighborhood resilience is a central ingredient to Norfolk's resilience because above all Norfolk is a city of neighborhoods. Through the Neighbors Building Neighborhoods model, Norfolk is identifying neighborhood assets that working with local communities to find effective ways to build cohesion that protects vulnerable populations during disruptive events.

Since the Nation's birth, Norfolk has suffered shocks and rebounded strongly. The future poses many new challenges, but Norfolk is well positioned to meet them, learn from them, and become a sought after place for families, businesses, and government. 
Ayyub, Bilal M., Gerald E. Galloway and Richard N. Wright, University of Maryland, and Robert E. Chapman, NIST

\section{About the Workshop}

\section{Background}

Advancements in measurement science are needed to estimate the economic burden of disasters. Disaster-related loss estimates should consider direct losses plus down-stream, indirect effects, such as business interruption, which can be large and have a significant effect on the sustainability of a local or regional economy. The Engineering Laboratory at NIST is developing such an economic guide to help key stakeholders make the business case for communities to invest in disaster resilience. The guide will enable a community to quantify net savings from a staged implementation of a mitigation strategy and its integration into the community's longrange planning strategy. NIST, ASCE and ASME held this workshop to address this challenge.

\section{Objectives}

The objective of the workshop is to bring together decision makers, community planners, policy makers, and subject matter experts in economics, engineering, insurance, finance, and risk analysis to collect information on the state-of-the-art in, and identify data and knowledge gaps relevant to, the economics of community disaster resilience. NIST's Community Disaster Resilience Initiative includes the development of an economic guide for a first-generation decision support methodology to aid communities in identifying cost-effective strategies for achieving their resilience performance goals. The outcomes of the workshop will enable NIST to better assist key stakeholders in identifying opportunities to support the decision making abilities of communities to plan, to mitigate, respond to, and recover from disasters. The discussion and outcomes will benefit the participants by enhancing their understanding of multidisciplinary perspectives, available methods, best practices, and associated uncertainties.

\section{Discussion Topics}

Discussion topics included:

- Resilience Planning and Deployment

- Dealing with Uncertainty

- Economics of Recovery

\section{Participants}

The workshop was attended by about 75 people. A complete list is provided in Appendix A with biographical information on speakers, moderators and organizers in Appendix B. 


\section{Agenda}

Evening of April 29, 2015: Dinner and Opening Discussion

\begin{tabular}{|c|c|c|c|c|}
\hline Time & Topic & Duration & Room & Speakers \\
\hline \multirow{2}{*}{$5: 00-6: 00 \mathrm{pm}$} & Registration & \multirow{2}{*}{60} & \multirow{4}{*}{$\begin{array}{l}\text { Sheraton } \\
\text { Reston Hotel } \\
\text { (Jr. Ballroom) }\end{array}$} & \multirow{2}{*}{ Sheraton Reston, VA } \\
\hline & Reception & & & \\
\hline \multirow{2}{*}{$\begin{array}{c}\text { 6:00-9:00 pm } \\
\text { Dinner seating } \\
\text { by breakout }\end{array}$} & Breakout 1. Resilience Planning and Deployment & 180 & & \multirow{2}{*}{$\begin{array}{l}\text { Bilal Ayyub, Lead Organizer, University of Maryland (UMD) } \\
\text { Robert Chapman, Sponsor, National Inst. of Standards and Tech. (NIST) } \\
\text { Topics: Background, objectives and plans of the breakout sessions }\end{array}$} \\
\hline & Breakout 3. Economics of Recovery & 180 & & \\
\hline \multicolumn{5}{|c|}{ April 30, 2015: Workshop } \\
\hline Time & Topic & Duration & Room & Speakers \\
\hline 7:30-8:30 & $\begin{array}{r}\text { Breakfast } \\
\end{array}$ & 60 & ASCE & \\
\hline \multirow{5}{*}{$8: 30-9: 20$} & Welcome and Introduction & 5 & \multirow{4}{*}{ Cardinal } & Bilal Ayyub, CEE Professor, UMD \\
\hline & Opening remarks & 10 & & Howard Harary, Director, Engineering Laboratory, NIST \\
\hline & Symposium program & 10 & & Bilal Ayyub, CEE Professor, UMD \\
\hline & Perspectives on resilience economics for the Nation & $20+5$ & & Sue Helper, Chief Economist, Department of Commerce \\
\hline & \begin{tabular}{|c|} 
Technical Presentations \\
\end{tabular} & & & Gerald Galloway, NAE, CEE Professor, UMD \\
\hline $9: 20-9: 40$ & Resilience planning and deployment - I & $15+5$ & Cardinal & Joseph Fiksel, Director, Center for Resilience, The Ohio State Un. \\
\hline 9:40-10:00 & Resilience planning and deployment - II & $15+5$ & Cardinal & Howard Kunreuther, Wharton at University of Pennsylvania \\
\hline $10: 10-10: 30$ & Dealing with uncertainty -1 & $15+5$ & Cardinal & Robert Prieto, Sr VP, Fluor \\
\hline $10: 30-10: 50$ & Dealing with uncertainty - II & $15+5$ & Cardinal & Richard Feigel, Former VP (retired), Hartford Steam Boiler \\
\hline 10:50-11:10 & Economics of recovery & $15+5$ & Cardinal & Stephanie Chang, The University of British Columbia \\
\hline $11: 10-11: 35$ & Perspectives on community needs & $20+5$ & Cardinal & Christine Morris, Chief Resilience Officer, City of Norfolk \\
\hline 11:35-11:55 & Perspectives on Community Disaster Resilience & $15+5$ & Cardinal & Adam Rose, University of Southern California \\
\hline $11: 55-12: 00$ & Breakout sessions: Knowledge gaps \& research needs & 5 & Cardinal & Richard Wright, NAE, CEE Professor, UMD \\
\hline \multirow{2}{*}{$12: 00-1: 00$} & \multirow{2}{*}{\begin{tabular}{|c|} 
Hosted Lunch \\
Perspectives on Community Disaster Resilience \\
\end{tabular}} & \multirow{2}{*}{60} & \multirow{2}{*}{ ASCE } & John W. van de Lindt, Colorado State University \\
\hline & & & & Thomas Simth (invited), Executive Director, ASCE \\
\hline \multirow{4}{*}{ 1:00-4:00 } & Breakout 1. Resilience planning and deployment & & \multirow{4}{*}{ Cardinal } & Joseph Fiksel, The Ohio State University (co-moderator) \\
\hline & Phase 1. Broad scope brainstorming & 60 & & Howard Kunreuther, University of Pennsylvania (co-moderator) \\
\hline & Phase 2. Prioritization and selections & 60 & & Douglas Thomas, Economist, NIST (co-facilitator) \\
\hline & Phase 3. Report preparation for joint session & 60 & & Gerald Galloway, NAE, CEE Professor, UMD (co-facilitator) \\
\hline \multirow{4}{*}{ 1:00-4:00 } & Breakout 2. Dealing with uncertainty & & \multirow{4}{*}{ DMJM } & Robert Prieto, Sr VP, Fluor (co-moderator) \\
\hline & Phase 1. Broad scope brainstorming & 60 & & Richard Feigel, Former VP, Hartford Steam Boiler (co-moderator) \\
\hline & Phase 2. Prioritization and selections & 60 & & David Butry, Economist, NIST (co-facilitator) \\
\hline & Phase 3. Report preparation for joint session & 60 & & Richard Wright, NAE, CEE Professor, UMD (co-facilitator) \\
\hline \multirow{6}{*}{ 1:00-4:00 } & Breakout 3. Economics of recovery & & \multirow{2}{*}{$\mathrm{CH} 2 \mathrm{M}$} & Stephanie Chang, University of British Columbia (co-moderator) \\
\hline & Phase 3. Report preparation for joint session & 60 & & Bilal Ayyub, CEE Professor, UMD (co-facilitator) \\
\hline & Summaries by Co-moderators: Joint Session & & & Robert Chapman, Chief Economist, Applied Economics Office, NIST \\
\hline & Report on Breakout 1. Resilience planning and deployment & $10+10$ & \multirow{3}{*}{ Cardinal } & Joseph Fiksel and Howard Kunreuther \\
\hline & Report on Breakout 2. Dealing with uncertainty & $10+10$ & & Robert Prieto and Richard Feigel \\
\hline & Report on Breakout 3. Economics of recovery & $10+10$ & & Stephanie Chang and Robert Chapman \\
\hline 5:00-5:15 & Post Workshop Plans and Adjournment & 15 & ASCE & Bilal Ayyub, CEE Professor, UMD \\
\hline
\end{tabular}

Workshop Venue: ASCE Headquarters, Bechtel Center, 1801 Alexander Bell Drive, Reston, VA 20191, (800) 548-2723

Recommended Hotel: Sheraton Reston Hotel, 11810 Sunrise Valley Drive, Reston, VA 20190

Hotel reservation for specioal rate: 703-620-9000 (Tel), 703-860-1594 (Fax), https://www.starwoodmeeting.com/Book/NISTASCEWorkshop 
Ayyub, Bilal M., University of Maryland, and Robert E. Chapman, NIST

\section{Workshop Program Rationale}

\section{Resilience Definitions and Metrics}

The concept of resilience appears in different domains ranging from ecology to psychology and psychiatry to infrastructure systems. It was formally introduced in ecology, defined as the persistence of relationships within a system (Holling 1973), and measured by the system's ability to absorb change-state variables, driving variables and parameters and still persist. Several reputable entities defined resilience in their high-impact documents, most notably the following (Ayyub 2014a):

- In the Presidential Policy Directive (PPD-21, 2013) on Critical Infrastructure Security and Resilience, the "term resilience means the ability to prepare for and adapt to changing conditions and withstand and recover rapidly from disruptions. Resilience includes the ability to withstand and recover from deliberate attacks, accidents, or naturally occurring threats or incidents."

- The National Research Council (2012) defined resilience as the ability to prepare and plan for, absorb, recover from or more successfully adapt to actual or potential adverse events as a consistent definition with U. S. governmental agency definitions (SDR 2005, DHS 2008 and PPD-8 2011) and NRC (2011).

- The ASCE Committee on Critical Infrastructure (ASCE Policy Statement 518, http://www.asce.org/Content.aspx?id=8478) states that resilience refers to the capability to mitigate against significant all-hazards risks and incidents, and to expeditiously recover and reconstitute critical services with minimum damage to public safety and health, the economy, and national security.

- The National Infrastructure Advisory Council defines infrastructure resilience as the ability to reduce the magnitude and/or duration of disruptive events. The effectiveness of a resilient system depends upon its ability to anticipate, absorb, adapt to, and/or rapidly recover from a potentially disruptive event.

- The Multidisciplinary Center for Earthquake Engineering Research (MCEER) of the State University of New York at Buffalo lists characteristics of resilience to include robustness, redundancy, resourcefulness and rapidity.

- The United Nations Office for Disaster Risk Reduction (UNISDR) characterized a resilient city by its capacity to withstand or absorb the impact of a hazard through resistance or adaptation, which enable it to maintain certain basic functions and structures during a crisis, and bounce back or recover from an event.

- The Civil Contingencies Secretariat of the Cabinet Office, London, UK (2003, www.cabinetoffice.gov.uk) defined resilience as the ability of a system or organization to withstand and recover from adversity.

Ayyub (2014a) suggested a resilience definition that builds on the PPD-21 (2013) and lends itself for measurement as follows:

"Resilience notionally means the ability to prepare for and adapt to changing conditions and withstand and recover rapidly from disruptions. Resilience 
includes the ability to withstand and recover from disturbances of the deliberate attack types, accidents, or naturally occurring threats or incidents."

This combination definition has intension and inclusion class features. A proposed definition that belongs to the intension class is as follows:

The resilience of a system is the persistence of its functions and performances under uncertainty in the face of disturbances.

This definition is intended to have a broad use ranging from infrastructures to networks to communities. It enables the measurement of resilience through metrics by meeting the following requirements as demonstrated by Ayyub (2014a): (1) building on previous notional definitions; (2) considering initial and residual strength, i.e., capacity and robustness; (3) accounting for abilities to prepare and plan for, absorb, recover from or adapt to adverse events; (4) treating disturbances as events with occurrence rates of stochastic processes; (5) permitting the use of several performance attributes; (6) accounting for changes over time, e.g., aging or improvements; (7) considering full or partial recovery and times to recovery; (8) considering potential enhancements to system performance after recovery; (9) being compatible with other familiar notions such as reliability and risk; and (10) enabling the development of resilience metrics with meaningful units.

Ayyub (2014a) suggested resilience metrics that are consistent with the resilience definition provided earlier as persistence of the system's functions and performances under uncertainty in the face of disturbances, and meet the requirements imposed on such a definition. The definition captures the details of resilience concept and lends itself for valuations as provided in Figure 1. The model allows for and facilitates the following considerations:

- Random disturbances

- Aging

- System enhancements

- Performance after recovery

- Failure profiles

- Recovery profiles

- Benefits and costs

- Investment strategies

- Resilience economics

A simplified version of this concept without aging is provided in Figure 2 based on a linear recovery model. Recovery models based on three cases studies were examined by Ayyub (2015) with the following findings:

- New Orleans, 2005 Katrina is following linear recovery

- I-35W bridge, 2007 has recovered by a single step function

- World Trade Center, 2001 is recovering in a multi-step function 


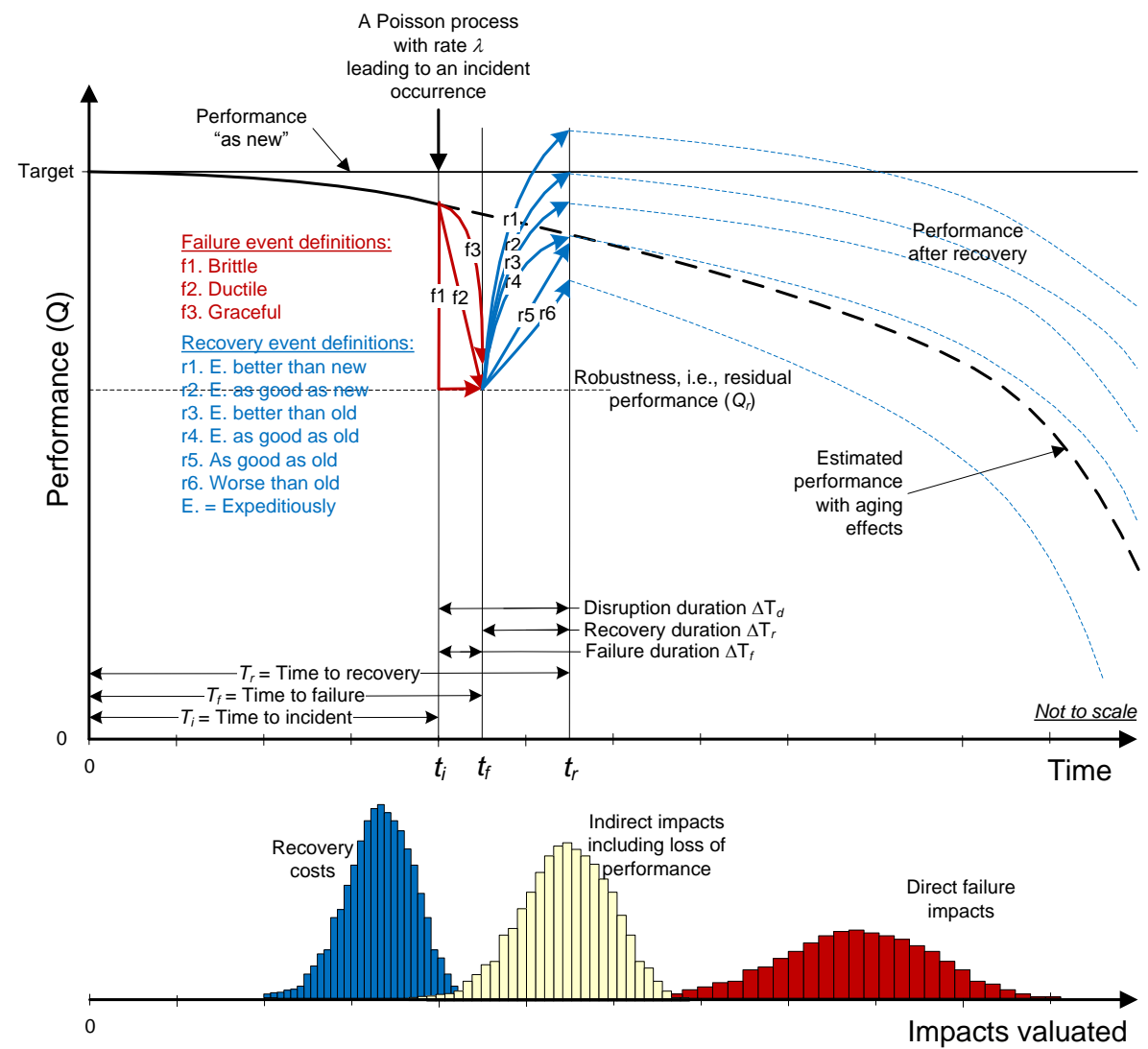

Figure 1. Proposed Definitions of Resilience Metrics (Ayyub 2014a)

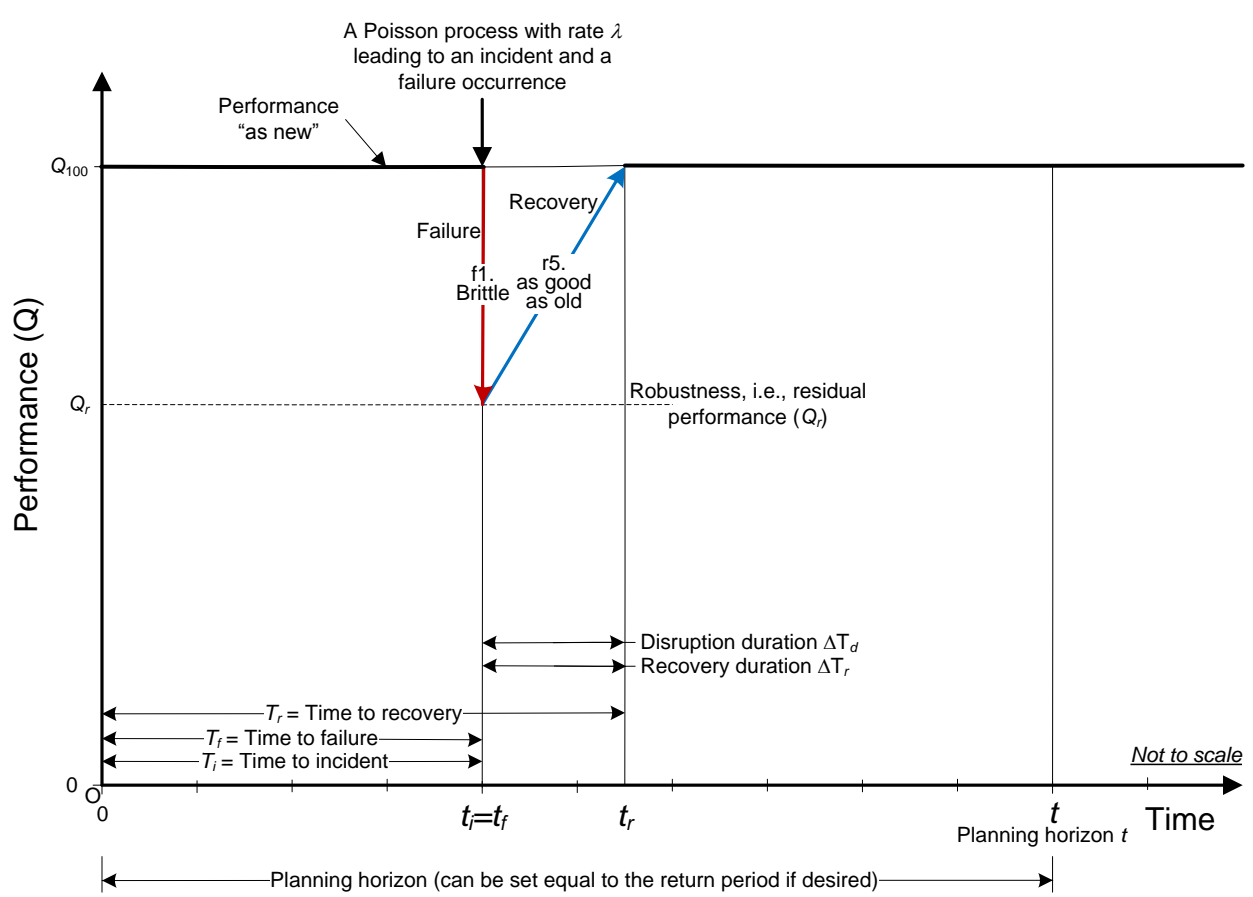

Figure 2. Fundamental Resilience Case I of Linear Recovery (Ayyub 2015) 


\section{Resilience Economics: Breakout Sessions}

Figure 3 shows the primary components of resilience economics: time, cost and benefits. The figure also shows the associated uncertainties. Figure 4 identifies the three breakout sessions in relation to Figure 3 as follows:

- Resilience Planning and Deployment

- Dealing with Uncertainty

- Economics of Recovery

Figure 5 examines varied strategies and the associated costs and benefits with uncertainties.

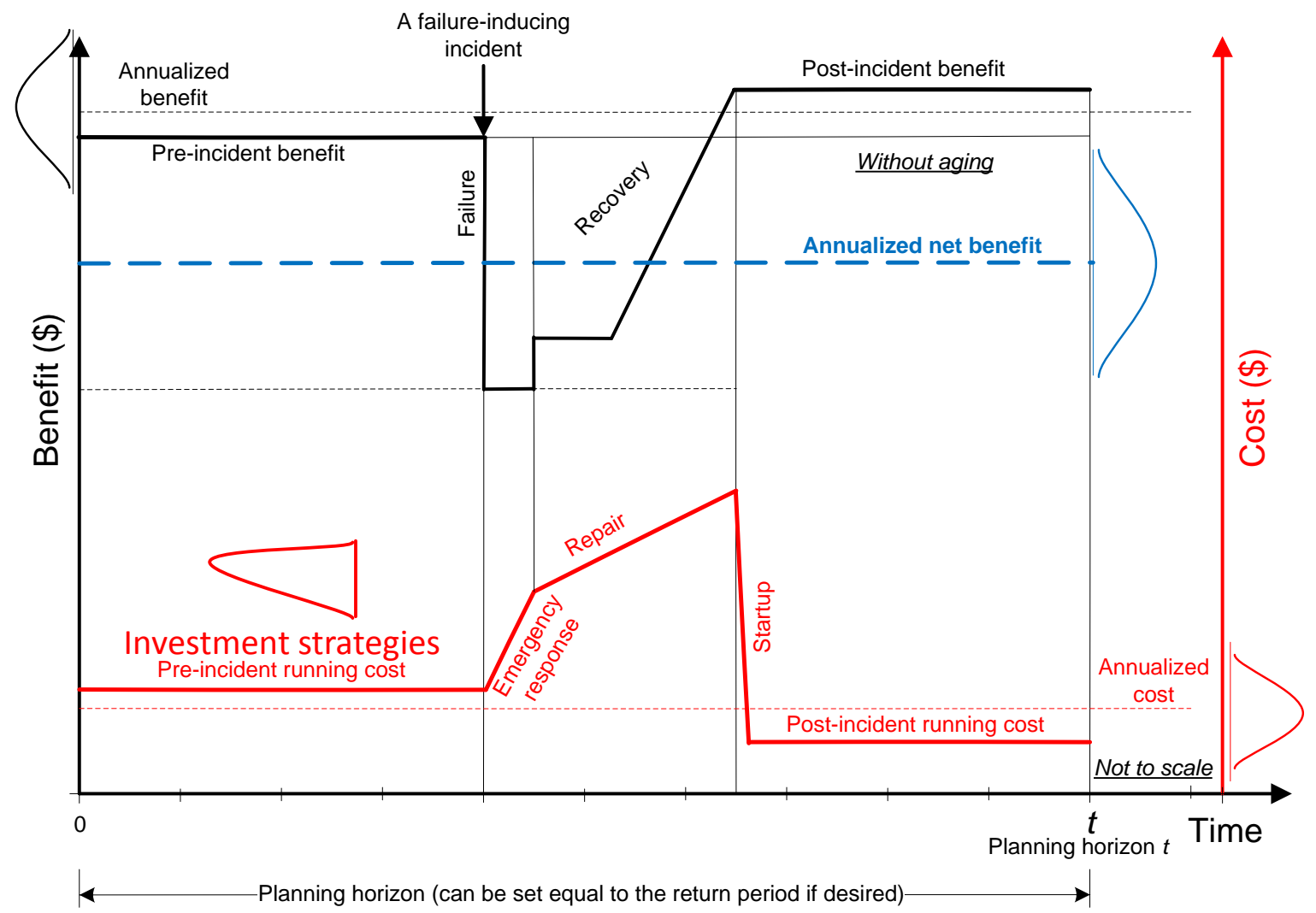

Figure 3. Resilience Economics: Time, Cost and Benefit 


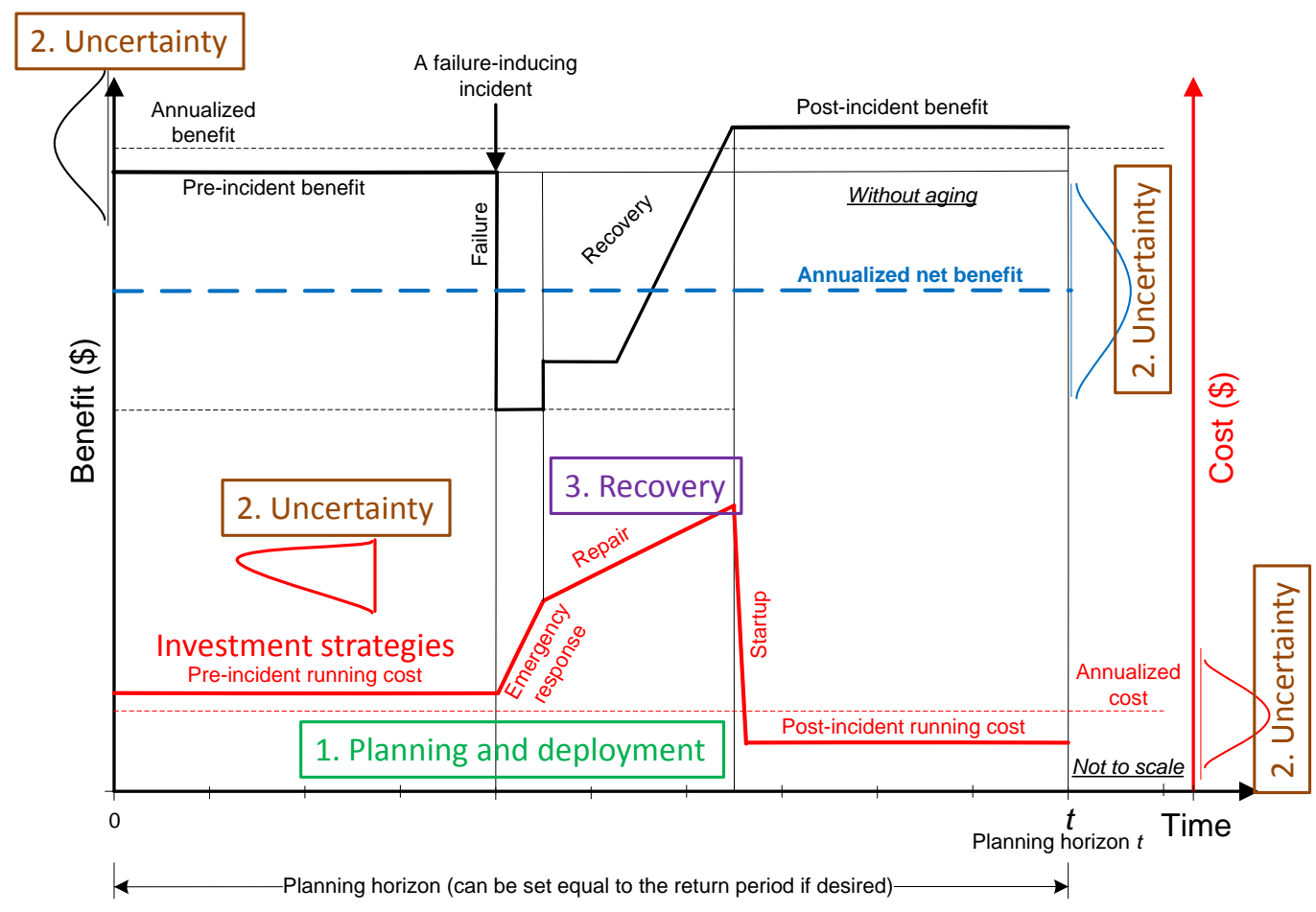

Figure 4. Resilience Economics: Time, Cost and Benefit

\section{Annualized net}

$\uparrow$ benefit (\$)

Analytical methods:

Benefit/cost ratios

Return on investment

Efficient frontier

Probability of not realizing benefit

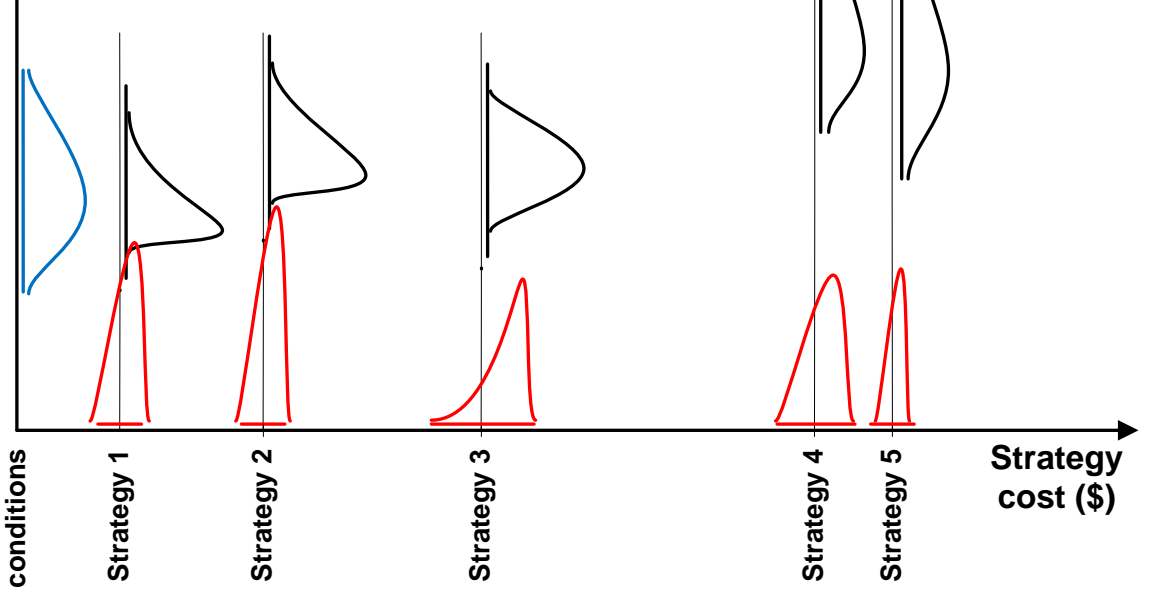

高

Figure 5. Resilience Economics: Tradeoffs 


\section{Bibliography}

Attoh-Okine, N., Cooper, A. T., and Mensah, S. A., 2009, "Formulation of Resilience Index of Urban Infrastructure Using Belief Functions,” IEEE Systems Journal, 3(2), 147-153.

Ayyub, B. M., 2015, Practical Resilience Metrics for Planning, Design and Decision Making, ASCE-ASME J. Risk Uncertainty Eng. Syst., Part A: Civ. Eng., DOI: 10.1061/AJRUA6.0000826. American Society of Civil Engineers.

Ayyub, B. M., 2014a, Systems Resilience for Multihazard Environments: Definition, Metrics, and Valuation for Decision Making, J. Risk Analysis, (34) 2, 340-355.

Ayyub, B. M., 2014b. Risk Analysis in Engineering and Economics, Second Edition, Chapman \& Hall/CRC, Taylor \& Francis Group, Boca Raton, NY.

Becker, G. S., 2005, Wall Street Journal. (Eastern Edition). New York, N.Y.: Jan 4, 2005. page A.12.

Bonstrom, H., and Corotis, R. B., 2014, "First-Order Reliability Approach to Quantify and Improve Building Portfolio Resilience," J. of Structural Engineering, ASCE, ISSN 07339445/C4014001(12).

Bruneau M., and Reinhorn, A., 2007, "Exploring the Concept of Seismic Resilience for Acute Care Facilities," Earthquake Spectra, 23(1), 41-62.

Chang, S. E., and Shinozuka, M., 2004, "Measuring Improvements in the Disaster Resilience of Communities," Earthquake Spectra, 20(3), 739-755.

Cimellaro, G. P., Reinhorn, A. M., and Bruneau, M., 2010, "Seismic Resilience of a Hospital System," Structure and Infrastructure Engineering, 6(1-2), 127-144.

DHS Risk Steering Committee, 2008. DHS Risk Lexicon. Department of Homeland Security, www.dhs.gov/xlibrary/assets/dhs_risk_lexicon.pdf

Ellingwood, B.R., \& Mori, Y., 1993, "Probabilistic Methods for Condition Assessment and Life Prediction of Concrete Structures in Nuclear Plants," Nuclear Engineering and Design, Vol. $142,155-166$.

Garbin, D. A., and Shortle, J. F., 2007, "Measuring Resilience in Network-Based Infrastructures," in Critical Thinking: Moving from Infrastructure Protection to Infrastructure Resiliency, J. A. McCarthy, Ed., George Mason University, VA.

Gilbert, S. W., 2010. Disaster Resilience: A Guide to the Literature. NIST Special Publication 1117, Office of Applied Economics, Engineering Laboratory, National Institute of Standards and Technology, Gaithersburg, MD.

Hashimoto, T., Stedinger, J. R., and Loucks, D. P., 1982, "Reliability, resiliency and vulnerability for water resources system performance evaluation," Water Resource Res., 18(1), 14-20.

Holling, C. S., 1973, "Resilience and Stability of Ecological Systems," Annual Review of Ecology and Systematics, vol. 4, pp. 1-23, 1973.

International Organization of Standardizations (ISO), 2009, Risk Management - Risk assessment techniques, ISO Standard IEC/FDIS 31010, iso.org, Geneva, Switzerland.

Kafali, C., and Grigoriu, M., 2005, "Rehabilitation Decision Analysis," ICOSSAR'05

Proceedings of the Ninth International Conference on Structural Safety and Reliability, 10-23 June, Rome, Italy.

Li, Y., and Lence, B., 2007, "Estimating of Water Resources Systems," Water Resources vol. 43, W07422.

McGill, W. L., Ayyub, B. M., 2009, "Regional Capabilities Performance Assessment for Homeland Security,” IEEE Systems J., 3(2), 192-198. 
Miles, S., and Chang, S., 2003. Urban Disaster Recovery: A Framework and Simulation Model. MCEER, Multidisciplinary Center for Earthquake Engineering Research (MCEER) of the State University of New York at Buffalo.

National Research Council (NRC), 2012. Disaster Resilience: A National Imperative. The National Academies Press, Washington, DC.

Omer, M., Nilchiani, R., and Mostashari, A., 2009, "Measuring the Resilience of the Global Internet Infrastructure System,” 2009 3rd Annual Systems Conference, IEEE, 156-162.

Presidential Policy Directive (PPD), Critical Infrastructure Security and Resilience. PPD-21, Released February 12, 2013, http://www.whitehouse.gov/the-pressoffice/2013/02/12/presidential-policy-directive-critical-infrastructure-security-and-resil

Presidential Policy Directive (PPD), National Preparedness. PPD-8, Released March 30, 2011, http://www.dhs.gov/xabout/laws/gc_1215444247124.shtm

Russell, B., 1993. Introduction to Mathematical Philosophy, Dover, New York, NY.

Shinozuka, M., Chang, S. E., Cheng, T.-C., Feng, M., O’Rourke, T. D., Saadeghvaziri, M. A., Dong, X., Jin, X., Wang, Y., and Shi, P., 2004, "Resilience of Integrated Power and Water Systems," MCEER Research Progress and Accomplishments: 2003-2004, MCEER-04-SP01, 65-86, NY.

Subcommittee on Disaster Reduction (SDR), 2005. Grand Challenges for Disaster Reduction, National Science and Technology Council, Washington DC.

Tierney, K., and Bruneau, M., 2007, Conceptualized and Measuring Resilience, TR News 250, pp. 14-17. http://onlinepubs.trb.org/onlinepubs/trnews/trnews250_p14-17.pdf 
Section $I$.

Community Resilience Economic Decision Guide for Buildings and Infrastructure Systems 
Chapman, Robert E., National Institute of Standards and Technology

\title{
Community Resilience Economic Decision Guide for Buildings and Infrastructure Systems - An Overview
}

\begin{abstract}
The Economic Guide provides a standard economic methodology for evaluating investment decisions aimed at improving the ability of communities to adapt to, withstand, and quickly recover from disasters. ${ }^{1}$ The Economic Guide is designed for use in conjunction with the National Institute of Standards and Technology (NIST) Community Resilience Planning Guide for Buildings and Infrastructure Systems, which provides a methodology for communities to develop long-term plans by engaging stakeholders, establishing performance goals for buildings and infrastructure systems, and developing an implementation strategy. The Economic Guide supports the NIST Planning Guide by providing a mechanism to determine the efficiency of resilience actions and prioritize them. Using the economic methodology frames the economic decision process by identifying and comparing the relevant present and future streams of costs and benefits - the latter realized through cost savings and damage loss avoidance - associated with new capital investment into resilience to those future streams generated by the status-quo. Topics related to non-market values and uncertainty are also explored. The Economic Guide provides context for increasing resilience capacity through focusing on those investments that target key social goals and objectives, and providing selection criteria that ensure reduction of risks as well as increases in resilience. Furthermore, the economic methodology aims to enable the built environment to be utilized more efficiently in terms of loss reduction during recovery and to enable faster and more efficient recovery in the face of future disasters.
\end{abstract}

\section{Keywords}

Benefit-cost analysis; community disaster resilience; economic analysis; economic decision tool; natural and man-made hazards; risk assessment; standards; vulnerability

\section{Introduction}

Communities in the United States experience natural and human-caused hazards every year. When a hazard severely disrupts a community's ability to function, it becomes a disaster. Severe storms, hurricanes, storm surge, tornados, wildfires, earthquakes, snow and ice, and humancaused disruptions lead to numerous Presidential disaster declarations and billions of dollars in losses every year. Community disaster resilience is recognized as a critical national priorityone that requires meaningful and rigorous measurement science to develop planning guidelines and tools, and to establish suitable performance metrics. To address this need, the Economic Guide (Gilbert, Butry, Helgeson, and Chapman, 2015) provides a means to increase the capacity of communities to objectively and effectively compare and contrast capital investment projects through consideration of benefits and costs while focusing awareness on the integrated systemof-systems aspects of community disaster resilience.

\footnotetext{
${ }^{1}$ This Overview provides a concise and comprehensive summary of the companion document, NIST Special Publication 1197, Community Resilience Economic Decision Guide for Buildings and Infrastructure Systems (Gilbert, Butry, Helgeson, and Chapman, 2015).
} 
The Economic Guide builds on both economic concepts drawn from the literature (Gilbert, 2010) and first-hand experience by key stakeholders. An earlier draft of the Economic Guide in the form of a White Paper (Gilbert and Butry, 2015) was provided as part of the read-ahead materials to the 70 plus registrants for the Economics of Community Disaster Resilience Workshop. Many Workshop attendees provided comments on the earlier draft; several of whom provided extensive sets of comments which have been incorporated into the Economic Guide.

The term resilience is used in many ways. The definition for the Economic Guide is contained in Presidential Policy Directive 21 (PPD-21, 2013), which states: “the term 'resilience' means the ability to prepare for and adapt to changing conditions and withstand and recover more rapidly from disruptions." Under this definition, resilience includes activities already conducted by communities, such as disaster preparedness, hazard mitigation, code adoption and enforcement, and emergency response. The phrase "prepare for and adapt to changing conditions" refers to preparing for conditions that are likely to occur within the lifetime of a facility or infrastructure system, such as a hazard event or physical conditions that may change over time. The second part of the definition, "withstand and recover quickly from disruptions," must be examined for the anticipated range of possible hazard events.

\section{Relationship to the NIST Community Resilience Planning Guide for Buildings and Infrastructure Systems}

The NIST Community Resilience Planning Guide for Buildings and Infrastructure Systems (NIST, 2015) provides a methodology for local government to bring together all the relevant stakeholders to establish performance goals to maintain the social and economic fabric when disruptive events occur. The NIST Planning Guide is intended to support long-term community planning. The methodology is focused on the role that buildings and infrastructure play in assuring that social and economic functions are able to resume in a manner that does not result in detrimental impacts after a disruptive event. When catastrophic events occur, the community will have plans in place to rebuild in a thoughtful way to be better prepared for future events, including coordination with state and federal agencies as outlined in the National Preparedness Goal. The National Preparedness Goal (Federal Emergency Management Agency (FEMA), 2015) is stated as: "a secure and resilient nation with the capabilities required across the whole community to prevent, protect against, mitigate, respond to, and recover from threats and hazards that pose the greatest risk." The NIST Planning Guide supports the National Preparedness Goal by providing planning guidance at the local level to support achieving the outcome of community resilience.

The NIST Planning Guide details a six-step process for community leaders to develop and implement a resilience plan. It creates a proactive process to ensure critical social functions of the community are supported during and after a disaster occurs. The six steps are briefly described below.

1. Form a Collaborative Planning Team

The objective is to identify the resilience leader(s) and critical team members, and engage with key public and private stakeholders for input into the planning and implementation stages. 


\section{Understand the Situation}

The objective is to characterize the social dimensions and built environment, by developing an understanding of the social functions that buildings and infrastructure systems support. The social institutions includes: family, health, economy, education, government, religious and cultural beliefs, community service, and the media. The built environment includes: buildings, energy, transportation, communication, and water and wastewater sectors.

3. Determine Community Goals and Objectives

The objective is to establish long-term community goals based on desired recovery performance goals for the built environment. It includes defining community hazards and the current expected performance of systems during and after hazard events in their ability to support social functions.

4. Plan Development

The objective is to perform gap analysis between the current and desired performance goals, and to identify and prioritize potential solutions as a basis for the implementation strategy.

5. Plan Preparation, Review and Approval

The objective is to document the resilience plan and implementation strategies, and to obtain approval from the community of stakeholders.

6. Plan Implementation and Maintenance

The objective is to execute the plan and to revisit it on a periodic basis.

The way in which the six-step process outlined in the NIST Planning Guide fits hand-in-glove into the Economic Guide methodology is illustrated in Figure 1. NIST Planning Guide steps 1 through 4 are listed under the heading of Select Candidate Strategies in Figure 1. NIST Planning Guide steps 5 and 6 are listed under the heading of Select Investments in Figure 1. It is important to note that the Economic Guide has step 4, Plan Development, as its primary focus. NIST Planning Guide steps 1 through 3 are used to identify the potential solutions referred to in step 4. The Economic Guide uses economic analysis techniques to prioritize the potential solutions, which is a key component of step 4. The analysis reports produced under the heading Perform Economic Evaluation provide the economic foundation for NIST Planning Guide steps 5 and 6 . Figure 1 is explained in greater detail in the following section. 


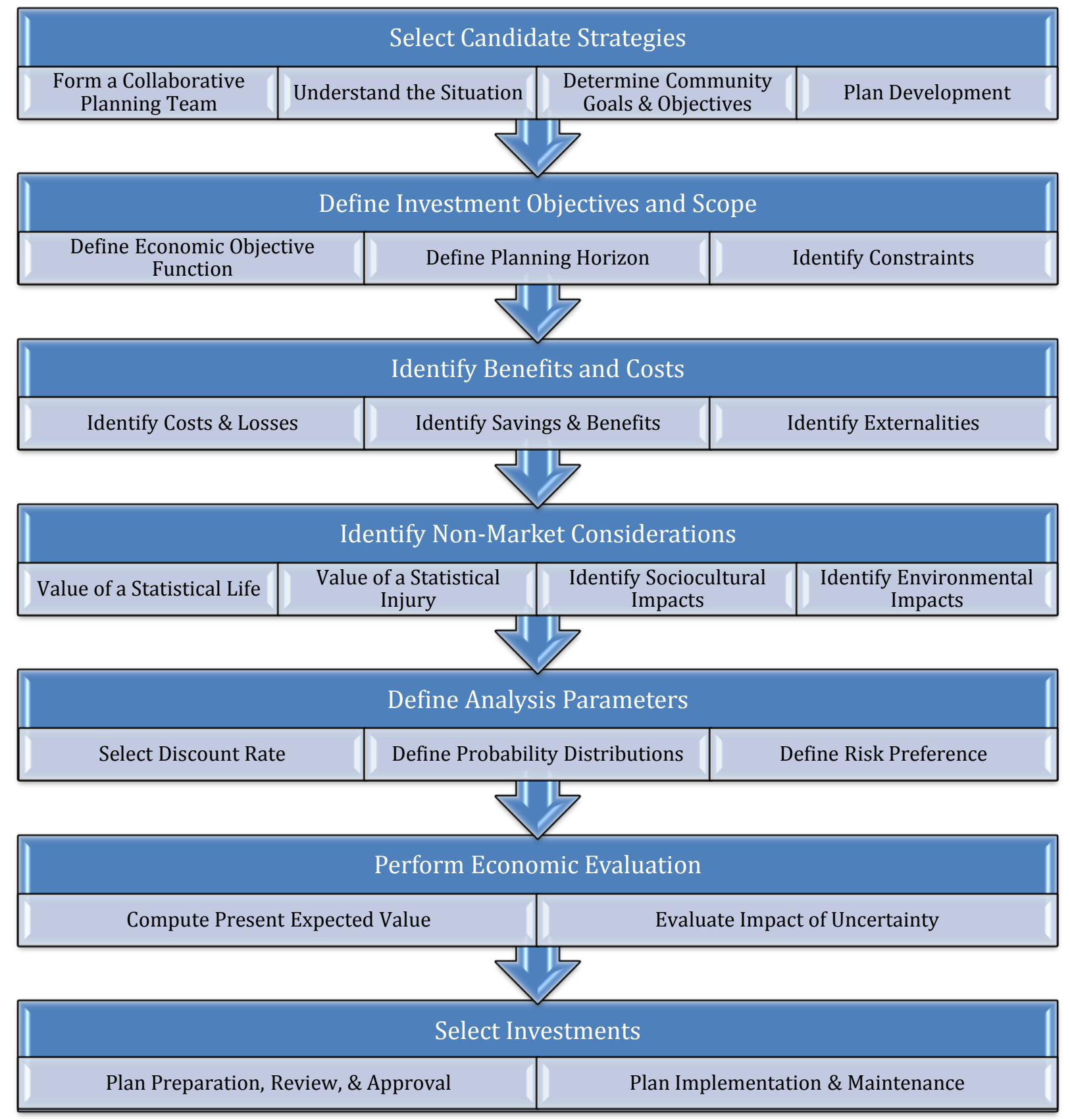

Figure 1. Procedure Underlying the Economic Methodology

\section{Economic Decision Guidelines}

Communities need an approach that helps them decide between alternatives that reduce damage levels and speed recovery while maintaining efficiency over limited economic resources. Ideally, resilience planning for physical infrastructure and related services will be woven into communities' social and economic growth plans/systems in a way that supports decreased vulnerability. Existing plans can be informed by and integrated with a comprehensive, systems level assessment of the community. The San Francisco Planning \& Urban Research Association 
and the state of Oregon are developing and implementing this approach for resilience planning (SPUR, 2009; Yu, Wilson, and Wang, 2014).

The Economic Guide provides a process for considering alternate methods for increasing community resilience through cost-effective investments in the built environment and other infrastructure. It includes the step-wise methodology shown in Figure 1 for analyzing the economics of competing capital improvements and ultimately selecting the most cost-effective investment strategies. Each of the steps in the methodology is described in the subsections which follow. Each step in the methodology corresponds to a numbered subsection; the subheadings under each step are highlighted.

\subsection{Select Candidate Strategies}

This subsection stresses the linkage between the first four steps in the NIST Planning Guide and the Economic Guide methodology. The material compiled by following the first four steps in the NIST Planning Guide produces the information needed to support the economic evaluation of the alternative community resilience investment strategies.

\section{Form a Collaborative Planning Team}

For resilience to be successful, leadership is needed to promote and integrate coordination and outreach activities. The resilience team should include representatives from local government (e.g., community development, public works, and building departments); private owners and operators of buildings and infrastructure systems; local business and industry leaders; representatives of social organizations and any other significant community groups. Some groups may already be working on aspects of resilience planning, such as land use planning, long-term economic development, mitigation, building inspections, or emergency management. The resilience team should compile information from published sources (Gilbert, 2010; Thomas and Chapman, 2008) and on best practices to assist them in their plan development effort.

\section{Understand the Situation}

Both the social dimensions and the built environment need to be characterized, and dependencies among and between the social services and supporting built environment identified. Buildings and infrastructure systems that support desired social services should be clearly identified for resilience planning. Characterizing the existing built environment includes identifying key attributes and dependencies for buildings and infrastructure systems within the community. Communities' building and public works departments and utilities may have much of the needed information available through their various databases. Characteristics that will help determine the current condition of the built environment include the owner, location(s), current use, age, construction types, zoning, maintenance and upgrades, and applicable codes, standards, and regulations, both at the time of design and for current performance. Information about dependence on other systems, or branches of systems, will help build an understanding of how the built environment is expected to perform if one of the systems, or a branch of the system, stops providing services.

\section{Determine Community Goals and Objectives}

Establishing community goals and objectives for the built environment needs input from all stakeholders, including local government offices for community development, emergency response, social needs, public works, and buildings; private owners and operators of buildings 
and infrastructure systems; local business and industry representatives; and social and economic organizations. Community resilience planning should be based on long-term goals to guide resilience planning and implementation. For example, a community may want to attract new business with its improved infrastructure or redevelop a floodplain to become a community park. Community goals also help with developing strategies and prioritization of resilience solutions. Each community has a set of prevalent hazards that should be considered in resilience planning. The NIST Planning Guide recommends that the performance of the community be evaluated at three levels for each hazard to help communities understand performance across a reasonable range of expected hazard levels. By understanding how social systems and the built environment will perform and recover over a range of hazard levels, community goals and objectives will be more informed.

\section{Plan Development}

Plan development is based on performance goals for the built environment which in turn are based on times to recovery or function. Recovery times are established at two levels: desired performance as a long-term goal and anticipated (actual) performance for existing systems. The performance goals should be based on the social needs of the community and consider the functions that buildings and infrastructure systems need to provide, as well as any dependencies between systems or cascading effects caused by failures. Comparison of desired and anticipated performance provides a basis for identifying gaps in performance that will impact community resilience and therefore need to be integrated into the alternative community resilience investment strategies. Community resilience investment strategies include mitigation, disaster preparedness, design and construction, emergency response, and pre-event recovery planning. Inclusion of desired performance goals versus anticipated (actual) performance of the built environment to hazard events, and expected recovery sequences, time, and costs provides a complete basis for communities to understand gaps in performance, prioritize improvements through the use of economic evaluation techniques, and allocate resources.

\subsection{Define Investment Objectives and Scope}

Economics deals with the efficient allocation of resources. At the heart of this allocation process is an optimization problem. In the context of resilience this is either the minimization of costs plus losses or the maximization of benefits minus costs, referred to hereafter as net benefits. Both problem formulations yield the same result, provided the objective function is subject to the same set of constraints, and the same planning horizon.

\section{Define Economic Objective Function}

The Economic Guide is designed to identify the community investment strategies with the greatest net benefit, accounting for all factors for which a value can be determined. An objective function seeks those investments that maximize the net benefits. It is important to note that in planning for disaster resilience, communities may choose to undertake a diverse approach that involves specific risk reduction and risk transfer actions related to buildings and infrastructure investments.

\section{Define Planning Horizon}

A planning horizon - the period over which alternatives are compared in terms of costs and benefits that occur during that period - needs to be selected for the analysis. The planning horizon - say 50 years - needs to be long enough to account for conditions that are likely to 
occur within the lifetime of a facility or infrastructure system. A longer time horizon also allows greater opportunity for "phasing in" resilience improving measures, recognizing the community's financial constraints. For a given planning horizon, care must be taken to ensure that costs and benefits are fully and correctly accounted for.

\section{Identify Constraints}

In some cases, political, legal, financial, and other considerations might serve as important limits on what a community can do. There are numerous factors that influence decisions whose impact on the well-being of a community may limit the choice of certain resilience improvements. One common constraint is a budget constraint. All local communities face funding limitations and budget constraints. Thus, the "packaging" of an alternative resilience strategy may require a combination of "phasing in" the timing of its costs and "resizing" components of that strategy, when their costs exceed the budget constraint in one or more years, over a period of several years during the planning horizon.

\subsection{Identify Benefits and Costs}

In order to formulate the problem through which net benefits are maximized, it is first necessary to construct the objective function and its associated constraints. The construction of the objective function and associated constraints requires the identification of all benefits and costs which compose the objective function and associated constraints.

\section{Identify Costs and Losses}

Costs and losses are classified into two categories. The first classifies costs and losses by their cause and measurability; it includes: mitigation costs, response and recovery costs, direct losses, indirect losses, and non-economic losses. The second classifies losses by what is damaged or destroyed; it includes: people, physical infrastructure, the economy, governmental services, social networks and systems, and the environment. Losses to people (primarily deaths and injuries), key governmental services, social networks and systems, and the environment generally fall into the category of non-economic damages. What distinguishes non-economic damages from economic damages (like damaged buildings and infrastructure, job losses, and business-interruption costs) is that there is generally no market price for the things that are affected by non-economic damages. The problem of dealing with non-economic costs and benefits is discussed in Section 3.4 below. It is also useful to distinguish between direct losses and indirect losses. Direct (economic) losses are largely limited to losses of physical infrastructure. Indirect losses are the result of other losses. Indirect losses often include the impacts to the economy, and include such things as business interruption costs and the costs of unemployment due to disaster-related job losses. Often indirect losses are a result of the inability to conduct business due to power or other infrastructure outages.

\section{Identify Savings and Benefits}

Benefits are primarily determined as the improvement in performance during a disaster over the status quo, i.e., those obtained directly or indirectly by implementation of the alternative resilience strategy. That improvement in performance includes both reductions in the magnitude of damages (e.g. to property and livelihoods) from a disaster and in the savings in costs of the response and recovery phases. Benefits also are considered to include positive effects (i.e. cobenefits) from a mitigation strategy that occur outside the time of a disaster. These can be analyzed in the same categories as disaster-related benefits: direct benefits, indirect benefits, and 
non-economic benefits. These should take into account benefits and costs which accrue during all phases associated with a disaster event and under business-as-usual circumstances. An example of a direct non-disaster-related benefit would be an infrastructure improvement that reduces current $\mathrm{O} \& \mathrm{M}$ costs. Indirect benefits might include reductions in business interruption losses due to non-disaster-related power or water outages. An example of non-disaster-related non-economic benefits could be reductions in highway deaths and injuries from highway improvements.

\section{Identify Externalities}

Externalities are costs or benefits that impact a third party that is not part of the direct decision to implement a given strategy. Externalities may be positive or negative; they may also be nonmarket in nature. Air pollution (which affects numerous people beyond the polluting entity) is an example of a negative externality. An example of a positive externality is basic research whose benefits extend far beyond the entity funding the research. Externalities present difficulties for two reasons. First, most externalities affect non-economic factors and are therefore difficult to value. Second and more importantly, externalities present problems because the person making the decision does not experience the full costs (in the case of negative externalities) or benefits (in the case of positive externalities) of their decision. As a result, investments with positive externalities tend to be under-supplied, and investments with negative externalities tend to be over-supplied.

\subsection{Identify Non-Market Considerations}

One approach that is considered to be consistent with economic theory is based on the willingness-to-pay concept. Willingness-to-pay values are computed according to how much decision makers are willing to invest to reduce their risk of death or injury by a certain fraction. Using evidence on labor and product market choices that involve implicit tradeoffs between risk and wage or between risk and price, economists have developed estimates of the value of a statistical life typically ranging from $\$ 4$ million to $\$ 9$ million with a median value of about $\$ 7$ million (in 2000 dollars) (Viscusi and Aldy, 2003).

\section{Value of a Statistical Injury}

The same willingness-to-pay approach that is used to estimate the value of a statistical life saved can be used to estimate the value of a statistical injury averted. In a survey of 31 studies from the U.S. labor market and eight studies of labor markets outside the United States, Viscusi and Aldy (2003) found estimates ranging up to 191000 with most of the estimates between $\$ 20000$ and $\$ 70000$ (in 2000 dollars). The U.S. estimates are mostly based on job-related injury rates and lost workday rates from the Bureau of Labor Statistics. Injuries associated with natural and man-made hazards that are non-workplace related may have different characteristics that place them at the higher end of the range given in Viscusi and Aldy. For example, Butry, Brown, and Fuller (2007) used data from the Consumer Product Safety Commission to estimate the costs of a fire-related injury in residential properties at \$171 620 (in 2005 dollars).

\section{Identify Sociocultural Impacts}

Social networks, associations and neighborhoods build cohesion and reflect the shared social and cultural values in a community. A hazard event can disrupt this cohesion and the community's shared values. In some cases, these disruptions can disproportionately affect certain groups or neighborhoods, especially those groups who are economically disadvantaged. Measuring these 
impacts is very challenging. There are two basic techniques used to estimate a value for noneconomic costs and benefits: contingent value surveys and hedonic valuation methods.

Contingent valuation surveys present respondents with a set of options, where each of the options is associated with a cost (known or unknown to the respondent), and asks them directly which they prefer. Hedonic valuation methods on the other hand look for situations where the non-market good is part of a larger bundle of goods that is available on the market and seeks to identify how much value the non-market good contributes to the larger bundle.

\section{Identify Environmental Impacts}

The loss of wetlands or other natural resources associated with the occurrence of a natural or man-made hazard adversely affects communities both in terms of their attractiveness to current and potential residents and their potential for future growth. As with sociocultural impacts, environmental impacts are difficult to measure. In the case of environmental impacts, however, there is a considerable literature associated with a technique known as life cycle analysis which is used for measuring the impacts of industrial products on the environment (Daniel et al, 2004). Whereas industrial products are produced via largely "controlled" processes, a hazard event is uncontrolled and therefore poses additional measurement challenges. The two basic techniques, contingent value surveys and hedonic valuation methods, in conjunction with life cycle analysis may provide a framework for estimating a value for environmental impacts.

\subsection{Define Analysis Parameters Select Discount Rate}

The discount rate is a key variable in the valuation process. The discount rate embodies a time preference of money and encapsulates the time preferences of the community. In general, it is commonly accepted that people tend to prefer consumption at present over future consumption. Discounting consumption that occurs in the future allows comparison between current and future consumption in equivalent terms. In this case, that means discounting future costs and benefits for the proposed resilience investment strategies. There are standard discount rates used by federal agencies, but an individual jurisdiction should be able to choose its own discount rate, as appropriate to the resilience investment strategies being assessed and consistent with its identified priorities. The combination of the length of the planning horizon and the discount rate dictate the relative importance of future benefits and costs.

\section{Define Probability Distributions}

The Economic Guide treats disasters as discreet, relatively rare events with known, fixed probabilities or rates of occurrence. The economic methodology requires some distributional information about the frequency of disasters and their potential outcomes (e.g., expected losses). Since the NIST Planning Guide and the Economic Guide are intended to cover risks from all hazards, needed is the rate of occurrence of any disaster occurring regardless of type. In addition, distributional assumptions are required to estimate expected costs and benefits associated with competing investment scenarios. Distributional assumptions for benefits - the expected reduction in losses - are required given the uncertainties related to disaster occurrence and outcome, while the assumptions needed for costs are due to typical uncertainties related to cost estimation, and with some stemming from the dependence on the timing and severity of the disaster itself (e.g., response and recovery costs). Information from the probability distributions is used in two ways: (1) in a baseline analysis where all parameters are fixed equal to their expected value and (2) in a sensitivity analysis where the baseline values are allowed to vary. 
First, the expected value for each input variable - the annual value for each cost, loss, and benefit - is used in the baseline analysis of each alternative resilience strategy. This corresponds to the traditional approach to project investment analysis, which applies economic methods of project evaluation to best-guess estimates of project input variables as if they were certain estimates and then presents the results in single-value, deterministic terms. Second, data points from each probability distribution for each alternative resilience strategy are used as inputs in a sensitivity analysis to measure how "sensitivity" the value of net benefits for the given resilience strategy is to changes in input variables.

\section{Define Risk Preference}

Risk preference is the willingness of a decision maker to take a chance on an investment of uncertain outcome. The Economic Guide assumes that jurisdictions are risk neutral. That means that the community decision maker acts on the basis of expected monetary value - the decision maker is indifferent between a payment with a sure cash value and a risky venture payment with the same expected cash value. This is different from a risk averse decision maker who would prefer a sure cash payment to a risky venture with known expected value greater than the sure cash payment. It is important to note that the assumption of a risk neutral decision maker is consistent with the traditional approach to project investment analysis, which applies economic methods of project evaluation to best-guess estimates of project input variables as is they were certain estimates and then presents the results in single-value, deterministic terms. Because the Economic Guide assumes jurisdictions are risk neutral, the economic methodology includes a structured sensitivity analysis to insure that the impacts of uncertainty are measured and analyzed. This step is important because when projects are evaluated without regard to uncertainty of inputs to the analysis, decision makers may have insufficient information to measure and evaluate the risk of investing in a project having a different outcome from what is expected.

\subsection{Perform Economic Evaluation}

Developing a cost-effective community resilience investment strategy is a complicated process, entailing two distinct levels of analysis. This method of analysis systematically adds increased detail to the decision-making process. The first level is referred to as the baseline analysis. Here we are working with our best-guess or expected value estimates. The baseline analysis provides a frame of reference for the treatment of uncertainty, which is the focus of the second level-the sensitivity analysis, which systematically varies selected sets of data elements to measure their economic impacts on the calculated values for net benefits for each alternative community resilience strategy.

\section{Compute Present Expected Value}

The starting point for conducting an economic evaluation is to do a baseline analysis. In the baseline analysis, all data elements entering into the calculations are fixed. For some data, the input values are considered to be known with certainty. Other data are considered uncertain and their values are based on some measure of central tendency, such as the mean or the median, or input from subject matter experts. Baseline data represent a fixed state of analysis. For this reason, the analysis results are referred to as the baseline analysis. The term baseline analysis is used to denote a complete analysis in all respects but one; it does not address the effects of uncertainty. Evaluate the calculated values for net benefits for each alternative community resilience investment strategy. Select the alternative community resilience investment strategy 
with the highest net benefits as the candidate for further development into the community's resilience plan. Document findings from the baseline analysis in an analysis report; include the results for all alternatives evaluated. Rank all alternatives examined from highest to lowest according to their net benefits. Include comparisons between the investment strategy with the highest net benefits and any alternatives which are considered strong contenders - listing both the pros and cons of each.

\section{Evaluate Impact of Uncertainty}

Sensitivity analysis measures the impact on project outcomes of changing the values of one or more key data elements about which there is uncertainty. Therefore, a sensitivity analysis complements the baseline analysis by evaluating the changes in net benefits when selected data inputs are allowed to vary about their baseline values. There are two forms of sensitivity analysis: deterministic and probabilistic. The key advantage of deterministic sensitivity analyses is that they are easily constructed and computed and the results are easy to explain and understand. Their disadvantage is that they do not produce results that can be tied to probabilistic levels of significance (e.g., the probability that the net benefits of an alternative community resilience investment strategy are less than 0). Probabilistic sensitivity analyses use some form of Monte Carlo simulation. Monte Carlo simulation varies a small set of key parameters either singly or in combination according to an experimental design. Associated with each key parameter is a probability distribution function from which values are randomly sampled. The major advantage of the Monte Carlo simulation technique is that it permits the effects of uncertainty to be rigorously analyzed through reference to a derived distribution of project outcome values. Using the highest mean (average) net benefits of the derived distribution as the decision criterion, recommend an alternative resilience investment strategy as the candidate for further development into the community's resilience plan. Document findings from the sensitivity analysis in an analysis report; include the results for all alternatives evaluated. Rank all alternatives examined from highest to lowest according to their mean net benefits. Include comparisons between the investment strategy with the highest mean net benefits and any alternatives which are considered strong contenders - listing both the pros and cons of each. If applicable, include a discussion of any rank reversals - circumstances under which the recommended alternative did not have the best measure of economic performance.

\subsection{Select Investments}

This subsection stresses the linkage between the last two steps in the NIST Planning Guide and the Economic Guide methodology. The analysis reports resulting from the baseline analysis and the sensitivity analysis provide the starting point for plan preparation, review, and approval.

\section{Plan Preparation, Review, and Approval}

Each of the alternative community resilience strategies consists of a set of investments. These investments are likely staged over a period of years, so they can be fitted into the community's capital budgeting process. The presentation, analysis, and recommendations from the baseline analysis and the sensitivity analysis are central to understanding and accepting the findings from the economic evaluation; they need to be carefully integrated into the community's resilience plan to promote a more complete understanding of its merits by key community decision-makers and stakeholders. If the presentation is clear and concise, and if the analysis strategy is logical, complete and carefully spelled out, then the results should stand up under close scrutiny. The following are the key economic considerations that need to be integrated into the resilience plan: 
- Recommend an alternative as the most cost-effect community resilience investment strategy.

- Provide a rationale for the recommendation. Include as part of the rationale findings from both the baseline analysis and the sensitivity analysis.

- If applicable, include a discussion of circumstances under which the recommended alternative did not have the best measure of economic performance.

- Describe any significant effects that remain unquantified. Explain how these effects impact the recommended alternative.

\section{Plan Implementation and Maintenance}

As the resilience plan moves into implementation, new information will become available on both costs and benefits. To insure that the resilience plan becomes an integral part of the community's economic development plan and other long-range plans, that information needs to be updated and maintained. In addition, any spillover benefits not accounted for in the original plan should be documented along with any unintended consequences that detract from the merits of the plan.

\section{Next Steps}

The Economic Guide provides a firm foundation for performing economic evaluations of alternative community resilience investment strategies. Although the Economic Guide provides the basis for performing these economic evaluations, additional resources are needed to insure that the economic evaluations are straightforward, transparent and repeatable both within a given community and across communities. To achieve this objective, two additional resources are needed: (1) industry consensus standards focused on the economics of community disaster resilience and (2) a user-friendly decision-support software tool based on those standards.

Industry consensus standards covering a wide range of economic topics have been developed by ASTM International (ASTM, 2012). Although these ASTM standards on building economics cover benefit-cost analysis, the treatment of risk and uncertainty, and multi-attribute decision analysis techniques capable of addressing non-market considerations, their focus is on individual buildings or collections of buildings in a campus setting. While they do not address the integrated system-of-systems aspects of community disaster resilience, they do provide the building blocks needed to fully address these important aspects. NIST has proposed to expand the current suite of ASTM building economics standards to insure that systems concepts are rigorously addressed. These new standards, once developed, will enable decision makers to compare and contrast alternative community resilience investment strategies in a consistent and repeatable manner.

Developing and evaluating a community resilience investment strategy requires team work and data inputs from a variety of sources. Framing the decision problem in the proper way not only significantly reduces the complexity of analyzing the merits of the proposed strategy but also promotes a better understanding of the results of the analysis. By developing a user-friendly decision-support software tool in collaboration with key industry/community stakeholders, NIST will insure that all required data elements - both benefits and costs - are properly accounted for and that the uncertainty associated with key assumptions and data elements is rigorously 
analyzed. The software tool will include a reporting feature that will summarize the results, highlighting assumptions used in performing the analysis and documenting the sensitivity of the results to those assumptions and other data elements. The reporting features will be designed in a way that assists analysts in communicating results in a condensed but understandable format to community leaders and other non-technical persons. These software features are aimed at translating the selected community resilience investment strategy into a proposed plan for review and approval by community leaders.

\section{References}

ASTM International. 2012. ASTM Standards on Building Economics: $7^{\text {th }}$ Edition. West Conshohocken, PA: ASTM International.

Butry, David T., M. Hayden Brown, Sieglinde K. Fuller. 2007. Benefit-Cost Analysis of Residential Fire Sprinkler Systems. NISTIR 7451. Gaithersburg, MD: National Institute of Standards and Technology.

Daniel, S., G. Tsoulfas, C. Pappis, and N. Rachaniotis. 2004. "Aggregating and Evaluating the Results of Different Environmental Impact Assessment Methods.” Ecological Indicators 4: 125-138.

Federal Emergency Management Agency (FEMA). 2015. National Preparedness Goal. Washington, DC: Federal Emergency Management Agency, http://www.fema.gov/nationalpreparedness-goal

Gilbert, Stanley. 2010. Disaster Resilience: A Guide to the Literature. NIST Special Publication 1117. Gaithersburg, MD: National Institute of Standards and Technology.

Gilbert, Stanley, and David T. Butry. 2015. Economic Framework for Community Disaster Resilience. White Paper. Gaithersburg, MD: National Institute of Standards and Technology.

Gilbert, Stanley, David T. Butry, Jennifer F. Helgeson, and Robert E. Chapman. 2015. Community Resilience Economic Decision Guide for Buildings and Infrastructure Systems. NIST Special Publication 1197. Gaithersburg, MD: National Institute of Standards and Technology.

National Institute of Standards and Technology (NIST). 2015. Community Resilience Planning Guide for Buildings and Infrastructure Systems, Volumes I and II. NIST Special Publication 1190. Gaithersburg, MD: National Institute of Standards and Technology.

SPUR. 2009. "When is a Building Safe Enough?" Urbanist 479: 4-21.

The White House. 2013. Presidential Policy Directive/PPD-21-Critical Infrastructure Security and Resilience. Washington, DC: The White House, https://www.whitehouse.gov/the-pressoffice/2013/02/12/presidential-policy-directive-critical-infrastructure-security-and-resil

Thomas, Douglas S., and Robert E. Chapman. 2008. A Guide to Printed and Electronic Resources for Developing a Cost-Effective Risk Mitigation Plan for New and Existing Constructed Facilities. NIST Special Publication 1082. Gaithersburg, MD: National Institute of Standards and Technology.

Viscusi, W. K., and J. E. Aldy. 2003. "The Value of a Statistical Life: A Critical Review of Market Estimates Throughout the World." The Journal of Risk and Uncertainty 27(1): 5-76.

Yu, Q. -S., J. Wilson, and Y. Wang. 2014. "Overview of the Oregon Resilience Plan for Next Cascadia Earthquake and Tsunami." Proceedings of the $10^{\text {th }}$ National Conference in Earthquake Engineering. Anchorage, AK: Earthquake Engineering Research Institute. 


\section{Section II. \\ Papers by Moderators}


Fiksel, Joseph, Elena Irwin, and Matthew Gnagey

\title{
Resilience Economics: A Systems Approach
}

\begin{abstract}
Natural disasters and other urban crises are becoming more frequent, while unsustainable development patterns place increasing pressures on natural resources and infrastructure. Communities are complex, adaptive systems, and traditional risk management approaches are not adequate for dealing with turbulent change and unforeseen disruptions. When crises occur, the responses are often driven by short-term priorities and may not consider systemic issues. A comprehensive conceptual framework and new computational tools are needed to balance the immediate requirements for community resilience with the long-term goals of sustainability and well-being. There exists a broad range of methods for cost-benefit analysis of resilience investments, including managerial accounting approaches and economic valuation of nonmonetary goods and services. By combining these methods with models of coupled humannatural systems, it is possible to develop an integrated approach based on an inclusive wealth framework that values economic, social, and natural capital. Although still in an early stage of development, these models can also be extended to account for the value of resilience improvement, which is critical for making investments and policy decisions that improve both the resilience and sustainability of a community.
\end{abstract}

\section{Keywords}

Community, resilience, economics, disaster, systems, investment, framework

\section{Background}

Community resilience has become an important concern due to the increasing scale and frequency of natural and technological disasters. Authoritative sources have issued guidance about how communities can better prepare for and cope with disasters, including the White House (2014), the National Research Council (NRC 2012), the Sandy Commission (NYS 2100 Commission, 2013), and The United Nations International Strategy for Disaster Reduction (UNISDR 2005).

The challenge for communities that wish to improve their resilience is essentially an economic dilemma. In the face of perennial budget pressures, how can they justify the investments required to hire and train staff, provide public incentives, assess vulnerabilities, upgrade infrastructure, protect ecosystems, establish early warning systems, and develop preparedness plans? Some communities that are repeatedly afflicted by floods or tornadoes may be motivated to improve their resilience, but for most city officials this presents a paradox - preparation for a disaster that may never arrive. Indeed, this is a perpetual challenge of risk management: justifying expenditures for hypothetical worst-case scenarios when there are a multitude of other real and immediate priorities.

Common sense dictates that resilience expenditures should be made prudently by identifying low-cost initiatives that will produce significant benefits-for example, by leveraging social media to disseminate information during a disaster. In addition, communities should ensure that their investments will help to realize other synergistic benefits, contributing to important goals such as public safety and security, urban livability, and sustainability. The complexity of these 
choices demands a rigorous approach to estimation of economic benefits in the presence of uncertainty. A systems approach is needed to characterize the interdependencies between a community and the broader economic systems, ecosystems, and supply chains with which it is coupled.

\section{Limitations of Risk Management}

The predominant paradigm that supports resilience thinking today is the classical risk management approach, which involves a sequential, step-by-step process of risk identification, risk assessment, and risk control (NRC 2009). While this process appears quite logical and thorough, it is rooted in a simplistic, "reductionist" world-view. The focus is on discrete events rather than gradual build-up of stresses. Each risk is identified and addressed independently, and hidden interactions are seldom recognized. There are several important limitations to the risk management paradigm:

- Risks cannot always be anticipated. A critical first step in risk management is risk or hazard identification. However, many of the risks that communities face are hard to predict. Rather than corresponding to discrete events, risks may result from cumulative changes, such as rising sea level, that trigger a tipping point. The possibility of cascading consequences and interdependence among risks requires a systemic rather than a reductionist approach.

- Risks may be hard to quantify. Even if risks can be identified, the lack of reliable statistical data can make it difficult to quantify their magnitude. This is especially a challenge for lowprobability, high-consequence events. For example, human error or deliberate malfeasance is a frequent cause of disruptions, but these initiating events are not easily modeled.

- Adaptation may be needed. When a disaster strikes, such as a hurricane or a terrorist attack, our instinct is to overcome the shock, assist the victims, and return to a stable equilibrium as soon as possible. Instead, communities should treat every disruption as a learning opportunity, and strive to strengthen their resilience through structural investment, policy reform, or process improvement based on root cause analysis and systems thinking.

The limitations of risk management have been recognized by the National Academy of Sciences, which found that "risk-based methods are not adequate to address complex problems such as climate change and loss of biodiversity, and more sophisticated tools are available that go beyond risk management" (NRC 2011). While the established approaches of risk management can be very useful for protecting against predictable risks such as fires or power failures, they are not adequate for dealing effectively with the turbulence and complexity that characterize today's global risk landscape. The most damaging disruptions - as well as unexpected opportunitiestend to result from extreme events that are difficult or impossible to anticipate, let alone quantify.

\section{Resilience in Complex Systems}

Long term stressors that lead to tipping points and abrupt changes are common features of coupled social and ecological systems. As complex systems approach these tipping points, they lose resilience and become more vulnerable to shocks. For example, gradual increases in nutrient run-off from agricultural and industrial land uses can push nutrient stocks beyond a threshold point and lead to abrupt emergence of harmful algal blooms in coastal and freshwater ecosystems. Similarly, chronic overfishing and declining water quality have left coral reefs less resilient to coral bleaching from ocean warming and acidification (Anthony et al. 2011). Social 
factors can also influence the resilience of complex systems. The 2004 Indian Ocean tsunami revealed that many rural communities were extremely vulnerable not just because of their coastal location, but also because of widespread poverty and lack of adequate infrastructure (Hughes $e t$ al. 2005).

What makes an ecosystem, economy or community more or less resilient to a shock? A key factor is "precariousness" - the proximity of the system to a tipping point. This is determined not only by biophysical constraints, but also by technological factors; for example, improved ecoefficiency can reduce dependence on natural capital stocks and facilitate resource conservation (Fiksel et al. 2014). Indeed, innovations such as the "green revolution" in agriculture have kept resource scarcity at bay for much of human history. This has inspired optimism among economists and others that gains in resource productivity alone can allow us to achieve a sustainable path (Weitzman 1999; Dobbs et al. 2012). However, efficiency can have unintended consequences - such as "rebound effects" that actually increase resource demands due to lower prices and new markets resulting from more efficient technologies.

Another key factor that influences resilience is the degree of interconnectedness among parts of the system. The more interactions exist among people, organizations, communities, and the environment, the more complex the system and the greater the chance of "reinforcing" feedback loops that may accelerate or magnify changes in the system. For example, globalization of industry has improved economic efficiency but has reduced the resilience of supply chains. A disruption to a single key supplier can cascade into costly ripple effects that cause business interruptions and impose significant costs on manufacturers and customers around the world, as illustrated by the 2011 Tohoku earthquake-generated tsunami in Japan and flooding in Thailand (Fiksel et al. 2015).

Resilience has been defined as the capacity of a system to remain in a given state, or "regime" (Holling 1973, 1996). The greater the resilience of a system, the larger the shock it can absorb without undergoing a regime shift, i.e., a switch to an alternate state. However, resilience may also include deliberate transformation of a system by shifting to a preferred state (Walker et al. 2004). For present purposes we adopt a more general definition of system resilience (Fiksel, 2006):

\section{Resilience is the capacity of a community (or any system) to survive, adapt, and flourish in the face of turbulent change and uncertainty.}

Resilience is clearly a prerequisite for long-term sustainability, which is concerned with tradeoffs between consuming society's resources and capital stocks today and conserving these for future generations. Sustainability and resilience are often mutually reinforcing, since conserving stocks helps to maintain resilience to unexpected shocks that can push a vulnerable community into crisis mode. At the same time, there are trade-offs between resilience and sustainability; for example, rainwater harvesting is an appealing sustainability practice, but is vulnerable to droughts. Similarly, adoption of "lean" business practices can improve efficiency and lower costs, but also eliminates redundancies and can leave communities exposed to shortages of critical supplies. Understanding the value of resilience is essential to help communities evaluate the trade-offs between resource consumption and conservation and to develop policies that support community well-being. This requires a systems view of how value is created for society, including not only economic wealth but also non-monetary wealth in the form of social and natural capital. 


\section{Taking a Systems Approach}

One approach that has proved useful for community decision-making is the Triple Value (3V) framework, which has been applied by U.S. EPA to address coastal sustainability and resilience in New England and other regions (Fiksel et al, 2014). As illustrated in Figure 1, the 3V approach considers the resource flows, interdependencies, and feedback loops among economic processes (e.g., agriculture, manufacturing), societal processes (e.g., education, governance), and natural processes (e.g., cycling of carbon, water, and nitrogen). Economic and societal systems are coupled by market transactions that mediate the flows of goods and services. Economic growth generally correlates with increases in material throughput, population, and demand per capita. This linkage between economy and society is a positive feedback loop, and without external constraints it theoretically enables perpetual growth with increasing human prosperity.

However, the linkages of these systems with the environment represent a negative feedback loop. Most developed societies are consuming ecosystem services faster than they can replenish natural capital, which includes fresh water, soil, forests, coral reefs, and glaciers. Moreover, they are generating large amounts of waste and emissions that degrade these very ecosystems. When markets fail to account for economic externalities such as gradual degradation of soil and water quality, the result is a loss of opportunity for future generations, known as an inter-temporal market failure. Many resource economists argue that we can prevent such market failures by replacing the traditional gross domestic product (GDP) indicator with more comprehensive indicators such as inclusive wealth measures, which explicitly assign value to social and natural capital.

The $3 \mathrm{~V}$ conceptual framework is useful for understanding the sustainability and resilience of community systems from an inclusive wealth perspective. Ideally, communities can achieve a dynamic equilibrium in which the depletion of material and energy resources is offset through investments in renewable natural capital stocks and other forms of community capital, including social and human capital. This can be achieved by introducing positive feedback loops to offset the depletion of natural resources. For example, the concept of a "circular economy" suggests that wastes have residual value, and can be recovered and reused instead of being sent to a landfill or released into the environment. On a broader scale, communities can invest in ecosystem restoration, thereby protecting the remaining natural capital and offsetting its previous degradation. However, sudden disruptions or gradual shifts can delay or derail progress toward sustainability, and can destabilize the balanced operation of these systems, leading to economic stagnation, social deprivation, and/or environmental degradation. Therefore it is important to build resilience into these systems in order to alleviate stresses and limit the potential for damaging shocks.

Examples of potential community shocks include natural disasters, infrastructure breakdowns that threaten the availability of energy or other critical resources, and political upheavals due to social unrest or governance failures. Urban communities are particularly vulnerable to sudden disruptions caused by a confluence of these forces of change. For example, there is increasing concern among policy-makers about potential cascading effects due to the "energy-water-food nexus" - the interdependence among municipal infrastructures and the value chains that support them. A potent example occurred in 2013, when Superstorm Sandy pounded the northeastern U.S. coastline. The resultant flooding also caused widespread power failures in much of New York City and New Jersey, and economic losses totaled about $\$ 70$ billion. 


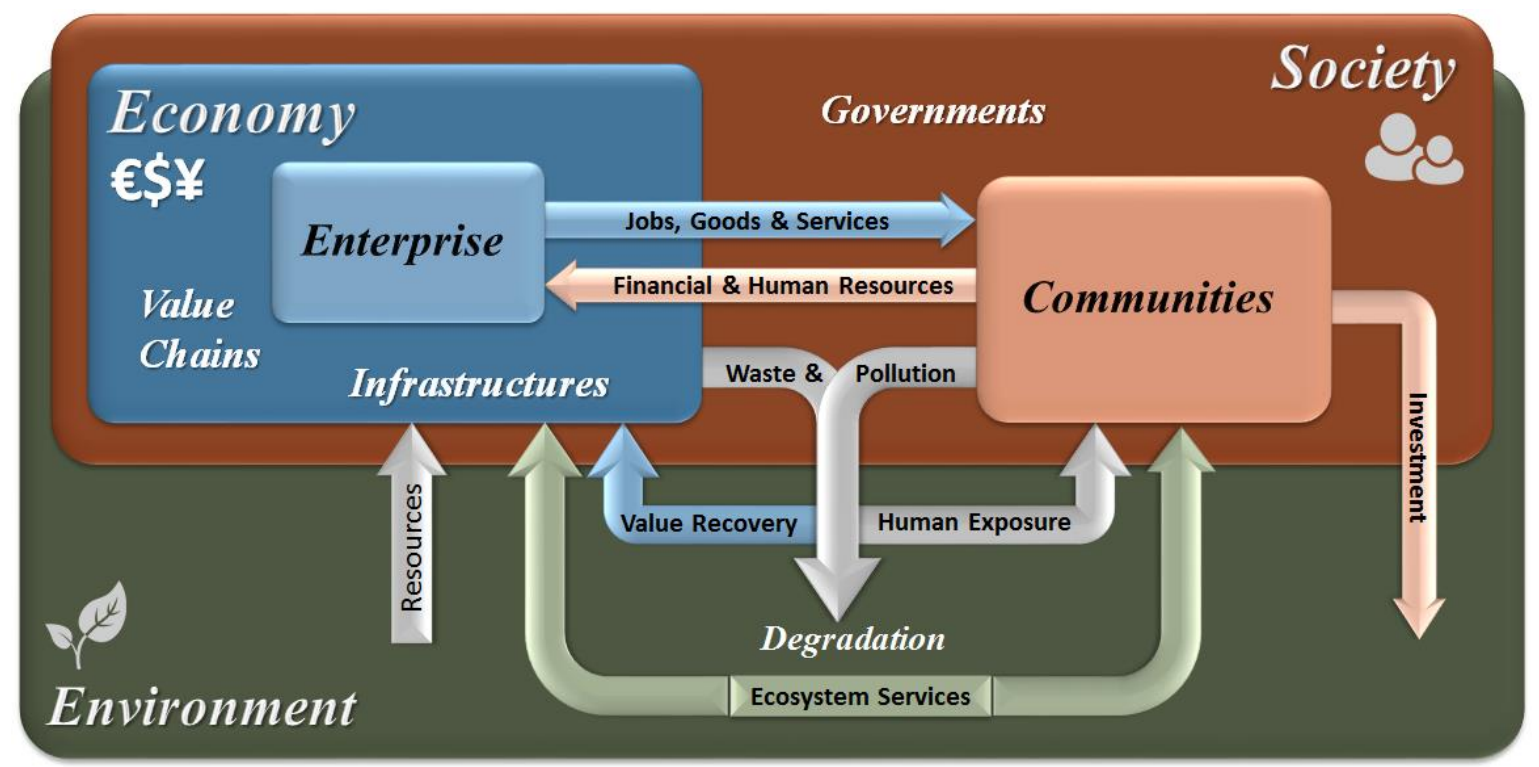

Figure 1. The Triple Value Framework for Inclusive Wealth

\subsection{Cost-Benefit Analysis in Managerial Accounting}

Cost-benefit analysis includes a very wide range of methods used to support decision-making. Conventional financial tools such as discounted cash flow analysis or net present value are often used to build a business case by comparing the capital investment and operating costs with the expected flow of returns. However, taking a systems approach means that decision-makers must go beyond conventional cost accounting methods to consider the broader costs and benefits incurred either by a community and its stakeholders over a long time horizon.

Making a case for resilience investments is particularly challenging, since we can only speculate about the types and severity of potential disruptions. If sufficient data are available, then techniques such as risk analysis and simulation-based scenario modeling can be used to explore the possibilities, but in the real world there will always be significant uncertainties. The best way to justify expenditures on improving resilience is to identify measurable benefits that will be realized even if no disruptions were to occur. For example, investing in alternative energy sources such as solar or geothermal systems can lower the costs of energy supply while improving process reliability (Evans and Fox-Penner, 2014).

Recognizing such synergies may require financial creativity, because conventional accounting methods often fail to capture the full range of costs and benefits associated with resilience improvements. For example, energy costs are often assigned to overhead accounts, and cannot easily be traced to a particular business decision. To overcome this problem, many organizations have adopted an approach called activity-based costing, also known as total cost assessment, which involves identification and quantification of direct, indirect, and other costs across the life cycle of a facility, product, or process. This is an extension of life cycle costing methods used in the defense sector to manage large, multi-year weapon system programs where major costs are associated with deployment, logistical support, and decommissioning. Similar techniques have 
been used in the computer and other industries to capture the total "cost of ownership" for enterprise assets.

To understand the full scope of life cycle costs and benefits, it is helpful to divide them into the following categories (McDaniel and Fiksel, 2000).

- Conventional: Material, labor, and other expenses and revenues that are commonly allocated to a project (often called "direct" costs).

- Potentially Hidden: Costs (or benefits) to the community that are not typically linked to a specific project, e.g., legal or insurance costs (often called "indirect" costs).

- Opportunity: Costs associated with opportunities that are foregone by not putting the community's resources to their highest value use, e.g., delay of urban renewal projects.

- Contingent: Potential liabilities or benefits that depend on the occurrence of future events, e.g., potential disaster recovery costs related to an oil spill.

- Good Will: Costs (or benefits) related to the subjective perceptions of community stakeholders, e.g., attractiveness to residents and businesses.

- External: Costs (or benefits) of a community's impacts upon the environment and society that do not directly accrue to the community, e.g., the global benefits of reduced greenhouse gas emissions due to energy conservation.

For example, Veolia, the global environmental services company, applied these concepts to develop a tool that measures the "true cost" of water (Veolia, 2014). The tool combines traditional capital and operating costs with estimation of water risks and their financial implications. It accounts for the direct costs of building and maintaining water infrastructures, the indirect costs such as legal expenses, and unexpected financial burdens during the life of these assets. These cost elements are organized in four categories: operational such as water shortages; financial, such as commodity price changes; regulatory, such as obligation to protect ecological status; and reputational such as loss of brand value or social license to operate.

\subsection{Methods for Valuing Resilience}

Managerial accounting takes the perspective of a single organization, such as a city government, but to understand financial trade-offs at a community level requires a broader view of public well-being, based on the concept of inclusive wealth (Arrow et al. 2003). A variety of economic valuation methods are available to approximate the non-monetary aspects of community sustainability and resilience, including social and environmental costs and benefits. Recent work on economics-based and biophysically-based analyses of ecosystem services has been helpful in classifying these methods (TEEB 2010). As shown in Figure 2, economic valuation methods quantify trade-offs in monetary terms based on measures of individual and societal preferences that depend on human values and beliefs. However, traditional valuation approaches are largely static and typically ignore the implications of physical thresholds and nonlinearities. In contrast, non-economic biophysical approaches represent the physical consumption of energy and materials and are useful for potentially identifying physical tipping points or limits, but ignore the value implications of these physical changes in terms of societal costs and benefits. 


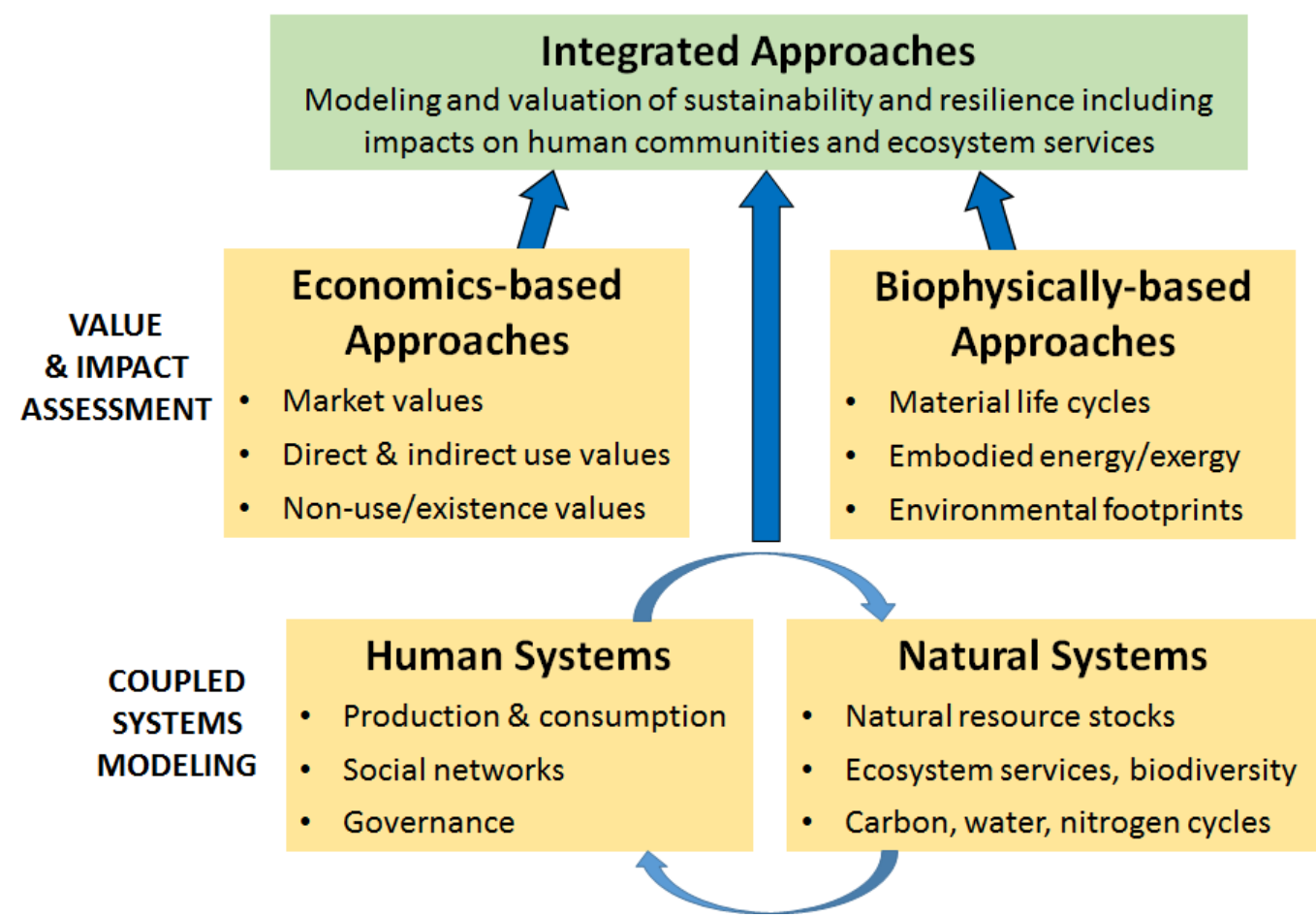

Figure 2. Integration of economic and biophysical methods for sustainability and resilience assessment and valuation

More recent approaches to non-market valuation have been developed in an attempt to value resilience. These approaches integrate economic and physical-based methods by relying on a coupled model of the natural and human systems to represent physical limits and nonlinear dynamics, as well as the implications of these dynamics for human well-being and trade-offs. Developing a coupled natural-human systems model to describe the dynamics of the system is a non-trivial, critical first step in this process. Given this, the model can be used to assess the implications of a regime shift to a less desirable state - that arise when a threshold is crossedby quantifying the gains and losses in human welfare due to the current and future expected changes in natural capital, and other forms of capital as well.

Mäler (2008) argues that resilience is a "stock" that protects the desired state of the system by reducing the risk of undesirable changes that would result from a regime shift—and thus, that the value of resilience is essentially an insurance value. For example, the resilience of a lake ecosystem to persistent harmful algal blooms is a quantifiable stock that evolves over time and depends on temperature, rainfall, land use, lake depth and nutrient levels. Like any resource or capital stock, as the resilience of a system grows scarcer, it becomes more valuable. However, like many ecosystem services, resilience is a public good-it is valuable to society, but its market price is zero because it is largely external to the market. Therefore we cannot rely on private markets to maintain resilience for public well-being.

How can public policy insure that optimal levels of resilience are maintained? This depends on understanding the value that resilience provides. Mäler and Li (2010) and Walker et al. (2010) develop a capital-theoretic approach to valuing resilience based on the inclusive wealth framework (Arrow et al. 2003). While this is not the only approach to valuing resilience and is 
still in an early stage of development, it is perhaps the most comprehensive and theoretically consistent approach. Conceptually, it involves three steps:

(1) Quantify the resilience of the system over time with respect to a specific threshold

(2) Estimate the shadow price of the current stock of resilience, defined as the value of a small change in the current stock of resilience

(3) Incorporate the value of the resilience stock into a measure of inclusive wealth that includes the value of other capital stocks, including natural, social, or manufactured capital stocks.

The last step enables assessment in monetary terms of the tradeoffs between resilience and other stocks; for example, increased development of coastal areas may simultaneously increase land value and resident wealth but may decrease community resilience to flooding. Given that resilience is not directly observable, there are substantial challenges in operationalizing this approach. The first challenge is quantifying the resilience of a system to a particular threshold or tipping point. Doing so requires a model of the system dynamics, including the location of the threshold boundary as a function of key state variables, initial conditions, and parameter values.

For example, Chen et al. $(2009,2012)$ developed a model of how urbanization degrades a lake ecosystem, reducing the amenities that attract people to the region. They find that the system has two possible regimes: a "sustainable" state, with a moderate level of population balanced with some lake pollution, and an "undesirable" state with a very small population and a fully restored ecology. The latter is the long-run steady state that results from too much human impact on the lake, which causes the system to cross a threshold: the lake "flips" from a healthy to unhealthy lake, causing outmigration of population from the region. To quantify resilience they use a phase plot diagram that defines the distance of any current state of the system to this threshold, as a function of both the level of pollution in the lake and the amount of urbanization in the watershed.

A second challenge is to estimate the shadow price of the current stock of resilience. The shadow price is the marginal social value of a small change in this stock of resilience and reflects both the current and future marginal benefits and costs of the change expressed in present discounted value terms. Intuitively, a small change in the current stock of resilience affects the probability of a regime shift today and into the future and thus, the change in the probability of crossing the threshold is a key component of the shadow price. The approach developed by Mäler and Li (2010) quantifies the marginal benefit of each additional unit of resilience, which is determined by calculating the difference in values between a "good" state and "bad" state, weighted by the change in probability of the bad state occurring.

Walker et al. (2010) applied this approach to calculate the value of resilience in the GoulburnBroken Catchment (GBC) in Southeast Australia, an important agricultural region. Removal of native vegetation has caused rising water tables and increased salinity, which reduces infiltration and inhibits crop growth. They identify a threshold at a $2 \mathrm{~m}$ water table depth, and they measure resilience of the system to a high saline regime by the distance from the water table to the $2 \mathrm{~m}$ threshold. Historical data are used to estimate the probability of the system shifting from the nonsaline to the saline regime as a function of this distance, enabling them to quantify the probability of entering the saline regime. They use the market price of agricultural land to 
translate this probability into value terms and then calculate the projected changes under a "business as usual" scenario versus one in which the water table is more actively managed.

\section{Conclusion}

Despite the monumental challenges to quantifying and valuing resilience, accounting for the value of resilience improvement is critical for making investment decisions that improve the resilience and sustainability of a community. Although this approach is still in a nascent stage and is not yet sufficiently developed as a practical tool that can support community decision making, the above examples illustrate an approach for determining the levels of natural capital stocks that are needed to ensure a desired level of resilience. Valuation of resilience can also be used to assess the benefits of policies that increase incentives for resilience-enhancing activities, particularly those that vary dynamically within systems, and the social costs of a loss in resilience. More generally, this approach provides a standardized method for communicating the value of resilience to decision makers and incorporating resilience thinking into long-term planning.

\section{Acknowledgments}

This paper was prepared for a workshop on the Economics of Community Disaster Resilience hosted by the National Institute for Standards and Technology and the American Society of Civil Engineers in April 2015, where Dr. Joseph Fiksel was a featured speaker. Dr. Fiksel gratefully acknowledges the assistance of his co-authors: Dr. Elena Irwin, Faculty Leader, Sustainable and Resilient Economy Program, and Professor, Department of Agricultural, Environmental and Development Economics at The Ohio State University, Columbus, Ohio; and Dr. Matthew Gnagey, Assistant Professor, School of Business and Economics, Weber State University, Ogden, Utah.

\section{References}

Anthony et al. 2011. Ocean acidification and warming will lower coral reef resilience. Global Change Biology 17, pp. 1798-1808.

Arrow, K. J., Dasgupta, P. \& Maler, K.-G., 2003. Evaluating projects and assessing sustainable development in imperfect economics. Environmental \& Resource Economics, 26(4), 647685.

Baumgartner, S. \& Strunz, S., 2014. The economic insurance value of ecosystem resilience. Ecological Economics, Volume 101, pp. 21-32.

Chen, Y., Irwin, E., \& Jayaprakash, C. 2009. Dynamic modeling of environmental amenitydriven migration with ecological feedbacks. Ecological Economics 68, pp 2498-2510.

Chen, Y., Jayaprakash, C. \& Irwin, E., 2012. Threshold management in a coupled economicecological system. Journal of Environmental Economics and Management, 64(3), pp. 442455.

Dobbs, R., J. Oppenheim, and F. Thompson, "Mobilizing for a resource revolution”, McKinsey Quarterly, January 2012.

Fiksel, J., "Sustainability and Resilience: Toward a Systems Approach," Sustainability: Science, Practice, and Policy, Vol.2, No. 2, pp. 14-21, 2006.

Fiksel, J., R, Bruins, A. Gatchett, A. Gilliland, and M. ten Brink. "The Triple Value Model: A Systems Approach to Sustainable Solutions." Clean Technology and Environmental Policy, June 2014. 
Fiksel, J., M. Polyviou, T. Pettit, and K. Croxton, "Embracing Change: From Risk to Resilience". Sloan Management Review, Winter 2015.

Holling, C. S., 1973. Resilience and stability of ecological systems. Annual Review of Ecological Systems, Volume 4, pp. 1-23.

Holling, C. S., 1996. Engineering resilience versus ecological resilience. In: P. C. Schulze, ed. Engineering within Ecological Constraints. Washington, D.C.: National Academy Press, 3144.

Hughes, T., D.R. Bellwood, C. Folke, R.S. Steneck, J. Wilson. New paradigms for supporting the resilience of marine ecosystems. TRENDS in Ecology and Evolution 20(7), pp. 380-86.

Maler, K.-G., 2008. Sustainable development and resilience in ecosystems. Environmental and Resource Economics, Volume 39, pp. 17-24.

Maler, K.-G. \& Li, C.-Z., 2010. Measuring sustainability under regime shift uncertainty: a resilience pricing approach. Environment and Development Economics, Volume 15, pp. 707719.

McDaniel, J. and J. Fiksel, The Lean and Green Supply Chain: A Practical Guide for Materials Managers and Supply Chain Managers to Reduce Costs and Improve Environmental Performance. EPA 742-R-00-001, January 2000.

NRC 2009. National Research Council, Science and Decisions: Advancing Risk Assessment. National Academy of Sciences Press; Washington, DC, 2009.

NRC 2011. National Research Council, Sustainability at the EPA, National Academy of Sciences Press, Washington, DC, Sept. 15, 2011.

NRC 2012. National Research Council, Disaster Resilience: A National Imperative, National Academy of Sciences Press, Washington, DC, November 2012.

NYS 2100 Commission, 2013. Recommendations to Improve the Strength and Resilience of the Empire State's Infrastructure. http://www.governor.ny.gov/sites/governor.ny.gov/files/archive/assets/documents/NYS2100. pdf

TEEB, 2010. The Economics of Ecosystems and Biodiversity: Ecological and Economic Foundations. Edited by Pushpam Kumar. Earthscan, London and Washington.

UNISDR, 2005. Ten Essentials for Making Cities Resilient. Accessed Oct. 1, 2014 at www.unisdr.org/2014/campaigncities/Scorecard\%20FAQs\%20March\%2010th\%202014.pdf

Veolia, 2014. The True Cost of Water. Accessed Oct. 1, 2014 at http://www.veoliawatertechnologies.com/en/sustainability/true-cost-water

Walker, B., C.S. Holling, S.R. Carpenter, A. Kinzig. 2004. Resilience, adaptability and transformability in socialecological systems. Ecology and Society 9.

Walker, B. et al., 2010. Incorporating resilience in the assessment of inclusive wealth: An example from South East Australia. Environmental \& Resource Economics, Vol. 45, 183202.

Weitzman, M. 1999. Pricing the Limits to Growth from Mineral Depletion. Quarterly Journal of Economics 114(2): 691-706.

White House (2014). President's State, Local, and Tribal Leaders Task Force on Climate Preparedness and Resilience: Recommendations to the President, November 2014. http://www.whitehouse.gov/administration/eop/ceq/initiatives/resilience/taskforce 
Kunreuther, Howard

\title{
Community Resiliency and Planning for Natural Disasters: A Framework for Understanding, Managing and Reducing Risk
}

\begin{abstract}
Individuals and communities often do not take steps prior to a disaster to undertake protective measures because they are prone to systematic biases with respect to their perception of the likelihood and outcomes from natural disaster when compared with expert risk assessments. They also tend to focus on the short-term and utilize simplified decision rules in determining whether to purchase insurance or invest in loss-reduction measures. Understanding how experts assess the likelihood and consequences of disasters as well as how individuals perceive these risks and make choices provide the ingredients for risk management strategies for communities to become more resilient with respect to hazards they face. Modifications to the National Flood Insurance Program (NFIP), such as risk-based premiums and vouchers coupled with loans for flood mitigation measures could make individuals in flood-prone communities more resilient.
\end{abstract}

\section{Keywords}

Insurance, Resilience, Natural Disasters, Decision Making, National Flood Insurance Program, Climate Change

\section{Introduction}

Hurricane Sandy caused an estimated $\$ 65$ billion in economic losses to residences, business owners, and infrastructure owners (Aon Benfield 2013). It is the second most costly natural disaster in recent years in the United States, after Hurricane Katrina in 2005, but it is not an outlier; economic and insured losses from devastating natural catastrophes in the United States and worldwide are climbing.

According to Munich Re (2015), real-dollar economic losses from natural catastrophes increased from $\$ 528$ billion (1981 to 1990 ), to $\$ 1197$ billion (1991 to 2000 ), to $\$ 1.23$ billion (2001 to 2010). During the past 10 years, the losses were principally due to hurricanes and resulting storm surge occurring in 2004, 2005, and 2008. Figure 1 depicts the evolution of the direct economic losses and the insured portion from great natural disasters over the period 1980 to 2014 .

Extreme events highlight the challenges policy makers face in encouraging residents in hazardprone areas to protect themselves against future disaster losses. A 1974 survey of more than 1000 California homeowners in earthquake-prone areas revealed that only 12 percent of the respondents had adopted any protective measures. Fifteen years later, there was little change despite the increased public awareness of the earthquake hazard. In a 1989 survey of 3500 homeowners in four California counties at risk from earthquakes, only 5 to 9 percent of the respondents in these areas reported adopting any loss reduction measures (Palm et al. 1990). 
Overall losses and insured losses 1980-2014 (in US\$ bn)

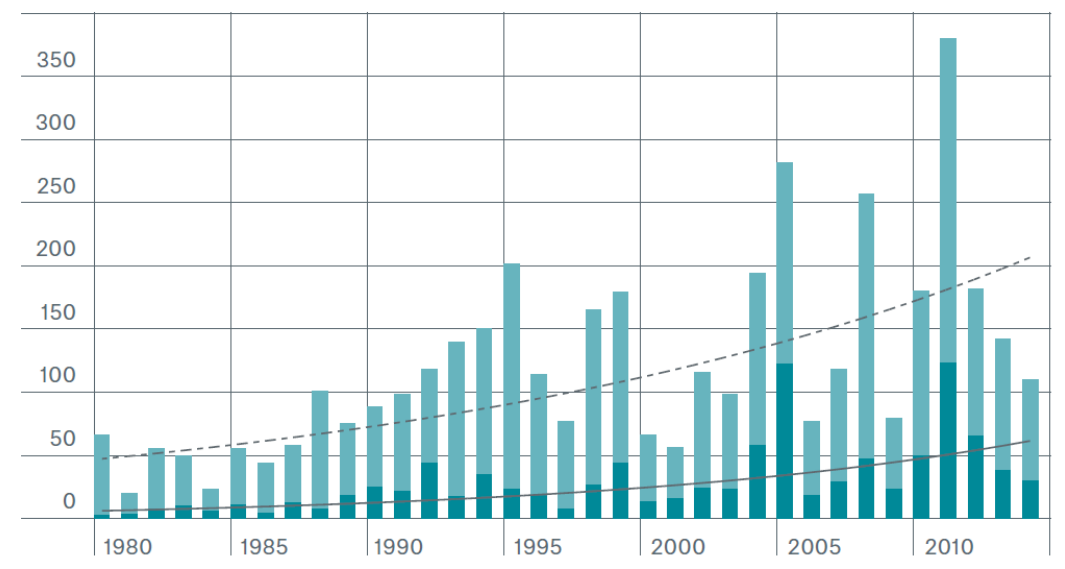

Overall losses

(2014 values)*

Of which insured losses (2014 values)*

-.- Trend in overall losses

- Trend in insured losses

* Values adjusted for inflation using the Consumer Price Index (CPI) of each country.

Source: Munich Re NatCatSERVICE

Figure 1. Overall and Insured Losses 1980 to 2014 (in US \$ billion)

Residents in flood and hurricane-prone areas have demonstrated a similar reluctance to invest in mitigation measures (Burby et al. 1988; Laska 1991). Even after the devastating 2004 and 2005 hurricane seasons, a large number of residents had still not invested in relatively inexpensive loss-reduction measures with respect to their property, nor had they undertaken emergency preparedness measures. A survey of 1100 adults living along the Atlantic and Gulf coasts undertaken in May 2006 revealed that 83 percent of the responders had taken no steps to fortify their home, 68 percent had no hurricane survival kit, and 60 percent had no family disaster plan (Goodnough 2006).

A survey of nearly 800 residents in coastal counties during Hurricane Sandy in 2012 revealed that only half of storm-shutter owners actually installed them to protect their windows before the hurricane came - despite believing there was a high chance that their homes would experience hurricane force winds. The most common reason was procrastination-when asked as the storm was approaching the most common answer was that it was "too soon" — an answer repeated until the storm was upon them (Meyer et al. 2014). This is an interesting example of mitigation measures being purchased but not utilized.

Key decision makers who authorize development in hazard-prone areas after dams or levees are built may unintentionally reinforce this behavior. There is compelling evidence that residents who move into these areas feel completely safe, when in fact they are still at risk for catastrophes should the dam or levee be breached or overtopped (Burby 2006). If a catastrophic disaster occurs, the damage is likely to be considerably greater than would have occurred had the lower but positive flood risk been correctly perceived. This behavior with its resulting consequences has been termed the levee effect. ${ }^{2}$

Public officials also exacerbate the problem by not enforcing building codes and implementing permissive zoning. A graphic example highlighting this point is the development of New Orleans

\footnotetext{
${ }^{2}$ For more information on the levee effect, see Tobin (1995).
} 
following Hurricane Betsy in 1965 after the Corps of Engineers agreed to build massive hurricane protection levees to surround New Orleans and nearby communities. The city planning commission approved new subdivisions between 1967 and 1972 in areas that had been flooded by Betsy (Colten and Giancario 2011).

This paper addresses the above problems by proposing a framework for making communities more resilient to natural hazards. Resilience is defined as "the ability to prepare and plan for, absorb, recover from, or more successfully adapt to actual or potential adverse events" (National Research Council 2012).

The framework highlights the importance of undertaking a comprehensive risk identification and assessment that communities face while at the same time recognizing the role of risk perception with respect to extreme events such as natural disasters. By linking these two elements one can develop a risk management plan that fosters community resilience. We then illustrate how the framework could be applied in modifying the National Flood Insurance Program. The paper concludes with a brief summary and suggestions for future studies.

\section{Risk Identification and Assessment ${ }^{3}$}

Identifying and assessing the risks communities face with respect to natural disasters involves expert estimates of the following elements:

Likelihood of a disaster. What are the chances that the community will be affected by a natural disaster? This estimate is a function of the probability of occurrence of the hazard event in the area as well as the chances that a disaster in a more distant place will impact the residents and businesses in the community.

Exposure of the community's assets. This refers to the composition of the residents, property and infrastructure in those parts of the community subject to damage from natural hazards.

Community vulnerability. The potential for harm from a disaster encompasses physical assets (building design and strength), social capital (community structure, trust, and family networks) and political access (ability to obtain assistance from the government following a disaster). Vulnerability also refers to how sensitive a population may be to a hazard or to disruptions caused by the hazard. The social structure of the community, as well as socio-economic characteristics of the population, such as age, income and education are likely to affect the ability of these populations to be resilient to disasters (National Research Council 2006; Cutter et al. 2003, 2008).

Consequences of a disaster. Losses from disasters are measured by their direct impacts (e.g., damage to property and infrastructure) as well as indirect effects (e.g., business interruption, evacuation of victims) due to local or interdependent damage to utilities, bridges and roads, contamination of the water supply, etc. The losses also include immediate and long-term environmental damage, loss of human lives, injuries and health effects as well as social/family and psychological impacts that affect the long-term well-being of the area (Heinz Center 2000). Consequences may also extend far beyond the area immediately affected by the hazard. For

\footnotetext{
${ }^{3}$ The material in this subsection is drawn from National Research Council (2012).
} 
example, cascading impacts on a supply chain may have a national or global effect due to interdependencies as illustrated by the inability of the auto industry in the U.S. to get key parts sourced from Japan following the 2011 Fukushima earthquake.

Impact of climate change. One also needs to take into account the impact that changing climate patterns might have on future flood-related damage due to potential sea level rise and more intense hurricanes. There is evidence that federal agencies and other bodies have underestimated the risks of damage from extreme weather events due to climate change (Repetto and Easton 2012). Hurricane Sandy has stimulated studies on ways that communities can be more prepared for future disaster damage as well as highlighting the need for a suite of policy tools including insurance to address the climate change problem. ${ }^{4}$

Uncertainty of risk estimates. When identifying and assessing the risk, it is important to highlight the degree of confidence experts have with respect to the likelihood and consequences of a particular disaster. Communities can then make decisions as to the robustness of investing in protective measures given the uncertainties associated with estimates of the risk. For example, if homeowners are considering elevating their homes, they will want to consider the likelihood of sea level rise of different magnitudes in the coming years and the resulting potential damage to their homes from future hurricanes and storm surge.

\section{Risk Perception}

Intuitive and deliberative thinking. A large body of cognitive psychology and behavioral decision research conducted during the past 30 years has revealed that individuals, small groups and organizations often make decisions under risk and uncertainty by undertaking processes that combine intuitive thinking with deliberative thinking. In his thought provoking book Thinking, Fast and Slow (2011) Nobel Laureate Daniel Kahneman has characterized the differences between these two modes of thinking. Intuitive Thinking (System 1) operates automatically and quickly, with little or no effort and no voluntary control.

Many of the biases and simplified decision rules that characterize human judgment and choice under uncertainty reflect automatic, emotional, nonanalytic thinking. In this regard, risk is often treated as a feeling rather than as a statistical concept (Loewenstein et al. 2001). In contrast, Deliberative Thinking (System 2) allocates attention to effortful and time-consuming activities, such as probability estimation, undertaking trade-offs implicit in benefit-cost analysis and examining relevant interdependencies and connectedness.

While intuitive perceptions of risk are relatively accurate over a broad range of situations, they can lead to systematic deviations from expert assessments, for low-probability, highconsequence (LP-HC) events such as natural hazards. Perceptions for these events are often guided by emotional reactions that lead to systematic biases or simple rules of thumb that have been acquired by personal experience.

Failure to purchase insurance until it is too late. One such bias is the availability heuristic where the judged likelihood of an event depends on its salience and memorability (Tversky and

\footnotetext{
${ }^{4}$ See, New York City (2013); New York City Panel on Climate Change (2015); and U.S. National Climate Assessment (2014).
} 
Kahneman 1973). There is thus a tendency to ignore rare risks until after a catastrophic event occurs. This is a principal reason why it is common for individuals to purchase insurance following a large-scale disaster rather than in an anticipation of a disaster, and for them to cancel their policies several years later if they have not suffered another loss.

A prime example of this behavior is the decision on whether to purchase flood insurance. A study of the risk perception of homeowners in New York City revealed that they underestimated the likelihood of water damage from hurricanes, which may explain why only 20 percent of those who suffered damage from Hurricane Sandy purchased flood insurance before the storm occurred (Botzen et al. 2014). An in-depth analysis of the entire portfolio of the National Flood Insurance Program revealed that the median tenure of flood insurance was between two and four years while the average length of time in a residence was seven years, indicating that a significant number of homeowners canceled their policies after several years (Michel-Kerjan et al, 2012).

A major reason that individuals cancel their policies is that they view insurance as an investment rather than a protective activity. When they don't make a claim for a few years they perceive their premiums as having been wasted. It is extremely difficult to convince individuals that the best return on an insurance policy is no return at all. A normative model of choice, such as expected utility theory, implies that risk averse consumers should value insurance as it protects them against large losses relative to their wealth. After purchasing insurance they should celebrate not having suffered a loss over a period of time rather than canceling their policy.

Lack of interest in loss reduction measures. There is also considerable empirical evidence indicating that residents in hazard-prone communities fail to invest in cost-effective loss reduction measures. When asked why they haven't undertaken protective measures that could reduce future disaster losses, individuals often respond by saying that "I live from pay day to pay day." This decision is reinforced by focusing on the upfront costs of risk reduction measures relative to the delayed benefits of the reduction of damage from floods that might occur in the future (Loewenstein and Prelec 1992; Laibson 1997).

Even before making this trade-off, individuals residing in harm's way may decide not to undertake mitigation measures if the likelihood of the disaster is below their threshold level of concern. In a laboratory experiment on purchasing insurance, many individuals bid zero for insurance coverage against low-probability events, apparently viewing the probability of a loss as so small that they were not interested in protecting themselves against it (McClelland et al. 1993). If individuals underestimate the likelihood of a disaster occurring, as was the case with respect to residents in NYC even after a future disaster, this will reinforce the lack of interest in undertaking protective measures until it is too late.

\section{Risk Management Strategies}

Risk management strategies that promise to enable communities to be more resilient with respect to natural disasters should be guided by expert risk assessments as well as the risk perceptions of those residing in hazard-prone areas. The strategies proposed in this section are designed so that the affected individuals and the community will pay attention to the risks they face while at the 
same time providing short-term economic incentives to encourage the investment in long-term protective measures.

Reframing probabilities. By presenting information on the likelihood of an LP-HC event occurring so that the risks are more transparent, key interested parties are likely to recognize the importance of undertaking protective measures now to reduce their losses from the next disaster. This is an example of what has been termed choice architecture. ${ }^{5}$ For example, the likelihood of an event is more likely to be considered when making protective decisions if it is presented using a longer time frame. A homeowner or manager is likely to take the risk seriously if told that the chance of occurrence of at least one flood with an annual probability of 1 in 100 occurring over a 25 year period is greater than 1 in 5 (Weinstein et al. 1996).

Property improvement loans and multi-year insurance. To reduce the tendency of individuals to not invest in protective measures because of the high upfront costs, long-term loans could be made available so the expenses are spread over a longer time horizon. Consider a property owner who would have to pay $\$ 1500$ to reinforce his roof to reduce wind damage by $\$ 30000$ from a future hurricane that has an annual probability of occurrence of 1 in 100. If insurers charged risk-based premiums, the mitigation measure would reduce the annual price of insurance by $\$ 300$ (i.e., $1 / 100$ x $\$ 30$ 000).

The insurance premium itself can act as a powerful signal as to the likelihood of a loss in the face of individuals' attempts to ignore the risk. Insurance also has the potential to encourage investment in loss reduction measures if homeowners can receive premium reductions based on investment in such measures, reflecting expected reduced claims following a disaster (Kunreuther, Pauly and McMorrow 2013).

Many property owners might still be reluctant to incur the $\$ 1500$ expenditure because of the relatively high upfront cost and their concern that they would get only $\$ 300$ back next year in lower insurance premiums. Given budget constraints and individuals' focus on short time horizons, it is difficult to convince these decision-makers that the expected discounted benefits of the investment over the expected life of the property exceeds the immediate upfront cost. The problems are compounded if homeowners underestimate their risk and perceive it to be below their threshold level of concern (Kunreuther, Meyer and Michel-Kerjan 2013). A 20-year \$1500 loan would solve these problems. Even with a high annual interest rate of 10 percent with yearly loan payments of $\$ 168$, the savings to the homeowner each year would be $\$ 132$ ( $\$ 300-\$ 168=$ $\$ 132$ ) in addition to the resulting mortgage interest tax-deductible amount.

As a complement to property improvement loans, insurers could consider designing multiyear insurance (MYI) contracts of three to five years. The insurance policy would be tied to the building rather than the property owner, and carry an annual premium reflecting risk that would remain stable over the length of the contract. Property owners who cancel the policy early would incur a penalty cost in the same way that those who refinance a mortgage have to pay a cancellation cost to the bank issuing the mortgage. With an MYI contract, insurers would have

\footnotetext{
${ }^{5}$ For more details on the use of choice architecture for framing problems see, Thaler and Sunstein (2008) and Johnson et al. (2012)
} 
an incentive to inspect the property over time to make sure that building codes are enforced, something they would be less likely to do with annual contracts.

Public-private partnerships. If insurance premiums were based on risk, then the public sector would need to assist those in hazard-prone areas who cannot afford coverage to address issues of equity and affordability. One option would be to provide means-tested vouchers. The amount of the voucher could be based on current income and determined by a specific set of criteria so as to make insurance affordable for those in need (National Research Council 2015). If the property owner were offered a multiyear loan to invest in mitigation measure(s), the voucher could cover not only a portion of the resulting risk-based insurance premium, but also the annual loan cost to make the package affordable. As a condition for the voucher, the property owner could be required to invest in mitigation.

An empirical study of homeowners in Ocean County, NJ reveals that the amount of the voucher is likely to be reduced significantly from what it would have been had the structure not been mitigated as shown in Figure 2 for property in a high hazard flood area (the V Zone) and a lower hazard area (the A Zone) (Kousky and Kunreuther 2014).

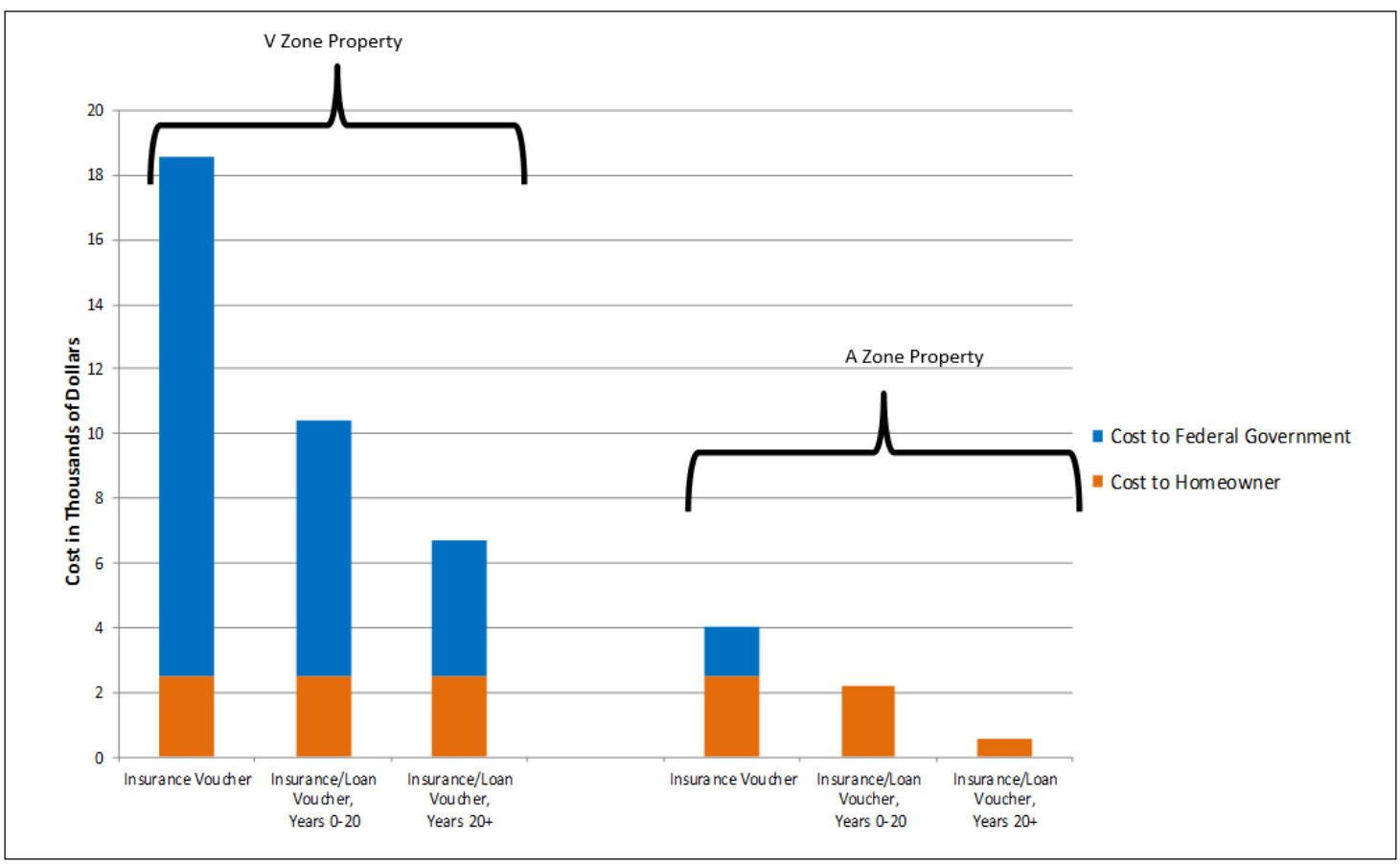

Figure 2. Cost of Program to the Federal Government and a Hypothetical Homeowner Source: Kousky and Kunreuther (2014)

Community-based programs. Communities can take steps to reduce future disaster losses and encourage wise development in hazard-prone areas to foster resilience. Well-enforced building codes are a key component in ensuring that those residing in hazard-prone areas adopt costeffective loss reduction measures. Licensed engineers, architects, contractors and inspectors could be instructed on the merits of loss reduction measures, as communities in Florida did after 
the passage of their new building codes. ${ }^{6}$ Local authorities could adopt zoning policies that do not permit development in high-risk portions of the community and rebuilding in damaged areas if the likelihood of another disaster is sufficiently high to merit these measures.

Communities and cities could design their taxation systems to encourage residents to pursue cost-effective mitigation measures. For example, the city of Berkeley encourages home buyers to retrofit newly purchased homes by instituting a seismic retrofit refund program that allows for up to $1 / 3$ of the property transfer tax to be refunded for voluntary eligible seismic upgrades to residential property. ${ }^{7}$ South Carolina allows individuals in hazard-prone communities to take state income tax credits for costs to retrofit homes. ${ }^{8}$

The community rating system (CRS) is a feature of the National Flood Insurance Program (NFIP) whose goal is to offer financial incentives through insurance premium reductions to encourage a comprehensive approach to floodplain management. The studies examining the extent to which CRS participation reduces flood claims and property damage generally find some reduction that is attributed to CRS actions such as open space protection, higher elevation requirements, and small flood control projects (Brody et al. 2007; Michel-Kerjan and Kousky 2010; Brody and Highfield 2013).

Communities are also reluctant to invest funds in risk-reducing measures for their facilities and infrastructure because they know that the federal government is likely to come to the rescue with relief should they suffer severe losses from a future disaster. Under the Stafford Act, communities are guaranteed federal funding to cover at least 75 percent of damage to public facilities and infrastructure for Presidentially declared disasters. For Hurricane Katrina, the government covered all of the losses. As a result, many hazard-prone communities have outdated or poorly designed infrastructure such as bridges, levees and dams and lack back-up facilities to deal with damage to transportation, water, electricity and telecommunications.

Data should be collected and examined as to what steps specific communities are taking to become more resilient under current disaster relief policies. The National Research Council Resilience Roundtable has taken a step in this direction by focusing on several communities that have expressed an interest in becoming resilient. Charleston, SC., Linn County, Iowa and Seattle have volunteered as initial case studies to reveal what measures they have undertaken to become more resilient and to consider other actions they could take in the future. By developing a common set of metrics for calibrating the resilience of these communities and the basis for their improved status may encourage other communities to follow suit.

\section{Modifying the National Flood Insurance Program}

The NFIP has an opportunity to implement a public private partnership that could eventually be extended to other natural disasters that reflects elements of the framework discuss above. The proposed design features of the program that could assist local and state authorities to make their communities more resilient to damage from riverine and coastal flooding are:

\footnotetext{
${ }^{6}$ More details on Florida's building codes and related programs can be found in www.FloridaBuilding.org

${ }^{7}$ For details on the program see http://www.ci.berkeley.ca.us/ContentDisplay.aspx?id=6282

${ }^{8}$ For details on the program see http://www.doi.sc.gov/faqs/CatSavingsAcct.htm.
} 
- Risk-based premiums based on updated flood maps so that private insurers have an incentive to market coverage. ${ }^{9}$

- Means-tested vouchers (that would address affordability issues) for those who undertake cost-effective mitigation measures. ${ }^{10}$

- Multiyear insurance (MYI) policies to provide stable premiums over time and prevent policyholders from canceling their policies

- Well-enforced building codes and zoning regulations to reduce damage from future disasters

- Redesigning the community rating system to encourage local officials to invest in projects that reduce the flood risk and lower residents' flood insurance premiums

- Reinsurance and risk-transfer instruments marketed by the private sector could cover a significant portion of the catastrophic losses from future floods. Some type of federal reinsurance would provide insurers with protection against extreme losses.

The social welfare benefits of this proposed program would be significant: less damage to property in flood-prone communities, lower costs to insurers for protecting against catastrophic losses, more secure mortgages, and lower costs to the government for disaster assistance.

\section{Summary and Suggestions for Future Studies}

Summary. Individuals and communities often do not take steps prior to a disaster to undertake protective measures because they are prone to systematic biases with respect to their perception of the likelihood and outcomes from natural disaster when compared with expert risk assessments. They also tend to focus on the short-term and utilize simplified decision rules in determining whether to purchase insurance or invest in loss-reduction measures.

Understanding how experts assess the likelihood and consequences of disasters as well as how individuals perceive these risks and make choices provide the ingredients for risk management strategies for communities to become more resilient with respect to hazards they face. More specifically, one needs to frame information in ways that individuals will pay attention to the long-term impacts of disasters and at the same time provide short-term incentives (e.g., property improvement loans coupled with multiyear insurance) complemented by well-enforced regulations and standards such as building codes. Modifications to the National Flood Insurance Program (NFIP), such as risk-based premiums and vouchers coupled with loans for flood mitigation measures could make individuals in flood-prone communities more resilient.

Suggestions for future studies. There is a need to examine more effective ways for the public sector to enforce regulations and standards such as building codes to encourage good construction practices. In this regard, Chile serves an example for the United States to emulate.

\footnotetext{
${ }^{9}$ FEMA is updating their flood-risk maps as recommended by a General Accounting Office (2008) study and as required by recent federal legislation to reform the National Flood Insurance Program.

${ }^{10}$ This proposal for risk-based premiums and means-tested vouchers are part of the Biggert-Waters Flood Insurance Reform Act that reauthorized the NFIP for five years in July 2012. This Act was modified in March 2014 as The Homeowner Flood Insurance Affordability Act of 2014 (HFIAA14) that delayed the implementation of risk-based premiums until issues of affordability of the NFIP were addressed. The National Research Council released a report on Phase I of the affordability study that was authorized by HFIAA2014 (National Research Council 2015).
} 
The country passed a law that requires the original construction company to compensate those who suffer due to structural damage from earthquakes and other disasters if the building codes were not followed. Furthermore, the original owner of a building is held responsible for damage to the structure for a decade and can be sentenced to prison. Well-enforced building codes in Chile account for the modest death toll from the powerful earthquake ( 8.8 on moment magnitude scale) that rocked the country on February 27, 2010 (Useem et al. 2015).

Future studies could also determine the types of private-public partnerships for utilizing insurance to encourage communities to invest in loss reduction measures if the percentage of public sector funding from the Stafford Act is significantly reduced following the next disaster. A multi-year insurance program where communities pay premiums to provide funds to restore their infrastructure following the next disaster could be complemented by dedicated mitigation loans to improve facilities. The upfront costs of these investments would be spread over time and the insurance premiums would be reduced to reflect the lower claim payments should a severe disaster occur. Insurance claims payments are likely to be provided to the communities in a more timely fashion than disbursements by the federal government via the Stafford Act. Not only would this strategy make communities more resilient, it would also create jobs and reduce taxpayers' expenditures following a disaster.

The areas in the Northeast United States affected by Hurricane Sandy are now fully aware of the need for taking steps to reduce losses from future disasters and their need for timely assistance to facilitate their recovery efforts. Mayor Michael Bloomberg's report, A Stronger, More Resilient New York issued in June 2013 recommends upgrading utilities, roadways, tunnels, subways and other infrastructure now so as to reduce losses in the future (New York City 2013). The Hurricane Sandy Rebuilding Strategy by a Federal Task Force under the leadership of Sean Donavan, Secretary of Housing and Urban Development (HUD 2013) raised a similar message: targeted financial incentives to incorporate resilience measures and risk mitigation into infrastructure projects and increased leverage of non-federal funds for infrastructure. The proposed program of multiyear insurance and loans for mitigation would be a step in this direction.

We know from past experience, however, that recommendations from important reports such as these often do not get implemented. When they are, it is because there is a perceived need for change by interested parties concerned with losses from extreme events. These include the real estate agents, developers, banks and financial institution, residents in hazard-prone areas as well as public sector organizations at the local, state and federal levels.

At the end of August we will be observing the tenth anniversary of Hurricane Katrina and at the end of October the third anniversary of Hurricane Sandy. Remembering these natural disasters, the two most severe that the country has ever experienced, can be used to suggest changes given that they are likely to be the focus of the public's attention.

\section{Acknowledgements}

This paper reflects research and helpful discussions with colleagues at the Wharton Risk Center and at other universities and research institutions, notably Jeff Czajkowski, Daniel Kahneman, Robert Meyer, Erwann Michel-Kerjan, Mark Pauly, Paul Slovic and Elke Weber. Special thanks 
to Carol Heller for her editorial assistance. Funding for this research comes from the National Science Foundation (SES-1061882 and SES-1062039); the Center for Risk and Economic Analysis of Terrorism Events (CREATE) at the University of Southern California; the Center for Research on Environmental Decisions (CRED; NSF Cooperative Agreement SES-0345840 to Columbia University), the Zurich Insurance Foundation on community flood resilience and the Wharton Risk Management and Decision Processes Center.

\section{References}

Aon Benfield, 2013. Annual Global Climate and Catastrophe Report: 2012. Chicago, IL: Aon Benfield Impact Forecasting.

Botzen, W.J.W., Kunreuther, H., and Michel-Kerjan, E., 2014. "Understanding Individual Flood Risk Perceptions and Flood Insurance Choices to Build More Resilient Communities: A Survey of New York City Residents.” Issue Brief. Philadelphia, PA: Wharton Risk Center Management Center, University of Pennsylvania

Brody, S., Zahran, S., Maaghelal, P., Grover, H., and Highfield, W.E., 2007. "The Rising Costs of Floods: Examining the Impact of Planning and Development Decisions on Property Damage in Florida." Journal of the American Planning Association 73 (3): 330-345.

Brody, S.D., and Highfield, W.E., 2013. Open Space Protection and Flood Mitigation: A National Study. Land Use Policy 32: 89-95.

Burby, R., 2006. "Hurricane Katrina and the Paradoxes of Government Disaster Policy: Bringing About Wise Governmental Decisions for Hazardous Areas." Annals of the American Academy of Political and Social Science 604: 171-191.

Burby, R. J., Bollens, S., Kaise, E. J., Mullan, D., and Sheaffer J. R., 1988. Cities Under Water: A Comparative Evaluation of Ten Cities' Efforts to Manage Floodplain Land Use. Boulder, CO: Institute of Behavioral Science, University of Colorado.

Colten, C., and Giancario, A., 2011. "Losing Resilience on the Gulf Coast: Hurricanes and Social Memory," Environment 53: 4, 6-19

Cutter, S.L., Boruff, B.J., and Shirley W.L., 2003. "Social Vulnerability to Environmental Hazards." Social Science Quarterly 84 (1):242-261.

Cutter, S L., Barnes, L., Berry, M., Burton, C., Evans, E., Tate, E., and Webb J., 2008. “A placebased model for understanding community resilience to natural disasters." Global Environmental Change 18 (4): 598-606.

Government Accountability Office (GAO) (2008). Flood Insurance. FEMA's Rate Setting Process Warrants Attention, GAO-09-12, Washington, DC: U.S. Government Accountability Office.

Goodnough, A., 2006. “As Hurricane Season Looms, State Aim to Scare,” New York Times, May 31.

Heinz Center, 2000. The Hidden Costs of Coastal Hazards Washington, DC: Island Press.

Johnson, E., Shu, S.B., Dellaert, B.G.C., Fox, C., Goldstein, D.G., Häubl, G., Larrick, R., et al., 2012. "Beyond nudges: Tools of a choice architecture." Marketing Letters 1-18.

Kahneman, D., 2011. Thinking, Fast and Slow. New York, NY: Farrar, Straus and Giroux.

Kousky, C., and Kunreuther H., 2014. "Addressing Affordability in the National Flood Insurance Program." Journal of Extreme Events 1(01).

Kunreuther, H., Meyer, R., and Michel-Kerjan E., 2013. "Overcoming Decision Biases to Reduce Losses from Natural Catastrophes," chapter 23 in E. Shafir, ed., Behavioral Foundations of Policy. Princeton, NJ: Princeton University Press. 
Kunreuther, H., Pauly, M.V., and McMorrow S., 2013. Insurance and Behavioral Economics: Improving Decisions in the Most Misunderstood Industry. New York, NY: Cambridge University Press.

Laibson, D., 1997. “Golden Eggs and Hyperbolic Discounting." Quarterly Journal of Economics 112: 443-478G.

Laska, S.B., 1991. "Floodproof Retrofitting: Homeowner Self-Protective Behavior." Boulder: Institute of Behavioral Science, University of Colorado.

Loewenstein, G., and Prelec D., 1992. "Anomalies in Intertemporal Choice: Evidence and an Interpretation," Quarterly Journal of Economics 107, no. 2: 573-597

Loewenstein, G.F., Weber, E.U., Hsee, C.K, and Welch N., 2001. "Risk as Feelings." Psychological Bulletin 127: 267-286

McClelland, G., Schulze, W., and Coursey D., 1993. "Insurance for Low-Probability Hazards: A Bimodal Response to Unlikely Events.” Journal of Risk and Uncertainty 7: 95-116.

Meyer, R., Baker, J., Broad, K., Czajkowski, J., and Orlove B., 2014. "The Dynamics of Hurricane Risk Perception: Real-Time Evidence from the 2012 Atlantic Hurricane Season." Bull. Amer. Meteor. Soc. 95, 1389-1404.

Michel-Kerjan, E., and Kousky C., 2010. "Come Rain or Shine: Evidence on Flood Insurance Purchases in Florida." Journal of Risk and Insurance 77(2): 369-397.

Michel-Kerjan, E., Lemoyne de Forges, S., and Kunreuther H., 2012. "Policy Tenure under the U.S. National Flood Insurance Program.” Risk Analysis 32(4): 644-658.

Munich Re, 2015. "Topics Geo. Natural Catastrophes 2015, Report.” Munich, Germany: Munich Re.

National Research Council, 2006. Facing Hazards and Disasters: Understanding Human Dimension. Washington D.C.: National Academies Press.

National Research Council, 2012. Disaster Resilience: A National Imperative. Washington, D.C.: National Academies Press

National Research Council, 2015. Affordability of National Flood Insurance Program Premiums - Report 1. Committee on the Affordability of National Flood Insurance Program Premiums. Washington, D.C.: National Academies Press.

New York City, 2013. PlaNYC: A stronger more resilient NYC. New York City, Mayor's Office of Long Term Planning and Sustainability. http://www.nyc.gov/html/sirr/html/report/report.shtml

New York City Panel on Climate Change, 2015. "Building the Knowledge Base for Climate Resiliency" Annals of the New York Academy of Sciences 1336:1-150.

Palm, R., Hodgson, M., Blanchard, R.D., and Lyons D., 1990. Earthquake Insurance in California: Environmental Policy and Individual Decision Making. Boulder, CO: Westview Press.

Repetto, R., and Easton R., 2012. "Climate Change and Damage From Extreme Weather Events." Environment 52: 2, 22-33,

Thaler, R., and Sunstein C., 2008 Nudge: The gentle power of choice architecture. New Haven, CT: Yale University Press.

Tobin, G.A., 1995. "The Levee Love Affair: A Stormy Relationship.” Water Resources Bulletin 31(3): 359-367.

Tversky, A., and Kahneman D., 1973. "Availability: A heuristic for judging frequency and probability.” Cognitive Psychology 5(2), 207-232. 
Useem, M., Kunreuther H., and Michel-Kerjan E., 2015. Leadership Dispatches: Chile's Extraordinary Comeback from Disaster. Stanford, CA: Stanford University Press.

U.S. Housing and Urban Development (HUD), 2013. Hurricane Sandy Rebuilding Strategy. Washington, D.C.: Hurricane Sandy Rebuilding Task Force. August.

U.S. National Climate Assessment, 2014. Climate Change Impacts in the United States Washington, DC: U.S. Government Printing Office.

Weinstein, N.D., Kolb, K., and Goldstein B.D., 1996. "Using time intervals between expected events to communicate risk magnitudes." Risk Analysis 16, no. 3: 305-308. 
Prieto, Robert

\title{
Economics of Community Disaster Resilience Dealing with Uncertainty
}

\begin{abstract}
This paper looks at uncertainty related to the economics of investments in community resilience and considers some of the unique characteristics of such investments. Uncertainty, as opposed to mathematical risk, is a pervasive fact of life and the paper explores first and higher order outcomes that impact our ability to achieve defined resilience objectives. A four part contextual definition of community is provided. Specific resilience outcome metrics, including Recovery Time Objective (RTO) and Resilience Value at Risk (RVR), are suggested and a community resilience life cycle model outlined. Actionable recommendations for managing uncertainty in economic evaluations related to community resilience are provided.
\end{abstract}

\section{Keywords}

Community, Economics, Uncertainty, Resilience, Recovery Time

\section{Value Systems and Valuations}

This paper looks at uncertainty related to the economics of investments in community resilience and considers some of the unique characteristics of such investments including:

- The long term nature of both initial investments but also utility and "return on investment"

- The need to meet the long term needs of multiple, interlocking stakeholder groups, with potentially differing views of risk, investment horizons and potential futures

- Consequences of getting it materially wrong

- The programmatic nature at scale, dealing with whole communities, broader than even many of today's giga-programs consisting of handfuls of projects. This system of systems perspective is increasingly important.

- Complexity, that only allows insights into how to prepare for tomorrow through almost unweighted consideration of scenarios

- The emerging nature of the problem and its likely relationship to many of the future projects we will undertake.

A framework for the economics of community resilience is provided and select uncertainty factors considered and are intended to advance our understanding of uncertainties involved and opportunities to address our data and knowledge gaps.

\section{Uncertainty and Economics}

"Uncertainty, as opposed to mathematical risk, is a pervasive fact of life" (The Economic Journal, 1985). This is nowhere more true than in the field of economics where, despite Keynes' contributions, an undue predisposition persists with respect to certainty in projecting the future. We know less about the future than we typically assume and this uncertainty opens the door to multiple potential futures limited only by the way we think about the world. Uncertain futures must not be confused with improbable futures since the relative probabilities of each of these futures is numerically indeterminate, not allowing them to be compared. 
We focus on determining the probability and consequences of the various estimates and events that we believe we may reasonably experience in a project context. Yet at the same time we know that the "tails" of the Monte Carlo analysis are too thin, underestimating rare events and perhaps failing to consider uncertain futures at all.

\section{Community Resilience Defined}

We do not have a common definition for resilience but rather many similar definitions. For example, the Community \& Regional Resilience Institute (CARRI) defines resilience as the "ability to anticipate risk, limit impact, and bounce back rapidly in the face of turbulent change." The definition contained in Presidential Policy Directive 21 (PPD-21) states, "The term 'resilience' means the ability to prepare for and adapt to changing conditions and withstand and recover rapidly from disruptions." In effect resilience is founded on our ability to identify threats; model them to predict risks; and create strategies to counter negative effects. Whether this definition is adequate is superseded by a shortcoming found in all definitions of resilience, namely, they lack sufficient specificity to actualize the achievement of resilience. This point is essential for understanding the key uncertainties we must focus our energies on.

In considering the economics of community resilience it is important to define what we mean by community and ensure our economic views are not limited by political correctness. For this paper we will define the "economic community" as encompassing four distinct stakeholder groups (but with overlapping memberships) who bear the costs, benefits and consequences of appropriate investment or disinvestment in community resilience. These include:

- Public sector

- Private sector (organized industry)

- Citizens (individuals comprising communities)

- Insurance industry

Figure 1 shows these groups.

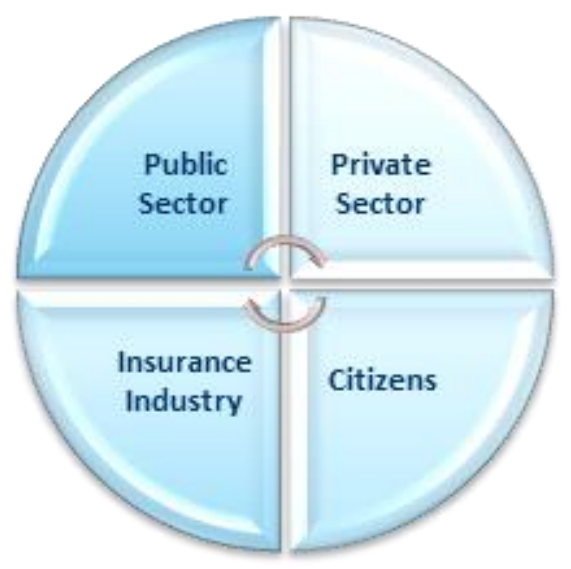

Figure 1. Groups Defining Community Resilience

\section{Resilience Outcome Defined}

Any consideration of the economics of resilience requires that we explicitly define a targeted outcome and score various investments' contributions towards closing the gap between where we 
are and the desired outcome at a future point in time. Failure to define clearly the Strategic Business Objectives we are trying to achieve, getting agreement on them, and then continuously communicating them is a principal failure we see in large programs that "under-perform". In the context of community resilience this leads to the definition of two key concepts:

- Recovery Time Objective (RTO) - This is associated with the desired resilience end state and CARRI's objective of "bouncing back rapidly". In a business context we define a "Recovery Time Objective" or RTO as the targeted duration of time, at a specified service level, within which a business process must be restored after a disaster (or disruption) in order to avoid unacceptable consequences associated with a break in business continuity. This definition is more broadly extended across the entire "economic community" previously described. As part of a comprehensive review Current Recovery Time (CRT) can be estimated; compared to the RTO; and gaps readily identified

- Resilience Value at Risk (RVR) - This recognizes that all actions undertaken to address identified gaps take time to deploy and during this period there is a Resilience Value at Risk (RVR) that is a function of the RTO - CRT gap and the rate at which that gap is closed.

Figure 2 illustrates a scenario where the planned RTO is deemed to be consistent with the Current Recovery Time (CRT). Over time we have a goal of improving the RTO but in the absence on necessary investment CRT worsens. The gap between our desired recovery time and actual recovery time widens with more value at risk.

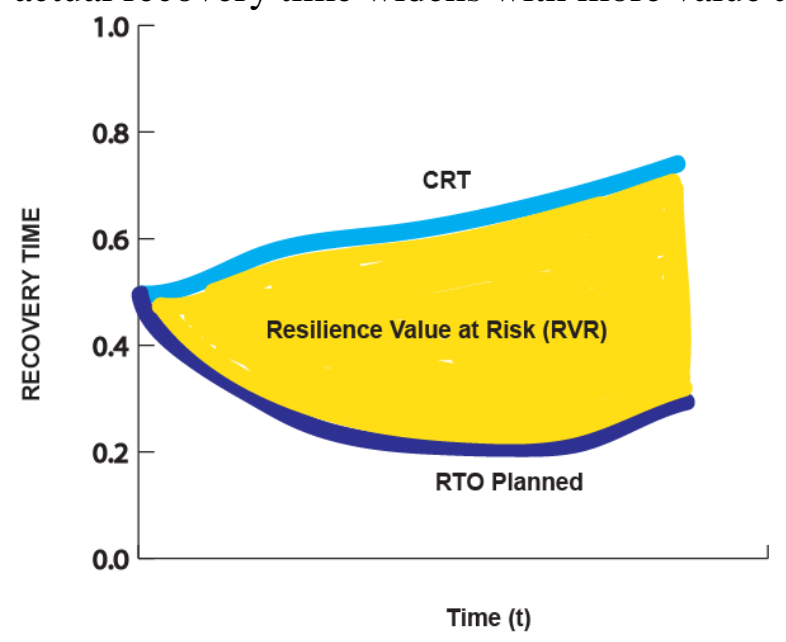

Figure 2. Comparing Recovery Time Objective to Current Recovery Time

\section{First Order Uncertainties}

There are several first order uncertainties which we risk glossing over as we seek to get more granular in defining uncertainties associated with the economics of community resilience. Principal among them is definition of Recovery Time Objectives by each stakeholder group accompanied by rationalization of those various RTOs. These RTOs must be defined for several economic framework elements that encompass:

- Lifeline capabilities, services and facilities (response, sustaining and protecting)

- Critical enabling capabilities, services and infrastructure (recovery and sustaining lifelines) 
- Restoration capabilities and services (long term recovery; economic recovery) Clear and consistent methodologies for defining economic framework elements does not exist; guidance on appropriate RTOs is lacking; and, even more fundamental, we do not understand the current recovery time (CRT) associated with a given impact scenario.

These uncertainties must be addressed to proceed in a well-founded way. Effective review of CRT requires:

- Comprehensive understanding of the current condition of key capabilities, services and infrastructure systems and key facilities

- Point and rate of degradation of these facilities

- Mapping of key interdependencies, value chain relationships and second (and higher) order coupling, including "constraint coupling"

- Insight into assumptions made with respect to critical enabling capabilities and their impacts on recovery timeframes

Data are broadly missing in many areas including comparable absence on interdependencies, value chains and coupling. Figure 3 illustrates these concepts.

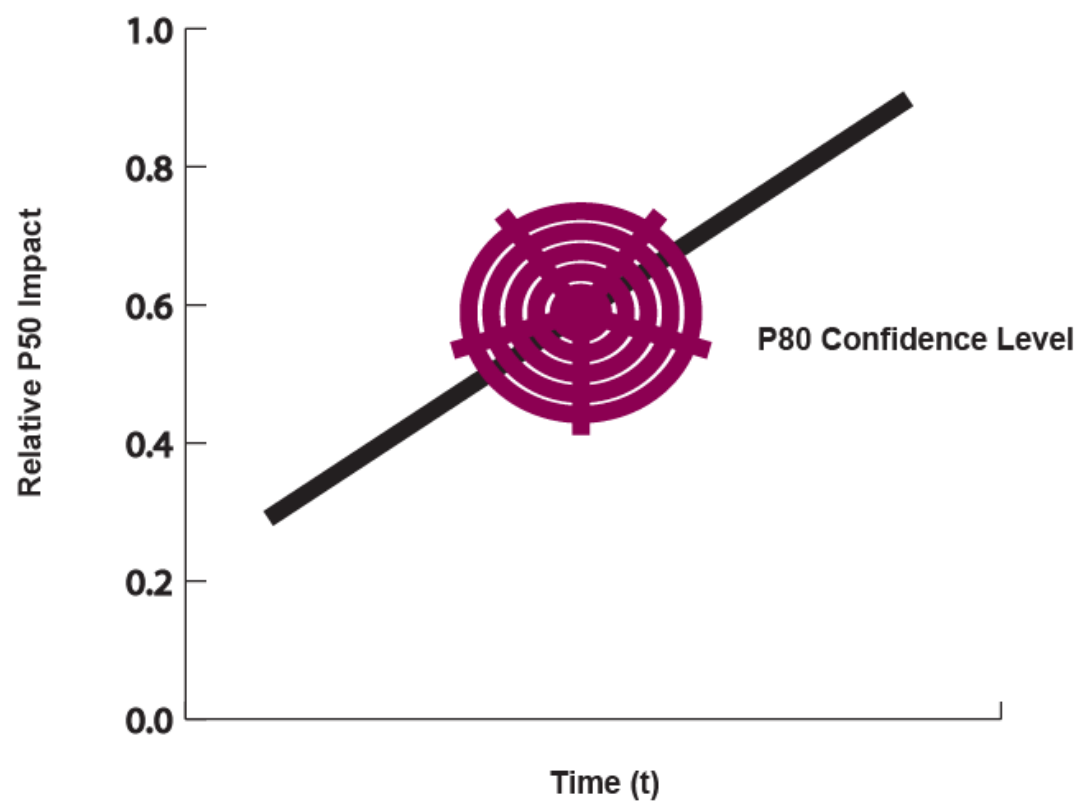

Both Impact and Temporal Uncertainty Must Be Considered

Figure 3. First Order Uncertainties

\section{Multiple Futures}

The future is uncertain.

In considering the economics of community based resilience it is essential that we consider a full range of potential futures, consciously not filtering out those very rare events which have the potential for greatest impact. The RTOs we establish as well as our assessment of CRT will vary with scenarios considered. For example, we may want our community to have no disruption (RTO $=0$ hours) for a snow event of 2 " but may be willing to incur a longer disruption for a 12" snow event ( $\mathrm{RTO}=8$ hours). Clearly, more extreme scenarios are of more interest. 
Some scenarios (climate change) evolve over longer timeframes than point source events (tornado; earthquake) and individual scenarios may have multiple failure modes that develop over time (extreme snow followed by flooding; NATECH event - natural disaster triggers a "technology" failure (Fukushima)). Uncertainties associated with the economics of community resilience for these longer evolving scenarios must focus on resilience value at risk (RVR).

As we evaluate investments in community resilience, in a world of multiple uncertain futures, we must envelope these potential futures and reflect their uncertainties in terms of impacts and timing. For a given scenario (climate change) our CRT grows over time, absent investments, but this growth has an impact uncertainty and timing uncertainty at each future point in time.

Temporal uncertainties can be described in terms of time series P50 values related to impact but with impact variance coupled with temporal variance.

Simple models for temporal variance of longer timeframe events are required.

\section{Economic Model Defined}

Our evaluation of community resilience needs a baseline economic model that assures we have:

- Captured all economic benefits and costs

- Reflects the value of time and its impact on economic benefits; capital efficiency; and Resilience Value at Risk (RVR)

- Recognizes that community resilience is not a static achievement but rather subject to changing externalities and normal "depreciation" of capabilities and capacities that require mitigating sustaining investments. (Resilience in the following figure may be thought of in many ways but the ratio RTO/CRT may be a useful parameter for assessing relative resilience. At $\mathrm{RTO} / \mathrm{CRT}=1$ the resilience objective has been met, subject to future changes in both RTO and CRT. As the ratio RTO/CRT decreases, the resilience challenge grows.) See Figure 4

- Considers quantitative uncertainties around key parameters as well as temporal uncertainties with respect to financial externalities (inflation rate; financing costs; debt tenor) and principal scenarios considered

- Considers multiple possible scenarios associated with an uncertain future as provided in Figure 5

This model allows us to:

- Better define and enhance this economic framework

- Assist key stakeholders in identifying opportunities to support the decision, making abilities of communities to plan to mitigate, respond to, and recover from disasters

- Enhance understanding of multi-disciplinary perspectives, available methods, best practices, and associated uncertainties.

The following economic model adopts a life cycle perspective that may be applied to capabilities, services and facilities collectively referred to as community assets. 


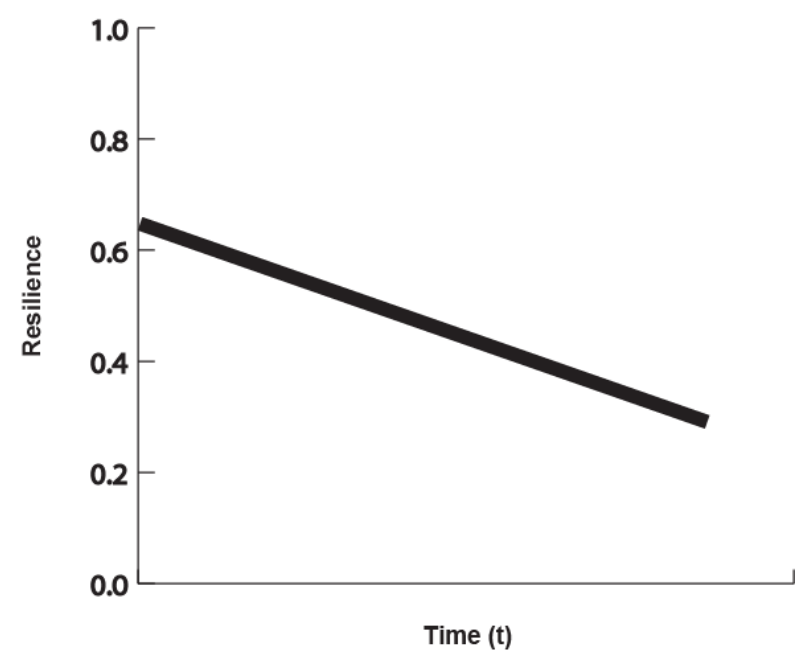

Community Resilience "Depreciates" Over Time Without Sustaining Investments

Figure 4. Community Resilience Absent Externalities

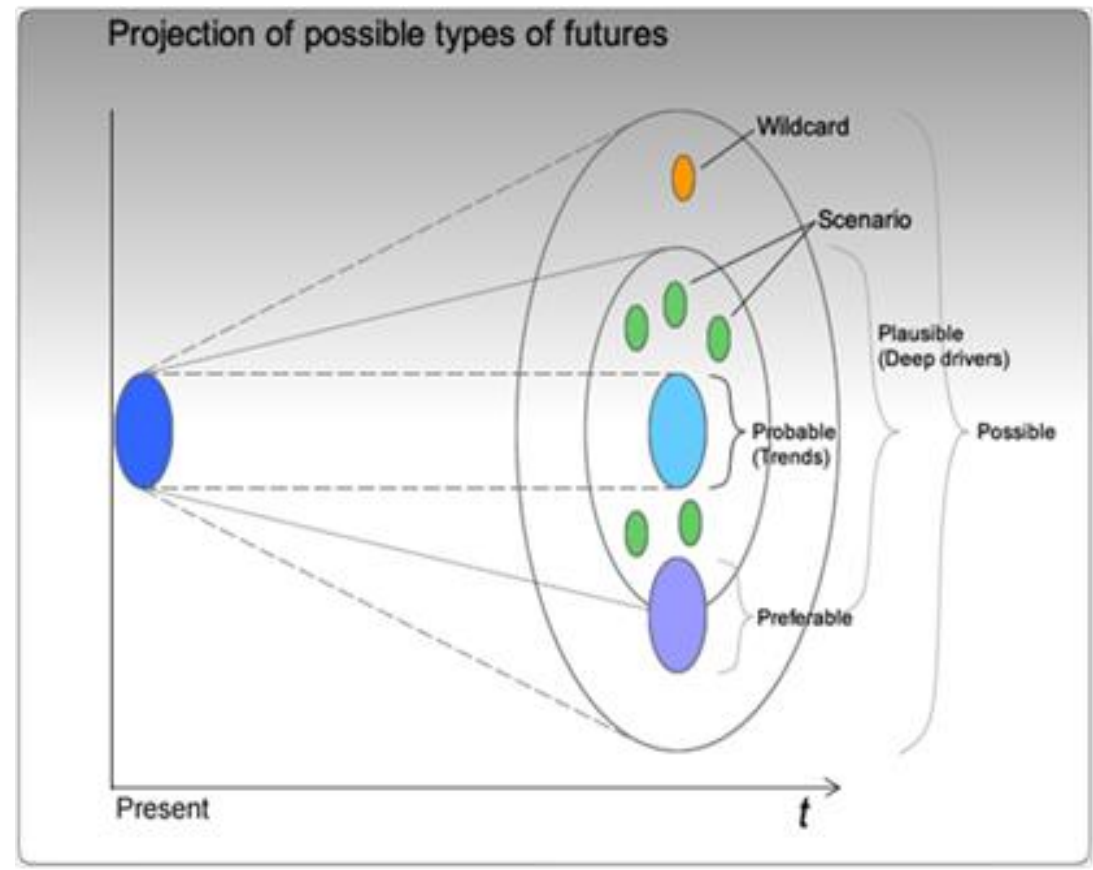

Figure 5. Projections of Possible Types of Future

\section{Community Resilience Lifecycle Model}

The life cycle model for community resilience encompasses:

- Economic benefits

- Asset life cycle costs and investments

- Indirect asset costs

- Externalities 
Life cycle analysis of community resilience provides a valuable option analysis tool, allowing consideration of future investments and their timing and, importantly, prioritization of investments. Risk, especially systemic risks, and uncertainty are fundamental aspects of a sound community resilience model.

\subsection{Economic Benefits}

Economic benefits associated with community resilience investments are those associated with avoided costs associated with:

- Direct damages from a threat

- Economic losses due to business interruption

Many of the design, procurement and construction costs described in the context of proactive resilience investments are incurred post disaster but with elevated uncertainty levels with respect to cost and schedule. This uncertainty is driven by many factors including the fact that the project framework is significantly modified post disaster (PM World Journal, 2013).

- In many instances community resilience investments will provide additional economic benefits associated with:

$\bigcirc$ Economic activity generated by the community resilience investment

$\circ$ Enhanced economic performance (improved productivity; acceleration of the economic cycle)

Economic benefits derived from avoided costs are a function of the threat scenario considered and RTO level achieved by the investments. The relationship between RTO, threat and costs (the ones which we want to avoid) is shown below. See Figure 6.

As threat magnitude increases, direct damages increase. As RTO increases, economic losses due to business interruption increase. The intersection line between the two surfaces (cost to mitigate (discussed in the next section) and economic losses) is the economic breakeven line. This represents the RTO for each threat magnitude that provides mitigated losses equal to the cost to mitigate. Superimposing current recovery time (CRT) allows us to calculate avoided costs. Principal uncertainties in this community resilience life cycle analysis factor include:

- Avoided (RTO - CRT) economic impact associated with direct damages from a particular scenario

- Avoided (RTO - CRT) economic losses due to business interruption

- Current assessment of economic impacts and losses associated with CRT (to enable avoided cost calculation)

- Economic activity associated with specific investments made to improve community resilience

- Enhanced economic performance associated with the investments made

- Probability of a particular scenario occurring and timing of the scenario

- Discount factor considering uncertainty of timing 


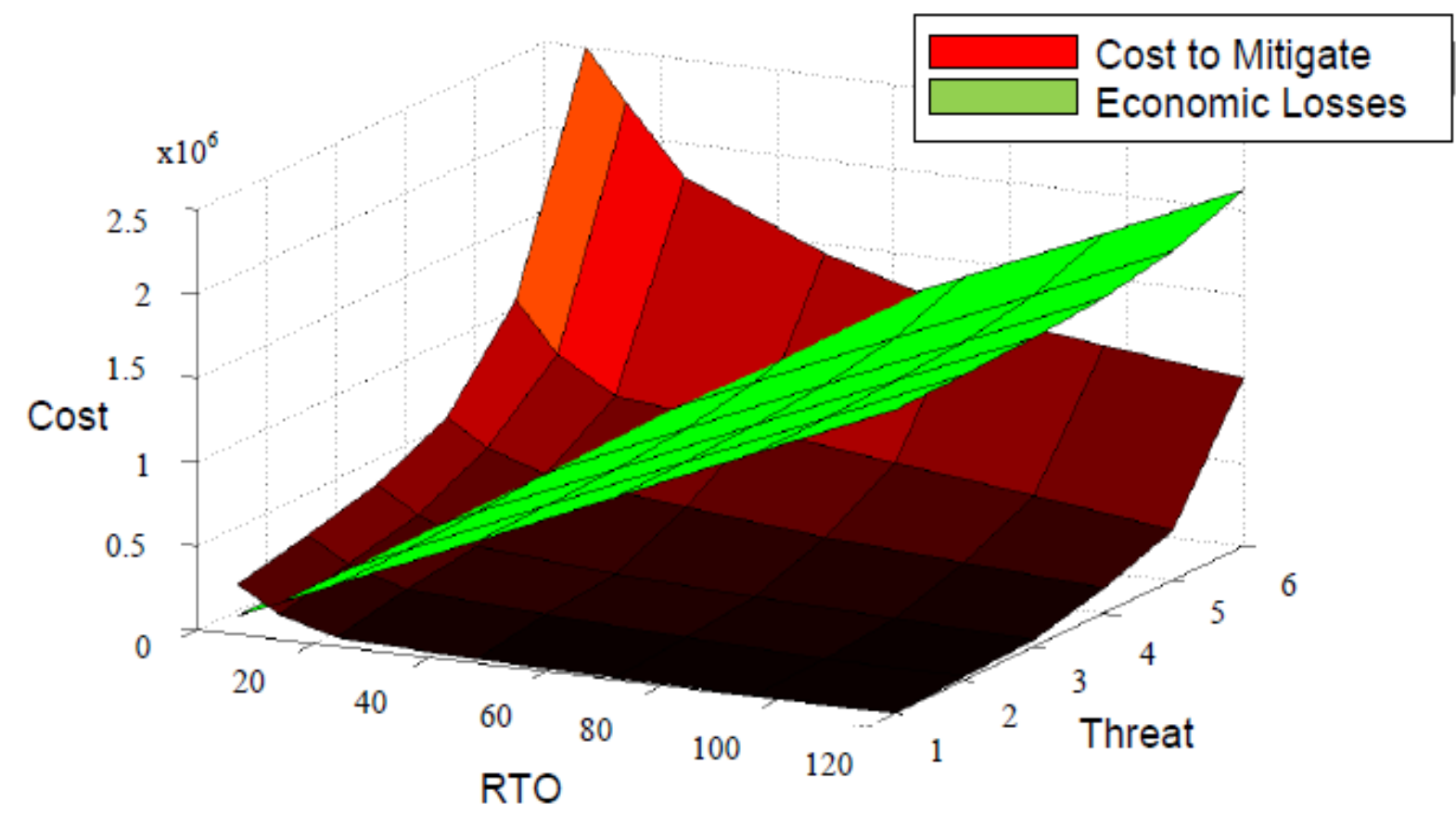

Figure 6. RTO, Threat and Cost

\subsection{Asset Life Cycle Costs and Investments}

Assets encompass capabilities, services and facilities. Life cycle costs (CMMA, 2013) associated with investments to meet RTO objectives and reduce economic impacts and losses at a given RTO level consist of:

- Planning and permitting

$\circ$ The principle costs here are those associated with the cost of time

- Resilience related permitting should be fast tracked

- Design

$\circ$ Design cost, time and confidence in the developed resilience strategies would be enhanced by:

- Transition to performance based standards incorporating resilience

- Requires improved methodologies and tools for assessing performance based design adequacy

- Improved guidance and resilience standard on Threat Hazard Identification and Risk Assessment (THIRA)

- Recovery times would be strengthened by expanding the basis of design (PM World Journal, 2014) developed to meet owner's project requirements to explicitly include:

- An initial construction basis of design

- An O\&M basis of design that support sustainment of resilience and other performance features through the assets life cycle

- Features to facilitate normal and off-normal repair and replacement

- Procurement and construction

- Procurement time frames may be impacted by changed regulations with short transition periods or overly prescriptive codes and standards (versus performance based standards) 
- Sourcing, degree of standardization and logistical constraints associated with initial asset delivery (or rehabilitation and improvement) need to be considered from a post-event context

- Initial construction uncertainties are associated with:

- Poorly defined and agreed to objectives; weak owner readiness

- Lack of owner - contractor alignment

- Scale (introduces complexity)

- Lack measure of complexity

- Incomplete basis of design - lacks construction, O\&M and resilience considerations

- Overly optimistic estimates (optimism bias), often driven by the planning fallacy

- Absence of good estimating data bases

- Lack of reference class forecasting

- Unrealized productivity improvements

○ Industry lacks systemic innovation

- Poor scope and change control

- Unnecessary "white space" risks associated with contracting and execution strategy

- Inadequate standardization, fabrication - too much bespoke design

$\circ$ Recovery times would be strengthened if changes to project execution post-event were considered in the initial EPC process

- Operations \& maintenance

- Predictive, preventive and routine maintenance

- Uncertainties and inconsistencies in maintenance levels and expenditure

- Weak or non-existent industry data in usable form

- Maintenance backlogs of state of disrepair show we don't have the balance right

- Repair or replacement of worn or failed assets

- Function of maintenance program quality

- Sustaining capital/capital refurbishment of major systems or assets

- $\quad$ End of life

- Resilience not a consideration in removal at end of life

Assets encompass capabilities, services and facilities. Life cycle costs (CMMA, 2013) associated with investments to meet RTO objectives and reduce economic impacts and losses at a given RTO level consist of:

LCAProg, $\mathrm{NPV}($ Confidence $)=$ AII $\Sigma$ PROJ=1 LCA NPV(Confidence), PROJ (Configx, Globals,Systemic ) - Intra-program transfers

Where:

- Config : Defines a project, PROJ, as being included in a specific program or portfolio configuration, $\mathrm{x}$, together with a set of associated characteristics that may act upon project specific values, uncertainties, scenarios, drivers and constraints) 
- Globals: Defines a global scenario set, s, consisting of global drivers and constraints that in turn may act upon, or limit, project specific values, uncertainties, scenarios, drivers and constraints across all projects comprising the portfolio or program

- Systemicr: Defines a program wide systemic risk set, $r$, including both internal and external risks, considered in determining the LCA value for a specific project in the portfolio

\subsection{Indirect Asset Costs}

Indirect asset costs associated with the economics of community resilience fall into the following categories:

- Land use

- Tax regimes

- Financing structures

- Common financial factors

Land use represents a particularly thorny community resilience strategy. In many instances buffer zones and preserves may act to provide added resilience for communities by limiting development in high risk areas or providing relief zones to accommodate flooding or provide buffers against other threats, manmade or natural.

The cost of these land use decisions in support of community resilience are a function of the land use strategy adopted.

Land use uncertainties revolve around time and cost of repurposing existing lands to enhance community resilience. In many instances this will require the use of eminent domain.

Tax regimes represent an opportunity area for encouraging non-public sector resilience enhancements similar to what was seen with respect to energy conservation and renewable based tax programs. Uncertainty over liability risks assumed by non-public stakeholders who make good intentioned efforts to enhance resilience but which sustain a subsequent failure represents a potential overhang on community resilience efforts.

Financing structures are key to meeting the level of investments required to address a rapidly deteriorating infrastructure base (reducing resilience and increasing CRT) and improve community resilience. A range of financing tools and structures are available, ranging from pure public sector expenditure through public-private partnerships (PPP) to pure private investments in business continuity. Key uncertainties in financing structures for long-lived assets include:

- Tax policy or other community resilience incentives

○ Regulatory taxes on negative resilience

- Subsidies for positive resilience investments

- Available loan facilities and tenors

- Refinancing risks

- Liability limitations on resilience based risk assumption and mitigation

- Catastrophic insurance coverage and costs

Common financial factors whose uncertainties can significantly impact the economics of community resilience modeling and investment include: 
- Planning horizon

- Discount rate as a function of time

- Inflation/deflation

- Uninsured portion of events of scale

- Assumption migration associated with longer investment time frames

- Changed risk premiums over time

- Changed materialization of long term evolving risks (climate change)

- Changed assessment of probability and severity of severe impact threats (increased frequency of terrorist events; nonlinear growth of severity with coastal urbanization)

\subsection{Externalities}

The economics of resilience is susceptible to uncertainty created by a wide range of externalities. These include:

- Financial factors, beyond those typically considered such as hyperinflation and depression

- Environmental factors, especially those with significantly change global climate change trajectories

- Social factors, such as changed user behavior and changes in the subject community with respect to the community resilience features adopted

- Correlated risks, such as those associated with:

- Scale and complexity

○ Dynamic risk modeling

- Disruptive economic factors

- Political and social action

○ Litigation

\section{Modeling Risk, Uncertainty and Confidence Levels}

Comprehensive life cycle analysis of resilience investments must address both risk and uncertainty, particularly in the comparison of significantly different timing, phasing, operating periods and financing structures.

Risk is used to describe those factors where probabilities can be estimated. Uncertainty describes those factors where probabilities cannot be estimated.

Table 1 shows some of the risks and uncertainties that must be considered utilizing a statistical approach such as Monte Carlo analysis.

The selection of confidence levels for both input parameters into economic evaluations related to community resilience and the accompanying confidence level in the economic analysis performed to drive resilience related investments is important.

Each input parameters carries with it a different confidence level and distribution which is best highlighted by example:

- A particular asset investment has a CAPEX value of X based on a P50 confidence level associated with Monte Carlo simulations run in consideration of a range of normal 
estimation uncertainty and project execution event risks. This same asset has a CAPEX value of $1.3 \mathrm{X}$ at a P80 confidence level.

- Frequency of rainfalls exceeding $X$ inches in a given year is assumed to grow over time based on a long range climatic model considering global climate change. At a P20 confidence level, the frequency of such events is expected to hit a threshold level of $\mathrm{T}$ in 20 years. At a P80 confidence level the T threshold would not be reached until year 50 .

Similarly, in evaluating the economic return from a resilience investment, we need to understand the confidence level we require in order to undertake such an investment. This required confidence level may vary by stakeholder group. For example:

- Public sector investments in capital improvements typically use a P50 CAPEX value in their planning and budgeting (higher half the time, lower half the time);

- Private sector providers of those capital improvements require higher confidence in achieving their targeted returns and may utilize a P80 level (achieve their target profit $80 \%$ of the time).

The simple example of Figure 7 illustrates the importance of establishing and understanding the implications of chosen confidence levels. How do we view these two resilience investments?

- Investment \#1 - Recovery time of lifeline capabilities, services and facilities within 48 hours $50 \%$ of the time; Probable economic losses of $5 \mathrm{X}$

- Investment \#2 - Recovery time of lifeline capabilities, services and facilities within 48 hours $90 \%$ of the time; Probable economic losses of X

The choice of confidence levels on inputs and outcomes is non trivial and requires special attention.

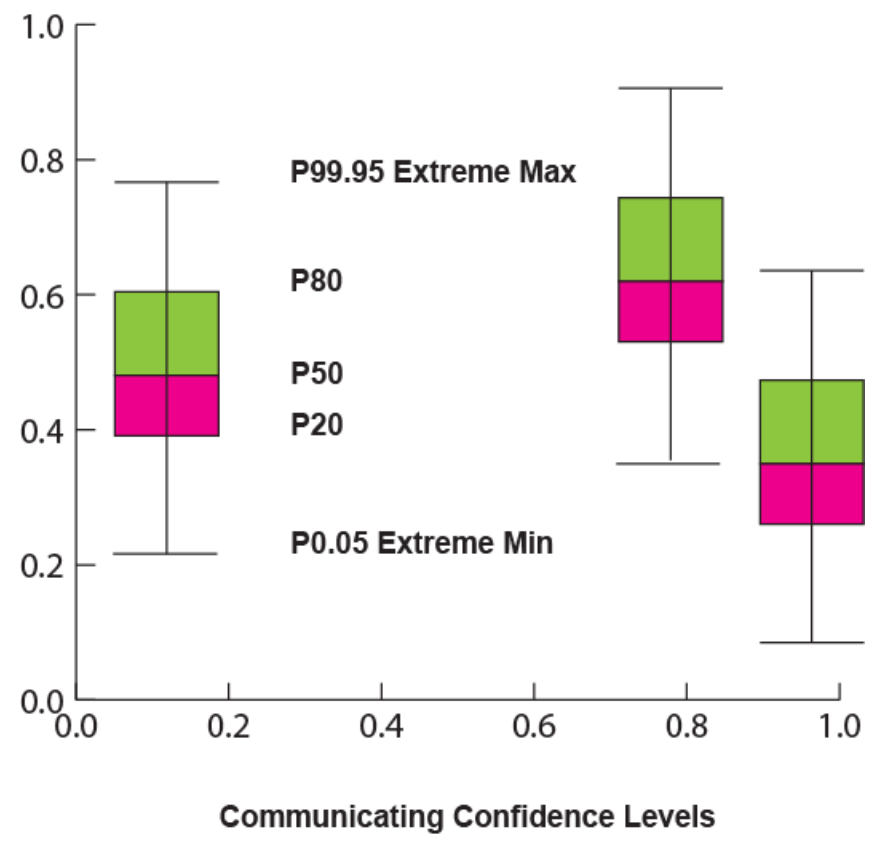

Figure 7. Example 
Table 1. Risks and Uncertainties to be Considered

\begin{tabular}{|l|l|}
\hline $\begin{array}{l}\text { Quantitative/estimate uncertainties (quantity, } \\
\text { unit price, and productivity) }\end{array}$ & Tax regime \\
\hline Duration uncertainties & Tax rates (over time) \\
\hline Sequencing or timing uncertainties & Planning horizons \\
\hline Resilience (RTO) factor & Assumption migration over extended timeframes \\
\hline Current Recovery Time (CRT) & Changed risk premium over time \\
\hline $\begin{array}{l}\text { Changing scenario probabilities and } \\
\text { severities }\end{array}$ & $\begin{array}{l}\text { Resilience coverage rate (associated with } \\
\text { resilience ramp up rate) }\end{array}$ \\
\hline $\begin{array}{l}\text { Discount rate considering uncertainty of } \\
\text { timing }\end{array}$ & Economic benefit levels over time \\
\hline Complexity & Maintenance level \\
\hline Land use & Asset availability and lifetime \\
\hline $\begin{array}{l}\text { Inflation/deflation rate (over time; by cost } \\
\text { category - general, labor, labor social and } \\
\text { benefit costs, energy, water, and feedstock) }\end{array}$ & Terminal value (if any) \\
\hline Refinancing timing & Confidence level selection and calculation \\
\hline Refinancing cost of capital & \\
\hline
\end{tabular}

\section{Stress Testing}

In community resilience investment optimization, we conduct an LCA undertaken initially for a base scenario and set of assumptions (CAPEX, discount rate, threat development rate). As we reach the final stages of optimization, the preferred alternative is stress tested by considering alternative assumptions and scenarios.

These can consist of improved as well as degraded alternatives including extreme failure. Consideration of these alternative scenarios can be seen in the following figures showing the probable distribution of economic return on planned resilience investments.

In the Figure 8, the behavior of economic returns for the planned investment with changed assumptions (green) shows little overlap with the economic distribution for the base case (blue) performance model.

In the second figure, the base case and stress case show a meaningful overlap in anticipated performance, demonstrating the degree of resiliency in the community resilience strategy we are contemplating. 


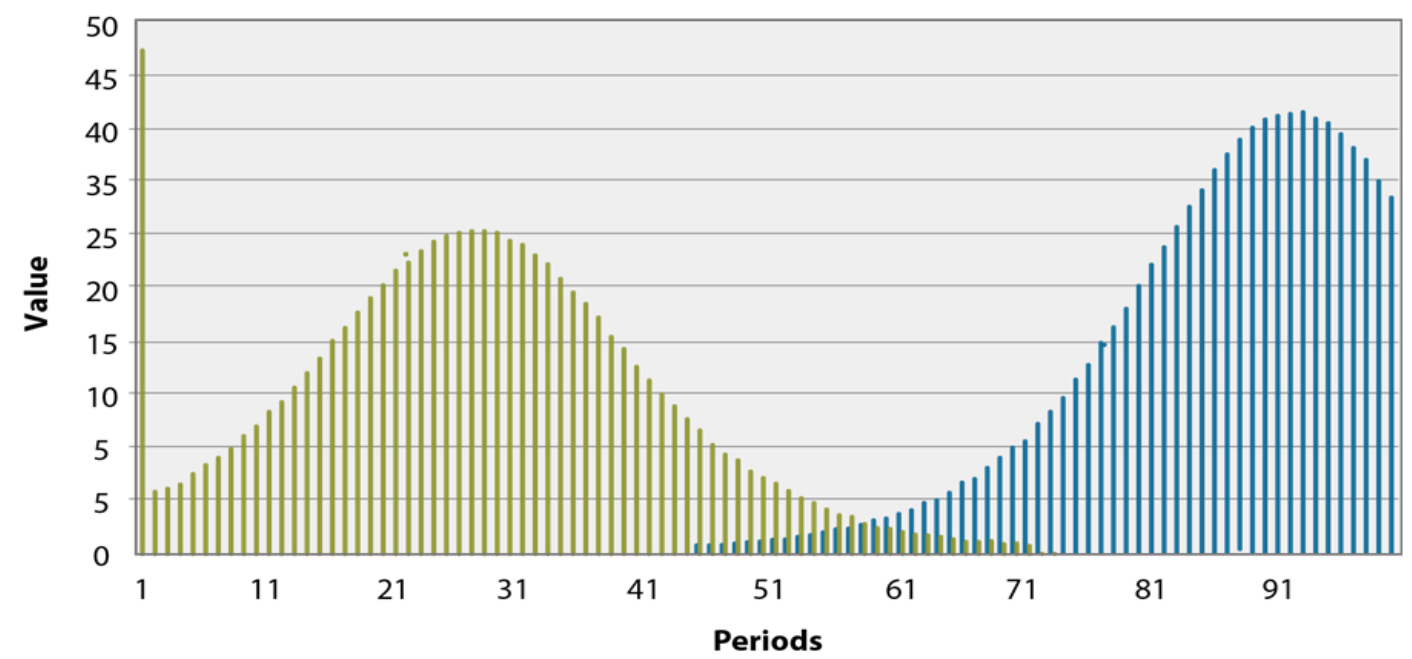

Figure 8. Behavior of Economic Returns for the Planned Investment with Changed Assumptions

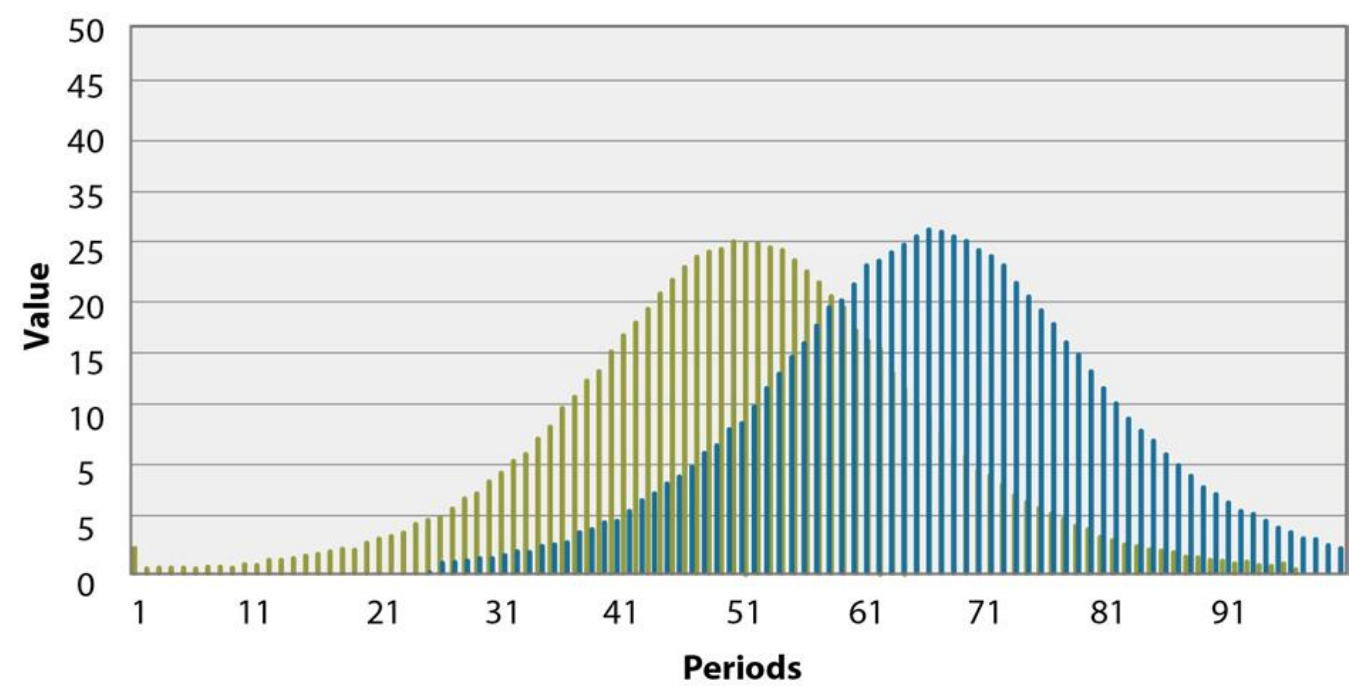

Figure 9. Comparing the Base Case with a Stressed case

\section{Conclusions}

This paper provides a framework for the economics of community resilience and touches upon some of the uncertainty factors. The following table captures some of the recommendations made throughout this paper with respect to managing these uncertainties. Other recommendations of merit are contained throughout the paper.

Key points worth reiteration include:

- Perceptions of risks and uncertainties will vary for each of the four stakeholder groups comprising the "economic community" affected by community resilience action and inaction

- Resilience outcomes require consistency and clarity of definition in order to support high confidence economic evaluations. Three such outcome measures have been touched upon in this paper and a fourth derivative value suggested:

- RTO - Recovery Time Objective

- CRT - Current Recovery Time

- RVR - Resilience Value at Risk 
- RTO/CRT - Relative resilience level

- $\quad$ RTO rationalization and selection requires a multi-stakeholder effort considering different economic framework elements:

- Lifeline capabilities, services and facilities (response, sustaining and protecting)

- Critical enabling capabilities, services and infrastructure (recovery and sustaining lifelines)

- Restoration capabilities and services (long term recovery; economic recovery)

- Multiple futures exist and each may evolve at differing rates. Simplified modeling of temporal variance in longer time frames is required. The concept of Resilience Value at Risk is introduced for these longer time frames.

- Life cycle modeling of community resilience is essential and must include indirect costs and externalities in addition to economic benefits and costs

- Economic benefits can be thought of in terms of avoided costs related to direct damages and economic losses from business interruption

- Life cycle costs associated with economic modeling of community resilience investments include a wide range of risks and uncertainties

- Indirect costs include those inherent in land use decisions; tax policy or other community resilience incentives; and a range of financial considerations

- Correlation of risks including coupling through constraints are important considerations

- Modeling must consider a range of scenarios and configurations

- Selection and understanding of confidence levels related to assumptions, inputs and outcomes is non-trivial and requires special attention.

- Stress testing of preferred scenarios for changes (better/worse) in key parameters is essential when dealing with an uncertain future

Table 2 shows recommendations for managing uncertainty in economic evaluations related to community resilience

Table 2. Recommendations for Managing Uncertainty in Economic Evaluations Related to Community Resilience

\begin{tabular}{|l|l|}
\hline $\begin{array}{l}\text { Develop simplified model for temporal } \\
\text { variance of longer timeframe events }\end{array}$ & $\begin{array}{l}\text { Improve guidance and resilience standard on } \\
\text { Threat Hazard Identification and Risk } \\
\text { Assessment }\end{array}$ \\
\hline Fast track resilience related permitting & $\begin{array}{l}\text { Improve quality of resilience related estimating } \\
\text { design bases (reference class forecasts) }\end{array}$ \\
\hline $\begin{array}{l}\text { Expand basis of design to include construction, } \\
\text { O\&M and resilience considerations }\end{array}$ & $\begin{array}{l}\text { Establish national policy on regulatory taxes } \\
\text { and subsidies related to resilience }\end{array}$ \\
\hline $\begin{array}{l}\text { Transition to performance based standards } \\
\text { incorporating resilience }\end{array}$ & $\begin{array}{l}\text { Establish national liability protections } \\
\text { associated with resilience mitigation }\end{array}$ \\
\hline $\begin{array}{l}\text { Improve methodologies and tools for assessing } \\
\text { performance based design adequacy }\end{array}$ & \\
\hline
\end{tabular}

\section{References}

Application of Life Cycle Analysis in the Capital Assets Industry; Construction Management Association of America (CMAA); June 2013; ISBN 978-1-938014-06-2 (eBook); ISBN 9781-938014-07-9 (Print). 
Understanding Interdependence as a First Step to Community Resilience; 2014 Critical Infrastructure Symposium; David Vaughn; Jeff Plumblee; Robert Prieto.

Intersection of Engineering, Construction and Logistics Post-Disaster; PM World Journal, July 2013.

"The 3 Rs: Lessons Learned from September 11th," presented at The Royal Academy of Engineering, London, UK, October 28, 2002.

Addressing Project Capital Efficiency through a Business Basis of Design; PM World Journal; April 2014.

Uncertainty and Economic Analysis; The Economic Journal, 95; December 1985. 
Feigel, Richard E. (Gene)

\title{
Economics of Community Disaster Resilience: Impact of Variability and Uncertainty
}

\begin{abstract}
Crafting rational resiliency strategies underpinned by defensible technical and economic models is a daunting endeavor. Both ex ante and ex post facto uncertainty exacerbate the problem of developing models and communicating them to a wide variety of stakeholders. While there is no perfect bright line, distinguishing between variability and uncertainty is important, both for developing models which differentiate between data and parameter uncertainty and probably more importantly, to fashion credible risk communication. Developing resiliency protocols is clearly a public policy issue.
\end{abstract}

\section{Keywords}

Variability, primary uncertainty, secondary uncertainty, stakeholders, cost/benefit, public policy

\section{Introduction}

The Halloween snowstorm of 2011 devastated much of New England. While the resultant property damage did not reach the level caused by major hurricanes, the economic impact was significant. New England is one of the most heavily wooded regions of the US. The early snowstorm occurred before trees (especially in southern New England) had shed their leaves. The combination of heavy, wet snowfall and fully leaved trees produced large numbers of broken limbs and fallen trees which caused downed power lines resulting in massive and widespread power outages. Large numbers of homes and businesses were without power for a week or more.

Both during the event and the lengthy post mortem, the performance of the electric utilities was roundly criticized in the press, by politicians, the public and the inevitable commissions established to study their response. Albeit this storm was the 'storm of the century', there was much to criticize and analyze - inadequate preparedness, deficient coordination with local authorities and poor communication with the public.

\section{Public and Private Goods}

The Halloween snowstorm event is a microcosm of the issues attendant to developing local resiliency strategies. One seemingly minor aspect of the massive public/private response bears scrutiny. In New England, a standard utility strategy to reduce electricity distribution line damage is limb trimming and tree removal. The obvious objective is to remove limbs and trees which may fall and damage distribution lines. In the aftermath of the Halloween snowstorm, utilities, especially in Connecticut, began more aggressive tree trimming programs. However, after substantial public opposition (citizens attended meetings brandishing signs emblazoned with "Save Our Trees Now"), the final tree trimming rules include a variety of requirements for notification and permission of local officials and citizens whose property abuts the intended tree trimming. The policy issue is not whether the utilities should have unrestrained rights to trim as they see fit or individual homeowners should be able to block tree trimming. The overarching 
issue is that the current political process employed to make many of these decisions is so ingrained in local cultures that replacing it with a more rational, yet participatory course of action will be exceedingly difficult.

These problems involve many of the standard decision analytics biases. A homeowner enjoys a tree every day. Removal of the tree may improve the robustness of the local electricity distribution system exposed to very infrequent events. Weighing the relative public/private benefits and costs in this sort of situation is problematic. The roles of well-organized interest groups and social media cannot be ignored.

\section{Variability and Uncertainty}

\subsection{Introduction}

Somewhat anecdotally, the tree trimming problem introduces the role of variability and uncertainty. Variability (aleatory uncertainty/stochastic variability) is a fundamental characteristic of the phenomenon or system of interest. Historical natural event data is used to model probabilities of future events. Obviously, this is problematic, since data for rare events such as earthquakes is scarce. Earthquakes happen in geological time, not human time. This is true for most extreme natural events such as the Halloween snowstorm described above. Fitting distributions to sparse data sets risks either under or overestimating short to mid-term outcomes. This applies to modeling both frequency and severity. Explicitly recognizing uncertainty (epistemic uncertainty), i.e. our level of ignorance concerning the underlying phenomena, is important both for technical reasons and to strengthen transparent risk communication. Figure 1 shows a simple example of modeling data variability only (thick blue line) and considering uncertainty. Explicitly incorporating uncertainty as well as the underlying event variability facilitates understanding their relative contribution to 'overall uncertainty' which is important for elucidating parameter uncertainty, risk communication and cost of information considerations.

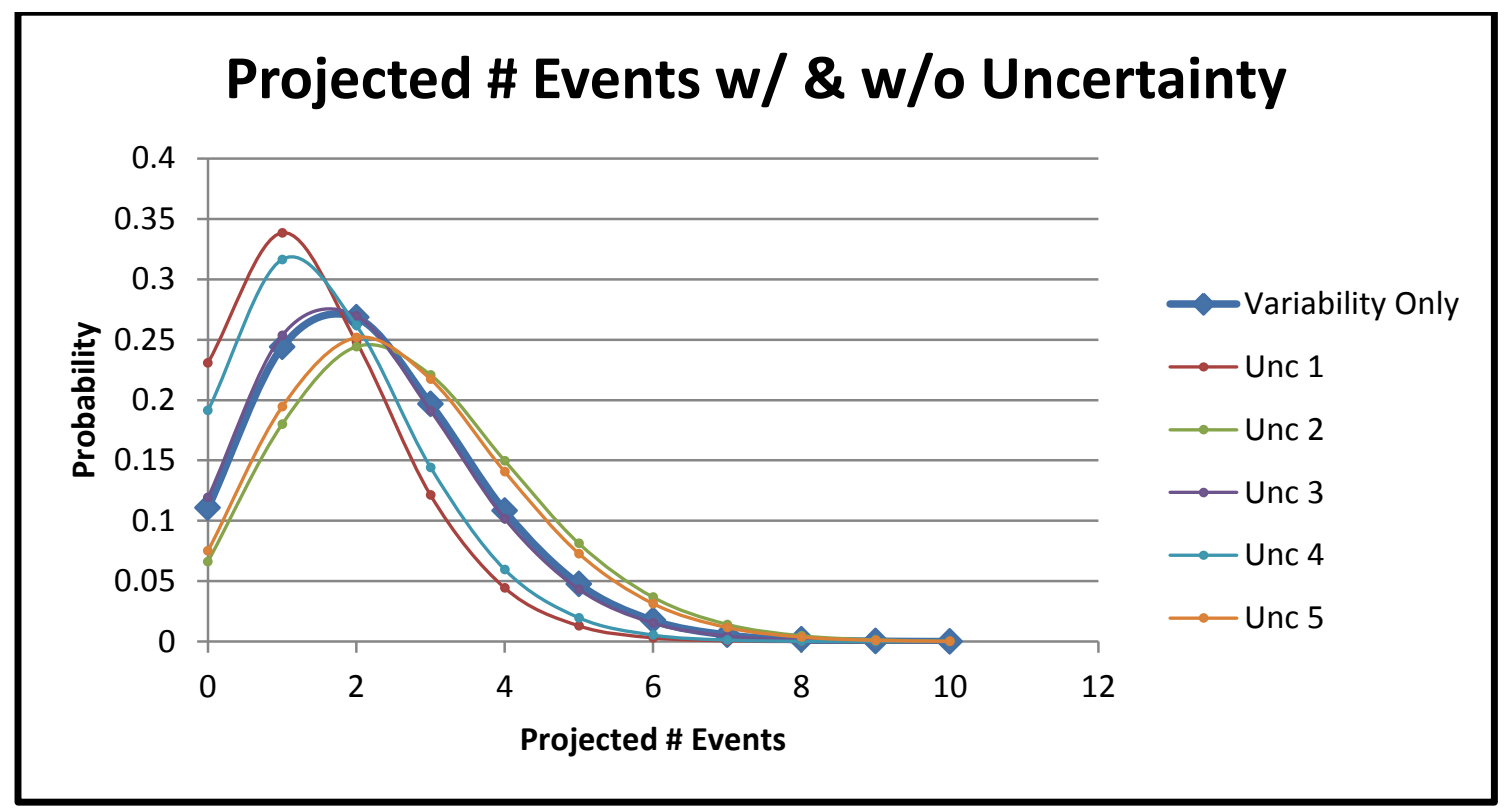

Figure 1. Modeled Uncertainty 


\subsection{Variations of Variability}

Focusing on event severity requires parsing the event severity itself from the exposure base. This distinction is well understood in natural catastrophe (CAT) modeling. Unfortunately, the industry standard terminology to some extent confuses the variability/uncertainty distinction. Primary uncertainty is the term used to denote information about actual events, e.g. location and intensity. Secondary uncertainty describes features of the event targets, e.g. exact location, surrounding terrain configuration and construction characteristics.

There is little control over the data for primary uncertainty. The quality of the data must be considered, but generally is fixed at a given time, although research and additional empirical data continually improve the available information. This limitation is at least partially addressed by various modeling approaches, usually employing sets of historical and stochastic events. On the other hand, secondary uncertainty can to great extent be reduced by rigorous data accumulation. Exact locations, construction characteristics and underlying soil types are all knowable. Any resiliency protocol should include acquiring detailed data to mitigate the impact of secondary uncertainty on risk decisions. Market forces aside, in the insurance industry, reinsurers charge primary property carriers more if their data submittals are less granular. For example, ZIP Code level location data is nearly useless for assessing storm surge vulnerability. Obviously, there is a cost to collecting and managing detailed data.

\subsection{Secondary Uncertainty Correlation}

Since the aggregate damage risk for a portfolio (in this context, a city, county, etc.) is built up from the damages of the individual exposures (homes, commercial buildings), the degree of correlation of damage of the individual locations is important. The bounds are:

- Perfect correlation, i.e. if location damage is perfectly correlated, the portfolio standard deviation is the sum of the location standard deviations:

$$
\sigma_{p}=\sum_{l} \sigma_{l}
$$

- Complete independence, i.e., if location damage if independent, the portfolio standard deviation is the square root of the sum of the location variances:

$$
\sigma_{p}=\sqrt{\sum_{l} \sigma_{l}^{2}}
$$

Obviously, there is some degree of partial correlation between the bounds. Commercial CAT models deal with this with a variety of combinatorial methods. If these models are not used, or analysts are addressing other events, consideration should be given to this matter; otherwise substantial over/under estimation of portfolio damage is likely. If more sophisticated weighting cannot be credibly developed, a simple averaging of the correlated and uncorrelated standard deviations is probably better than ignoring the issue. 


\section{Cost/Benefit Analysis}

\subsection{Overview}

Inevitably, some structured cost/benefit analysis (CBA) will be required as an important aspect of successful resiliency planning. Careful thought about the structure is needed for a variety of reasons:

- Funding for major projects whether preventative or for post event mitigation will compete for scarce resources.

- The process will inevitably be politicized (see discussion above.)

- There is considerable opposition to traditional CBAs, especially those involving some cost of life (or surrogate) component.

- Involving stakeholders is critical. Defining 'stakeholders' is not easy.

- Realistic impact on human resources must be considered. For example, today volunteer fire departments are already burdened with training time and responsibilities for a variety of risks unaddressed less than a generation ago.

\subsection{Structuring a Cost/Benefit Analysis}

There is a substantial body of literature discussing the structure, merits and flaws of CBAs. One of the principal public policy guidelines is the Office of Management and Budget Circular OMB4, which provides guidance for federal regulatory agencies' implementation of Executive Order 12866, Regulatory Planning and Review. Unsurprisingly, particular uses of OMB-4 and related regulatory decision methods have been contentious ${ }^{11}$. In the author's experience as member of an industry advisory group to a major regulatory agency, the CBAs performed to support proposed regulatory actions nearly universally violated two critical principles discussed above, i.e. they were deterministic with no serious attempt to quantify variability or uncertainty; and they were presented to stakeholders as fait accompli 'for comment.' Generally a significant availability bias is at play, e.g. a recent significant accident.

While the parallel between federal rulemaking and community resiliency planning is imperfect, some lessons learned are transferable:

- There is a general belief that costs are easier to establish than benefits. From a deterministic perspective, this seems straightforward since the costs of a project can presumably be estimated with reasonable accuracy even including variable financing costs and inflation. On the other hand, benefits are subject to future states with some uncertainty. Unfortunately, the average project, particularly infrastructure projects with long lead times, is over budget. At the least, a credible budget variation distribution should be incorporated in a CBA.

- Stakeholders should be involved from the outset. Identifying public stakeholders with legitimate standing can be difficult. Generally, public stakeholders will self-identify. The use of social media by all parties can have a significant impact on framing the problem. Correlatively, while rigorous analysis should be promoted, human factors are ignored at experts' peril.

- The uncertainties of ex ante quantification of indirect damage and business interruption costs are problematic and must be considered carefully.

${ }^{11} \mathrm{http}: / /$ science.house.gov/sites/republicans.science.house.gov/files/documents/20111222.pdf 
- As noted above (remember the 'save our trees' response to tree trimming), cost/benefit analyses cannot ignore difficult to quantify issues. These principally take two forms: quality of life and ethically sensitive subjects such as value of life calculations. This is not only socially contentious, but involves technical issues around normalizing qualitative and quantitative input as well as characterizing uncertainties.

- Technically, CBAs should be simulations. This is the only credible way to incorporate requisite variability and uncertainty. The propensity to perform scenario analyses is both technically inferior and actually makes risk communication more difficult. However, since simulations are unfamiliar to most public officials and the general public, effort will be necessary to configure comprehensible model results. Exceedance probability does not easily roll off the average citizen's tongue.

- Commonly, public benefits will entail private costs. This is especially true for lifeline services such as electricity. Whether and how to incorporate these costs must be addressed. Different approaches for private utilities, in most cases already subject to a well-defined regulatory regime, and unregulated businesses may be required.

- In many cases, data will be sparse or non-existent. In these instances, well-structured expert elicitation will be an important tool. Formal elicitation of experts is increasingly common. Done correctly, expert elicitation will capture the experts' uncertainty rather simple point estimates. Extending formal elicitation to public stakeholders may be problematic, given the long history of 'public hearings', but nevertheless should be carefully considered. Technical issues of combining experts' opinion, including decisions about weighting, are difficult but not insurmountable (see Figure 2 below.)

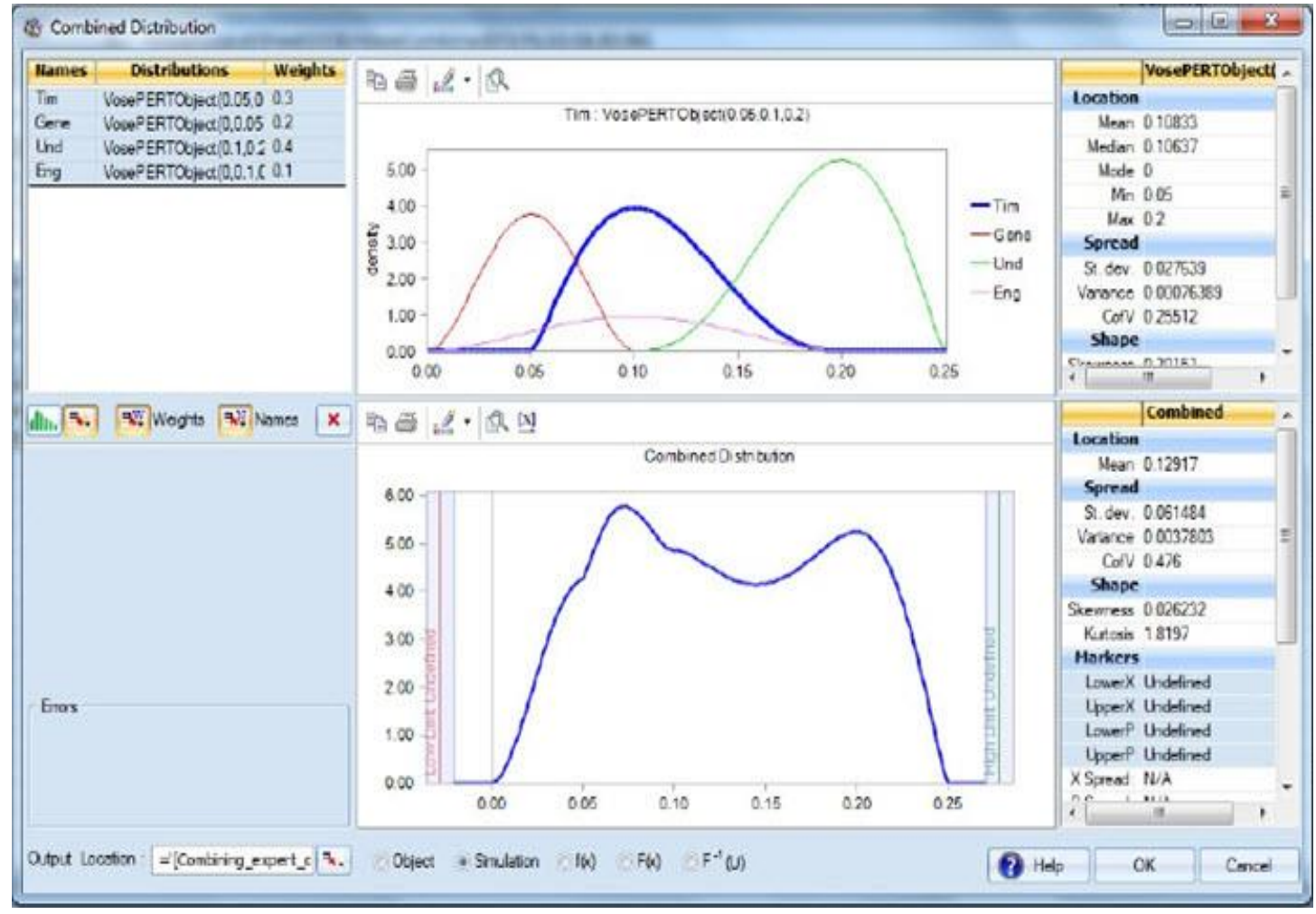

Figure 2 Combined Expert Opinion 


\subsection{Cost/ Benefit and Return on Investment (ROI)}

While CBA and ROI analyses are not interchangeable, they are closely related. ROI is commonly used in the private sector to evaluate whether to make an investment. In its simplest form, ROI can be expressed as:

\section{Return on Investment $(\%)=($ Net Profit $/$ Investment $) \times 100$}

Metrics for evaluating ROI can be competing projects, internal hurdle rates and risk free or market rate investments. While the profit motive is largely absent in the public sector (with the exception of some user fee based infrastructure projects), the concept of ROI is translatable for studying the impact of investments on a variety of public services. In the case of resiliency investments, net profit is in effect costs avoided. The quantified results of CBAs become the numerators for ROI assessment.

The situation is more complicated for the public sector than for most private sector ROI decisions. As discussed above, resiliency investment decisions must incorporate various qualitative issues, which are usually at best tangential for private sector ROI analyses. Risk appetite in the private sector, for example decisions to purchase CAT reinsurance, are driven primarily by fairly objective criteria, e.g. capital preservation and ruin avoidance. More subjective utility functions are usually involved, but not dominant.

Accounting for the exposure time frame is a critical issue for resiliency investment. How do we compare relatively high frequency, low severity events to rare, but catastrophic events? In simplistic objective terms, ten mean $\$ 1 \mathrm{M}$ loss events are equivalent to a single $\$ 10 \mathrm{M}$ event. The discounted investment time span for resiliency investments may alter ROI decisions substantially.

As noted elsewhere, two aspects of uncertainty which are unfortunately often neglected must be seriously considered in resiliency protocols - exposure data and indirect risks such as business interruption costs. In other words, the total range of vulnerability data is as important as understanding the initiating hazard(s).

Finally, developers of resiliency protocols should consider whether and how to address ROI of portfolios of risks. The simplest question is whether to develop technical/economic models at a local/regional level only, or to also consider how to tackle a large portfolio of risks faced with inevitably limited financial resources. Many local resiliency analyses will produce a positive ROI, but cannot be entirely funded locally. Inevitably, this necessitates a broader context for ranking discrete ROIs. Possibly, existing state departments of emergency preparedness could be engaged in consolidating local CBAs/ROIs. Normalizing multiple ROIs will be difficult. Whether to rank ROIs absolutely or based on some per capita formula needs further investigation. Considering the global issues will obviously complicate the effort, but deserves study.

\section{Integrating Existing Risk Tools}

A survey of relevant risk analysis tools (see references for a partial list of sources) should be undertaken. Most, if not all, of the events requiring a resiliency response have been studied at 
length and methods and tools for assessing their physical and financial effects have been developed. There is considerable, and healthy, debate over the accuracy of most of these tools, whether proprietary or public. Some of the criticism is technically well founded, but much is based on misplaced self-interest. Homeowners in Florida want lower premiums and deductibles for hurricane insurance than can be supported from the application of commercial CAT models. This has resulted in politically motivated market distortions embodied in the creation of the Citizens Property Insurance Corporation. My point is not to defend private insurers or the accuracy of commercial CAT models, but rather to raise the generic issue of the conflict between political pressure and best available (albeit imperfect) science. Any realistic resiliency protocol must not be naïve about the former, while promoting the latter. All of the available modeling tools can potentially be used to provide inputs to a robust resiliency protocol. None have all of the capability required to analyze event response requirements.

If any of the existing tool(s) is used, it is critical to understand its structure, strengths and limitations ${ }^{12}$. These complex models cannot be used as black boxes. This raises questions about trade-offs between employing sophisticated models and the price of the learning curve or employing experienced consultants.

"Those who are performing the study must, at minimum, have a basic understanding of hurricanes and their consequences. In many cases, the results will be presented to audiences (i.e., city councils and other governing bodies) that have little technical knowledge of the hurricane loss problem." (FEMA Hazus Manual)

Most of the more advanced models provide both probabilistic and deterministic modeling capabilities. Probabilistic models are preferable for helping to configure a resiliency framework. For natural events which typically have some lead time, e.g. hurricanes and floods, consideration should be given to performing pre-event deterministic analyses to focus resources with the latest information. Pre-event analysis, although often imperfect, helps avoid costly under (over) deployment of resources. This is standard practice in the insurance industry for allocating and deploying claims resources before and immediately after an event.

\section{Recommendations}

Following is a summary of recommendations on resiliency uncertainties and potential areas of additional research:

- Secondary uncertainty must be taken seriously. Much of the data needed to reduce it is available. The effort to acquire and use it will pay dividends in improved risk characterization.

- Indirect costs such business interruption should be quantified as best as possible.

- The role of published information, e.g. census data should be investigated to reduce potentially redundant local efforts to develop data. Databases tailored to resiliency efforts can be developed to facilitate use of this data.

- Use of existing catastrophe models should be investigated in detail. Gap analysis for hazards of concern not currently covered will lead to detailed research in these areas.

\footnotetext{
${ }^{12}$ Unfortunately, commercial CAT model background papers describing data used and parameterization methods are considered proprietary under user license agreements.
} 
- Final risk models should be integrated, i.e. incorporate hazard, vulnerability and finance (both costs and benefits.)

- Mitigation cost uncertainty as well as hazard/vulnerability uncertainty must be included. Further research is required. There is a fairly large body of literature on construction project cost variation which provides a credible starting point.

- Risk models must be probabilistic. This will necessitate appropriate training of all stakeholders and policy makers in these techniques.

- The technical form of ROIs, especially if portfolios are considered, needs further study. Rather than defaulting to simple rank ordering, the adaptation of efficient frontier analysis should be investigated.

\section{Conclusions}

Community resiliency planning requires both understanding the underlying risk and crafting mitigating responses, human actions as well as potential infrastructure hardening. This paper has primarily focused on several issues related to understanding and quantifying the risks and offered some thoughts on crafting cost/benefit analysis. Decisions about tradeoffs between model robustness, with increased complexity, and human resource constrained models, with less accuracy, are inevitable. For example, Hazus offers a default inventory of data for most characteristics which can be used in lieu of detailed user supplied data. Regardless of the approach employed, the decision must be transparent for the outcomes to be credible. Other input, addressing issues such as quantifying stakeholder utility, will be critical. Today, corporate cost/benefit decisions explicitly address factors largely ignored a generation ago, e.g. reputational risk and life cycle costs. In the public sector, the complexity is exacerbated by qualitative factors which are real, but difficult to quantify. In short, the difficult challenges are human rather than technical.

\section{References}

Citations

FEMA. FEMA Hazus Manual https://www.fema.gov/media-library/assets/documents/20469

\section{CAT Modeling Resources}

AIR Worldwide http://www.air-worldwide.com/Models/About-Catastrophe-Modeling/ CoreLogic EQECAT http://www.eqecat.com/catastrophe-models/

Federal Emergency Management Agency (FEMA); Hazus https://www.fema.gov/hazus

Federal Emergency Management Agency (FEMA); Flood Insurance Rate Map (FIRM) http://www.fema.gov/floodplain-management/flood-insurance-rate-map-firm

Karen Clark \& Co. http://www.karenclarkandco.com/

National Weather Service (National Hurricane Center); Sea, Lake, and Overland Surges from Hurricanes (SLOSH) http://www.nhc.noaa.gov/surge/slosh.php

Risk Management Solutions http://www.rms.com/products/models-cat

US Army Corp of Engineers; Flood Damage Reduction Analysis (HEC-FDA)

http://www.hec.usace.army.mil/software/hec-fda/ 
Ehlen, Mark A., Prabuddha Sanyal, and Mark A. Pepple

\title{
A Framework for Guiding Homeland Security Programs from Risk to Resilience
}

\begin{abstract}
Many government agencies are currently moving from risk-based to resilience-based policies; a good example is the current transition from community risk-based mitigation planning to resilience planning embodied in the draft NIST Community Resilience Planning Guide. What is not obvious to this transition is whether the new resilience plans will adequately address the existing risk needs, and whether the new resilience-based plans will be truly based on resilience and not just "resilience equals low risk." To help understand and reconcile these two concepts, we present a basic mathematical framework that can be simultaneously achieve three important policy goals - minimized risks, ensured mission, and maximized resilience - by achieving any one of the three. Risk and resilience policies can be developed and promulgated in an internally consistent, effective, and efficient manner. Examples include the pharmaceuticals and community resilience arenas.
\end{abstract}

\section{Keywords}

Risk; resilience; homeland security policy; chemical sector, community resilience.

\section{Introduction}

\subsection{The Need to Move from Risk to Resilience}

In the early days of U.S. homeland security, federal policies took a "guns, gates, and guards" risk-based approach, identifying threats, vulnerabilities, and potential consequences, first from terrorist attack and then after Hurricane Katrina, to natural disasters. Through DHS-sponsored RAMCAP risk methodologies and other methods, the U.S. Department of Homeland Security (DHS) developed a consistent risk-based approach based on threats, vulnerabilities, and consequences. In the late 2000s, however, it became clear that there were too many threats and assets to protect, and the Department shifted focus away from pure risk management of individual assets to resilience planning of systems of assets. But while acknowledging the systematic interdependence of many of these assets was easy, developing whole-system resilience metrics and management processes has been more difficult. An overview of DHS chemical sector policy helps illustrate some of these difficulties.

The U.S. chemical sector provides significant value to the nation's way of life, purifying the water we drink, creating lifesaving medicines, protecting armed forces, and contributing \$760 billion in annual economic activity (ACC, 2013). But chemicals present their own risks, to essential military, healthcare, and economic functions: in 2003 an acute shortage of para-aramid fibers, a chemical product commercially marketed as Kevlar and used in body armor, "reduced [military] operational capability and increased risk to troops in Iraq" (GAO 2005). In 2008, an acute disruption of acetonitrile supply, 70 percent of which is used as a key ingredient in pharmaceutical production, risked the effectiveness and safety of life-sustaining medicines. U.S. 
chemical facilities are at risk to attack and theft, ${ }^{13}$ and the impacts of such attack could be significant to the chemical facilities themselves, to the products that use their chemicals, and to the broader nation and its government.

To mitigate these chemical-facility risks, the U.S. government enacted legislation that focuses on asset-based risks; the policies essentially reduce national risks one asset at a time. DHS has broader policies for reducing sector-level risks and increasing sector-level resilience, but that are potentially at odds with the chemical-sector asset-level regulations. The National Infrastructure Protection Plan (NIPP) (DHS, 2009) uses a risk approach that includes "resilience and response measures." The DHS Chemical Sector-Specific Plan (CSSP; DHS 2010b) states that the role of the NIPP "is to identify and take action to protect or improve the resilience of [critical infrastructure]" and "that resilient operations and effective loss prevention are a part of managing risk." The CSSP helps achieve "risk-based, cost-effective sector-wide protective programs that increase asset-specific resilience" and the broader goal of "a safe, secure, and resilient America through enhanced protection of [critical infrastructure]," all through a process that "ensures that resources are applied where they contribute the most to resilience and risk mitigation." Finally, the DHS National Critical Infrastructure Prioritization Program (NCIPP) helps "identify the Nation's lost critical, highly consequential domestic assets and systems ... to support the growing DHS role in incident response and recovery" (DHS, 2010b).

When combined, however, these risk and resilience policies create practical problems for risk analysis, management, and planning (it's fair to say that resilience analysis, management, and planning are in their infancy). DHS has provided guidance for measuring and reducing risk (threat, vulnerability, and consequence) - RAMCAP (ASME, 2009) is a good example - but uses disparate approaches across programs (GAO, 2014) and gives little guidance for measuring and increasing resilience. And there is little guidance for conducting combined risk and resilience analysis that ensures resources are applied where they contribute the most to both objectives. Chemical facilities-level risk models exist - for example, DOD (2000), NIJ (1997), Moran et al (2004), and FBI (2003) - but there are few facilities-level resilience-assessment models. A notable exception is the J100/RAMCAP model (AWWA, 2010) for water purification facilities; J100/RAMCAP does prescribe the measurement of both risk and resilience for individual assets, but does not provide clear guidance on how risk and resilience are related and can be simultaneously achieved.

Another problem is in using asset- and sector-based policies to increase resilience: reducing risks from acts of terrorism by regulating particular chemical facilities may actually reduce the resilience of the overall chemical sector. For example, one outcome of DHS chemical sector regulations is that chemical companies are reducing the production and stored amounts of hazardous chemicals, a reduction which does reduce risks to public health and safety, but also removes potentially important redundancies in chemical production capacity and where so, potentially lowers the resilience of the overall sector.

\footnotetext{
${ }^{13}$ DOJ (2000): "[I]ndividuals have indeed attempted to use chemical releases from individual facilities as makeshift WMD both domestically and abroad. Some of these events have involved countries or factions hostile to the United Sates."
} 


\subsection{Community Disaster Risk and Resilience Management}

As described in NIST (2015), an estimated 24000 communities representing 80 percent of the U.S. population have conducted disaster mitigation plans in accordance with FEMA guidance. These mitigation plans are fundamentally risk based and while the NIST Community Resilience Planning Guide notes that "expanding the scope to resilience is the next logical step" and "community resilience plans can be built around existing mitigation plans using the framework techniques related to the built environment," there is as of yet no clear distinction between risk management and resilience management, how to reconcile the two, and how to ensure that a resilience management strategy correctly manages priority risks (and vice versa). For example, our review of J100/RAMCAP water risk analyses has found that when given the opportunity to define the J100-required inclusion of a resilience measure, utilities define it as the economic consequence itself, the intuition being that high economic consequence suggests low resilience.

\subsection{The Need for a Common Framework}

Identifying risks and resilience are potentially highly conflicted policy requirements. What is needed is a basic framework that ensures that risk and resilience policies are first understood and then implemented in a consistent, effective, and efficient manner. This article suggests a preliminary framework for understanding these two concepts, side by side, in policy development that integrates risk, mission-assurance (shown herein to be closely related to risk), and resilience policy objectives. The framework, while initial in its constructs, is designed to inform government agencies as they move from risk-centric to resilience-centric policies. In support of the NIST Disaster Resilience Guide and the FEMA's Local Mitigation Planning Handbook, the framework provides constructs in which risk and resilience can be compared, and ultimately used together to ensure that a community plan both reduces community risks and increases community resilience. Section 2 describes the framework and a formulation that directly relates risk with resilience and highlights how the solutions for reducing asset-based risks to mission are sometimes sector-based. Section 3 summarizes and concludes.

\section{Risk-Assurance-Resilience Framework}

To develop effective risk-and-resilience policy, policymakers need a strong foundation of how their policies do three things: (i) reduce risks, (ii) ensure mission, and (iii) increase resilience. The following model articulates the fundamental relationships of the three in ways that can lead to internally consistent DHS policy. For clarity of exposition, it uses policy language and examples from U.S. chemical sector policy, but is generalizable to any set of homeland security policies that have risk, assurance, and resilience objectives.

Current chemical-sector terrorism-risk public law, carried out by DHS, seeks to (i) reduce risks to the U.S. economy (a private sector mission, supported through homeland security policy) and human life by identifying facilities that have "potential severe economic consequences and the potential loss of human life in the event of the facility being subject to attack, compromise, infiltration, or exploitation by terrorists" (6 USC $\S \S 621-628$ ). Mission is (ii) assured, through the minimization or transfer of these risks (continuity of economic activity and preservation of life). Next, DHS defines resilience as "the ability of systems, infrastructures, government, business, communities, and individuals to resist, tolerate, absorb, recover from, prepare for, or 
adapt to an adverse occurrence that causes harm, destruction, or loss" (DHS 2010a). ${ }^{14}$ DHS promotes a number of policies designed to (iii) increase chemical-sector resilience. DHS then has all three objectives for the chemical sector.

The above risk-related "potential severe consequences" and resilience-related "ability to adapt" statements are intuitively but not explicitly related; the former sets requirements on how to minimize disruptions to a given (terrorism-risk) mission through identification of (chemical facility) risks; the latter sets requirements on how to maximize the ability of systems to meet mission, through prevention or adaptation to disruptions (resilience). The solution to the first is apparently to identify and then remove the risks, while the second is to potentially recast the entire risk management. The first is at best a local optimum for the risk objective, while the second suggests but does not reveal a process for global optimum for risk management.

While the strategies for minimizing risks and its corollary, ensuring mission, are fairly well defined, the strategies for maximizing resilience are not. Our framework needs a definition of a strategy that maximizes resilience. Consider a government agency whose responsibility is to effectively plan and allocate resources to accomplish a mission. Missions could, for example, include federal policy actions and private-sector economic activities. This agency can allocate its mission-related resources using one of three alternate perspectives:

1. a risk perspective: minimize the use of resources for mitigating the risks to its particular mission;

2. a mission-assurance perspective: maximize the probability of mission outcome, given the risks and available resources to mitigate them; or

3. a resilience perspective: maximize the probability that mission will be achieved through planned ad-hoc adjustments to potential disruptions.

The agency has a number of alternate operational strategies to choose from, each with an associated cost and contribution toward reducing risks, assuring mission, and improving - if not maximizing - resilience. If the goal of this agency is to pick a particular set of strategies that optimizes these outcomes, we can define the resilience-maximizing strategy as follows:

The resilience-maximizing strategy is the one among alternate strategies that, for a given targeted mission and budgeted level of resources, maximizes the ability of the agency to prepare for, resist, tolerate, absorb, recover from, or adapt to disruptions that could cause significant loss of mission.

The definition harmonizes risk and mission-assurance concepts: it addresses the need to allocate resources that maximize the ability to meet mission, including selecting actions that reduce the potential for risk-related "significant loss of mission." It also addresses the need to find the

\footnotetext{
${ }^{14}$ Current definitions do not always lend themselves naturally and intuitively to measurement and the development of consistent metrics with clear relationships to metrics of other relevant abstract notions, such as reliability and risk (Ayyub, 2014; Wu and Azarm, 2001; Farhang-Mehr and Azarm 2003). For example, Ayyub (2014) recently examined resilience definitions as they relate to quantification and metrics, linking both sustainability and resilience metrics to system performance enhances decision making processes and resource allocation abilities. Wu and Azarm (2001) and Farhang-Mehr and Azarm (2003) devised metrics such as entropy for evaluating solutions to multiobjective optimization problems. Similar approaches can be undertaken for sustainability with a focus on construction and manufacturing.
} 
strategy that maximizes the resilience of the agency's ability to carry out missions, specifically to adapt its actions so as to ensure the targeted level of mission at its given budgeted resources. Risk-resilience harmonization comes through formalizing a strategy that reduces potential disruption-based losses to mission through the abilities to adapt to these disruptions.

We illustrate this risk-assurance-resilience framework with a mathematical model that captures the relationships between risk, mission, and resilience; and shows how targeting one of these can achieve all three - reduced risk and increased mission and resilience for mission stakeholders. We illustrate this harmonization by first casting the risk-assurance-resilience problem as an example of the duality problem common in optimization theory.

\subsection{The General Duality Approach}

In many cases, a mathematical constrained optimization - "maximize or minimize an objective given a set of constraints" - can be viewed one of two ways, as a primal or dual problem (MasCollel et al, 1995). The true utility of this dual approach is that under the right conditions, the solution found for the primal is the same as that for the dual - solving one solves both. In microeconomic theory, the most common duality example is of an economic firm that has both maximize-production and minimize-cost objectives. The solution to the firm's problem of maximizing profits is the same as that found when minimizing costs. A quick review of this example lays the foundation for an analogous government risk, assurance, and resilience problem.

In microeconomics a firm's objective is to maximize output given inputs and their associated costs. Letting $l$ and $k$ be the labor and capital inputs to production $q, w$ and $r$ their respective unit costs, and $\bar{C}$ the budget the producer has to spend on purchasing input factors, the producer's problem is to select $\hat{l}$ and $\hat{k}$ that solve the (primal) problem of maximizing output while not spending more on input materials than $\bar{C}$ :

$$
\max q(l, k) \text { subject to } w l+r k \leq \bar{C} \text {. }
$$

The most commonly used function for $q(l, k)$ is the Cobb-Douglas production function $q(l, k)=$ $A l^{\alpha} k^{1-\alpha}$, where $0<\alpha<1$. Cobb-Douglas is not required for this example, but we do need $q(l, k)$ to be monotonically increasing in $l$ and $k$, concave, and twice-continuously differentiable. To solve this optimization, we first construct the mathematical Lagrangian

$$
\Gamma=A l^{\alpha} k^{1-\alpha}+\lambda(\bar{C}-w l-r k)
$$

where $\lambda$ is the Lagrange multiplier. First-order conditions with respect to $k$ and $l$ result in the condition that the ratio of the marginal benefit of each input factor to its respective cost must be equal, for all factors of production:

$$
\frac{A \alpha l^{\alpha-1} k^{1-\alpha}}{w}=\frac{A l^{\alpha}(1-\alpha) k^{-\alpha}}{r} ;
$$


that is, the marginal benefit-cost ratio of each input must be the same. Substituting in the constraint equation and then solving equation 3 , we have the production-maximizing inputs $\hat{l}$ and $\hat{k}$ :

$$
\hat{l}=\frac{(1-\alpha) \bar{C}}{w}, \quad \hat{k}=\frac{\alpha \bar{C}}{r} .
$$

Two insights from this are important to later sections: first, the inputs $\hat{l}$ and $\hat{k}$ are defined solely in terms of available budget $(\bar{C})$ and input costs $(w$ and $r$ ). Second, the marginal increase in production of an additional unit of available budget resource $\bar{C}$ is equal to the Lagrangian multiplier, which itself is based solely on the technology coefficient $A$, resources, and costs:

$$
\lambda=\frac{A \alpha l^{\alpha-1} k^{1-\alpha}}{w}=\frac{A l^{\alpha}(\alpha-1) k^{-\alpha}}{r} .
$$

Finally, the optimal level of production can be described solely in terms of the parameters $A, \alpha$, $w$, and $r$ : letting $\gamma$ be defined as

$$
\gamma=\frac{A \alpha^{\alpha}(1-\alpha)^{1-\alpha}}{r^{\alpha} w^{1-\alpha}}
$$

Production is defined in terms of the budget constraint: $\bar{q}=\gamma \bar{C}$.

An important contribution from duality theory is that this producer could just as easily solve for $\hat{l}$ and $\hat{k}$ by minimizing the costs associated with producing output $\bar{q}$. To illustrate this, equation 1 can be re-cast as selecting $\hat{l}$ and $\hat{k}$ that solves

$$
\min (w l+r k) \text { subject to } q(l, k)=\bar{q} \text {. }
$$

Using the same Cobb-Douglas function, the Lagrangian is

$$
\Gamma=(w l+r k)+\lambda\left(\bar{q}-A l^{\alpha} k^{1-\alpha}\right)
$$

which is very similar in structure to equation 2 . From first-order conditions, the solution to this dual problem is the same as in equation 3 . Given that the respective production and budget constraints are related by $\bar{q}=\gamma \bar{C}$, the solutions for $\hat{l}$ and $\hat{k}$ from this dual problem are the same as those in the primal problem. Figure 1 summarizes the relationship between these two objectives. 

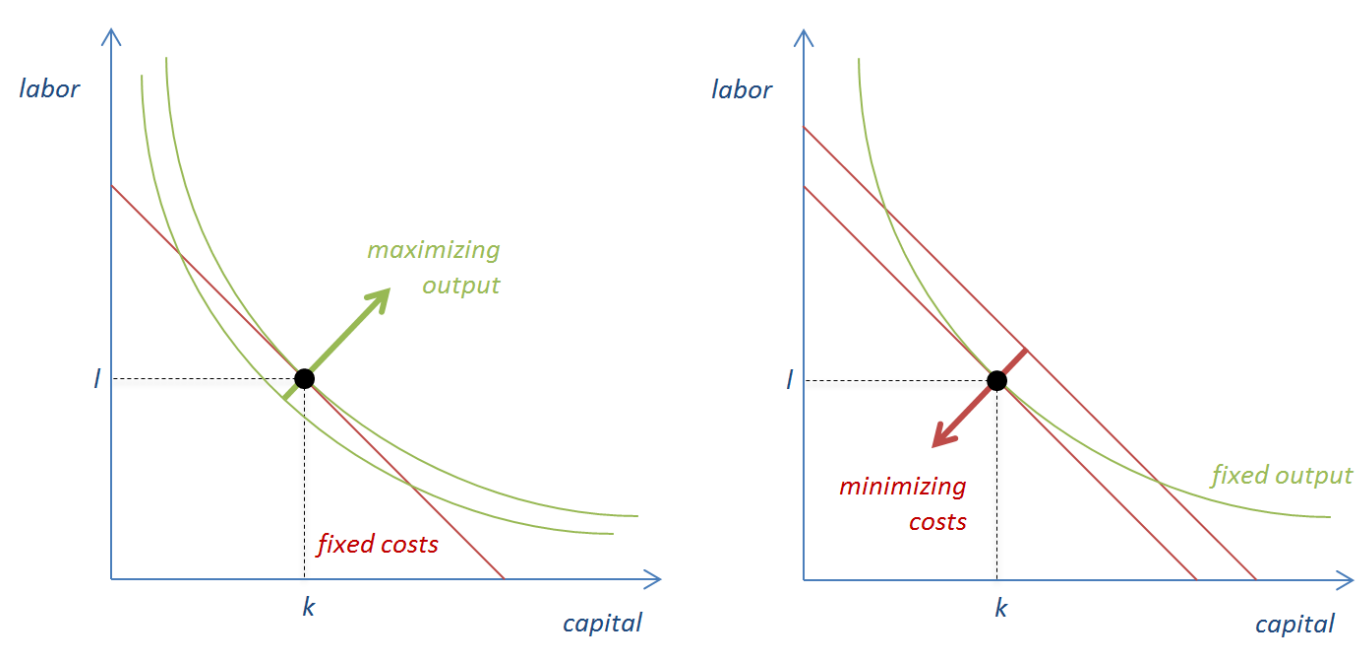

a. Maximizing Output

b. Minimizing Costs

Figure 1. Primal and Dual Economics Problems

Each panel in the figure shows potential allocations of capital (horizontal axis) and labor (vertical axis). The red lines show the loci of iso-budget points that can be purchased for a given budget and input prices; the green lines show the loci of iso-production lines achievable with the different allocations of inputs. The left panel illustrates how output is maximized given a fixed level of costs: the agency can allocate its budget toward all labor (where it hits the vertical axis), to all capital (on the horizontal axis), or any combination of the two along the red line. Each green iso-output line indicates the amount of output that can be made from different combinations of labor and capital. The solution $\{\hat{l}, \hat{k}\}$ (the black dot) is that level of output that is on the (red) budget line. The right panel shows how this same allocation can be achieved by minimizing the costs $w l+r k$ given a fixed level of output. This dual understanding of output and costs is crucial to our risk and resilience approach for a government agency.

\subsection{The Mission-Risk and Mission-Assurance Dual Problem}

For a given government mission, there are two inherent but analogous opposing objectives: the first is to maximize the expected mission given the baseline costs of the mission and costs of preparing for or responding to the disruption of mission-related assets (Figure 2). For example, in the NIST Community Resilience Planning Guide, the mission would achieve the "social needs of the community." We call this the primal mission problem. This same mission objective can be viewed as one of minimizing the total costs (operating and disruption-related costs) of conducting a given level of mission. A government agency typically has limited resources overall, and these resources need to be spent in ways that ensure that the agency's mandated missions are met. This same agency also attempts to minimize the costs associated with achieving the target mission. We call this the dual mission problem. 


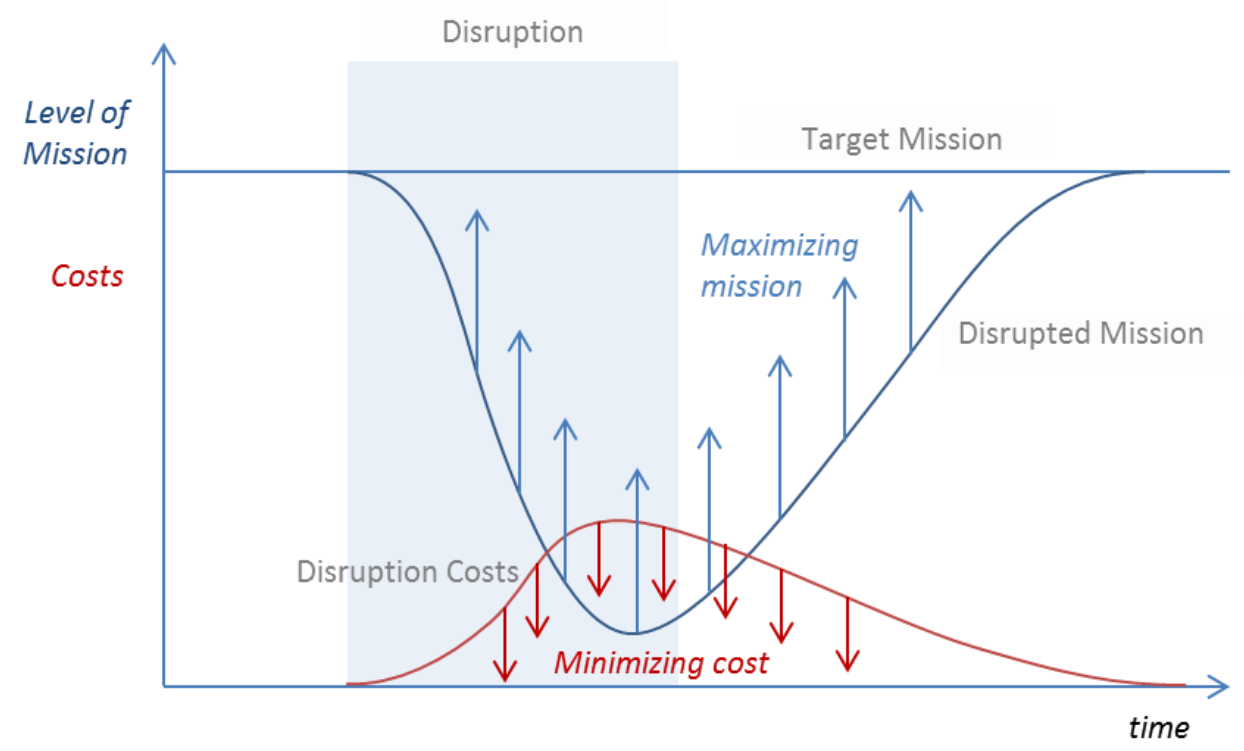

Figure 2. The Dual Objectives of Maximizing Mission and Minimizing Costs

\section{The Model}

We formulate the problem as that of an agency that must perform a mission that includes a set of assets $\{j\} \in J$, subject to potential disruptive events $\{i\} \in I$, each with probability $p_{i}$. Assets include individual facilities/built environment, supporting critical infrastructure systems, and social entities. Each disruption $i$, if it occurs, causes an associated consequence or in our case loss of mission, $c_{i j}$, to the associated asset $j$. The $a$ priori expected loss in mission by asset, $\left\{c_{i}\right\}, i \in I$, can be expressed as

$$
\begin{aligned}
\text { Expected asset- } i \text { loss } & =E[P \times C] \\
& =\left[\begin{array}{lllllll}
p_{1} & \ldots & p_{i} & \ldots & p_{I}
\end{array}\right] \times\left[\begin{array}{cccccc}
c_{11} & \ldots & c_{1 j} & \ldots & c_{1 J} \\
\ldots & \ldots & \ldots & \ldots & \ldots \\
c_{i 1} & \ldots & c_{i j} & \ldots & c_{i J} \\
\ldots & \ldots & \ldots & \ldots & \ldots \\
c_{I 1} & \ldots & c_{I j} & \ldots & c_{I J}
\end{array}\right] \\
& =\left[\begin{array}{llllll}
c_{1} & \ldots & c_{i} & \ldots & c_{I}
\end{array}\right] .
\end{aligned}
$$

For each disruption $i$ and associated consequence $c_{i j}$ experienced by asset $j$, the agency has at its disposal a set of countermeasures or strategies $\left\{s_{i j}^{m}\right\}, m \in M$, measured in units of effort and an associated per-unit cost, $r_{i j}^{m}$. In initial planning and in response to a particular event, the agency must "produce" the loss of mission the disruption caused. Assuming economies of scope in these strategies - where conducting some of each alternate is better than conducting only a few - we can use a Cobb-Douglas production function for "producing lost mission" (the upper lostmission area shown in Figure 2). We mathematically quantify the production for regaining this mission as: 


$$
\text { Regained mission }=A \prod\left(s_{i j}^{m}\right)^{\alpha_{m}},
$$

where $A$ is a technology constant and $0<\propto_{m}<1$ and $\sum_{m \in M} \propto_{m}=1$. The $\propto_{m}$ term represents the individual contribution of the particular strategy to the overall ability to regain mission, through synergy with the other strategies. As an example, to produce lost mission for a plan that has one asset and two strategies $\left\{m_{1}, m_{2}\right\}$, the restore-mission production function is $A\left(s^{1}\right)^{\propto_{1}}\left(s^{2}\right)^{\alpha_{2}}$.

Figure 3 illustrates this dual set of objectives. A government agency has a well-formed mission, with potential risks of disruption to this mission. The agency can assign a number and expected levels of disruption prevention and mitigation costs, which increase with their ability to reduce the resulting loss of mission. Given this relationship between disrupted mission and disruption costs, the graph can be used to articulate (disrupted) mission-maximizing strategies given a fixed budget for disruption costs, or to articulate a (disruption) cost-minimizing strategy given a target mission. (These mission and cost lines are actually "lumpy," or discrete, where the mission outcome and its costs jump from one discrete state to another.)

Using the definition above, the resilience-maximizing mission strategy is the one that maximizes the ability of government to resist, tolerate, absorb, recover from, or adapt to a disruption. Following the method in the previous section, either the primal or dual mission problem will maximize this ability. A government agency can achieve mission resilience by minimizing the costs of disruptions for a given level of mission, since this is equivalent to maximizing the mission outcome. The following duality illustration helps make this point.
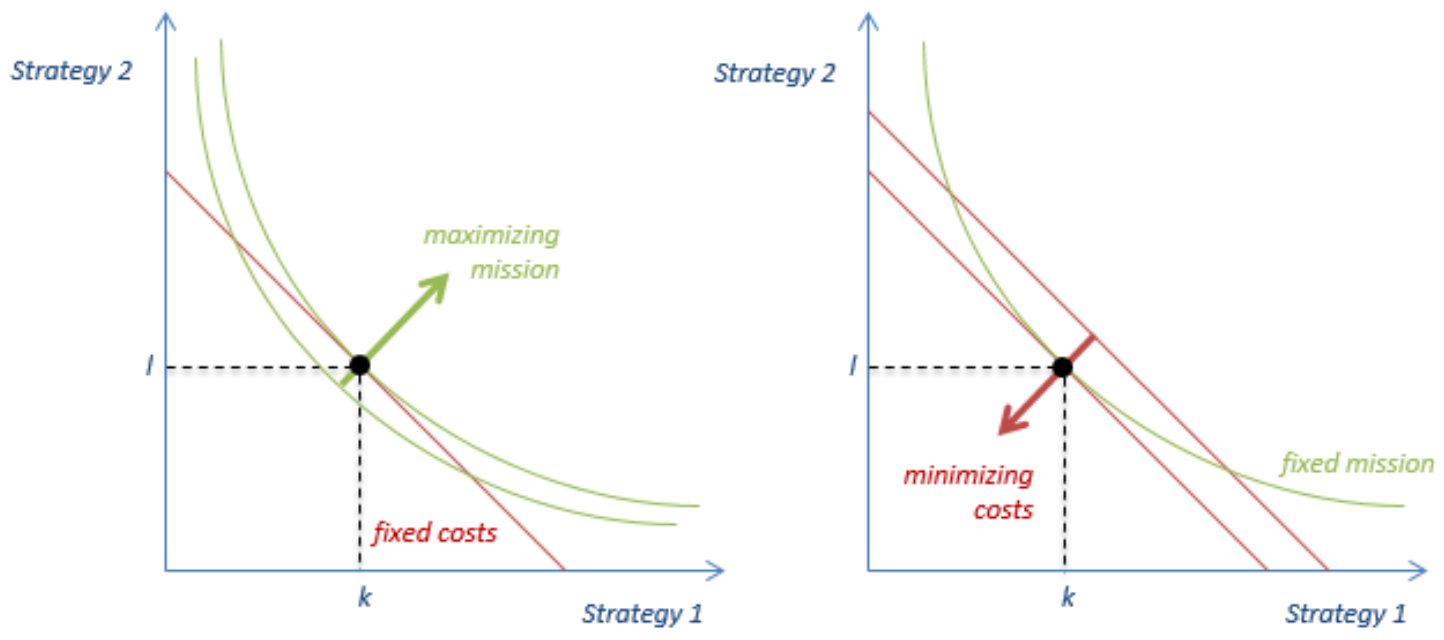

Figure 3. Primal and Dual Mission Problems

\section{The Primal Mission Problem: Assuring Mission}

Analogous to the economic firm above, consider a government agency that plans the resources and actions taken to conduct a particular mission, for example, the delivery of safe and effective pharmaceuticals (FDA, 2014). To "produce" a mission at level $\bar{q}$, the agency must spend operating costs $c^{o p}$ and carry out a strategy $\left\{s^{m}\right\}$ of potential actions for reducing the impacts of disruptions $\{i\}$ to the agency's assets $\{j\}$. (Since the operating costs are identical between strategies, they ignore them.) Figure 4 illustrates a set of such disruptions, organized by their probability of occurring and if they occur, their consequence to mission. 


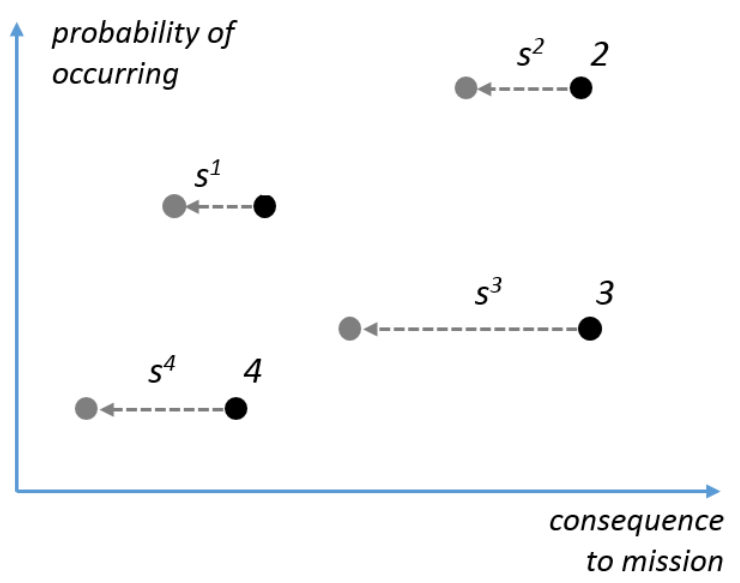

Figure 4. Mission Disruptions and Disruption-Response Strategies

In RAMCAP language, each disruption $i$ is associated with a particular asset $j$, creating a $\{i, j\}$ RAMCAP threat-asset pair.

Each of these actions, taken from a full set of potential strategies $S$, is designed to either prevent disruption of mission or to mitigate the losses to mission caused by the disruption. The strategies specify prevention/mitigation actions on, and associated costs, for (i) individual mission assets such as chemical facilities and manufacturers that use the chemicals and other materials to make mission products, and (ii) system-level assets such as transportation routes, ports, and other critical infrastructure that support these facilities and manufacturers. For simplicity of exposition, these response strategies do not change the probabilities of occurring; that condition is described in Section 0 . The $\left\{s_{i j}^{m}\right\}$ can be thought of as real options in that they are paid for, in advance, so that action can be taken if and when the particular disruption occurs. For decisions in complex, high-resource-commitment, and high-uncertainty environments like government missions, risk management techniques such as scenario planning with real options (Varum, 2010; Alessandri et al, 2004; Miller \& Waller, 2003; Cornelius et al, 2005; Raynor et al, 2004; Williams, 2012) provide the means for identifying high risks to mission, identifying options for action given these events occur, and estimating the benefits and costs of keeping those options available. For example, a particular mission might potentially be disrupted by earthquake, flooding, or act of terrorism; the agency can build in low-cost options that allow it to effectively respond to all of these. The risk-assurance-resilience framework herein helps identify what the resilience actions can and should be.

Each disruption event $i$ has a probability of occurring $p_{i}$, a level of effort to mitigate loss of mission $s_{i j}^{m}$, and a fixed cost $r_{i j}^{m}$ of the action of addressing the event in a way that reduces the potentially lost mission. ${ }^{15}$ Potential efforts to prevent, adapt, and recover lost mission include

\footnotetext{
${ }^{15}$ This cost breakdown could be considered a generalization of the FAA (2000) criticality approach, where total "impact of loss" is quantified as the sum of initial asset cost, temporary asset replacement, permanent replacement, and related costs such as flight delays and human life. It is also related to the RAMCAP (ASME, 2009) standard that identifies risk in terms of threat-asset pairs.
} 
maintaining backup supplies of mission products, increasing security at the chemical and 'downstream' manufacturers, and increasing modes of available transportation of product.

Next, we assume that increases in these disruption-reduction efforts increase the mission outcome, but that there are decreasing returns from these efforts and costs (each additional dollar of effort gives a lower reduction in loss of mission): ${ }^{16}$

$$
\frac{q}{s^{m}}>0 \text { and } \frac{{ }^{2} q}{\left(s^{m}\right)^{2}} \quad 0 \quad m \text {. }
$$

Operating costs are taken as given and required for any mission, regardless of the particular $\left\{s^{m}\right\}$ risk strategy taken. Simplifying the problem by focusing on an agency formulation that has one asset, one event, and multiple strategies, we formalize this primal problem mathematically as selecting the set of $\left\{s^{m}\right\}$ that solves

$$
\max q=q(\{s\}) \text { subject to } \sum_{m \in M} p_{i} s_{i}^{m} r_{i}^{m} \leq \bar{R} \text {. }
$$

After forming the Lagrangian and solving for first-order conditions we have the condition (analogous to equation 3 ) that the marginal contribution of each mission producing/restoring activity per unit cost (or benefit-cost ratio) be the same:

$$
\frac{\partial q / \partial \hat{s}^{m}}{p_{i} r_{i}^{m}}=\frac{\partial q / \partial \hat{s}^{n}}{p_{i} r_{i}^{n}} \forall m, n \in M .
$$

This condition is shown in Figure 3, where the cost line touches the iso-production curve. As was the case in the previous economic-dual problem, this optimal allocation of efforts $\left\{s_{i j}^{m}\right\}$ is solely a function of the given parameters, in this case the effectiveness of mission-assuring activities, the probability of events and the cost per unit effort when responding to these events.

\section{The Dual Mission Problem: Minimizing Resource Costs}

Given the quasi-concavity of the mission-restoration function $q$ and the linearity of restoration costs, the dual problem of minimizing disruption-related costs subject to a given level of mission is equivalent to the primal problem, that is, its solution is the same allocation of disruptionrelated resources:

$$
\min R=\sum_{m \in M} p_{i} s_{i}^{m} r_{i}^{m} \text { subject to } q(\{s\}) \geq \bar{q}
$$

Note that the product $p_{i} s_{i}^{m} r_{i}^{m}$ can be the direct measure by which mission critical assets are identified, i.e., as the assets that have the highest combination of probability $\left(p_{i}\right)$ of consequence - or effort $\left(s^{m}\right)$ and cost $\left(r^{m}\right)$ associated with maintaining mission. The implications of such a result are significant: the equations suggest that efficient government resilience policy occurs when the policy maximizes the mission outcome at lowest cost, where cost is measured by the

\footnotetext{
${ }^{16}$ That is, $q$ needs to be monotonically increasing in the efforts to increase mission, concave, and twice-continuously differentiable.
} 
cost of disruption; mission criticality assessment is a systematic measure of those high-cost sources of disruption. To determine the mission critical assets, we expand the Lagrangian

$$
\Gamma=\left(\sum_{i \in I} p_{i} s_{i}^{m} r_{i}^{m}\right)+\lambda[q(\{s\})-\bar{q}] .
$$

and inspect first-order conditions the same way:

$$
\frac{\partial q / \partial \hat{s}^{m}}{p_{i} r_{i}^{m}}=\frac{\partial q / \partial \hat{s}^{n}}{p_{i} r_{i}^{n}} \forall m, n \in M
$$

The equation ensures that the solution to the mission-cost minimization problem is the same as the solution to the mission-maximization problem, that this solution is the optimal solution. ${ }^{17}$ Most importantly, given our definitions above, both of these solutions are also the resiliencemaximizing solution, that is, they both maximize the probability of achieving mission given the ability to (and costs of) responding, adjusting, and adapting. This approach also ensures that the strategy selected identifies the mission-critical assets and ultimately maximizes chemical sector resilience to these security-related disruptions.

\subsection{Important Extensions to the Framework}

As constructed so far, though, the only means of maximizing resilience is to select the set of operational tasks and responses that support the potential states $\left\{s^{m}\right\}$ that occur over the analysis period. A number of logical extensions to this framework significantly increase its ability to maximize resilience while preserving the basic condition that one approach simultaneously achieves the risk, mission, and resilience objectives.

The first extension is dynamic optimization. Above, the decision maker optimizes the resource allocation only once, at the beginning of the time period. In an expanded dynamic optimization formulation, the decision maker makes an initial allocation and then re-optimizes, for example, when (i) a disruption occurs or ends, or (ii) there is a significant change in resources or mission. The decision maker uses the updated, realized information to ensure efficient use of resources and maximized mission from that point forward. Figure 5 illustrates how sequential optimizations are conducted, in particular when there is a disruption.

\footnotetext{
${ }^{17}$ That is, this solution $\left\{s^{m}\right\}$ is mathematically local and global optimum to the maximization and minimization problems.
} 


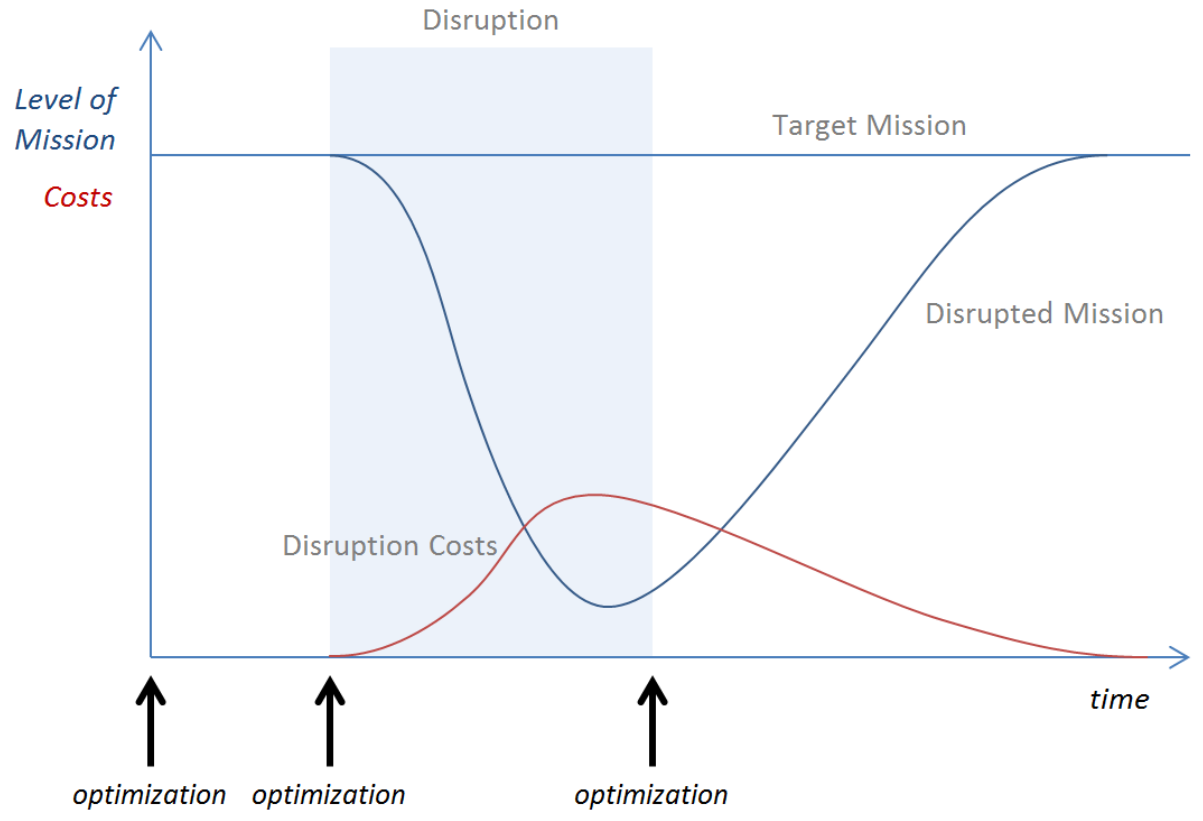

Figure 5. Resilience-Maximizing Dynamic Optimization

Assuming that there is a small cost to this optimization process, the decision maker will continually re-optimize in response to new information until the expected benefit of optimizing is less than its cost, similar to the sequential search rules found in, for example, Carlson \& McAfee (1983). Optimal control techniques (Chiang, 1992) provide methods for ensuring that this piece-wise optimization over time is a priori equivalent to the overall temporal optimization, even under disruption uncertainties and particular outcomes. That is, this sequential optimization can provide a resilience-maximizing disruption strategy.

The second extension to this framework is the process of wholesale reconstruction of the overall set of circumstances that dictate operational and disruption actions. The initial mathematical construct above describes how an agency decision maker can optimize outcomes, resources, and resilience for a given set of alternative strategies. Resilience design is a process whereby the agency decision maker redesigns the mission itself, that is, reformulates the strategy, to further maximize resilience (and therefore minimize risks and maximize assurance). In the vernacular of the above agency problem, resilient design focuses more on developing a new mission and therefore new strategies $S$ - for example, new capital investment over the long term - that categorically increase the ability of the agency to adapt to and recover from the disruptive events. When formulated correctly, the three-way optimization still holds.

As suggested by the figure, the agency can redesign the problem so as to transfer or remove certain risks. Finally, the framework can be made more general by implementing a constant elasticity of substitution (CES) production function, which, as a specific case, includes the CobbDouglas function. 


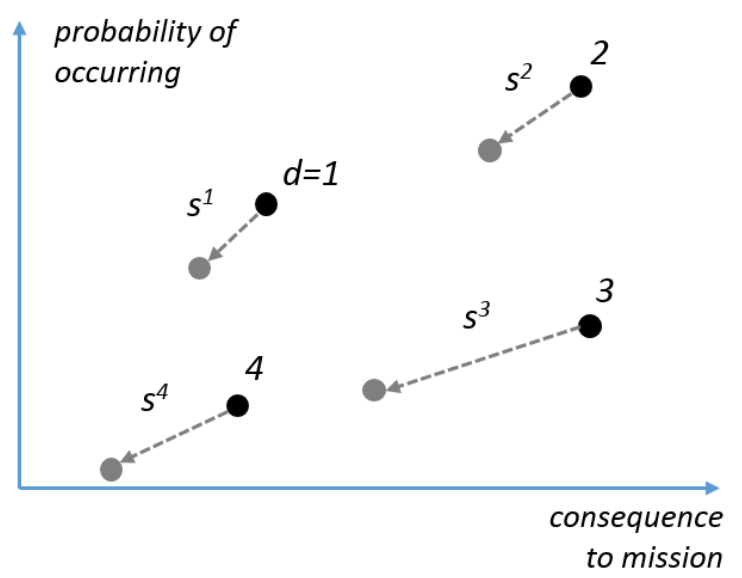

Figure 6. Effects of Resilient Design on Probability and Consequences of Events

\subsection{Application Example: the Pharmaceutical Industry}

U.S. pharmaceuticals facilities are regulated through a number of federal policies, including the U.S. Food and Drug Administration (FDA), which as an agency has a mandate to ensure the sufficient supply of safe pharmaceuticals. The FDA has direct control through regulations on pharmaceuticals facilities, and indirectly through other regulations. If and when there is a disruption of an individual pharmaceutical facility, or asset within its mission, it has a number of responses in place to ensure mission, including (i) asset-level: increasing inventories of key pharmaceuticals (prophylaxis, anti-virals) and using secondary production facilities, and (ii) system-level: importing pharmaceuticals from overseas. Given the chronic shortages the FDA faces in over 100 medically necessary drugs, the framework provides a means for assessing the relative benefits and costs of these alternate response strategies, and also for assessing the overall ability of the strategy to maximize resilience.

Second, DHS, through multiple agencies, ensures the safe production, use, storage, and transport of chemicals, given the threat of terrorism theft/release and destruction. It works to ensure that facilities have minimized the risk of attack, destruction, and theft/diversion, through site security plans that are based on risk-based performance standards. Other federal policies regulate the transport of chemicals to minimize the risk of terrorist threat, destruction, or diversion. Potential policy measures have included diverting if not halting the transport of particular chemical shipments until the threat was identified and removed. While such policies may be effective in reducing public safety impacts, they could have significant detrimental impacts to the economy and important government missions. With economic or mission as targeted performance, the framework makes clear what the disruptions are, the alternate potential responses, their comparative resilience benefits, and the overall risk-assurance-resilience strategy that can minimize terrorist risks and maximize sector resilience.

\subsection{Application Example: Disaster Resilience Management}

The current NIST Planning Guide (Figure 7) illustrates how development of a disaster resilience strategy must include a clear statement of resilience and risk objectives. Table 1 maps our current framework with the NIST Community Resilience Planning Guide (NIST, 2015) and the NIST Economic Decision Guide (Gilbert, Butry, Helgeson, and Chapman, 2015). 
The selection of strategies in the NIST guide must include both "left of bang," preparedness strategies and "right of bang," restorative activities, the latter of which are broken down into short, medium and long term (Figure 7). Figure 8 illustrates how strategies and their ability can be compared based on their comparative abilities to use valuable resources and the most current information to dynamically optimize resources toward a low-risk, resilience outcome.
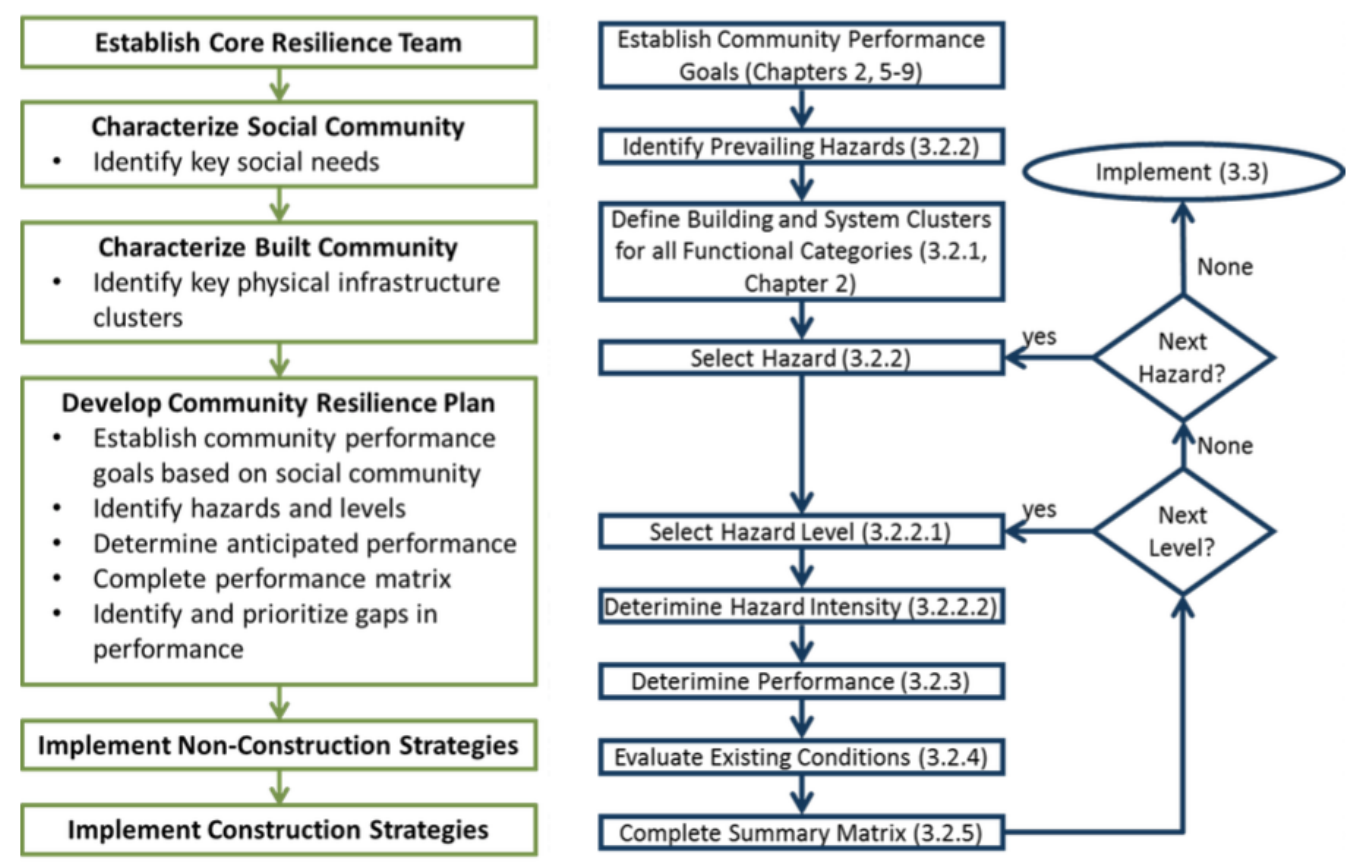

Figure 7. NIST Flow Chart for Developing Resilience Plan

Table 1. Mapping of Concepts Between Our Framework and NIST Guide

\begin{tabular}{|l|l|l|}
\hline Framework & NIST Disaster Guide & NIST Economic Guide \\
\hline $\begin{array}{l}\text { Stated mission and } \\
\text { constraints }\end{array}$ & $\begin{array}{l}\text { "key social needs" } \\
\text { "key community performance goals" }\end{array}$ & $\begin{array}{l}\text { "Determine objective function" } \\
\text { "Identify constraints" }\end{array}$ \\
\hline Assets of concern & "key physical infrastructure clusters" & \\
\hline Risks to mission & "identify hazards and levels" & \\
\hline $\begin{array}{l}\text { Consider alternate } \\
\text { restorative strategies }\end{array}$ & "Implement non-construction & $\begin{array}{l}\text { "Select candidate plans" } \\
\text { /construction strategies" }\end{array}$ \\
\hline
\end{tabular}




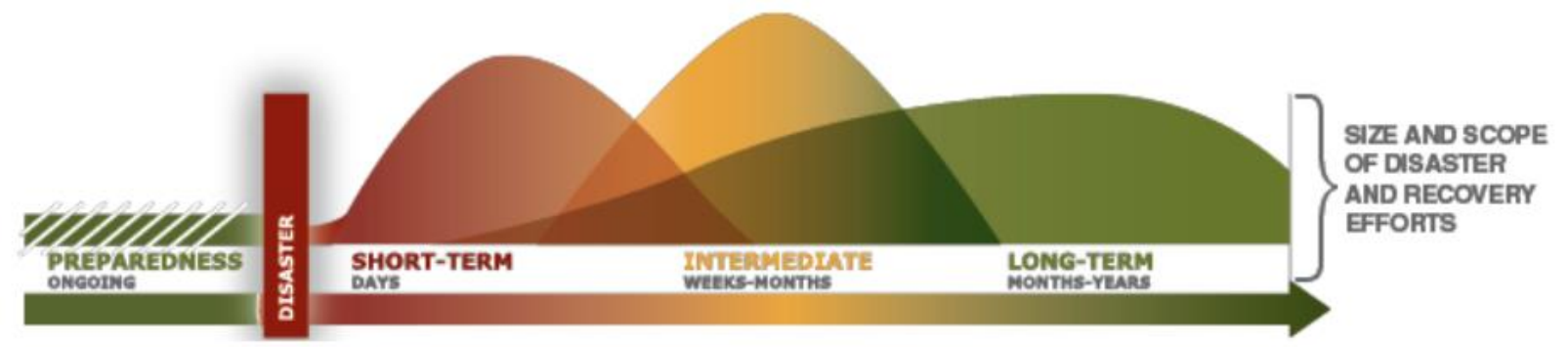

Figure 8. NIST Chart Describing Level of Recovery Efforts: Short, Medium, Long Terms

\section{Summary and Conclusions}

To address the lack of specific DHS guidance on how to simultaneously meet risk and resilience mandates, we present a risk-assurance-resilience framework that uses examples from the chemical sector. This appears to be the first approach that directly meets the combined requirement to "ensure that resources are applied where they contribute the most to resilience and risk mitigation" (DHS 2010b). The framework can be used, for example, to rank DHS assets by their ability to both (i) reduce asset and sector risks and (ii) increase sector-wide resilience. This can be used to identify resilience-maximizing strategies that involve the least-cost risk activities that do not involve individual facilities or assets.

The framework in its initial form herein is largely expository; more developed versions will need to take into account the ability to make changes in risk and resilience plans, and reallocate resources during and after a disruption, to ensure mission. More research is needed to fully develop the constructs that will allow chemical-sector policy analysts to evaluate the broader set of options for mitigating homeland security risks and ensure sector resilience.

\section{Acknowledgements}

The authors would like to acknowledge financial support from the U.S. Department of Homeland Security Science and Technology Directorate.

\section{References}

Alessandri, Todd M., et al. (2004) Managing risk and uncertainty in complex capital projects. The Quarterly Review of Economics and Finance 44.5: pp. 751-767.

American Chemistry Council (ACC) (2013) The Business of Chemistry by the Numbers, June 2013, http://www.americanchemistry.com/chemistry-industry-facts, accessed March 2014.

ASME Innovative Technologies Institute. (2009) All-hazards risk and resilience: Prioritizing critical infrastructure using the RAMCAP PlusSM approach. New York: American Society of Mechanical Engineers.

American Water Works Association (AWWA). (2010) J100-10 (R13) Risk and Resilience Management of Water and Wastewater Systems (RAMCAP), 9781583217887. AWWA.

Ayyub, B. M. (2014). Systems resilience for multihazard environments: definition, metrics, and valuation for decision making. Risk Analysis, 34(2), 340-355.

Carlson, J.A. and McAfee, R.P. (1983) Discrete Equilibrium Price Dispersion. Journal of Political Economy, Vol. 91, No. 3, pp. 480-93.

Chemical Facility Anti-Terrorism Standards, 6 USC $\S \S 621-628$ (2014).

Chiang, A. C. (1992) Elements of dynamic optimization. New York: McGraw-Hill. 
Cornelius, P., Van De Putte, A., and M. Romani. (2005) Three decades of scenario planning in Shell, California Management Review 48, pp. 92-109.

Federal Bureau of Investigation (FBI), Mueller, Robert S., III, Director. (2003) Testimony before the Senate Select Committee on Intelligence, Feb. 11, 2003, accessed at http://www.intelcenter.com/resource/2003/mueller.pdf on visited Feb. 4, 2005.

Farhang-Mehr, A., \& Azarm, S. (2003). An information-theoretic entropy metric for assessing multi-objective optimization solution set quality. Journal of Mechanical Design, 125(4), 655663.

FAA (Federal Aviation Administration). (2000) "Security Risk Management Guide," accessed at http://fast.faa.gov/Riskmgmt/Secriskmgmt/secriskmgmt.htm on June 25, 2014.

Gilbert, S.W. (2010) "Disaster Resilience: A Guide to the Literature," National Institute of Standards and Technology, NIST Special Publication 1117, September.

Gilbert, S., D. Butry, J. Helgeson, and R. Chapman (2015) Community Resilience Economic Decision Guide for Buildings and Infrastructure Systems. NIST Special Publication 1197. Gaithersburg, MD: National Institute of Standards and Technology.

Mas-Colell, A., Whinston, M. D., and J.R. Green. (1995) Microeconomic theory. New York: Oxford University Press.

Miller, K.D. and H. G. Waller (2003) Scenarios, real options and integrated risk management, Long Range Planning 36, pp. 93-107.

Moran, K., Ackerman, G., and J. Bale. (2004) Assessing Terrorist Motivations for Attacking Critical "Chemical" Infrastructure. Washington, D.C: United States. Dept. of Energy.

National Institute of Justice (NIJ) (1997). A Method to Assess the Vulnerability of U.S. Chemical Facilities. Washington, DC: U.S. Dept. of Justice, Office of Justice Programs.

National Institute of Standards \& Technology (NIST) (2015) Community Resilience Planning Guide for Buildings and Infrastructure Systems. NIST Special Publication 1190. Gaithersburg, MD: National Institute of Standards and Technology.

Raynor, M.E. and X. Leroux (2004). Strategic flexibility in R\&D, Research-Technology Management 47, pp. 27-32.

Sandia National Laboratories (2006). "A Risk Assessment Methodology (RAM) for Physical Security," white paper; accessed at http://www.sandia.gov/ram/RAM\%20White\%20Paper.pdf on June 25, 2014.

U.S. Department of Defense (DOD) (2000). Insider Threat Integrated Process team (2000). "DOD Insider Threat Mitigation: Final Report of the Insider Threat Integrated Process Team." April 24. Accessed at https://acc.dau.mil/GetAttachment.aspx?id=37478\&pname=file\&lang=en-US\&aid=9018 on October 14, 2013.

U.S. Department of Homeland Security (DHS). (2009) National Infrastructure Protection Plan, Washington, D.C.

U.S. Department of Homeland Security (DHS), Risk Steering Committee. (2010a) DHS Risk Lexicon.

U.S. Department of Homeland Security (DHS). (2010b) Chemical Sector-Specific Plan: An Annex to the National Infrastructure Protection Plan.

U.S. Department of Justice (2000). "Assessment of the Increased Risk of Terrorist or Other Criminal Activity Associated with Posting Off-Site Consequence Analysis Information on the Internet." Washington, D.C. April 18, p. 24. 
U.S. Food and Drug Administration (FDA). (2014) "Promoting Safe and Effective Drugs for 100 Years," website. Accessed at http://www.fda.gov/AboutFDA/WhatWeDo/History/ProductRegulation/PromotingSafeandEf fectiveDrugsfor100Years/ on June 25, 2014.

U.S. Government Accountability Office (GAO). (2005) Defense logistics: Actions needed to improve the availability of critical items during current and future operations: report to Congressional committees. Washington, D.C.: U.S. Government Accountability Office.

U.S. Government Accounting Office (GAO). (2014) DHS Action Needed to Enhance Integration and Coordination of Vulnerability Assessment Efforts [Reissued on September 17, 2014]. GAO-14-507: Published: Sep 15, 2014. Publicly Released: Sep 15, 2014

Varum, C.A. \& C. Melo. (2010). "Directions in scenario planning literature - a review of the past decades." Futures 42.4: 355-369.

The White House. (2013) Presidential Policy Directive 21 - Critical Infrastructure Security and Resilience, http://ww.whitehouse.gov/the-press-office/2013/02/12/presidential-policydirective-critical-infrastructure-security-and-resil, accessed June 13, 2013.

Williamson, Peter J (2012). Strategy as options on the future. Sloan Management Review 40.3.

Wu, J., \& Azarm, S. (2001). Metrics for quality assessment of a multiobjective design optimization solution set. Journal of Mechanical Design, 123(1), 18-25. 
Chang, Stephanie

\title{
Incorporating Recovery into Economic Analysis
}

\begin{abstract}
In current practice, economic analysis of disaster risk reduction often neglects time-dependent losses such as business interruption and income losses that accrue over time during post-disaster recovery. This paper argues that incorporating time-dependent losses is critical to making investment decisions that foster disaster resilience. Drawing from previous empirical and modeling work, the paper argues that incorporating economic impacts of short-term service outage and restoration is relatively straightforward and can be readily accomplished under certain assumptions -- most notably, assumptions of stable economic structure. Economic recovery is complex and highly context-dependent, however, and will remain very challenging to model, particularly for catastrophic events. To illustrate these points, examples are drawn from several cases in the U.S., Japan, and New Zealand.
\end{abstract}

\section{Keywords}

Community, Recovery, Economic, Disaster resilience, Infrastructure, Business interruption

\section{Introduction}

This paper addresses the need to incorporate recovery into economic analysis, such as benefitcost analysis, of disaster risk reduction options and strategies. In current practice, such economic analysis generally considers benefits as losses avoided as a result of the investment under consideration, where losses include monetized values of property damage and, in some cases, human casualties and government costs of emergency response. While time-dependent losses such as business interruption are occasionally included (notably, in MMC (2005)), they are frequently neglected, and standardized methods for estimating time-dependent losses do not yet exist.

This paper makes three principal arguments. First, incorporating time-dependent losses into economic analysis is important: neglecting them can lead to sub-optimal decisions that detract from communities' disaster resilience. Second, incorporating time-dependent losses can be relatively straightforward and readily accomplished with certain key assumptions -- specifically, that losses are experienced in the short term and the economic structure remains unchanged by the disaster. Third, these assumptions are very restrictive and abstract away from some of the fundamental processes of disaster recovery, particularly in the case of catastrophic events. These arguments are explored in Section 2 with a discussion of how economic recovery can be conceptualized and measured; in Section 3 with case study analysis of seismic retrofit options for a municipal water utility in Portland, Oregon; and in Section 4 with an overview of empirical literature and two disaster case studies. Section 5 provides a concluding discussion and recommendations.

Throughout, the term "economic recovery" is used to refer to post-disaster economic activity at the scale of communities (e.g., cities) and constituent sectors and units (e.g., businesses). The 
term "economics of recovery" is used to refer to economic analysis (e.g., benefit-cost analysis) that incorporates time-dependent processes related to economic recovery.

\section{Time-dependent Losses}

Economic recovery can be considered as "the process by which businesses and local economies return to conditions of stability following a disaster" (Chang and Rose, 2012, p.171). Consensus measures of economic recovery do not, however, yet exist. Chang (2010) notes that a key challenge pertains to defining the baseline. Does recovery refer to (a) a return to "pre-disaster" conditions, (b) attaining "without-disaster" conditions, or (c) reaching a post-disaster "stable state" that may differ from both of these? Each entails methodological limitations. Referencing pre-disaster conditions ignores economic changes (e.g., decline) that would have taken place even if the disaster had not occurred. Referencing "without-disaster" trends requires forecasting these trends and introduces considerable uncertainties. Referencing a new "stable state" requires determining when that state has been attained.

These distinctions are critical in the case of large-scale disaster events where the "pre-disaster," "without disaster," and "stable state" conditions may differ markedly; in other words, where the disaster causes substantial impacts to the community's economic structure and long-term economic trajectory. For smaller disasters, on the other hand, economic disruption may be temporary and recovered conditions may closely resemble pre-disaster states. It may be appropriate to conceptualize and model recovery as a return to "normal" conditions. Similarly, for certain segments of a community, such as an individual business or a neighborhood that is not especially hard hit, recovery can be modeled as a short-run phenomenon.

The concept of a return to normal conditions is also applicable when applied to the restoration of services provided by urban infrastructure systems. For example, in a limited sense, a water system's recovery can be considered complete when repairs allow water service to be restored to all the customers. Note that at that time, while the customers (e.g., businesses) would no longer be experiencing economic losses due to water outage, they could very well be suffering continuing economic losses due to other reasons.

\section{Infrastructure Service Restoration}

\subsection{Restoration Patterns}

Service restoration can be defined relatively easily for urban infrastructure systems. The percent of customers with electric power service at a given time $t$ after a disaster, for example, is a relatively common metric. Transportation service can be measured in terms of network connectivity or accessibility. Two examples of empirical restoration curves are shown below: Figure 1a compares service restoration times for different infrastructure systems in the 1995 Kobe earthquake, and Figure 1b compares transportation service restoration in the 1994 Northridge earthquake for different service measures (for further details, see Chang and Nojima, 2001).

Similar empirical data on restoration timeframes have been gathered for other disasters and systems. Statistical and other predictive models of restoration have also been developed (e.g., Liu et al., 2007). Because lifeline infrastructure service is essential for activities throughout an urban economy, and because service restoration is accomplished over a relatively short 
timeframe (typically within hours, days, or weeks), accounting for time-dependent economic losses related to infrastructure disruption should be a high priority in economic analysis of disaster risk reduction.

(a)

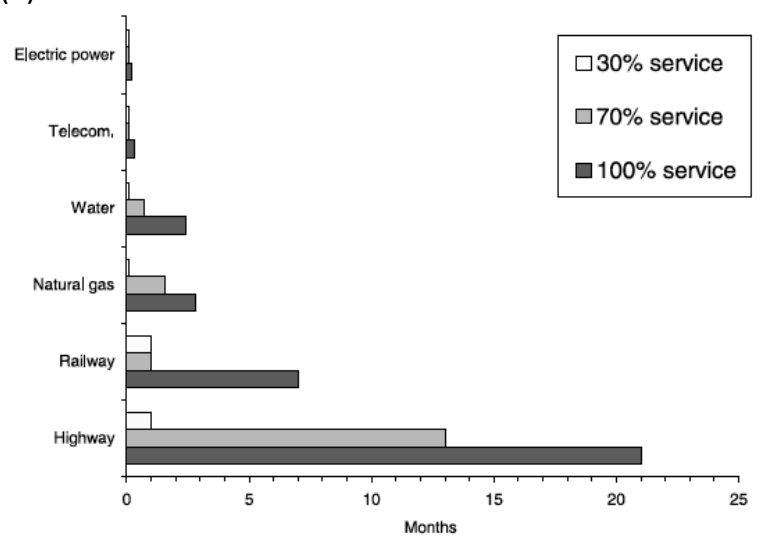

(b)

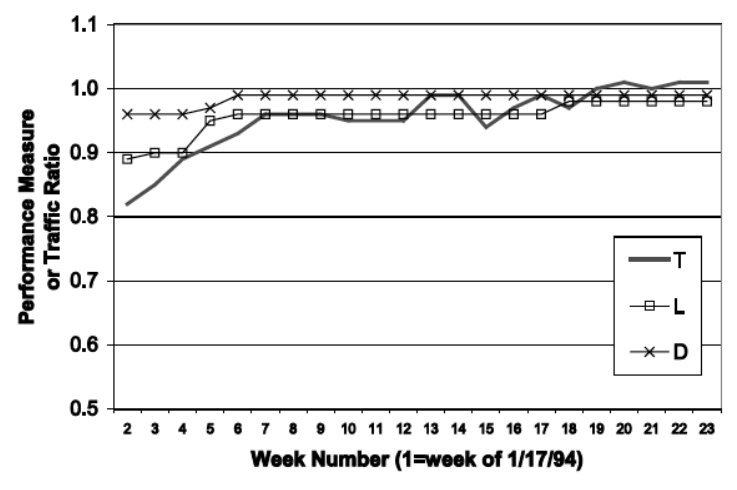

Figure 1. Infrastructure restoration curves. (a) for different systems in 1995 Kobe earthquake, (b) according to different service measures (T, L, D) for highway transport service in the 1994 Northridge earthquake. (source: Chang and Nojima, 2001)

\subsection{Incorporating Restoration in Economic Analysis}

At least one applied example strongly suggests the importance of doing so. Chang (2003) conducted an economic analysis of three seismic upgrade alternatives for the water delivery system in Portland, Oregon. In addition to a "no upgrade" option, the analysis considered a costly, extensive pipe replacement strategy and a more limited approach of only upgrading system tanks and pumps. These strategies differed in several respects, including initial costs, maintenance costs over a 50-year time horizon, and damage and system performance in potential earthquakes. Recovery time -- the number of weeks required to restore water service under different earthquake scenarios -- directly influenced estimates of the utility's revenue losses, as well as business interruption losses to the utility's customers.

If recovery-dependent losses are excluded, the optimal strategy from a cost-minimization standpoint is the "no retrofit" option (Table 1). In this case, analysis is based solely on costs of seismic retrofit, maintenance, and expected earthquake repairs for the water system. Discounted annual costs over the 50-year time horizon are $\$ 32.8$ million (in inflation-adjusted 2000\$) for the "no retrofit" option, which is lower than the $\$ 394.8$ million for pipe replacement and $\$ 34.7$ million for tank and pump upgrades. On the other hand, if recovery-dependent losses are included, tank and pump upgrades would have much lower total costs (\$331.7 million) than "no retrofit" (\$373.1 million), so this seismic retrofit strategy would be justifiable and preferred. 
Table 1. Economic Analysis of Seismic Retrofit Strategies, Portland Water System ${ }^{(1,2)}$

\begin{tabular}{lrcr}
\hline Cost category & \multicolumn{3}{c}{ Retrofit strategy } \\
\cline { 2 - 4 } & No retrofit & Pipe replacement & $\begin{array}{c}\text { Tank/pump } \\
\text { upgrade }\end{array}$ \\
\hline Recovery-independent & 0.0 & 377.9 & 2.1 \\
$\quad$ Seismic retrofit & 30.5 & 15.8 & 30.5 \\
Maintenance & 2.3 & 1.1 & 2.1 \\
Earthquake repair & 32.8 & 394.8 & 34.7 \\
SUBTOTAL & & & 0.9 \\
Recovery-dependent & 1.0 & 0.4 & 296.1 \\
Utility revenue loss & 339.2 & 118.5 & 297.0 \\
Users' b.i. loss $(2,3)$ & 340.2 & 118.9 & 331.7 \\
SUBTOTAL & 373.1 & 513.7 & \\
\hline TOTAL & & & \\
\hline
\end{tabular}

Notes: (1) adapted from Chang (2003); (2) costs in constant 2000 \$; (3) b.i. = business interruption.

Note that users' business interruption losses due to water outage are very large. In the "no retrofit" case, for example, they are approximately 10 times the size of the utility's costs. Note also that the scope of business interruption losses in this analysis was limited to direct losses, or business interruption deriving from water outage at the site of production; indirect losses related to inter-industry linkages are not included and would have further accentuated the study's conclusions. Some studies have found that indirect or multiplier effects can even exceed direct business interruption impacts in some cases (Cochrane 2004). In other words, accounting for time-dependent losses can alter the conclusions of economic analysis regarding cost-effective disaster risk reduction investments.

\section{Economic Recovery}

As noted earlier, infrastructure service restoration represents an important component, but does not provide a complete depiction, of economic recovery. Measuring post-disaster recovery is complicated by both conceptual and practical challenges (see Chang, 2010), and a variety of methods have been proposed (e.g., Wu et al. 2014; Burton, 2015). Section 4.1 below demonstrates that it may be possible to develop overall economic recovery trajectories for disaster-affected communities. As discussed in Section 4.2, however, important factors, processes, and impacts that have been identified in the literature on economic recovery cannot be adequately captured in quantitative recovery trajectories. Section 4.3 provides two earthquake recovery examples to illustrate the complexity of contextual factors in economic recovery.

\subsection{Recovery Trajectories}

Very few studies have been conducted to that seek to measure and compare economic recovery trajectories for disaster-affected communities. Findings from an exploratory study by Chang (2012) are presented here to indicate some preliminary findings and hypotheses for further research. Data on economic indicators were gathered at the community scale (i.e., city or county) for several coastal localities that have experienced devastating disasters. Data pertained to gross regional product (GRP), income, employment, unemployment, business reopening rates, port traffic, and retail sales, among others. In order to enforce consistency across cases while 
allowing for differing levels and types of data availability, recovery data were mapped onto a 7category scale of economic recovery. Events included both natural disasters (hurricanes, earthquakes, and tsunamis) and human-induced events (marine oil spills).

While this approach measures recovery in a highly simplified manner, it allows for the recovery trajectories to be compared consistently and semi-quantitatively. Preliminary results suggest two main findings: first, that for natural disasters, recovery trajectories appear to be related to initial levels of disruption. As shown in Figure 2a, recovery trajectories for three tsunami-impacted cities in the 2011 Tohoku disaster in Japan appear similar to recovery trajectories for other earthquake and hurricane disasters with similar levels, respectively, of initial disruption. Figure $2 \mathrm{~b}$ plots recovery trajectories for two communities affected by the Deepwater Horizon oil spill. Their recovery trajectories seem very different from the reference natural disasters, but similar to reference oil spill events. While preliminary, these findings suggest that at a very high level, different types of events may exhibit different recovery "signatures" -- in the case of oil spills, the "signature" is likely to be strongly influenced by the massive injection of cleanup and response monies into communities following such disasters. Further analysis and additional case studies are needed to test these hypotheses.
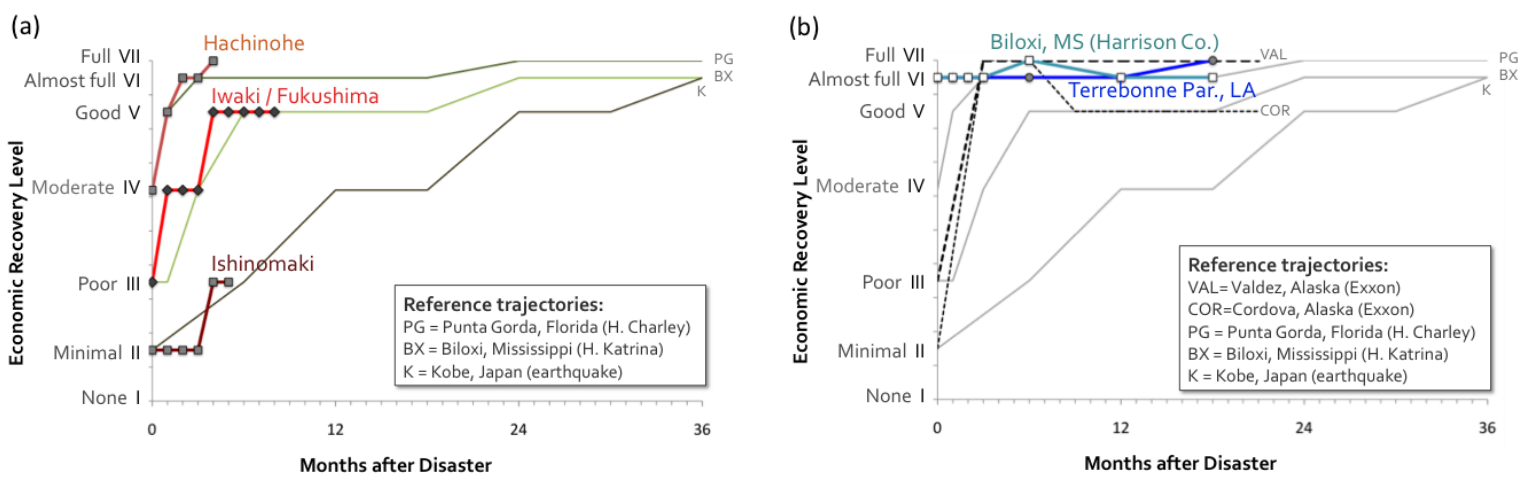

Figure 2. Economic recovery trajectories. (a) Natural disasters: 3 cities affected by 2011 Tohoku tsunami. (b) Oil spills: 2 counties affected by 2010 Deepwater Horizon oil spill. (source: Chang, 2012)

\subsection{Recovery Patterns and Issues}

Such overall recovery trajectories, while broadly informative and useful for making comparisons, cannot capture many of the important factors, processes, and impacts that have been identified in the literature on economic recovery. Three key findings from this literature are highlighted here (for a more complete review, see Chang and Rose (2012)).

First, economic impacts and recovery are typically very uneven within a community. Some types of businesses and economic sectors tend to have greater difficulty in disaster recovery; in particular, small businesses, locally-oriented businesses (e.g., in retail and some service sectors) and financially marginal businesses. This differential vulnerability and the corresponding difficulty in recovery relate to many factors, including lack of resources and occupancy of more physically vulnerable buildings. In the case of locally-oriented businesses, it is compounded by the disaster's impacts on the local customer base. On the other hand, some sectors -construction, in particular -- often gain in the post-disaster period, at least in the short term, due to the stimulus of repair and reconstruction activities. In other words, disasters are characterized 
by differential impacts and recovery outcomes, and the emergence of winners and losers (see also Xiao and Nilawar, 2013).

Second, economic impacts and recovery are affected by the interaction of numerous factors, many of which are exogenous to the decision-making unit. The recovery trajectory of a particular business, for example, may depend only in part on factors that are within the business's control, such as preparedness planning and pre-disaster risk mitigation investments in the business's building. Damage to and restoration of transportation, water, electric power, and other infrastructure systems will be important. Neighborhood effects may also affect the business's recovery -- a business that has survived a storm or earthquake intact may nonetheless suffer losses because neighboring businesses and buildings are heavily damaged, thus dissuading potential customers and reducing access to the site. Broader conditions of competition will also factor into recovery, as will be illustrated in the Kobe example below. Public policies such as disaster assistance mechanisms and resource flows also matter, as alluded to in the earlier discussion of oil spill trajectories.

Third, economic recovery is affected by decision-making. For a business, these may include predisaster actions such as business continuity planning, purchasing of insurance, and building retrofit investments. Post-disaster resilience actions also affect disaster recovery. Rose et al. (2007, 2011) modeled low-cost resilience responses to water and power outages, such as conservation and production recapture, and found that some actions could reduce business disruption by up to $90 \%$. Rapid relocation can also be effective, as demonstrated in the aftermath of 9/11 (Rose et al. 2009). Post-disaster recovery plans and policies can also have strong effects on recovery trajectories, as will be demonstrated in the Christchurch example below.

\subsection{Case: Port of Kobe}

The importance of context is strikingly illustrated in the case of the Port of Kobe, Japan (Chang, 2000). As with the city as a whole, the Port was devastated in the 1995 earthquake. Physical reconstruction was completed in two years; however, the Port has never fully recovered economically. In the year prior to the earthquake, Kobe had been the fourth largest container port in the world, based on cargo volume handled. In the year after it fully reopened, it was ranked 17th. Over a decade later, it was ranked 49th in the world (Chang, 2010).

This decline must be understood in historical, geographical, and competitive context (Chang, 2000). Kobe's relative decline in global standings was not initiated by the disaster, but rather, accelerated by it. In the 1970s, it had been the second-largest container port in the world. In the years prior to the earthquake, competing ports around Asia had been gaining ground, in part by developing new facilities. Moreover, the global geography of manufacturing had been shifting away from Japan, with rapid manufacturing and export growth in China and other Asian countries.

The Port of Kobe's experience is not unique, in the sense that disasters have frequently been observed to accelerate pre-disaster trends. For example, Okuyama (2014) found the Kobe earthquake to have accelerated the structural shift and "hollowing out" of the economy generally that had been ongoing prior to the disaster. In such a dynamic context, the process of economic recovery involves profound changes in economic structure and relations. The assumption of a stable economic structure as the baseline for estimating economic impacts does not hold. 


\subsection{Case: Christchurch Central Business District}

The difficulty of predicting economic recovery trajectories, and in particular the role of policy and decision-making, is further demonstrated with the case of the 2011 earthquake in Christchurch, New Zealand. Although there was extensive damage to buildings in the Christchurch central business district (CBD), the damage levels alone cannot explain the current state of the CBD in which, four years after the earthquake, the majority of commercial buildings have been demolished and not yet replaced. Many buildings were demolished that were physically repairable. Analysts have attributed this to several factors, including the central government's decision to cordon off the entire CBD immediately after the earthquake (the cordon was reduced over time and completely lifted in June 2013), the high level of insurance penetration in New Zealand, and the government's CBD redevelopment plan that calls for substantial changes to the downtown core, including a shrinking of the built area (Chang et al., 2014; Miles et al., 2014). In the meantime, businesses previously in the CBD have relocated, many to suburban areas. Many factors aside from building damage, such as businesses' networks, affected their recovery (Stevenson et al. 2014).

The Christchurch CBD experience is also not unique, in the sense that building damage levels have often been observed to correlate only loosely with economic disruption to the businesses that occupy the buildings. The assumption that physical damage leads directly and predictably to economic loss and recovery timeframes, which is commonly made in economic impact models of disasters, may not hold in large-scale disasters.

\section{Conclusions}

In sum, it is important but challenging to incorporate recovery into economic analysis of disaster risk reduction strategies. Building disaster-resilient communities requires risk reduction investments that consider not only limiting physical damage but also enabling rapid recovery. If the time-dependent economic impacts that accrue during disaster recovery are neglected, as shown in the Portland water case, economic analysis could easily lead to underinvestment in disaster risk reduction. The challenges derive from the many difficulties associated with predicting economic recovery trajectories, particularly over longer periods of time (e.g., years) and in very severe disasters.

Three recommendations are made here in the context of developing guidelines for incorporating recovery into economic analysis. First, guidelines should be developed for quantitatively addressing limited aspects of the problem. These should specifically pertain to short-run analysis that can consider economic disruption losses assuming that baseline economic structures remain unchanged. It is especially important to develop (and implement) such guidelines in the case of infrastructure systems, where the consequences of service disruption to the community vastly exceed the consequences to the infrastructure owners.

Second, systematic efforts should be made to gather and share empirical and modeled data on recovery trajectories. Building such an extensive knowledge base can help to develop and test new models of economic recovery. For example, a library of electric power restoration curves can help establish reasonable ranges for estimates of power outage under different disaster scenarios, which in turn can help develop guidelines for estimating the consequent economic disruption losses. 
Third, quantitative guidelines should be complemented with qualitative insights that may help decision-makers to interpret the outcomes of the analysis, recognizing many aspects of economic recovery that may be important (e.g., loss of market share) but not quantified. Unlike the engineering problem of designing structures to design levels of physical performance under given conditions, the interdisciplinary problem of fostering community disaster resilience is highly context-dependent, variable, and as yet poorly understood.

\section{References}

Burton, C.G., 2015, "A Validation of Metrics for Community Resilience to Natural Hazards and Disasters Using the Recovery from Hurricane Katrina as a Case Study," Annals of the Association of American Geographers, vol. 105, no. 1, pp. 67-86.

Chang, S. E., 2000, "Disasters and Transport Systems: Loss, Recovery, and Competition at the Port of Kobe after the 1995 Earthquake," Journal of Transport Geography, vol. 8, no. 1, pp. 53-65.

Chang, S. E., 2003, "Evaluating Disaster Mitigations: Methodology for Urban Infrastructure Systems," Natural Hazards Review, vol. 4, no. 4, pp. 186-196.

Chang, S. E., 2012, "Resilience to Coastal Disasters," presentation at 2012 AAAS conference, Vancouver, Canada.

Chang, S. E., 2010, "Urban Disaster Recovery: A Measurement Framework and Its Application to the 1995 Kobe Earthquake," Disasters, vol. 34, no. 2, pp. 303-327.

Chang, S. E. and N. Nojima, 2001, "Measuring Post-Disaster Transportation System Performance: The 1995 Kobe Earthquake in Comparative Perspective," Transportation Research Part A: Policy and Practice, vol. 35, no. 6, pp. 475-494.

Chang, S. E. and A. Z. Rose, 2012, "Towards a Theory of Economic Recovery from Disasters," International Journal of Mass Emergencies and Disasters, vol. 32, no. 2, pp. 171-181.

Chang, S. E., J. E. Taylor, K. Elwood, E. Seville, D. Brunsdon, and M. Gartner, 2014, "Urban Disaster Recovery in Christchurch: The Central Business District Cordon and Other Critical Decisions," Earthquake Spectra, vol. 30, no. 1, pp. 513-532.

Cochrane, H., 2004, "Economic Loss: Myth and Measurement," Disaster Prevention and Management, vol. 13, no. 4, pp. 290-296.

Liu, H., R.A. Davidson, and T.V. Apanasovich, 2007, "Statistical Forecasting of Electric Power Restoration Times in Hurricanes and Ice Storms," IEEE Transactions on Power Systems, vol. 22, no. 4, pp. 2270-2279.

Miles, S., D. Brechwald, R. Davidson, K. Demeter, D. Johnston, S. Pampanin, and S. Wilkinson, 2014, "Building Back Better: Case Study of the 2010-2011 Canterbury, New Zealand Earthquake Sequence," EERI, Oakland, CA.

Multihazard Mitigation Council (MMC), 2005. Natural Hazard Mitigation Saves: An Independent Study to Assess the Future Savings from Mitigation Activities. Washington, DC: National Institute of Building Sciences. Vol. 1 - Findings, Conclusions, and Recommendations.

Okuyama, Y., 2014, "Disaster and Economic Structural Change: Case Study on the 1995 Kobe Earthquake," Economic Systems Research, vol. 26, no. 1, pp. 98-117.

Rose, A., S. Liao and A. Bonneau, 2011, "Regional Economic Impacts of a Verdugo Earthquake Disruption of Los Angeles Water Supplies: A Computable General Equilibrium Analysis," Earthquake Spectra, vol. 27, no. 3, pp. 881-906. 
Rose, A., G. Oladosu, and S. Liao, 2007, "Business Interruption Impacts of a Terrorist Attack on the Electric Power System of Los Angeles: Customer Resilience to a Total Blackout," Risk Analysis, vol. 27, no. 3, pp. 513-531.

Stevenson, J. R., Y. Chang-Richards, D. Conradson, S. Wilkinson, J. Vargo, E. Seville, and D. Brunsdon, 2014, "Organizational Networks and Recovery Following the Canterbury Earthquakes," Earthquake Spectra, vol. 30, no. 1, pp. 555-575.

Wu, J., N. Li, W. Xie, Y. Zhou, Z. Ji, and P. Shi, 2014, "Post-Disaster Recovery and Economic Impact of Catastrophes in China," Earthquake Spectra, vol. 30, no. 4, pp. 1825-1846.

Xiao, Y. and U. Nilawar, 2013, "Winners and Losers: Analysing Post-Disaster Spatial Economic Demand Shift," Disasters, vol. 37, no. 4, pp.646-668. 
Section III.

Papers by Participants 
Asche, Elizabeth

\title{
The Nature of Resilience
}

\begin{abstract}
The concept of creating resilience is commonly thought of as beginning at the community level and building through the local, state, and federal levels. However, it may be more beneficial to consider creating and understanding resilience from different perspectives, such as the business and individual perspectives within the community before aggregating at the community level. Also, within government, people sometimes discuss the concept of resilience as a public good, and this may not be the most appropriate way to think about the concept. This paper focuses on providing a clearer understanding of the terms that are generally used to define and talk about resilience at the community level and above.
\end{abstract}

\section{Keywords}

Community, Economics, Disaster, Resilience, Public Good, Business.

\section{Defining Resilience}

The origin of the term resilience is often credited to ecologists, but its roots actually stretch far back into history across a wide variety of disciplines. ${ }^{18}$ The term has been used in psychology, engineering, and other fields; psychologists use it to describe human response to traumatic stress and engineers use it to describe the "bounce back" or return to normal of a system after an event or shock. Resilience definitions, although varied across disciplines, have a common theme: the ability of something or someone to resist and/or recover from a stressor.

The Department of Homeland Security (DHS) defines resilience in accordance with Presidential Policy Directive 21 as "the ability to prepare for and adapt to changing conditions, and withstand and recover rapidly from disruptions. Resilience includes the ability to withstand and recover from deliberate attacks, accidents, or naturally occurring threats or incidents." ${ }^{19}$ This definition leaves resilience open to interpretation because it is too broad and can be internally inconsistent. For example, an action that prepares a unique individual or business for changing conditions could adversely affect the surrounding community when the time comes for recovery.

When we talk about resilience, we need to clearly define the perspective or problem space. A resilient business will have different characteristics than a resilient residential neighborhood. The nature of resilience from a business perspective is fundamentally different than resilience from an individual homeowner's perspective. Therefore, from a government perspective, we need to consider different dimensions of resilience before aggregating these perspectives and creating community level solutions. Defining community resilience is an important first step in reaching these solutions.

\footnotetext{
${ }^{18}$ For a review of the term's history, see D.E. Alexander, "Resilience and disaster risk reduction: an etymological journey," Natural Hazard and Earth System Sciences, November 5, 2013.

${ }_{19}$ Presidential Policy Directive 21, "Critical Infrastructure Security and Resilience," The White House, February 12, 2013, 12.
} 


\section{Defining Community Resilience}

RAND defines community resilience as "a measure of the sustained ability of a community to utilize available resources to respond to, withstand, and recover from adverse situations." ${ }^{20}$ This straightforward definition is in keeping with the etymology of the word resilience, but in order to truly understand what it means, we still need an understanding of community. The Federal Emergency Management Agency (FEMA) suggests that community is comprised of at least individuals, businesses, and government in their description of a Whole Community Approach as an approach that "attempts to engage the full capacity of the private and nonprofit sectors, including businesses... and the general public, in conjunction with the participation of... government partners." ${ }^{21}$ Combining these two definitions, a possible working definition of community resilience could be "a measure of the sustained ability of businesses and the general public to utilize available resources to respond to, withstand, and recover from adverse situations. ${ }^{, 22}$

When discussing community resilience as a whole, it is important to understand that resilience from a business perspective may be in conflict with resilience from an individual perspective, even within the same community. As a concrete example, a business could invest in a structural measure that would make its factory less likely to experience flood damage, but would also change the hydrology of the surrounding land and increase flood risk to nearby homes. The consequence of this action would be a negative externality from the individual perspective, but positive from the business's perspective. This begs the question: what is the nature of resilience as a good?

\section{The Nature of Resilience as a Good}

In policy and other non-economic disciplines, resilience is sometimes discussed as a public good. A public good, as defined by economists, is one that is "non-rivalrous and non-excludible." The first aspect concerns the good's consumption: consumption by one individual does not change the cost or benefit to others consuming the good. The second aspect concerns the good's provision: the provider of the good cannot exclude others from enjoying its benefits. There are few true public goods; two examples often used are national defense and public parks. Table 1, shows a graphic that is typically be used when discussing natural resource economics. The table breaks goods into their "nature," for lack of a better word, and includes an example of each for explanation.

Resilience could be any of these types of goods (rivalrous or non-rivalrous/excludible or nonexcludible) from the individual or business perspective, which is in conflict with the idea of resilience as a public good. The characterizations of resilience in this context can give us some insight into the appropriate government action (if any) to ensure optimal provision.

\footnotetext{
${ }^{20}$ RAND Corporation, Community Resilience, http://www.rand.org/topics/community-resilience.html, accessed March 11, 2015.

${ }^{21}$ FEMA, "A Whole Community Approach to Emergency Management: Principles, Themes, and Pathways for Action," December 2011, 4.

${ }^{22}$ For simplicity, this paper considers only businesses, government entities, and individuals, but communities are comprised of more than these groups.
} 
Table 1. The Nature of Goods

\begin{tabular}{|l|l|l|}
\hline & Excludible & Non-Excludible \\
\hline Rivalrous & $\begin{array}{l}\text { Private Good } \\
\text { Clothing }\end{array}$ & $\begin{array}{l}\text { Common Pool Resource } \\
\text { Ocean Fishing }\end{array}$ \\
\hline Non-Rivalrous & $\begin{array}{l}\text { "Club" Good } \\
\text { Toll Road (no congestion) }\end{array}$ & $\begin{array}{l}\text { Public Good } \\
\text { National Defense }\end{array}$ \\
\hline
\end{tabular}

\section{Business Resilience}

Measures that enhance resilience from a business perspective can be both rivalrous and excludible, or neither. For example, a proprietary technology employed by the business's IT department could allow that company to come back online before any of its competitors. This is both rivalrous and excludible. On the other hand, a plan to shelter the community using business facilities in case of a disaster can be non-rivalrous and non-excludible. Rather than thinking about resilience as a good, we should think about the decision making process of a business that is trying to become more resilient.

In elementary economics, students learn about the representative firm and its constraints by studying the profit equation:

$$
\text { Profit }=\text { Revenue }- \text { Costs }
$$

While the equation is simplified here, it gives us a framework for considering a profit-motivated business's decisions; these businesses are expected to make choices that affect factors within this equation to increase profit by increasing revenues and decreasing costs. If a physical measure that enhances resilience from the business's perspective provides more benefit than cost, they will likely undertake that measure. On the other hand, a business may opt for leanness and reduce redundancies (or resilience) to minimize costs, relying on insurance in case of a hazard or disaster.

Similarly, revenue can be defined by the following equation:

$$
\text { Revenue }=\text { Price } \mathrm{x} \text { Quantity }
$$

In words, it is the price of the good or service that a business produces multiplied by the quantity of goods or services produced. For this discussion, it is assumed that any activity that makes a business more resilient and positively affects price or quantity produced, with all else being held equal, would be viewed as positive by the business because it would increase profit. An activity that reduced price or quantity with all else being held equal would decrease profit, and would likely be viewed negatively by the business.

The "cost" part of the equation above can be more complicated. Basically, cost includes any expenditure incurred in producing the good or service that the business sells. This could include wages multiplied by hours worked, taxes, interest on loans, rental or operating costs, insurance, and the purchase of intermediate goods or capital. Depending on the business, cost could also include other expenses in both the short and long term. It is also assumed in this discussion that any activity which makes a business more resilient and causes overall "cost" to decrease, holding all else constant, would be viewed as positive by the business because it would increase profit. 
Likewise, an investment in resilience that increased costs would need to be well justified in order for a business to make the investment and forgo profits.

Given the above construct, we can assume that the federal government has several options to ensure business resilience. ${ }^{23}$ First, it could attempt to encourage businesses to undertake measures that could affect the profit equation; it is possible that the government could have more information than the business on the nature of the threats or hazard the business faces, and could influence behavior by sharing information. Second, it could develop regulation defining and requiring resilience measures and force businesses to comply.

\section{Whole Community Resilience: not just the sum of its parts}

More research needs to be conducted into the nature of resilience from the perspective of disparate community parts. It is possible, if not probable, that business and individual resilience are at odds in some scenarios. This paper focused on the nature of resilience from the point of view of the business or firm, but a business is only one part of a community. Further research should be conducted to determine where the conflicts between individual and firm resilience arise and how to resolve these conflicts.

This paper has addressed two main points:

(1) Resilience should be considered from the different perspectives within a community before it is aggregated to the community level.

(2) Resilience should not be termed a public good, regardless of the perspective.

When we think about community resilience, we should consider the value to the parts of the community (business and individual) as well as the value or importance to the community as a whole. We also need to find and resolve conflicts between resilience in disparate parts of a community. Furthermore, we should be clear with the terminology that we use to describe resilience in order to avoid confusion or conflict.

\section{References}

Alexander, D.E. "Resilience and disaster risk reduction: an etymological journey." Natural Hazard and Earth System Sciences, November 5, 2013.

FEMA. "A Whole Community Approach to Emergency Management: Principles, Themes, and Pathways for Action." December 2011, 4.

Presidential Policy Directive 21, "Critical Infrastructure Security and Resilience." The White House, February 12, 2013, 12.

RAND Corporation, Community Resilience, http://www.rand.org/topics/communityresilience.html.

\footnotetext{
${ }^{23}$ This assumes that firms have a sub-optimal level of resilience from a government perspective. This has in no way been established; both the level of "resilience" in the private sector and the public are currently unknown.
} 
Ayyub, Bilal M., Athanasios A. Pantelous, and Jia Shao

\title{
Towards Resilience to Catastrophic Events: Financing Liabilities via Catastrophe Risk Bonds
}

\begin{abstract}
Catastrophic accidents include nuclear and chemical accidents, extreme storms, volcanic eruptions, pandemics, etc. For example, in light of the 2011 Fukushima disaster, recent discussion has focused on finding the best nuclear storage options, maximizing the oversight power of global institutions and strengthening safety measures. In addition to these, the development of dependable liability coverage that can be tapped in an emergency is also needed and should be considered thoughtfully. To succeed, financing is essential using special purpose instruments from the global bond market, which is as big as US\$175 trillion in 2015 dollars. Thus, in this paper, for the very first time, a two-coverage type trigger nuclear catastrophe (NCAT) risk bond for potentially supplementing the covering of US commercial nuclear power plants beyond the coverage per the Price Anderson Act as amended, and potentially other plants worldwide is proposed and designed. The N-CAT peril is categorized by three risk layers: incident, accident and major accident. The pricing formula is derived by using a semi-Markovian dependence structure in continuous time.
\end{abstract}

\section{Keywords}

Nuclear power risk, catastrophe risk bonds, global market, liability, special purpose vehicle, twocoverage type trigger, semi-Markov environment

\section{Introduction: Catastrophic Risk}

Catastrophic risk is defined as a hypothetical future event with the potential to inflict serious damage to human well-being on a large scale including crippling society. Such events include nuclear and chemical accidents, extreme storms, volcanic eruption, pandemics, etc. This paper focuses on nuclear accidents for the purpose of illustration and developing a framework for financing liability.

With a nuclear renaissance underway, the worldwide inventory of nuclear power plant (NPP) units is expected to increase from 439 to 508 (European Nuclear Society, 2015) with corresponding increases in net electric outputs as shown in Figure 1. Without accounting for the variation in nuclear technology, regulatory regimes, operators' experience and NPP units' ages, the worldwide probability of a catastrophic nuclear accident can be estimated as significantly greater than the levels provided by the Presidential Commission on Catastrophic Nuclear Accidents in 1990. The Fukushima and Chernobyl disasters of 2011 and 1986, respectively, provide empirical evidence for such levels (see Figures $2 \mathrm{a}$ and $2 \mathrm{~b}$ ). The underlying computations are approximate to allow for using simple multiplication to account for the increase in unit-years. Such computations yield acceptable accuracy for small probabilities; however as the probabilities increase, the use of stochastic processes would become necessary in order to enhance the numerical accuracy and maintain the axiomatic requirements of probability theory (Ayyub, 2003). These computations show catastrophic nuclear accidents could increase based on current practices, and growth in number of units and their ages as demonstrated in 
Figure 3. The curves in Figure 3 are based on the Presidential Commission on Catastrophic Nuclear Accidents of 1990 updated by the increase in NPP units, and are not updated to account for accidents occurred afterwards, such as the Fukushima and Chernobyl disasters. Also, they are not updated to account for improved monitoring, relicensing evaluations, retirements of older units, etc. A number of older units in the United States have been retired due to economic decisions by their operators. It can be argued that as the first generation units are retired, the industry safety could actually improve. And the new generation of plants coming on line as construction restarts would be modular and have increased safety levels.

Assessing the adequacy of liability coverage requires examining the consequences of historic and postulated nuclear accidents. Most notable nuclear accidents in the civil power sector include: the 1979 Three Mile Island in which the containment remained intact and resulted in 1993 US\$1 billion dollar cleaning-up cost performed over 14 years; and the 1986 Chernobyl disaster in the former Soviet Union resulting in 37 lives lost, about 5000 people with long-term effects, and US\$ 15 billion of direct loss. It is estimated that the damages could accumulate to US\$ 305 billion for Ukraine and US\$261 billion for Belarus in the thirty years following the Chernobyl accident. Various estimates of the total damage could be caused by accidents at nuclear power plants range from US\$110 billion to as much as US\$7 trillion (Raju and Ramana 2010).

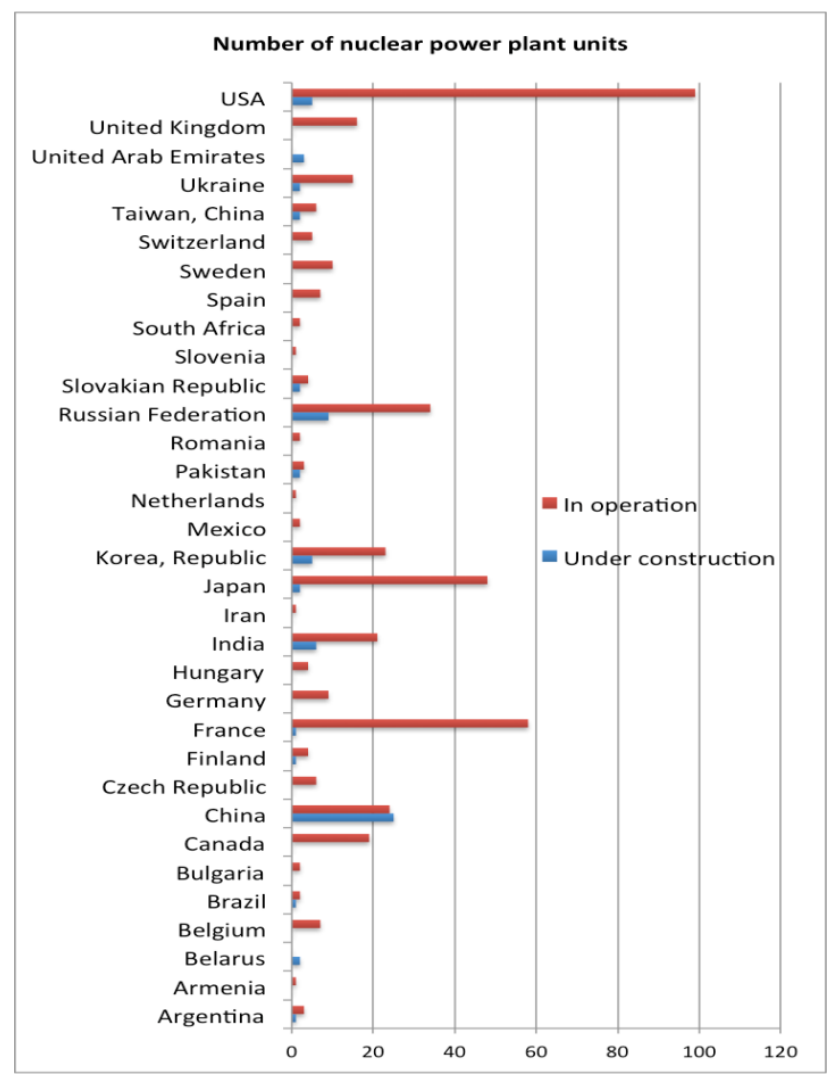

(a) Number of plant units



(b) Electric net output

Figure 1. Nuclear power plant units worldwide, in operation and under construction, as of March 10, 2015, (European Nuclear Society, 2015) 


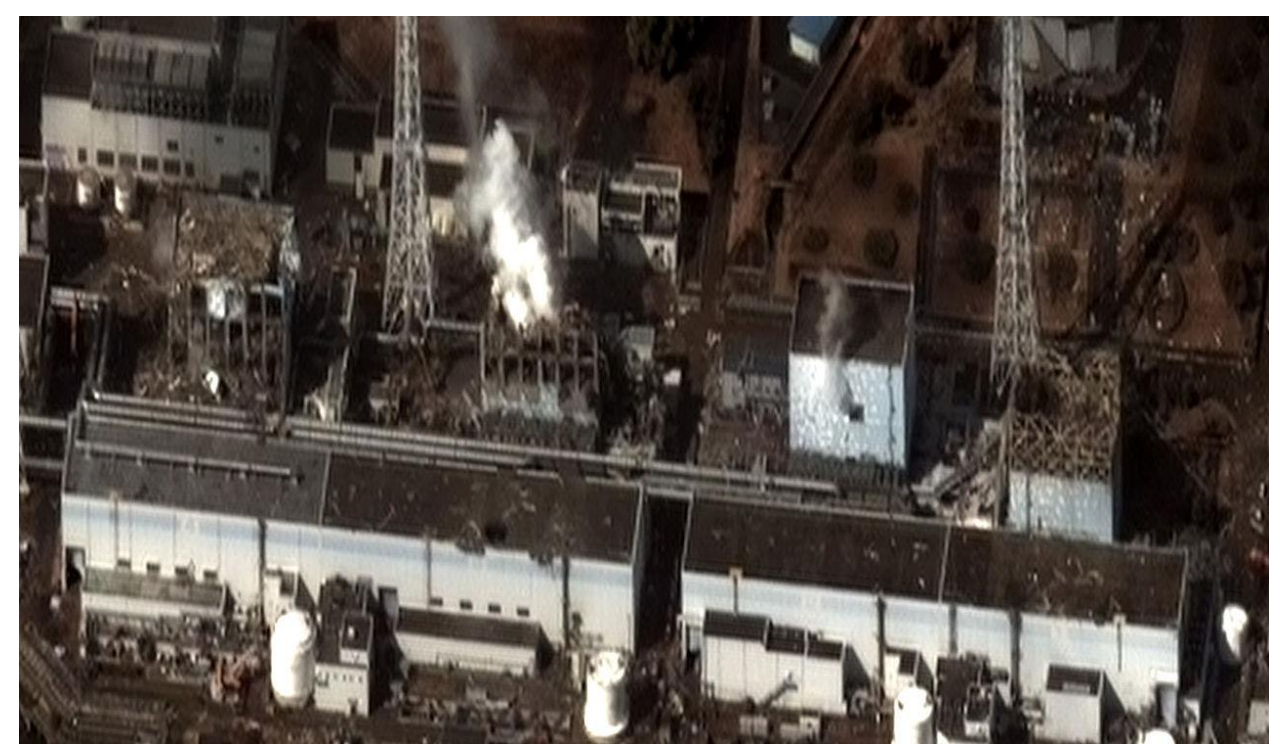

Figure 2 (a). Fukushima Daiichi nuclear disaster, 16 March 2011, showing the four tall damaged reactor buildings with much of the damage caused by hydrogen-air explosions, Fukushima, Japan Source: https://en.wikipedia.org/

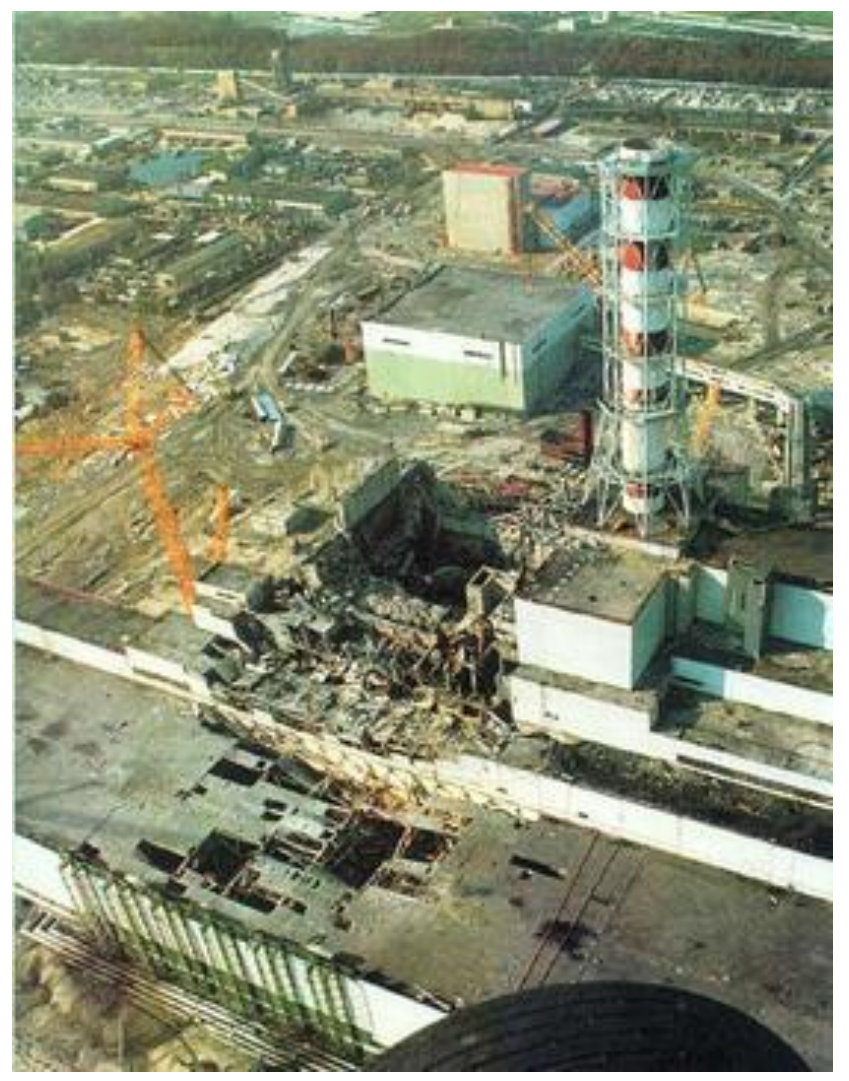

Figure 2 (b). The Chernobyl nuclear reactor after the disaster. Reactor 4 (center). Turbine building (lower left). Reactor 3 (center right), on 26 April 1986, Pripyat, (former Ukrainian SSR, Soviet Union) Source: https://en.wikipedia.org/ 


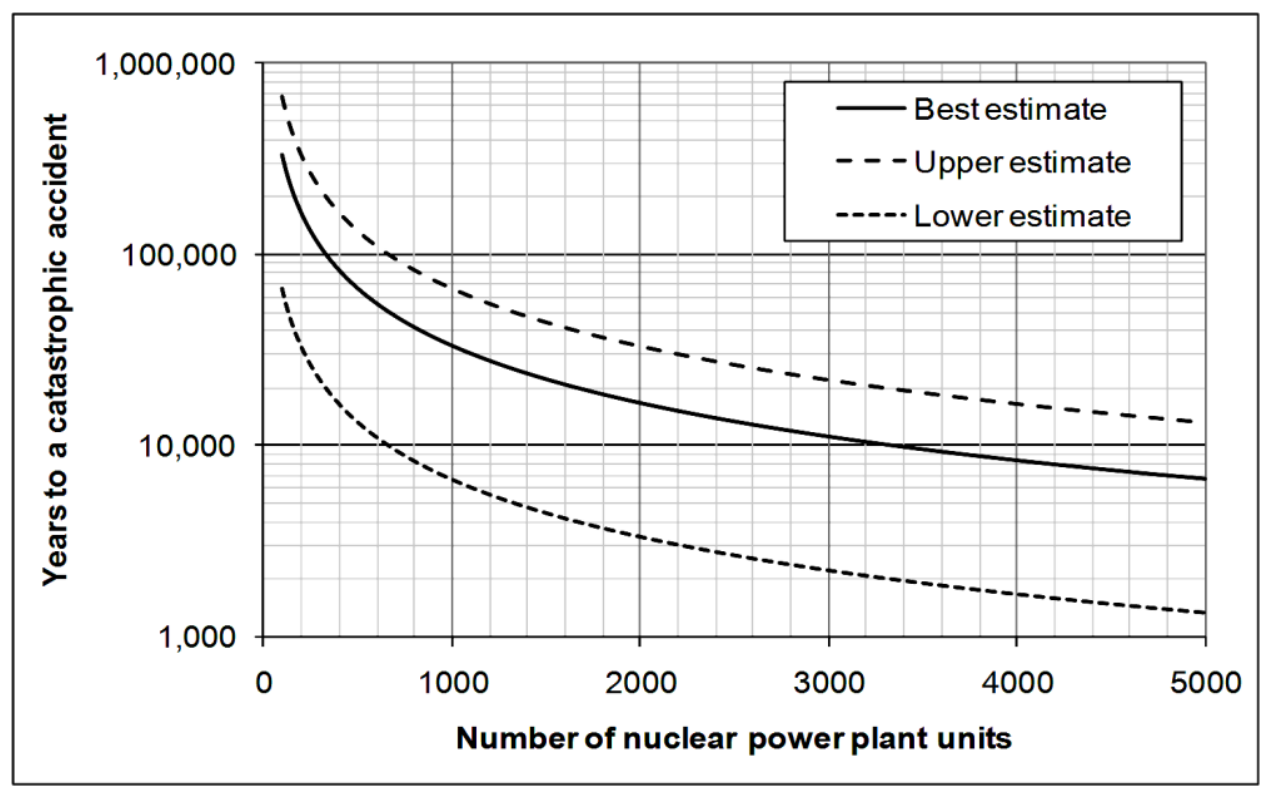

Figure 3. Time to a catastrophic nuclear accident as a function of the number of nuclear power plant units worldwide

\section{Liability Limitation Regimes}

As of 2015, thirty-three countries have 439 operating NPPs for civil purposes (see Fig. 1). Unlike the US, where the Price-Anderson Act governs nuclear liability, many other countries with established nuclear regimes are governed both by their own legislation, and by compliance with international conventions on civil nuclear liability (Balachandran, 2010 and ANI, 2013). The national regimes implement the conventions' principles, and impose the financial security requirements that vary from country to country. The thirty-three countries that possess NPPs can be grouped as follows:

- The first group includes those countries that are parties to one or more of the conventions, and which have their own legislative regimes. Prominent examples are France, Germany, Spain and the United Kingdom, all of which are parties to the Paris Convention (PC); and the Argentina and Romania, both of which are parties to the Vienna Convention (VC) and Revised Vienna Convention (RVC). Parties of the Brussels Supplementary Convention (BSC) must also be parties to the PC and Revised Brussels Supplementary Convention (RBSC, not yet in force), for example Finland, France and Germany. Since 1988, parties to the Joint Protocol (JP) are treated as if they are parties to both the VC and the PC. Seventeen countries have signed the Convention on Supplementary Compensation for Nuclear Damage (CSC), including Czech Republic, Canada, Romania, Ukraine and India, but most have not yet ratified it. In November 2014 Japan passed legislation to ratify the CSC. In total, twenty-two countries belong to this group and are party to one of the conventions.

- The second group includes those countries that are not parties to the conventions, but which have their own legislative regimes. Prominent examples are USA, Canada, Japan and Republic of Korea (South Korea). These countries impose strict liability on their nuclear 
installation operators. So they conform with the channeling requirements of the Paris and Vienna Conventions, despite not being parties to those conventions.

- The final group of countries neither being parties to the conventions nor having their own legislative regimes. Although these countries are relatively few, China is the most prominent example that has issued directives stating its position on nuclear liability, but has not yet developed a specific regime. China's nuclear liability directives were issued in 1986 as an interim measure in connection with the French-designed Daya Bay nuclear power plant. It contains most of the elements of the international nuclear liability conventions, e.g., channeling of absolute nuclear liability to the plant operator and exclusive court jurisdiction. Other countries in this group include Pakistan, with 3 NPPs. Pakistan is neither members of any international convention nor have any national legislation.

Table 1 provides a summary of the convention and membership by country.

In this paper, we presented so far exposures from the perspectives of the public, operators and government; however, what does all this mean for a designer, builder, or supplier? If the products or services are provided to a nuclear installation in a country subject to the PC or VC, the supplier likely does not need nuclear liability insurance. The supplier should not be held liable for damages resulting from a nuclear incident. Liability should be channeled to the facility operator.

The primary exposures (World Nuclear Association, 2015) for suppliers are, however, in countries with nuclear programs established and yet without being parties to the conventions, such as Japan, South Korea and Taiwan that have nuclear legislation with legally channels liability to the facility operator. These counter, however, do not adhere to international conventions, and the protection afforded a supplier might be considered as less secure than what the conventions guarantee due to jurisdiction related considerations.

Another source of exposure is what commonly referred to as cross-border liability. In this case, victims in countries, that are not parties to the conventions injured because of a nuclear incident in a convention-adhering country, bring claim against a supplier alleging that supplier's responsibility for the injury. The supplier might be held liable in such cases.

Additionally, an operator's available financial security is both finite and subject to market conditions. Although insurance or other financial security is to be available for each nuclear incident, in practice insurance might be available only for a specific time period. The absence of insurance does not relieve the operator of responsibility to maintain financial security. But the end result might be that victims seek recourse against a supplier, particularly one whose product or service arguably caused the victims' damages.

These exposures might necessitate suppliers to purchase their own insurance. The decision whether to purchase insurance often reflects how risk averse a supplier and its risk-management philosophy. The American Nuclear Insurers (2013) makes available a foreign Supplier's and Transporter's policy (called S\&T policy) for this purpose that indemnifies the insured for thirdparty bodily injury or property damage resulting from the nuclear energy hazard, which is defined as "the radioactive, toxic, explosive or other hazardous properties of nuclear material." The policy is continuous from inception until cancellation or termination, at which time the 
insured has ten years to report claims for damages that took place during the policy period. The policy's current maximum limit of liability is US\$50 million available in all insured countries except Japan, Mexico, South Africa, Spain and Sweden, where the available limit is US\$ 15 million because of reinsurance commitments. The policy excludes several countries for various reasons, most notably the United States (US), Canada, China, India and Russia. Other exclusions worth noting are: worker's compensation and employer's liability; contractual liability, other than a warranty of materials, parts or equipment; bodily injury or property damage arising out of any nuclear weapon, or resulting from nuclear material used for military purposes; bodily injury or property damage arising out of war; bodily injury or property damage arising out of a terrorist act; bodily injury or property damage arising out of any radioactive isotope; bodily injury or property damage with respect to which any government indemnity or avail insurance; property damage, including business interruption and loss of use, to any nuclear facility or to any property at the facility, arising out of nuclear material at the facility.

Table 1: Nuclear power countries and liability conventions to which they are party, [5].

\begin{tabular}{|c|c|c|c|}
\hline Countries & Conventions party to & Countries & Conventions party to \\
\hline Argentina & VC; RVC; CSC & Lithuania & VC;JP; (CSC signed) \\
\hline Armenia & $\mathrm{VC} ;$ & Mexico & $\mathrm{VC}$ \\
\hline Belgium & PC; BSC; RPC; RBSC & Netherlands & $\begin{array}{l}\text { PC; BSC; JP; RPC; } \\
\text { RBSC }\end{array}$ \\
\hline Brazil & $\nabla C$ & Pakistan & \\
\hline Bulgaria & $\mathrm{VC} ; \mathrm{JP}$ & Romania & VC; JP; RVC; CSC \\
\hline Canada & (CSC signed) & Russia & $\mathrm{VC}$ \\
\hline China & & Slovakian Republic & VC;JP \\
\hline $\begin{array}{l}\text { Czech } \\
\text { Republic }\end{array}$ & VC; JP; (CSC signed) & Slovenia & $\begin{array}{l}\text { PC; BSC; JP; RPC; } \\
\text { RBSC }\end{array}$ \\
\hline Finland & $\begin{array}{l}\text { PC;BSC; JP; RPC; } \\
\text { RBSC }\end{array}$ & South Africa & \\
\hline France & PC; BSC; RPC; RBSC & Spain & PC; BSC; RPC; RBSC \\
\hline Germany & $\begin{array}{l}\text { PC;BSC;JP; RPC; } \\
\text { RBSC }\end{array}$ & Sweden & $\begin{array}{l}\text { PC;BSC;JP; RPC; } \\
\text { RBSC }\end{array}$ \\
\hline Hungary & $\mathrm{VC} ; \mathrm{JP}$ & Switzerland & PC; RPC; BSC; RBSC \\
\hline India & $($ CSC signed)* & Taiwan, China & \\
\hline Iran & & Ukraine & VC; JP; (CSC signed) \\
\hline Japan & $\mathrm{CSC}$ & $\begin{array}{l}\text { United Arab } \\
\text { Emirates }\end{array}$ & RVC; CSC \\
\hline Kazakhstan & $\mathrm{RVC}$ & United Kingdom & PC;BSC; RPC; RBSC \\
\hline Korea & & United States & CSC \\
\hline
\end{tabular}

$\mathrm{PC}=$ Paris Convention (PC). RPC = 2004 Revised Paris Protocol. Not yet in force.

BSC $=$ Brussels Supplementary Convention. RBSC $=2004$ Revised Brussels Supplementary Convention. Not yet in force.

VC = Vienna Convention. RVC $=$ Revised Vienna Convention

$\mathrm{JP}=1988$ Joint Protocol.

CSC = Convention on Supplementary Compensation for Nuclear Damage (CSC), in force from 15 April 2015.

* India has not ratified CSC, and it is not clear whether their domestic liability law conforms with the requirements of the convention.

\section{Catastrophe (CAT) Risk Bonds}

Losses and recovery costs from catastrophic accidents are typically covered by a combination of utility companies, special insurance programs and/or governments. For example losses from the 2011 Fukushima disaster were covered primarily by the government of Japan. Resources for this purpose are often inadequate, and require a cash reserve that could be challenging to maintain. In emerging markets with nonexistent or immature legal regimes, liability could lead to international tensions and potentially wars particularly in cases of cross-border exposures. 
Using a catastrophic accident rate of $10^{-6}$ per year, 500 policies, and loss per accident of US $\$ 5$ trillion, and price of a policy for the breakeven point can be computed to be US\$10 000 per year. Obviously, an insurance model of this type would not sustain itself and would bankrupt upon the occurrence of the first catastrophic accident within the life of the present NNP population.

To succeed, financing is essential using special purpose instruments from the global market. Figure 4 provides an estimate of 2012 the global outstanding bonds and loans to be US\$175 trillion out of the total US\$225 trillion of capital stock (outstanding bonds, loans and equity) with stocks at US\$50 trillion. Despising 2008 financial crisis, global bonds and loans market is increasing consistently over the past twenty years from US\$45 trillion in 1990. In this paper, for the very first time, a catastrophe risk bond for financing nuclear liability is proposed based on a concept conceived by Ayyub and Parker (2011). The model is fashioned after the catastrophe (CAT) bond financial products, and similarly tied to the global bond market.

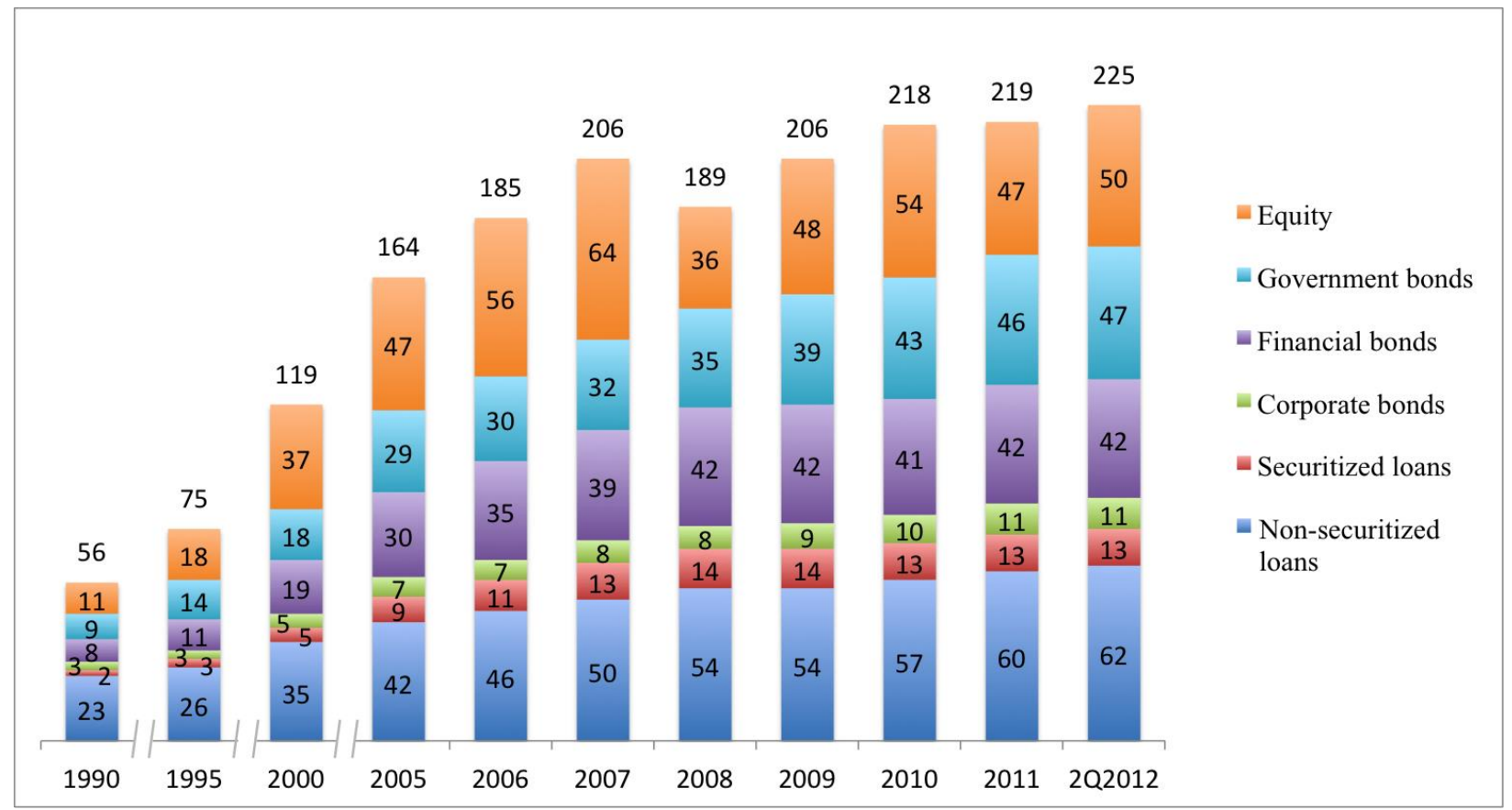

Figure 4. Global stock of debt and equity outstanding (Lund et al., 2013)

CAT risk bonds (or Act-of God bonds) are born for these extreme events and sharing the risk to another level - global financial market, which is the only pool of cash large enough to underwrite such losses lies in capital markets - the collection of big investors like pension funds, hedge funds and sovereign wealth funds that normally invest in stocks and bonds. It directly transfers the financial consequences of catastrophe events to capital markets, in contract to cover the possible huge liabilities through traditional reinsurance providers or governmental budgets. The first experimental transaction was completed in the mid- 1990s after the Hurricane Andrew and Northridge earthquake with insurance losses of US $\$ 15.5$ billion and US $\$ 12.5$ billion, respectively, by a number of specialized catastrophe-oriented insurance and reinsurance companies in USA, such as AIG, Hannover Re, St. Paul Re, and USAA, GAO (2002). Catastrophe bond market reached historical best record at US $\$ 7$ billion in 2007 compared with US $\$ 2$ billion placed during 2005, despite the financial crisis in 2008 and 2009. Then, issuers 
raised approximately US\$7 billion worth of new catastrophe bonds in 2013 (McGhee et al. 2008, Anger and Hum, 2014).

The CAT risk bonds are inherently risky, non-indemnity-based multi period deals that pay a regular coupon to investors at end of each period and a final principal payment at the maturity date if no predetermined catastrophic events have occurred. A major catastrophic event in the secured region before the CAT risk bond maturity date leads to full or partial loss of the capital. For bearing catastrophe risk, CAT risk bonds compensate a floating coupon of LIBOR plus a premium at rate between $2 \%$ and $20 \%$ (Cummins, 2008, GAO, 2002). In the literature, CAT risk bonds can be categorized into five basic trigger types: indemnity, industry index, modeled loss indices, parametric indices and hybrid triggers (Hagedorn et al., 2009, Burnecki et al., 2011). Issuers do not directly issue the CAT risk bond, but use special purpose vehicle (SPV) for this transaction. SPV can be interpreted as a focused insurer whose only purpose it is to write one insurance contract. The existence of SPV minimizes the cost of raising and holding capital and increases the confidence of the insurer that the fund will be available when needed. Furthermore, sufficient high endowment of the SPV eliminates the counterparty risk. Finally, the feature of correlation of the traditional stock market allows CAT bonds investors to still gain in a bad economic circumstance. CAT risk bonds reduce barriers to entry and increase the contestability of the reinsurance market (Froot, 2001).

\section{Nuclear CAT Bonds}

In the global financial market, nuclear CAT risk bonds are nonexistent, which specifically are designed for covering losses from nuclear disasters, like the 2011 Fukushima disaster.

Expanding the use of nuclear power, particularly in emerging markets, could contribute towards addressing global climate change and sustainability concerns. Nuclear CAT risk bonds covering nuclear related perils can facilitate this expansion. It shifts the liability to the market and helps this sector to grow through increased participation of various service and product providers. The presentence of catastrophe risks requires an incomplete markets framework to evaluate the CAT risk bond price, because the catastrophe risks cannot be replicated by a portfolio of primitive securities (Cox and Pedersen, 2000). Cox and Pedersen (2000) used a time-repeatable representative agent utility. Their approach is based on a model of the term structure of interest rates and a probability structure for catastrophe risks assuming that the agent uses the utility function to make choices about consumption streams. Finally, their theoretical structure and interesting findings have been applied to price the Morgan Stanley, Winterthur, USAA and Winterthur-style risk bonds. On the same page, Zimbidis et al. (2007) adopted the Cox and Pedersen (2000) framework for pricing a Greek bond for Earthquakes using equilibrium pricing theory with dynamic interest rates. Extensions involving a multi financial and catastrophe risks framework were investigated by Shao et al. (2015a), with applications to a structured multiperiod coupon earthquakes CAT risk bond. Lee and Yu (2002) additionally introduced default risk, moral hazard, and basis risk with stochastic interest rate. Shao et al. (2015b) constructed a model using a Markov-dependent environment as an extension of the approach of Ma and Ma (2013), and employ the dependency between the claims sizes and the claim inter-arrival times.

Previous literature focused on one type of coverage (either per-occurrence or annual aggregate). In this paper a nuclear perils focused CAT risk bond with two-coverage type is proposed. An example of multi coverage type CAT risk bond is Residential Reinsurance $2012 \mathrm{Ltd}$. on behalf of 
USAA, which provide per-occurrence coverage for the all perils and also provides coverage on an annual aggregate basis.

\section{Two Coverage Type Trigger Nuclear CAT bond}

According to The International Nuclear Event Scale (INES) [24], events are classified on the Scale at 7 levels, which can be categorized by three risk layers: incident (level 1 to 3), accident (level 4 to 6) and major accident (level 7). Figure 5 provides example risk perils for each layer. In this paper, a nuclear CAT risk bond, termed N-CAT risk bonds, covered all nuclear power plants (104 operating reactors) in US which triggers are determined by the losses due to each peril is modeled. An incident is defined to include, for instance, failures in safety provisions and lost or stolen highly radioactive sealed source, where the event with insignificant off-site impact and affordable in-site impact. An accident includes the release of radioactive material, cost of fitting a core machine, etc., which has severe in-site and off-site impact. A major accident is defined to include nuclear reactor core failure with widespread health and environmental effects, such as 2011 Fukushima disaster with total economic losses to US\$210 billion.

\section{Major accident (level 7)}

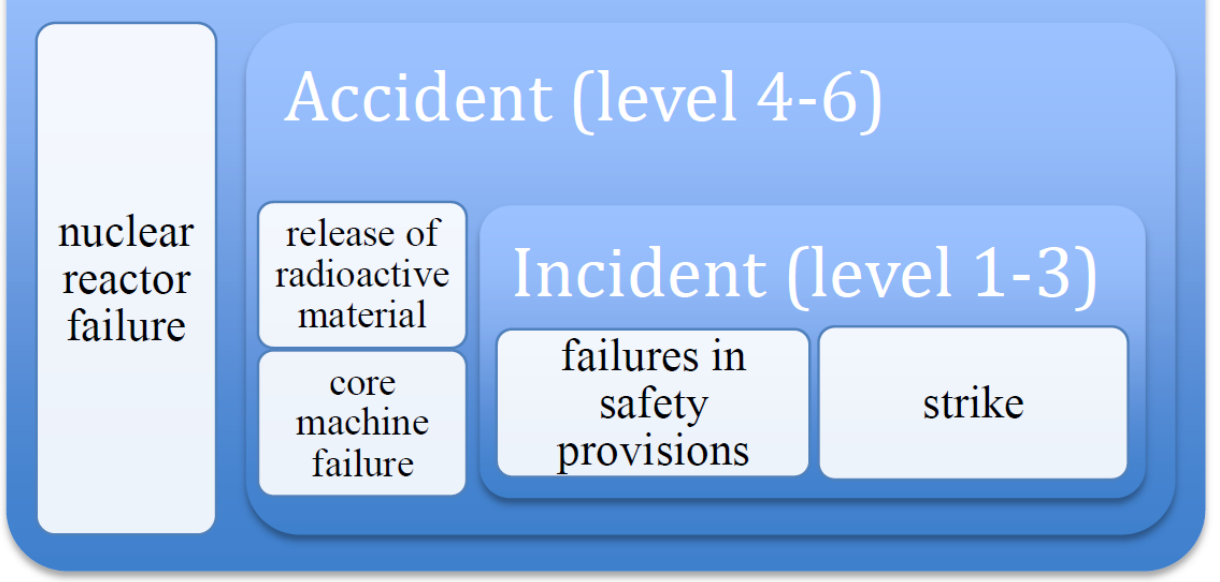

Figure 5. The nuclear power risks 


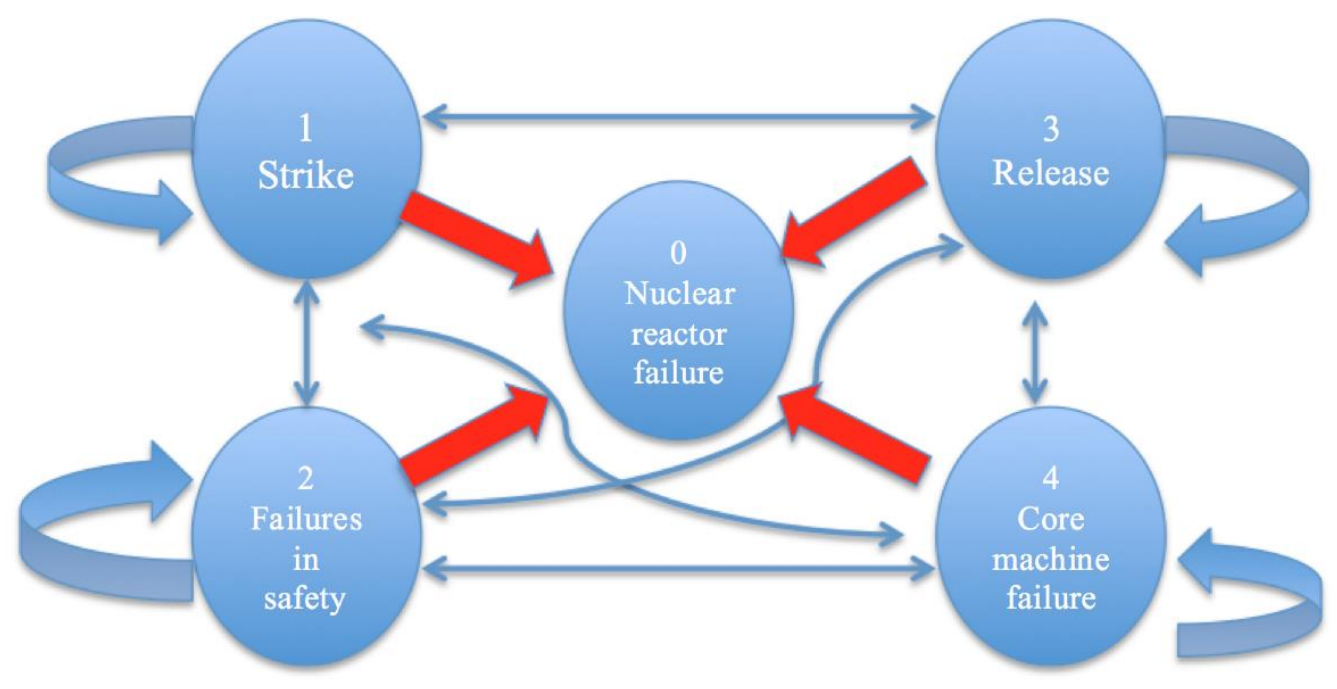

Figure 6. Possible states changes of the system

Consider a semi-Markovian dependency structure in continuous time on a complete probability space $(\Omega, \mathcal{F}, \mathbb{P})$, where the process $\left\{J_{n}, n \geq 0\right\}$ represents the successive type of claims or environment states, which take their values in $\{0,1,2,3,4\}$. For notation convenience, we denote $J^{\prime}=\{1,2,3,4\}$, therefore, $J=\{0\}+J^{\prime}$.

Here states $J$ ' called work of the system which refers to the minor and intermediate risks, and state 0 is the failure of the system and refer to the nuclear reactor failure risk in this case.

Define $\left\{X_{n}, n \geq 1\right\}$ as a sequence of successive claim sizes from all 104 NPPs in US, $X_{0}=$ 0 a.s. and $X_{n}>0, \forall n$, and $\left\{T_{n}, n \in N+\right\}$ is the epoch time of the $\mathrm{n}^{\text {th }}$ claim. Suppose that $0<T_{1}<T_{2}<\ldots<T_{n}<T_{n+1} \ldots, T_{0}=U_{o}=0$ a.s., and $U_{n}=T_{n}-T_{n-1}\left(n \in N^{+}\right)$ denotes the sojourn time in the state $J_{n-1}$. Also, $\{N(t), t \geq 0\}$ is the total number of claims occurring on time $(0, t]$.

Moreover, assume that the embedded Markov Chain $J_{n}$ is ergodic and that a sequence of unique probabilities $\left(\Pi_{1}, \ldots, \Pi_{4}\right)$ exists, which represents the stationary probability distribution, $\Pi_{1}+$ $\cdots+\Pi_{4}=1$ and $\Pi_{1}, \ldots, \Pi_{4} \in[0,1]$. Assuming that the Markov chain jumps to state $j$ at each claim instance with a claim size distribution of $F_{j}(D)=\mathbb{P}_{j}\left(X_{k} \leq D\right)$, where $D$ is a pre-defined threshold level.

In order to price the catastrophe risk bond, we start by defining a hypothetical of zero coupons $\mathrm{CAT}$ bond at the maturity date with face value $\mathrm{Z}$ :

- If at expiring time $T, L(T)=\sum_{k=1}^{N(t)} X_{k} \geq D(D \geq 0)$ and $J_{k} \neq 0(\forall k)$, bond holder will loss part of their capital and receive $p_{1} Z$;

- If a major accident (state 0 event) $\left(J_{n}=0\right)$ occurs before the expiry date $T, N$-CAT bond expire immediately and bond holder will receive partial of their principle $p_{2} Z$;

- Otherwise bond holder will receive Z.

Formally, the payoff function described above is given mathematically by 


$$
P_{C A T}=\left\{\begin{array}{c}
Z, \text { for } L(T) \leq D, \text { and } J_{k} \neq 0, \\
p_{1} Z, \text { for } L(T)>D, \text { and } J_{k} \neq 0 \\
p_{2} Z, J_{k}=0 .
\end{array}\right.
$$

Cox and Pedersen (2000) suggested that the payoff function is independent of the financial risks variable (interest rate) under the risk-neutral measure $\mathbb{Q}$. Then, after some rigorous mathematical calculations which are omitted, we have the value formula of the CAT bond, which is given by

$$
\begin{aligned}
& V(t)=\mathbb{E}^{\mathbb{Q}}\left(e^{-\int_{t}^{T} r_{s} d s} P_{C A T}(T) \mid \mathcal{F}_{t}\right)=\mathbb{E}^{\mathbb{Q}}\left(e^{-\int_{t}^{T} r_{s} d s} \mid \mathcal{F}_{t}\right) \mathbb{E}^{\mathbb{Q}}\left(P_{C A T}(T) \mid \mathcal{F}_{t}\right) \\
& =B_{C I R}(t, T) Z\left[p_{1}+\left(1-p_{1}\right) \sum_{i=1}^{4} \sum_{j=1}^{4} \Pi_{i} \sum_{n=0}^{\infty} \int_{0}^{t}\left(1-H_{j}\left(t-t^{\prime}, \infty\right)\right) d \mathbb{Q}_{i j}^{* n}\left(t^{\prime}, D\right)\right. \\
& \left.+\left(p_{2}-p_{1}\right) \sum_{i=1}^{4} \Pi_{i} \sum_{n=1}^{\infty} \mathbb{Q}_{i 0}^{* n}(t, D)\right],
\end{aligned}
$$

where $i, j \in\{1, \ldots, 4\}, B_{C I R}(t, T)$ is the pure discounted bond price with the CIR interest rate model (Shao et al. 2015b), and

$$
H_{j}(t, \infty)=\mathbb{P}\left(U_{n} \leq t \mid J_{0}, \ldots, J_{n-1}=j\right), \text { and } \mathbb{Q}_{i j}^{* n}=\mathbb{P}\left(J_{n}=j, T_{n} \leq t, L_{n} \leq x \mid J_{o}=i\right),
$$

where $L_{n}$ is the total loss of the first $n$ claims. One can value this $n$-fold convolution matrix recursively.

\section{Conclusions and Future Research}

In this paper, for the very first time, a two-coverage type trigger nuclear catastrophe (N-CAT) bond is proposed for financing nuclear liability, which can be categorized by three risk layers: major accident, accident and incident. In the Global CAT risk bond market, a similar trigger peril of a total size of US $\$ 400$ million has been proposed recently by Residential Reinsurance 2012 Ltd. (Series 2012-2) (see Artemis, 2012) for covering U.S. hurricane, U.S. earthquake, U.S. severe thunderstorm, U.S. winter storm and California wildfire. After the 2011 Fukushima disaster, the development of dependable liability coverage that can be tapped in an emergency is of significant importance in the many countries with significant number of NPPs. For instance, with 104 operating reactors, the U.S. has a total of about US $\$ 12$ billion in coverage (as of 2011) (U.S. Nuclear Regulatory Commission, 2011) before congressional authorization for additional funding estimating the damage due to a catastrophic accident from US\$110 billion to as much as US\$7 trillion.

The accurate pricing of such type of bonds is always a challenging issue, as the presentence of catastrophe risks requires an incomplete markets framework, because the catastrophe risks cannot be replicated by a portfolio of primitive securities (Cox and Pedersen, 2000). In the case of an incomplete market, there is no universal pricing theory that successfully addresses issues such as specification of hedging strategies and price robustness. In our case, the pricing formula is derived by a semi-Markovian dependence structure in continuous time where the claim interarrival times are dependent on the claim sizes. Another challenging aspect is the estimation of the parameters involved in the model as the collection of historical data for losses due to 
catastrophic events in commercial NPPs is rather limited, which makes the accuracy of the pricing method even more challenging. Additionally, the analysis of the impact of N-CAT risk bonds-specific variables on premiums is also a very interesting question, and particularly considering complexity in terms of the number of insured peril types or regions. Finally, it is useful to investigate how the future nuclear disasters (especially in emerging markets, like China and India) and financial crises might affect N-CAT bond premiums and demand.

\section{Acknowledgements}

The authors would like to acknowledge the gracious support of this work through the EPSRC and ESRC Centre for Doctoral Training on Quantification and Management of Risk and Uncertainty in Complex Systems and Environment. The first author acknowledges the financial support of the national Security Analysis Department at the Applied Physics Lab of the Johns Hopkins University during his sabbatical leave from the University of Maryland, College Park.

\section{References}

Anger, C. and Hum, C. 2014, Catastrophe bond update: Fourth quarter 2013. Guy Carpenter \& Company.

American Nuclear Insurers 2013, Need for Foreign Nuclear Liability Insurance, Glastonbury.

Artemis 2012, Residential Reinsurance 2012 Ltd. (Series 2012-2) http://www.artemis.bm/deal_directory/residential-reinsurance-2012-ltd-series-2012-2/

Ayyub, B. M., and Parker, L. "Financing Nuclear Liability," Science, 334, 16 December 2011, 1494.

Ayyub, B. M. 2003, Risk Analysis in Engineering and Economics, Chapman and Hall/CRC Press, Boca Raton, FL, http://www.amazon.com/Analysis-Engineering-Economics-BilalAyyub/dp/1584883952

Balachandran, G. 2010, The Civil Nuclear Liability Bill, Institute for Defense Studies and Analyses, IDSA Brief No. 26, Development Enclave, Rao Tula Ram Marg, New Delhi, http://idsa.in/system/files/ib_CivilNuclearLiabilityBill.pdf.

Burnecki, K., Kukla, G. and Taylor, D. 2011, Pricing of catastrophe bonds. In Statistical Tools for Finance and Insurance, pages 371-391. Springer.

Cox, S.H. and Pedersen, H.W. 2000, Catastrophe risk bonds. North American Actuarial Journal, 4(4):56-82.

Cummins, J. D. 2008, Cat bonds and other risk-linked securities: State of the market and recent developments. Risk Management and Insurance Review, 11(1):23-47.

European Nuclear Society, Nuclear Plants, World-wide, 2015, www.euronuclear.org/info/encyclopedia/n/nuclear-power-plant-world-wide.htm

Froot, K. A., 2001, “The Market for Catastrophe Risk: A Clinical Examination," Journal of Financial Economics, 60, 529-571.

GAO. CATASTROPHE INSURANCE RISKS: The Role of Risk-Linked Securities and Factors Affecting Their Use. Gao-02-941, 2002.

Hagedorn, D., Heigl, C., Mueller, A. and Seidler, G. 2009, Choice of triggers. The Handbook of Insurance-Linked Securities, pages 37-48.

Lee, J.-P. and Yu, M.-T. 2002, Pricing default-risky cat bonds with moral hazard and basis risk. Journal of Risk and Insurance, 69(1):25-44.

Lund, L., Daruvala, T., Dobbs, R., Härle, P., Kwek, J.-H. and Falcón, R., 2013, Financial globalization: Retreat or reset? McKinsey\&Company. 
http://www.mckinsey.com/insights/global_capital_markets/financial_globalization

Ma, Z.-G. and Ma, C.-Q. 2013, Pricing catastrophe risk bonds: A mixed approximation method. Insurance: Mathematics and Economics, 52(2):243-254.

McGhee, C., Clarke, R. Fugit, J. and Hathaway, J. 2008, The catastrophe bond market at yearend 2007: The market goes mainstream. Guy Carpenter \& Company, LLC.

Raju, S., and Ramana, M.V., 2010, The Other Side of Nuclear Liability, Economics \& Political Weekly, XLV, 16.

Shao, J., Pantelous, A.A. and Papaioannou, A. 2015a, Catastrophe risk bonds with application to California earthquakes. European Actuarial Journal, to appear.

Shao, J., Papaioannou, A. and Pantelous, A.A. 2015b. Pricing and simulating CAT bonds in a Markov-dependent environment. Preprint.

World Nuclear Association 2015, Liability for Nuclear Damage, (updated July 2015). http://www.world-nuclear.org/info/Safety-and-Security/Safety-of-Plants/Liability-forNuclear-Damage/

United States Congress from the Presidential Commission on Catastrophic Nuclear Accidents in 1990 Rasmussen's comparison of WASH-1400 and NUREG-1150, http://www.state.nv.us/nucwaste/news/rpccna/pcrena12.htm

U.S. Nuclear Regulatory Commission 2011, "Fact for foreign nuclear liability insurance" (www.nrc.gov/reading-rm/doc-collections/fact-sheets/funds-fs.html)

Zimbidis, A.A., Frangos, N.E. and Pantelous, A.A. 2007, Modeling earthquake risk via extreme value theory and pricing the respective catastrophe bonds. ASTIN bulletin, 37(1):163-183. 
Ballen, Debra

\title{
Economics of Community Disaster Resilience: An IBHS Perspective
}

\begin{abstract}
IBHS has identified the following five concepts as central to the economics of community disaster resilience: 1) the importance of "going green and building strong"; 2) residential and commercial building performance; 3 ) emergency preparation and response as a shared responsibility; 4) building codes as a threshold, but not end goal; and 5) the need for a variety of public and private sectors incentives.

Keywords

Adaptation, disaster resistance, preparation, mitigation, building codes, FORTIFIED, incentives
\end{abstract}

\section{Background}

The Insurance Institute for Business \& Home Safety (IBHS) is a 501(c)(3) organization, wholly supported by the property (re)insurance industry. IBHS conducts objective, scientific research to identify and promote effective actions that strengthen homes, businesses, and communities against natural disasters and other causes of loss. IBHS does this by identifying and advocating improved property design, construction, strengthening, maintenance, repair, and preparation practices.

The centerpiece of our research program is the IBHS Research Center in Chester County, South Carolina. It is the only laboratory of its kind in the world. Using a 105-fan array and other specialized equipment, IBHS engineers can recreate a variety of highly realistic wind, rain, fire and hail events. The ability to mimic Mother Nature in a controlled, repeatable way allows IBHS to demonstrate the effectiveness, affordability and financial value of stronger building codes and better-built structures; identify effective solutions to building vulnerabilities; strengthen the relationship between theoretical and real building performance; and validate/improve current scientific bases for designing and installing building products and systems. Our goal is to translate the results of this research into better public policy and market-based approaches to mitigation, in order to provide the most cost-effective protection possible across America. Achieving this goal will transform the built environment as well as significantly improve social and economic preparation for and response to extreme events - moving our nation toward true resilience.

\section{Key IBHS Resilience Concepts}

1 . Both "going green" and "building strong" are important

Increasingly, the related concepts of adaptation, mitigation, and resilience are being promoted as a proactive means of preparing for and responding to extreme events at the local, regional, and national levels, including the potential effects of climate change. While IBHS strongly supports this goal, the reality is that communities across the U.S. are not prepared for the severe weather and other extreme events that confront them today. Each year, natural disasters cause widespread damage, destroy communities, and leave states with mountains of debris that will eventually end up in landfills. The American Institute of Architects estimates that 25 percent to 40 percent of 
solid waste results from construction/reconstruction debris, much of it from structures that are destroyed by severe weather or other disasters (AIA, 2008).

Recognizing that sustainable, or "green," building practices are intended to provide meaningful environmental benefits, these practices must not inadvertently compromise a business's resistance to natural hazards, such as high winds, earthquakes, floods, or wildfires. According to research conducted by FM Global, benefits gained from green construction and energy efficiency can be negated by a single fire event. This is due in part to the carbon dioxide and other greenhouse gases generated when combustible material burns, as well as the carbon associated with the disposal of burned materials. High volume water streams used to extinguish fires also create run-off that may be contaminated by debris or toxic chemicals (Wieczorek, 2011).

Another area of concern relates to so-called "green" roofs (roof gardens that may contain shade trees, ornamental plants, grass, and vegetable gardens). From an environmental perspective, green roofs may improve air quality and reduce energy consumption, but they also can become fuel for a wildfire or projectiles during a hurricane or tornado. Additionally, the weight that green elements add to a roof may be further increased following torrential rains or due to water flows from fire-fighting operations, leading to full or partial collapse of the roof and the subsequent failures of load bearing walls and the floors below.

In fact, green building and disaster resistant construction can and should work in tandem to reduce greenhouse gas emissions, reduce air and water pollution, and improve the carbon footprint of individual businesses and their communities. For example:

- Building owners working toward LEED certification should make sure their design includes elements in each category that improve disaster resistance.

- Whether or not owners are seeking LEED certification, they should follow environmentally focused site selection criteria (e.g., LEED, IGCC, or another appropriate standard) to help reduce adverse environmental impacts and mitigate against flood and hurricane damage.

- It is important to understand how various green design features, such as a roof or solar panels, will perform in the face of the natural hazards in a particular region.

- It is also important to design and install green features in a hazard-appropriate manner e.g., proper bracing and the attachment of light-weight insulation, such as foam sheathing, in parts of the building that may face wildfire risk or have to withstand high winds.

- The process of inspecting for energy efficiency improvements offers the opportunity to identify disaster resistance gaps as well. For example, sealing energy leaks that are found through an inspection can help make a building both more air tight (hence more energy efficient) and more water tight (thus eliminating or reducing water intrusion). Similarly, it is easy and cost-effective to choose new windows and doors that are both energy efficient and disaster resistant.

$\underline{\text { 2. Both residential and commercial building performance must be a central tenet of resilience }}$

Resilience is a holistic concept encompassing land use, agriculture, energy policy, infrastructure, evacuation plans, disaster communications, and a wide range of other imperatives. Without 
diminishing the importance of each element of this equation, it is important to underscore that stronger residential and commercial building performance is a key feature of resilient communities.

Housing is a basic necessity of life and the cornerstone of every community. Even after the recent housing and mortgage crisis, owning a home is still the American dream for many and a potential source of physical and financial security. In explaining her decision to strengthen her home to better withstand natural disasters (by building to resilience standards of the IBHS FORTIFIED Home ${ }^{\mathrm{TM}}$ designation), one Alabama homeowner noted "I am confident that our home will not only make it through the next storm, but that it will be here long after we are gone; we are leaving a legacy.’'(IBHS accessed in 2015)

Likewise, the level of resilience in the business sector is inextricably linked to a community's economic vitality as it recovers from an extreme event. Business continuity planning and structural hardening are essential to protecting the job base and tax revenue. In many communities, small business is the dominant private sector employer. According to a report by the Council on Finance, Insurance and Real Estate (CFIRE) of the National Institute of Building Science (NIBS), small commercial buildings (defined as less than 50000 square feet) comprise a significant portion of the nation's commercial building stock, both by number and area (93.9 percent and 49.5 percent, respectively (NIBS, 2015)). Additionally, approximately 50 percent of the working population is employed by a small business (SBA, 2012) many of which are housed in small commercial buildings; such structures may not be highly engineered or have trained building safety experts on staff. Widely cited statistics indicate that at least one in four businesses that close for more than 24 hours because of a disaster never reopens, causing job losses and sapping a community's economic vitality.

Testing of residential and commercial structures at the IBHS Research Center confirms that using the right construction materials and installing them correctly greatly reduces storm damage to buildings and associated disruption to the people and businesses that occupy them. Operationalizing these research results is critical to building resilience.

\section{Emergency preparation and response is a shared responsibility}

Emergency preparation and response involves a range of proactive steps needed to protect people and property from physical and economic damage should disaster strike, as well as those to be taken directly following an extreme event. This is not solely within the purview of government emergency managers; rather, it is a shared responsibility among the people who live and work in every community. Not having a plan, or a having poorly prepared or misunderstood plan, could lead to disorganized preparation or confused response, with the possibility of mass injury or death.

While the specifics of emergency planning vary depending on the type and severity of the hazard, every home and business emergency plan should focus first on life safety, and include protections such as emergency contact numbers, shelter in place strategies including supplies, evacuation plans and routes, and plans for how to locate family members or employees after an event. Additionally, for storms and other natural hazards that allow for advanced notice, there are 
specific damage mitigation actions that should be taken five days, three days, one day, and immediately before, during, and after an event.

Public/private partnerships can play an important role in emergency planning and response. For example, local authorities can work with a variety of trusted private sector organizations including chambers of commerce, individual employers, houses of worship, and non-profits - to reach out to their constituents to underscore the urgency of being prepared, heeding evacuation warnings, and how best to shelter in place. It is especially important to include vulnerable populations in these outreach efforts, and make sure that their needs are taken into account for community-wide planning. These same public/private partnerships can play an important role in speeding and facilitating recovery, particularly if they gain trust during an emergency.

\section{$\underline{4 .}$ Building codes are a starting point of community resilience}

Building codes are the minimum acceptable regulatory standard used to regulate design, construction, and maintenance of residential and commercial structures for the purpose of protecting the health, safety and general welfare of building users. Strong codes - and adequate enforcement - play a vital role in public safety and loss prevention, which can reduce the need for public disaster aid and increase a community's resilience. Codes also establish predictable, consistent minimum standards that help assure the quality of construction materials, products and systems used in buildings.

Without minimizing the importance of building codes, it is important to recognize that they are consensus documents drafted through input from a wide range of parties. While they appropriately focus on life safety protection, it is both possible and practicable to use more resilient, hazard-specific design, materials, and installation in the construction and renovation of residential and commercial buildings - on a voluntary basis, beyond what is required by building codes. This is the predicate of the IBHS FORTIFIED program, which combines building science "best practices" with a third-party verification process designed to make sure that designated structures really are built to the science-based design and construction standards that underlie FORTIFIED. Homes built to these standards are expected to incur significantly less damage from natural disasters, protecting lives and livelihoods, reducing economic damage, and improving communities' ability to withstand and recover quickly from disasters.

In order to operationalize resilience, the U.S. Department of Homeland Security (DHS) created a new pilot program called Resilience STAR ${ }^{\mathrm{TM}}$ designed to encourage construction and retrofitting of homes to become more disaster-resistant. Resilience STAR is modeled after the successful ENERGY STAR® program, which recognizes superior energy efficiency in homes, commercial buildings, and a wide range of products. DHS chose the IBHS FORTIFIED program as the technical basis for a Gulf Coast Resilience STAR pilot project, which was conducted in 2014. The pilot built upon the strong, grassroots commitment to resilience that has been nurtured in Alabama and Mississippi coastal communities devastated by Hurricane Katrina. The goal of voluntary programs such as FORTIFIED and Resilience STAR is to create the same consumerdriven market demand for stronger building as has lifted automobile safety standards beyond regulatory requirements. 
5 . A variety of incentives are needed to encourage steps toward resilience

Although there is general consensus among mitigation experts on steps needed to improve community resilience, a gap between identification and implementation of solutions remains. One way to close this gap is through development of public and private sector incentives to encourage mitigation at all levels. To date, there have been only sporadic federal, state, and local attempts (largely through grant programs) to reduce or offset the cost of individual mitigation measures. For example, the South Carolina Safe Home program provided grant money to individual homeowners to make their property more resistant to hurricane and high-wind damage (http://scsafehome.com/).

While some of these programs have achieved specific goals, they are not coordinated, and have been too narrowly drawn to lead to widespread transformation and a nation of resilient communities. For this to occur, there must be a broad recognition at the federal level of the social, economic, and environmental imperatives of reducing our nation's collective vulnerability and controlling the scale of loss from natural disasters. The goal should be to invest more, and more wisely, in pre-disaster mitigation in order to spend less in post-disaster recovery assistance (often in an unplanned, inefficient manner). Improving the hazard resistance of structures against known and commonly predicted events, rather than putting the same brittle buildings back in the same vulnerable places once again after catastrophe strikes, would be smarter spending of taxpayer dollars at all levels of government.

Many people look to the property insurance industry to provide mitigation incentives and incorrectly assume that these alone will motivate action and offset the costs of more resilient homes and businesses. There is indeed a role for insurance discounts - for example, both Alabama and Mississippi require insurers to file discounts for homes that are built to the IBHS FORTIFIED standard discussed above, through programs administered by the state departments of insurance. These requirements have proved workable because insurers have confidence in the technical standards and the verification process that underlie FORTIFIED, and they believe that the regulatory requirements have been administered fairly.

While there are other publicly available examples of insurer incentives provided to policyholders who have undertaken proven mitigation improvements, there also are legal and financial impediments to the concept of insurance incentives as a transformative agent. From a legal perspective, insurers are subject to antitrust laws that prohibit them from coordinating underwriting or pricing strategies. They also are subject to rate regulatory constraints and other regulatory requirements (such as mandatory residual market participation) which in many states undermine the principles of risk-based underwriting or pricing that is critical to incentivizing resilience. Additionally, the disaster-related component of most property insurance policies is relatively small, and consequently, the potential savings from applying resilience incentives are limited. Finally, when considering the concept of community resilience, it is important to understand that private insurers are concerned about the risk characteristics of specific homes or businesses, not those of the community as a whole, and thus not generally in a position to offer discounts to home or business owners simply for living/operating in "resilient communities."

Despite these constraints, insurers will continue to play a leading role in encouraging and incentivizing resilience. But it is also imperative to broaden the range of stakeholders who 
incorporate resilience into their financial models by bringing together a wide range of business and financial interests, including banks, utilities, bond rating companies, and investments firms, noting that "the crux of this effort is to make resilience in the built and natural environment part of each stakeholder's approach to asset management, and conducting business and community operations." Achieving this goal is a key milestone in the transformation to community resilience.

\section{Conclusion}

The economics of community disaster resilience are compelling, at the individual, neighborhood, and community, state, and national levels. All of these pieces must be attended to, with compelling incentives for action by home and business owners, as well as public policymakers and other stakeholders in the built environment. Truly resilient communities will invest in the both pre- and post-event strategies discussed above (along with others). Such investments will pay tremendous dividends by significantly reducing the human, social, and financial costs related to extreme weather.

\section{References}

American Institute of Architects (AIA). Construction Waste Management Strategies, 2008. Available at http://www.aia.org/aiaucmp/groups/secure/documents/pdf/aiap072739.pdf, Accessed on October 19, 2015.

Insurance Institute for Business \& Home Safety (IBHS). Homeowner testimonial about IBHS' FORTIFIED Home program. www.disastersafety.org/fortified-main/fortified-home/, Accessed on October 19, 2015.

National Institute of Building Sciences (NIBS). Financing Small Commercial Building Energy Performance Upgrades: Challenges and Opportunities, 2015. Available at http://c.ymcdn.com/sites/www.nibs.org/resource/resmgr/CC/CFIRE_CommBldgFinanceFinal.pdf.

Small Business Administration (SBA), Frequently Asked Questions, 2012. Available at https://www.sba.gov/sites/default/files/FAQ_Sept_2012.pdf, Accessed on October 19, 2015.

Wieczorek, CJ "Fire Safety: An Integral Part of Sustainability" in Fire Protection Engineering Magazine, October 1, 2011. Available at http://magazine.sfpe.org/fire-protection-design/firesafety-integral-part-sustainability. 
Bellomo, Doug, and J. Rolf Olsen

\title{
Economics of Community Disaster Resilience: Four Orders of Resilience Written in Terms of Risk
}

\begin{abstract}
This paper proposes a general framework for measuring resilience through the use of common definitions and a straight-forward equation for risk. Building from these definitions and the risk equation, four orders of resilience are proposed. First order resilience is an object or system's ability to withstand a stress and by definition does not include any time for recovery. Second order resilience is a measure of both the systems deformation and its ability to recover to a prestress state. Third order resilience is an integration of different second order resilience values over a single threat of various magnitudes and fourth order resilience is a measure of the system or objects ability to withstand and recover from a variety of different threats. Use of a common framework for measuring resilience across a wide variety of fields will allow for meaningful comparisons, tracking over time, and ultimately aid in helping government officials, business owners, and the broader public make more informed risk management decisions.
\end{abstract}

\section{Keywords}

Risk, Resilience, Measurement, Framework, Management

\section{Background}

Many different professions are talking about "increasing resilience" - from those in the economic arena, to those involved in social vulnerability, as well as environmental organizations. Resilience has become a key factor for disaster planning. The Subcommittee on Disaster Reduction in its Grand Challenges for Disaster Reduction said "Communities must break the cycle of destruction and recovery by enhancing their disaster resilience" and "disaster resilience must become inherent to our national culture and a natural right of all people"(1). The United Nations International Strategy for Disaster Reduction promotes building the resilience of nations and communities to disasters. ${ }^{(2)}$ The Department of Homeland Security National Infrastructure Protection Plan includes resiliency strategies as part of the risk management of critical infrastructure and key resources. ${ }^{(3)}$ Despite the extensive use of the term resilience, there is limited to no agreement on a common framework for measuring "resilience" from a technical perspective. This paper proposes a general framework to measure resilience across a wide variety of fields which will allow for meaningful comparisons, tracking over time, and ultimately to aid in making informed risk management decisions.

\section{Resilience Defined}

There are multiple definitions of resiliency in the academic literature, but it is useful to define resiliency as it is commonly used by the public and decision-makers. Below are definitions from two different authoritative sources:

American Heritage Dictionary -

1. The ability to recover quickly from illness, change, or misfortune; buoyancy.

2. The property of a material that enables it to resume its original shape or position after being bent, stretched, or compressed; elasticity. 


\section{Collins English Dictionary -}

1. Also called resiliency the state or quality of being resilient.

2. (Life Sciences \& Allied Applications / Environmental Science) Ecology the ability of an ecosystem to return to its original state after being disturbed.

3. (Physics / General Physics) Physics the amount of potential energy stored in an elastic material when deformed

The above definitions as well as others in literature generally describe "resilience" as both the ability to withstand and to recover from a force. For the purposes of this paper and the general framework proposed, resilience will be defined as:

"the ability of an object or system to withstand and recover from a stress without any external assistance."

To break the words down further an "object" would be anything that is uniform in nature that is something singular not having multiple parts. A "system" would be anything made up of multiple parts that are inter-related and work together. A "stress" is something that would cause damage or decreases the value of the object or system. Importantly, "without external assistance" helps set the bounds for the system or object being investigated. This means all components assisting in recovery from an impact must be included as part of the system; however, all objects and systems will likely have a "breaking point" beyond which they cannot snap back without some external assistance.

There are a wide variety of definitions of resiliency in government and academic literature. The Subcommittee on Disaster Reduction and the United Nations International Strategy for Disaster Reduction both define resiliency as "the capacity of a system, community or society potentially exposed to hazards to adapt, by resisting or changing in order to reach and maintain an acceptable level of functioning and structure" (UN/ISDR, 2006).

Haimes defines resilience as "the ability of the system to withstand a major disruption within acceptable degradation parameters and to recover within an acceptable time and composite costs and risks." ${ }^{(4)}$ Hollings ${ }^{(5)(6)}$ distinguishes between engineering and ecological resilience. He says engineering resilience "concentrates on stability near a steady state" and resilience is based on a speed of return to that state. Ecological resilience, on the other hand, is measured by the "magnitude of disturbance that can be absorbed before the system changes its structure."(6) Wang and Blackmore noted three interdependent aspects of resilience: 1) crossing a performance threshold, 2) response and recovery after disturbance, and 3) adaptive capacity. ${ }^{(7)}$

Resiliency has also been defined mathematically. Hashimoto et al defined resiliency in terms of how quickly a system is likely to recover or bounce back from failure once a failure has occurred. If $T_{F}$ is the length of time a system's output remains unsatisfactory after a failure, the resiliency of a system can be defined as the inverse of the expected value of $T_{F}{ }^{\left({ }^{(8)}\right.}$

Another mathematical definition was given by Bruneau et al. ${ }^{(9)}$ The loss of resilience $R$ given a specific event "can be measured by the size of the expected degradation in quality (probability of failure), over time (that is, time to recovery)." ${ }^{,(9)}$ The mathematical definition of the loss of resilience is 


$$
R=\int_{t_{0}}^{t_{1}}[100-Q(t)] d t
$$

where $Q(t)$ is the quality of the infrastructure at time $t$.

Chang and Shinozuka defined resilience as the "probability that the system of interest will meet predefined performance standards $A$ in a scenario seismic event of magnitude $i$, or $\operatorname{Pr}(A \mid i)$. ."(10) They further defined broad system resilience $\left(Z_{A}\right)$ across the entire range of seismic scenario events:

$$
Z_{A}=\sum_{i}[\operatorname{Pr}(A \mid i) \operatorname{Pr}(i)]
$$

This paper will build on these mathematical definitions to develop a holistic framework for evaluating resilience for disaster planning and risk management. Mathematical definitions of different orders of resilience will be given.

\section{Proposed Model}

Four orders of resilience are proposed. The first order of resilience is an object or system's ability to withstand a stress and by definition does not include any time for recovery. It can be thought of as a systems deformation given a stress without any bounce back. Second order resilience would include bounce back over a specified time horizon from the point of impact.

Third order resilience is an integration of different second order resilience values over a single threat of various magnitudes (event horizon). For example, if flooding is the threat, floods of different magnitudes would be imposed onto the system (or object) each resulting in a second order resilience value for a consistent time horizon. Plotting second order resilience values against flood magnitude and then integrating under that line would yield a third order resilience value for the threat of flooding.

Fourth order resilience is a simple average of third order resilience values over multiple threats or hazards. For example, the third order resilience of flood, fire, wind, and earthquake would be averaged to yield a fourth order natural hazard resilience value given those hazards and a specified time horizon.

\subsection{Integrating Risk and Resilience}

In its simplest form, the risk equation is written as the product of the probability of something negative happening and the consequences of that event. Risk for an event is commonly written as:

$$
\text { Risk }=\text { Probability of the event } \mathrm{x} \text { Consequences of the event }
$$

Because risk is thought of as the potential for loss (the opposite being "opportunity"), consequences can be re-written as the value of something before the "event" minus the value after the "event" where the event can be an instantaneous impact or force, or it can be stretched out over time to include the recovery phase after impact. Regardless it can be written as:

$$
\text { Consequences }=\text { Value Before Event }- \text { Value After Event }
$$


Importantly, "value" can take on many different units of measure. Value can be measured in dollars, population (thus lives lost), acres of habitat, jobs, the percentage of children attending school, widget production rate, and many more.

Given the previous written definition of resilience, this expression of consequences, and the fact that "value" can be measured in a variety of units, any meaningful measurement of resilience would need to be non-dimensional. Therefore the most straightforward expression for resilience is:

Resilience $=$ Value After Event $/$ Value Before Event

Given this expression, resilience would take on values between 0 and 1 , where 0 means nothing of value remains after the event and 1 means nothing is lost as a result of the event. Numbers greater than 1 would suggest the "event" is an opportunity not a risk.

The Value After the Event is equal to the Value Before the Event minus the consequences (or loss in value), so resilience can be re-written as:

Resilience $=($ Value Before Event - Consequences of the event $) /$ Value Before Event

Consequences therefore can be written in terms of resilience and plugged back into the risk equation:

$$
\begin{aligned}
& \text { Consequences = Value Before Event x }(1-\text { Resilience }) \\
& \text { Risk = Probability of the event x [Value Before an Event x }(1-\text { Resilience })]
\end{aligned}
$$

The term ( 1 - Resilience) can also be thought of as "vulnerability". When vulnerability equals 0 , resilience equals 1 , thus the risk is zero. When vulnerability equals 1 , resilience equals 0 , and loss is complete.

\subsection{First Order Resilience}

Since first order resilience $\left(\mathrm{R}_{1}\right)$ does not involve recovery of the system, it can be written as:

$$
\mathrm{R}_{1}=\text { Value After Impact / Value Before Impact }
$$

or mathematically, if $\mathrm{V}_{0}$ is the value of a measure before the event and $\mathrm{V}_{\mathrm{e}}$ the value of the measure after the event. The first order resilience is:

$$
\mathrm{R}_{1}=\frac{\mathrm{V}_{\mathrm{e}}}{\mathrm{V}_{0}}
$$

Using a simple investment example (as shown in Figure 1), say a stock is worth $\$ 10$ before a possible spike in materials prices and it's estimated to be $\$ 6$ after the spike. In that case, the stock would have a first order resilience against a spike in materials prices of $6 / 10=0.60$. 


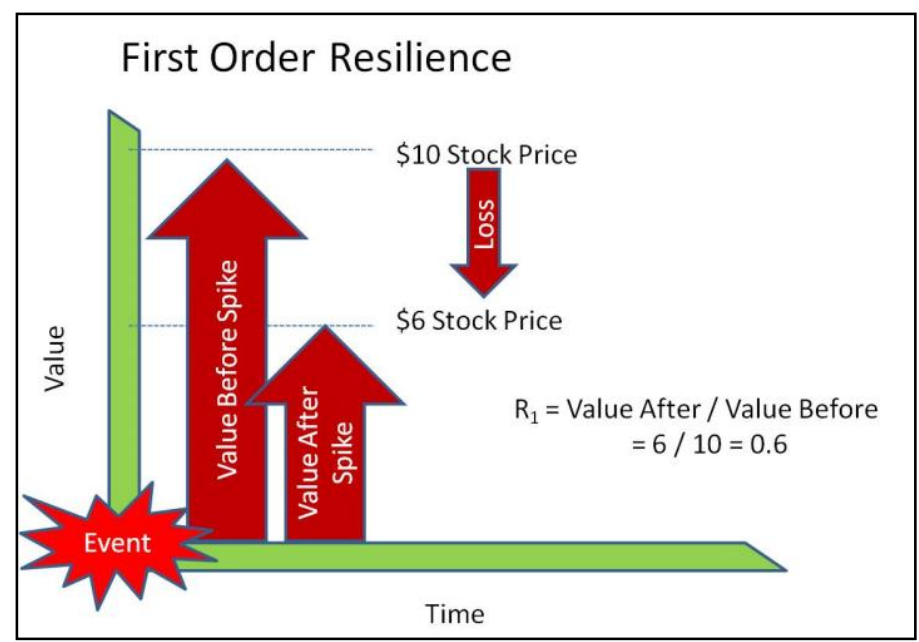

Figure 1 - First Order Resilience

\subsection{Second Order Resilience}

Second order resilience $\left(\mathrm{R}_{2}\right)$ includes within the value calculation the amount of recovery from the initial impact over a given time horizon. In other words, the "event" is stretched out over time to include bounce back or recovery along with initial impact.

$$
\mathrm{R}_{2}=\text { Value With Event / Value Without Event (over a given time horizon) }
$$

Let $V(t)$ be the value of the measure at time $t$ after the event and $t_{r}$ the time until full recovery, then

$$
\mathrm{R}_{2}=\left[\int_{\mathrm{t}_{0}}^{\mathrm{t}_{\mathrm{r}}}\left[\mathrm{V}_{0}-\mathrm{V}(\mathrm{t})\right] \mathrm{dt}\right] /\left[\mathrm{V}_{0} \mathrm{t}_{\mathrm{r}}\right]
$$

The second order resilience can be determined at any time following the event. If $t_{h}$ is an arbitrary time horizon, then the second order resilience at time $t_{h}$ is

$$
\mathrm{R}_{2}\left(\mathrm{t}_{\mathrm{h}}\right)=\left[\int_{\mathrm{t}_{0}}^{\mathrm{t}_{\mathrm{h}}}\left[\mathrm{V}_{0}-\mathrm{V}(\mathrm{t})\right] \mathrm{dt}\right] /\left[\mathrm{V}_{0} \mathrm{t}_{\mathrm{h}}\right]
$$

The example in Figure 2 below is one of factory output before and after a flood. Area 1 in dark blue is the "Value With Event" which includes recovery. Area 2 is the "loss triangle" and is essentially the lost value due to the event. The "Value Without Event" is Area $1+$ Area 2. Therefore,

$$
\begin{aligned}
\mathrm{R}_{2} & =(\text { Value Without Event }- \text { Loss Triangle }) / \text { Value Without Event } \\
& =(1000 \times 1500-1 / 2 \times 600 \times 1500) / 1000 \times 1500=0.70
\end{aligned}
$$




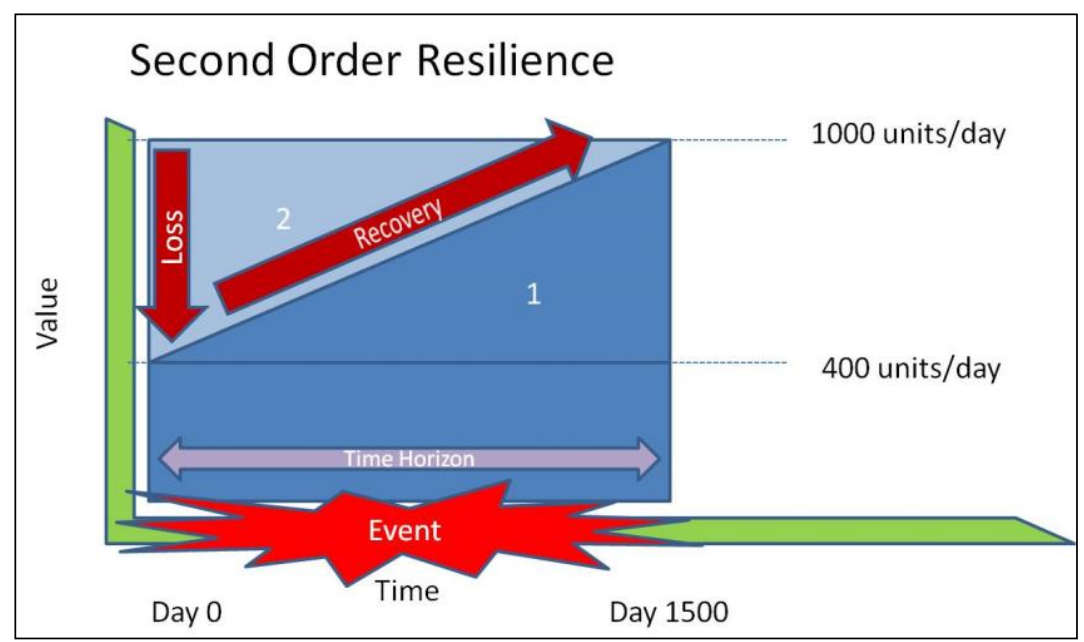

Figure 2. Second Order Resilience

When a consistent time horizon is used, the value of $\mathrm{R}_{2}$ can be shown to increase when initial impact is decreased, time to recovery is reduced, or a combination of both occurs. Note the importance of selecting a consistent and representative time horizon when computing multiple values of $\mathrm{R}_{2}$ for comparative purposes.

In a linear example like this, arbitrarily shortening the time horizon increases the "loss triangle" size relative to the total value (thus decreasing resilience) whereas increasing the time horizon will diminish the size of the "loss triangle" relative to the total value (thus increasing resilience). In order to equitably compare two factories or the effect a factory modification or change in response procedures might have on resilience, a consistent time horizon must be used. Given decision makers are often interested in understanding the time to full recovery for the current system, it may make a good time horizon to choose.

Figure 3 below demonstrates this more clearly. Both factory 1 and factory 2 have the same $\mathrm{R}_{2}$ value when different time horizons are considered (500 days and 1500 days), yet clearly the factory that recovers more quickly (along dark dashed line) is more resilient. Using either 500 days or 1500 days as a consistent time horizon solves this issue allowing a meaningful comparison. Further, using a consistent time horizon across a variety of threats or hazards of different magnitude allows for a computation of third order resilience. 


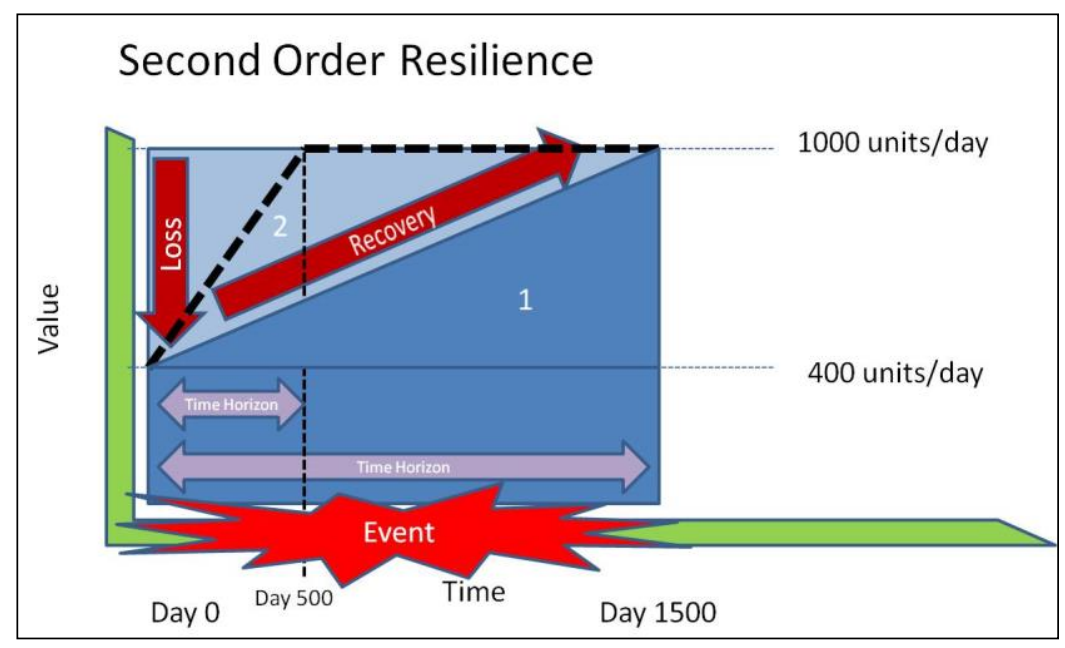

Figure 3. Second Order Resilience Comparison

\subsection{Third Order Resilience}

Third order resilience is the integration of $\mathrm{R}_{2}$ over the same threat or hazard but having different magnitudes. If comparison of $\mathrm{R}_{3}$ values are being performed, it is important to maintain a consistent "event horizon" (family of event magnitudes) for the same reason selecting a consistent "time horizon" is for comparing $\mathrm{R}_{2}$ values. Another similarity in this regard is the potential for arbitrary increases in $R_{3}$ by using many small events which have $R_{2}$ values of 1 . Doing this will disproportionately increase $\mathrm{R}_{3}$. Conversely, including multiple events which result in $\mathrm{R}_{2}$ values of 0 will disproportionately decrease $\mathrm{R}_{3}$

Using Figure 4 below, third order resilience $\left(R_{3}\right)$ is Area $1 /$ (Area $1+$ Area 2$)$. The greater $R_{3}$, the more resilient the system is against the threat for the selected family of events.

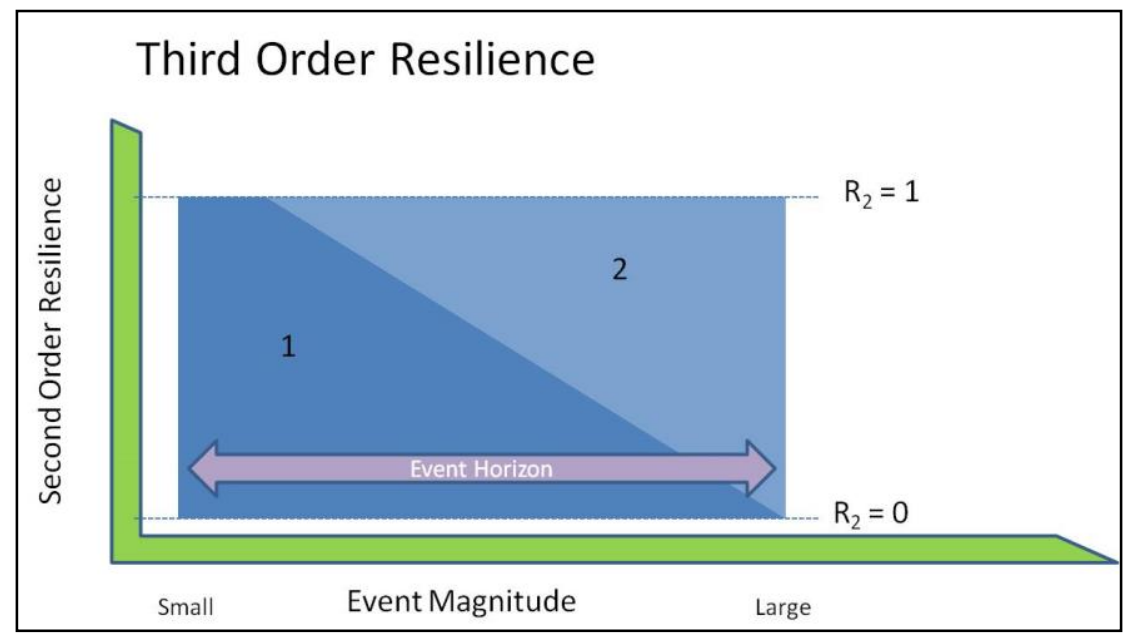

Figure 4. Third Order Resilience

Let the event magnitude be Q; as an example, the event magnitude could be the discharge for a flood. The second order resilience is a function of the magnitude $Q: R_{2}(Q)$ and would decrease with the size of $\mathrm{Q}$, since there will be a larger initial impact and a longer recovery time for a larger Q. Let $\mathrm{M}$ be some arbitrarily large event magnitude where the second order resilience is close to zero. 


$$
R_{3}=\left[\int_{0}^{M} R_{2}(q) d q\right] / M
$$

In practicality integrating the second order resilience over a large range of event magnitudes is infeasible. The third order resilience would be approximated by summing the second order resilience over a range of representative event magnitudes from small to very large, as shown in the figure below.

$$
\mathrm{R}_{3}=\left[\sum_{0}^{\mathrm{M}} \mathrm{R}_{2}\left(\mathrm{q}_{\mathrm{i}}\right)\right] / \mathrm{M}
$$

The event magnitude can be related to a probability of occurrence as shown in Figure 5. If $F(Q)$ is the cumulative distribution function of event $Q$ and $R_{2}(Q)$ is the second order resilience of $Q$, then the third order resilience can be calculated as

$$
\mathrm{R}_{3}=\sum_{0}^{\mathrm{M}}\left[\mathrm{R}_{2}\left(\mathrm{q}_{\mathrm{i}}\right)\left(\mathrm{F}\left(\mathrm{q}_{\mathrm{i}}\right)-\mathrm{F}\left(\mathrm{q}_{\mathrm{i}-1}\right)\right]\right.
$$

When a very broad range of possible event magnitudes are considered, $\mathrm{R}_{3}$ might be thought of as describing the degree of adaptation against the specific threat being analyzed. The closer $\mathrm{R}_{3}$ is to 1 , the more adaptable it is. In other words, the system or object has been shown to withstand a multitude of events from small to large without experiencing a significant loss in value making it highly resilient and thus in all likelihood highly adaptable.

\subsection{Fourth Order Resilience}

The third order resilience can be calculated for different types of threats, such as flood, earthquakes, fire and wind. If $\mathrm{R}_{3}$ is calculated using probabilities for each threat and the threats are assumed to be mutually exclusive, the fourth order resilience can be averaged across threats.

$$
\mathrm{R}_{4}=\left[\sum_{\mathrm{s}=1}^{\mathrm{S}} \mathrm{R}_{3}(\mathrm{~s})\right] / \mathrm{S},
$$

where $s=1,2, \ldots \mathrm{S}$ are the threats considered. For example, given $\mathrm{R}_{3}=0.75$ for floods; 0.85 for earthquakes; 0.65 for fire; and 0.95 for wind -

$$
\mathrm{R}_{4}=(0.75+0.85+0.65+0.95) / 4=0.80
$$




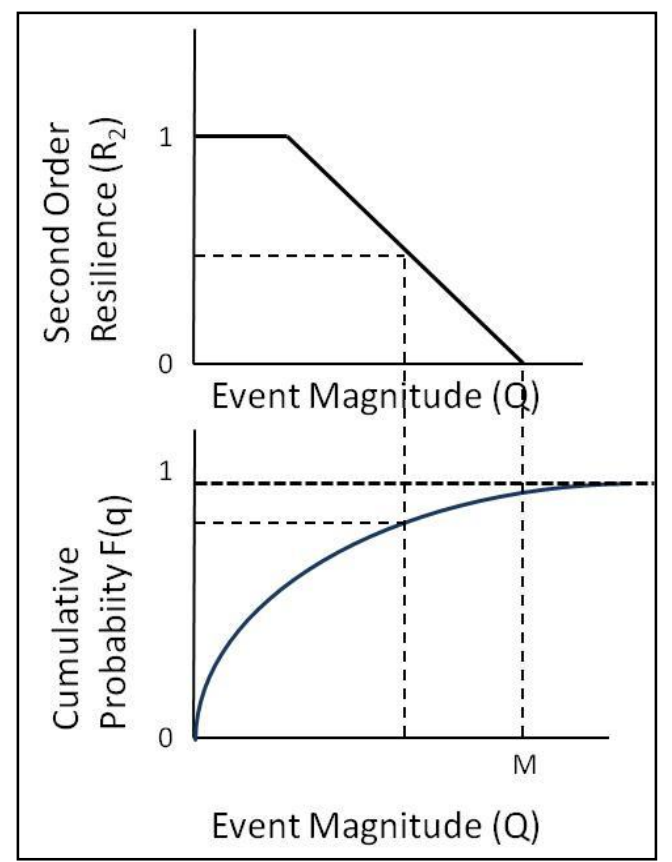

Figure 5a

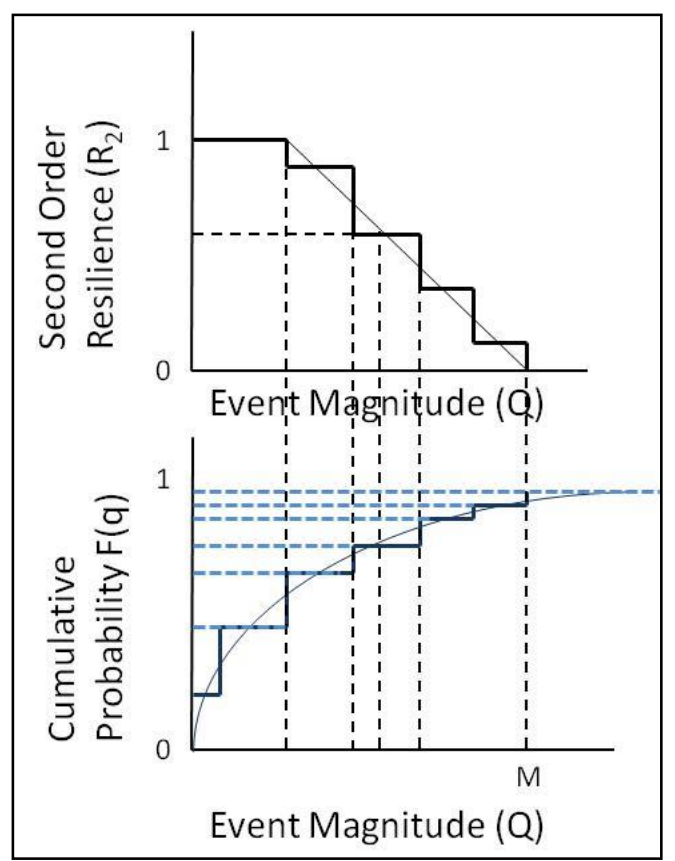

Figure $5 b$

Figure 5a - Relationship of second order resilience with event magnitude $Q$ and cumulative probability of Q; Figure 5b - Discrete cumulative probability intervals used to estimate third order resilience.

This is a particularly useful measure when a system is exposed to multiple threats. Similar to other orders of resilience, presenting an $\mathrm{R}_{4}$ value without any context would be nearly meaningless. In the example above, it would be important to present $\mathrm{R}_{4}$ as in the context of natural hazards (flood, earthquake, fire, and wind). It would also be important to communicate what time horizon was used for each threat. For example, the fourth order resilience presented could be said to have included $\mathrm{R}_{3}$ values based on floods whose probabilities were $5 \%, 1 \%$, and $0.2 \%$ annually, three earthquakes with an epicenter at location Y and of magnitudes 5, 7, and 9 on the Richter scale, three different wildfire scenarios based on historical events, and three wind events of $45 \mathrm{mph}$; $65 \mathrm{mph}$; and $85 \mathrm{mph}$ (6 hour sustained). Providing this context is critical in that it communicates the robustness of the analysis performed.

In actuality, threats are not strictly mutually exclusive. It is possible (although less likely) that an earthquake will be followed by a flood, or a wind storm and flood will occur together. Possible compound events should also be analyzed. The second order resilience of compound events will likely not be an addition of the separate events. In some cases, two events together may delay recovery, and in other cases additional damages from the second event may be less because systems were already damaged.

\section{Conclusions}

This paper presents mathematical definitions of resiliency to use in a holistic framework for disaster planning and risk management. The approach focuses on the consequences side of the risk equation. Reducing consequences is an important part of mitigating loss when threat probabilities are uncertain. First order resiliency $\left(\mathrm{R}_{1}\right)$ is determined by initial damages from an event, while second order resiliency $\left(\mathrm{R}_{2}\right)$ is primarily influenced by recovery time. Comparing 
first order and second order resilience values provides a means of comparing how different actions can improve resilience. Calculating $\mathrm{R}_{1}$ and $\mathrm{R}_{2}$ provides a comparison of damage reduction efforts (reducing impact) with efforts to improve response and recovery. Third order resiliency $\left(\mathrm{R}_{3}\right)$ provides a measure of resiliency across events of different magnitudes, while fourth order resiliency $\left(\mathrm{R}_{4}\right)$ can be used to evaluate resiliency across multiple threats. Consistent time horizons must be used when computing and comparing second, third, and fourth order resiliency values.

The proposed definitions of resilience provide a systematic way for communities to consider resiliency in disaster planning and preparation. A community can use the resilience measures to evaluate damage reduction alternatives and response and recovery strategies systematically. Resiliency is defined in non-dimensional units. The definitions provide a consistent way of measuring resilience (and vulnerability) regardless of what is being measured. Because the values are dimensionless, communities and organizations can set measures that align with what they value and thus can compare resiliency for different aspects of their system.

While the units used to measure value differ between economic, social, and environmental sectors, by selecting a consistent time horizon and series of threat magnitudes, it is possible to compare how proposed alternatives would affect resilience in these different accounts. Principles could be put in place which would prohibit increasing resilience in one account at the cost of decreasing it in another.

Importantly, while the framework requires certain analytical computations be performed, the analytical process in turn facilitates a healthy risk management process aimed at understanding vulnerabilities and increasing resiliency. Questions that should be answered as part of the process of measuring and improving resilience include:

- What do we value and how do we measure that value?

- What threatens what we value? What scenarios should be considered when we determine the threats?

- What damages (consequences) would occur if that threat happened?

- At what thresholds will damages or recovery times increase non-linearly?

- How would we recover after the initial impact? Are there any dependencies we are counting on to recover and if so, at what thresholds?

- Can we do anything to decrease the impact of the event or improve the way we recover?

- Does the threat come in different sizes and if so, how might that change the initial impact and our recovery?

- Is that the only threat or are there others that might cause similar losses in value?

Answering these questions and evaluating resiliency will support a holistic approach to disaster planning and a systematic evaluation of damage reduction and response and recovery alternatives across multiple potential hazards.

\section{References}

Subcommittee on Disaster Reduction). Grand Challenges for Disaster Reduction (SDR). National Science and Technology Council (NSTC) Committee on Environment and Natural Resources, 2005. Available at 
http://www.sdr.gov/SDRGrandChallengesforDisasterReduction.pdf, Accessed on January 9, 2012.

United Nations International Strategy for Disaster Reduction (UN ISDR). Hyogo Framework for Action 2005-2015: Building the Resilience of Nations and Communities to Disasters, 2006.

Available at http://www.preventionweb.net/english/professional/publications/v.php?id=1037, Accessed on January 9, 2012.

Department of Homeland Security (DHS). National Infrastructure Protection Plan, 2009.

Available at http://www.dhs.gov/xlibrary/assets/NIPP_Plan.pdf, Accessed on January 9, 2012.

Haimes YY. On the definition of resilience in systems. Risk Analysis, 2009; 29(4):498-501.

Holling CS. Resilience and stability of ecological systems. Annual Review of Ecology and Systematics, 1973; 4:1-23.

Holling, CS. Engineering Resilience versus Ecological Resilience. In: Schulze PC, editor. Engineering Within Ecological Constraints. Washington, DC: National Academy Press; 1996, p. 31-43.

Wang C, Blackmore JM. Resilience Concepts for Water Resource Systems. Journal of Water Resources Planning and Management, 2009; 135(6): 528-536.

Hashimoto T, Stedinger JR, Loucks DP. Reliability, resiliency, and vulnerability criteria for water resource system performance. Water Resources Research, 1982; 18(1): 14-20.

Bruneau M, Chang SE, Eguchi RT, Lee GC, O’Rourke TD, Reinhorn AM, Shinozuka M, Tierney K, Wallace WA, von Winterfeldt D. A framework to quantitatively assess and enhance the seismic resilience of communities. Earthquake Spectra, 2003; 19(4): 733-752.

Chang SE, Shinozuka M. Measuring improvements in the disaster resilience of communities. Earthquake Spectra, 2004; 20(3): 739-755. 
Castaldi, Andrew

\title{
A Reinsurers Perspective of Why We Need to Improve the Economic Consequences of Extreme Events
}

\begin{abstract}
Very few industries understand the risk that we as a society face due to extreme events as much as a reinsurer does. A reinsurer's core business model is to understand and quantify the impact of these events. Reinsurers build technologies to evaluate todays risk as well as tomorrows. For over twenty five years Swiss Re has been discussing the additional risk that we face due to climate change as well as our increasing vulnerability to today's risk. The potential losses due to natural events are growing at an alarming pace and we need to slow down that trend if not possible to reverse it. This is a problem that we all share and have to work together to reduce.
\end{abstract}

\section{Keywords}

Insurance, Economics, Disaster Finance, Mitigation, Risk

\section{Introduction}

Extreme atmospheric and geological events are potentially devastating phenomena that we, as of yet, are unable to control. Nevertheless the risks to our life, property, and financial stability from these events are well within our control. Swiss Re believes that we as a society can become more resilient to these events and can reduce our exposure through hazard mitigation, building codes, zoning codes, community planning, and the use of insurance or similar products when all else fails. A combination of physical and financial protection measures are needed to improve the resiliency of our local, urban, and rural communities.

We often think that larger is better but disaster planning is required everywhere and is nowhere more urgent than in the world's biggest cities simply because of the catastrophic effects that a natural catastrophe can have in densely populated areas. We often think of earthquake and windstorm as the most threatening hazards. Nevertheless our thoughts should not be so limited. Flooding endangers more people than any other natural catastrophe (climate change and sea level rise could increase this risk further). Around 3 million people live in the US today at less than 3 feet above average high tide. In New York alone the value of insured commercial and residential properties in coastline counties is almost $\$ 3$ trillion.

Larger economic losses are neither unusual nor unexpected and they can happen almost anywhere. Hurricane Sandy should not have been a surprise. As much as it may have been considered as a "shock to the system" it was one that the insurance industry has long been expecting and was prepared for. Our immediate coastlines are extremely vulnerable to wind and storm surge while the rest of the region, especially residential properties, is vulnerable to wind and flood. Sandy was the second largest nominal event yet it lacked the severe winds and extensive rainfall induced flooding that could have cause worse damages and suffering. Even so Sandy demonstrated just how vulnerable we are to natural events, especially in areas typically not frequented by hurricanes (185 fatalities [121 in the US], economic loss: USD 68 billion, over 650000 homes damaged/destroyed). Our infrastructure, dependence on technology such as 
electricity and cell phones, wealth, zoning, population density, and lack of upkeep have made events such as Sandy more complex and costly to recover from. Events of this size have become more commonplace and are expected to increase in economic loss during the near future absent any climate change. The influence of climate change can only increase the magnitude of these events.

\section{Insurance}

The fundamental concept behind insurance is as old as society itself - to spread and share the risk of one to many. Individually many of us could not withstand a devastating financial event without insurance. Imagine a single home destroyed by fire. The risk is small but the cost is devastating and often too great for any one of us to bear. However if we share the risk with many, then the burden upon each of us becomes bearable. An insurer is an expert at understanding and measuring the direct and indirect financial risk associated with many activities including building a home, operating a business, developing a product, etc. Our role is to facilitate the measuring and sharing of risk between two or more entities with similar or at times different risks.

The risk sharing mechanism works well when there is little or no dependency between risks. The risk transfer mechanisms may not be as efficient in situations where many insureds can be impacted at the same time. Natural catastrophes, earthquakes, flood, hurricanes, and other atmospheric events that impact large areas and populations at one time are examples where the risk sharing community may be too small. Although infrequent to an individual these events occur numerous times throughout the United States each year and can have a long lasting impact on the community, its financial situation, and its ability to recover.

Reinsurers insure insurance companies and governments from these large-scale events. We take the risks and further diversify it throughout the world. Extreme events are what drive our business model. As such, we have become experts in studying, modeling, preparing, and financing these events.

\section{Escalating Losses}

Losses continue to rise. The average community in the United States has become wealthier. Home size and values have increased, the amount of goods we own has risen, residential, commercial, and industrial properties have become increasingly dependent on new and expensive technologies as well as extensive supply chains. These technologies are not only more expensive to own, replace, or repair but are also more vulnerable to damage. Our infrastructure supporting our population has become more complex, older, spread out, and quite often not maintained properly nor current with today's needs.

The population has migrated to the coasts. Many of these coastal areas are prone to wind, storm surge and earthquake. As the population grows communities seek to continue growing by developing new areas, areas that are at higher risk or destroy natural defenses to natural hazards. Absent of any increased hazard due to climate change we expect that on average the insured losses due to natural hazards will double approximately every ten years. More alarming is the widening gap between insured, uninsured, and total economic losses. 
More and more of the financial loss due to natural hazards are falling on the local, state and federal government. This only increases the burden of the post event community who is consuming its fiscal budget funding humanitarian, civil, and basic survival needs. Whether it be in taxes or insurance premiums it is ultimately the people who pay. Post event financing typically comes at a time when the community impacted is already financially distressed thereby making it more costly to rebuild. Pre event financing and mitigation are more efficient and less costly.

We are already too vulnerable to today's risk let alone future risk. Current levels of resilience are insufficient to manage the impacts of severe weather today let alone a future with a more severe climate. With such a large existing inventory of old structures built to less than adequate code and years of poor catastrophe risk zoning we have tremendous amounts of equity at risk.

Even without the exaggerating effects of climate change any historical event, if it were to occur today, would cost multiples to recover from due to the changes in coastal demographics, wealth, and building costs. Yet in many ways the present is more difficult to correct than it is to correct for the future. New structures can be designed for current and future problems whereas the current inventory of buildings and infrastructure is often outdated for today's hazards let alone tomorrows. Structures, infrastructures, and utilities have life spans.

\section{We Need to Change our Mindset and Act Quickly}

We need to incorporate better codes and zoning to both the new and replacement structures. After a loss, our impetus is to make whole and rebuild quickly all too often to existing rather than updated codes - this needs to change. But to get moving on this we need to overcome a few hurdles. We need to educate ourselves on just what and where the additional climate changed induced hazards are, we need to understand the true cost and benefit for mitigating, building or doing nothing are, we need to communicate this to policy makers, and together we must develop plans for better resiliency.

When an insurer looks at a natural catastrophe risk, we annualize the future expected losses into one average annual rate assuming that the values and hazard is constant (static inflation, growth, or climate conditions). If the loss exposure (values), hazard (i.e. climate) or the risk (vulnerability) increases then this average annualized rate would likewise increase. In its simplest form this is cost of financing the risk. When you factor in climate change, such as sea level rise, the hazard increases and when combined with increasing exposure values and more exposures in riskier areas, then the cost of financing these risk rise. A recent study initiated by New York City (and supported by Swiss Re) demonstrated that unless suitable resilience building measures are implemented then the annual expected loss from severe weather impacts for NYC could increase from $\$ 1.7$ billion today to $\$ 4.4$ billion by the 2050 s at the current exposure (no changes in values and vulnerably).

Whether this increased cost is reflected in higher insurance premiums or taxes eventually the loss burden will become too much to bear without intervention. Intervention in better building codes, zoning, and hazard mitigation will slow down and may reverse this trend. Without intervention the risks may become uninsurable due to the higher risk requiring higher premiums required to 
fund the loss. Similarly many of our structures may become stranded assets that no longer can be used.

Insurance is one of the better ways to hedge taking a risk. Without insurance the financial risk may be too costly to undertake. Without taking risks we limit our opportunities to grow and innovate. Insurance and risk transfer products are natural components of a resilience-building program because they provide financial compensation when disasters strike. People and businesses recover better when they have an insurance policy to fall back on. Insurance also reinforces risk prevention measures by putting a price tag on the exposure to natural hazards and climate risks. Lower versus higher insurance premiums can offset the cost of undertaking incentivizing investments in risk reduction measures.

We need to understand the risk we are facing and plan accordingly. Typically this means how we build, what we build and where we build. We have to understand not just the risk landscape of today, but how that could change due to climate change tomorrow. New York City's recent Economics of Climate Change study identified areas of opportunity to mitigate New York City's future risk today.

A property may not be in a flood zone today but will it be 20 years down the road? We saw what happens if we don't keep flood mapping up to date. As flood maps were redrawn post, Sandy we found that there where almost double the number of residents living at risk in NYC compared to 1983 (398 000 against 218 000). The number of buildings in floodplains was 35000 in 1983 and likely to increase to 88700 by the 2020s (New York study: "A stronger more resilient New York")

\section{Conclusion}

We must continue to enhance our understanding of climate science and even more important than abstract numbers (e.g. atmospheric concentrations of $\mathrm{CO} 2$ (parts per million)) what it means for us. What happens to the risk landscape if as expected sea level rises by 1-2 feet up and down the Atlantic coastline? As a society we must start to integrate climate risk considerations into the planning and retro-fitting programs.

To me the initial barrier is to understand what additional risk we are facing, how these changes will impact us in terms of lives, damages, and what the cost will be for not doing anything. Once that is accomplished we can make an initial decision but we then face the biggest challenge of convincing individuals that they have to move, mitigate, consume less, or make other modifications to their lifestyle that they do not want to do - no less pay for. This is especially true when the tangible savings will arrive decades later or when they no longer have any interest in the location mitigated. This will be the most difficult obstacle to overcome. Until the majority of individuals start experiencing the negative daily impacts of climate change I am worried that nothing substantial will be done. We also run the risk of class bias between the affluent and poor - the affluent can afford independent mitigation while the poor cannot.

Resilience is a long-term issue. We invest now with the expectation that we will make use of that investment at a future date. There may not be an immediate pay-off which is a difficult sell 
in today's economic climate. We need to provide incentives for mitigation and treat mitigation as an opportunity and economic stimulant rather than lost earnings.

To overcome these barriers we need to a lot of things, fundamentally we need to better articulate the risk we face and think of ways to monetize resilience. We also need to address perverse incentives that provide short-term gains but long-term problems. New developments in coastal areas may make sense to the developer today (increased tax base, jobs and development), but leave a costly legacy for the community in years to come.

As a reinsurer we must create new mechanisms to transfer risk and take it off of the tax payer's hands-around $40 \%$ of the cost Sandy was covered by private (re)insurance. We need to develop the new, innovative insurance products to help people and governments manage the risk. But this can only be accomplished in tandem with better building, zoning, and mitigation practices.

Recently the insurance industry has developed many new products that can help communities respond to extremes events. Products that can aid in the cost of evacuations, humanitarian aid, infrastructure repair, bridging the gap between federal and local aid, or rebuilding. These products could range from indemnity-based contracts to parametric-based products using single of multiple triggers to release payments. 
Chang, Wen-Huei, Dena Abou-El-Seoud, and Yue Cui

\title{
An Introduction to the US Army Corps of Engineers Regional Economic System
}

\begin{abstract}
The US Army Corps of Engineers (USACE) is one of the world's largest public engineering, design, construction and management agencies, and its civil works mission areas include navigation, flood risk management, hydropower, water supply, recreation, and environment with an annual budget of US\$5 billion. To estimate total regional economic impacts of USACE's programs, a Regional Economic System (RECONS) model that includes more than 1500 area specific input-output models was developed for all civil works project regions. RECONS has been used as a means to document the performance of USACE investment spending as directed by the American Recovery and Reinvestment Act (ARRA). It also allows the USACE to evaluate project and program expenditures associated with the annual Civil Works $(\mathrm{CW})$ budgets of the eight business lines managed by the USACE. In addition, RECONS offers users the ability to evaluate "stemming-from effects" of USACE programs and infrastructure. RECON has also incorporated the Environmental Extended Input-Output Model (EEIO) approach by augmenting the technical coefficients matrix to reflect energy consumption and the greenhouse gas emissions. The total amount of carbon dioxide produced for each economic activity is available at the industry sector level in addition to jobs, income, sales and other economic effects. This paper describes the capabilities of RECONS.
\end{abstract}

\section{Keywords}

Economic, Impacts, Greenhouse, Jobs, Income, Benefits

\section{Background}

The US government supports a complex and comprehensive water infrastructure from coast to coast that generates substantial benefits to the nation's and to local economies. The US Army Corps of Engineers' (USACE) is the largest public agency for water resources management in the US, with civil works mission areas in navigation, flood risk management, hydropower, water supply, recreation, and environment. Water resources projects funded by the federal government and implemented by the Corps are subject to a detailed benefit-cost analysis which includes quantification of benefits that accrue at the national and regional levels. The Corps has well established methods to estimate benefits at the national level associated with its projects. The deep economic crisis of 2009 and the associated loss of thousands of jobs brought the need to estimate regional impacts, particularly jobs created or sustained by investments on infrastructure. Given the complexity and magnitude USACE's projects with an annual budget of $\$ 5$ billion, it was difficult to use readily available models to estimate regional impacts of Corps projects.

RECONS was developed to provide reliable and consistent estimates of jobs, incomes and other economic impacts associated with USACE spending. It also allows the USACE to evaluate project and program expenditures associated with the annual Civil Works $(\mathrm{CW})$ budgets of the eight business lines managed by the USACE. In addition, RECONS offers users the ability to evaluate "stemming-from effects" of USACE programs and infrastructure. Stemming-from 
effects are the economic contribution of industries and activities that are dependent on or benefit from USACE programs and infrastructure.

\section{Analysis Framework}

RECONS was originally developed and used to document and manage the performance of direct investment spending of the Corps as directed by the American Recovery and Reinvestment Act of 2009 (ARRA). Its functionality is now being expanded to allow the Corps to evaluate direct investment spending associated with the annual Civil Works budget of the eight programs managed by the Corps and to assess the carbon emissions impacts of various operations and maintenance activities. An additional purpose of RECONS is to evaluate the economic contribution of industries and activities which are dependent on or benefit from Corps programs and infrastructure; these downstream effects are termed "stemming from effects." Stemming from effects can be estimated for the following programs: navigation, hydropower, environment, and recreation. RECONS adapts input-output multipliers from the 1500 regional models.

\subsection{Economic Impact Analysis (EIA)}

Economic impact (contribution) analysis estimates the change (impact) or existence (contribution) in economic activity (economic output, labor income, value added, and employment) associated with new or already occurring economic stimulus to an economy. RECONS estimates economic impacts or contribution of these activities to the economy by utilizing input-output (IO) modeling techniques to calculate the multiplier effects that USACE expenditures or industry revenues create through backward linkages to the industries, businesses, and households supplying the goods, services, and labor (Hewings 1985).

There are two components to an economic impact analysis; to directly convert the action into monetary values such as sales, income, and jobs, and to estimate the indirect and induced (secondary) effects that are associated with the action (Pleeter 1980; Alward 2009). Multipliers capture the size of the secondary effects, usually expressed as a ratio of total effects to direct effects (Miller and Blair 2009). The larger the multiplier, the greater the impact a dollar of final spending will have on the region's economy.

\subsection{Spending Profiles}

Reliable estimates of the regional effects of the Corps program require precise and current measures of money spent on construction, maintenance and operation of the navigation program (Chang and Jackson 2003). Government expenditures are typically arrayed as "spending profiles," which are vectors of average amounts spent (for itemized goods and services) in conjunction with the navigation program. Results from existing database indicate that spending patterns associated with Corps projects were highly variable across regions and types of projects. For example, in the case of dredging, which is the largest expenditure associated with the Corps' navigation program, it is difficult to estimate spending profiles using existing models. The development of spending profiles by project types in this case needs to be accomplished through a comprehensive approach that includes data analysis, research, and interviews (USACE 2009).

\subsection{Study Area Identification: Functional Economic Areas}

The ability to evaluate impacts at various geographical levels is of upmost importance when developing an economic impact analysis model. The smallest level of geography should be based on the nature of the specific project or program being evaluated and the geographic extent of the project (e.g. discrete project location such as single lock rehabilitation versus a linear project 
such as a channel dredging project spanning multiple counties). For most projects, the study area encompasses one or more counties that together form a Functional Economic Area, as defined by labor flows (Retzlaff 2009). For projects located in a metropolitan area, the Metropolitan (population 50000 and more) and Micropolitan (10 000 to 50 000) Statistical Areas as defined by the US Office of Management and Budget (OMB) can be used to capture the interdependencies of the industries in the study region (U.S. Census Bureau 2010). For projects that are not located in a metropolitan area, the use of the US Department of Agriculture Forest Service Protocols for Delineation of Economic Impact Analysis Areas on non-metro project locations should be used to ensure consistency with the OMB criteria and with the definitions of the US Department of Labor Bureau of Economic Analysis (BEA) and the Bureau of Labor Statistics (USDA 2003).

\subsection{Microcomputer-Based I-O Models}

Because of the ability of advanced microcomputers, Input-Output (I-O) models have been packaged as ready-to-use computer software and database (Chang 2001). Among these ready-touse I-O models, BEA maintains an I-O model of the entire U.S. economy called RIMS II and can provide sector-specific multipliers for the U.S. or sub-regions. IMPLAN, on the other hand, provides software and database for estimating local models and impacts in a microcomputer Windows $^{\mathrm{TM}}$ environment. Another commercially available economic impact model is REMI (Regional Economic Models, Inc.). REMI is an economic simulation model that uses econometric and general equilibrium models to trace the total effects over time of changing economic conditions in a study area. REMI includes some I-O model embedded functions such as the computation of inter-industry relationships, plus additional functions to forecast effects of future changes. However, economic simulation models involve greater analytic sophistication and cost than I-O models (Weisbrod and Weisbrod 1997).

\section{RECONS Model}

Work activities for CW and ARRA Federal spending include the types of USACE projects or activities that support USACE infrastructure, programs, and business lines. Work activities associated with each of the USACE CW business lines were researched and identified, as well as work activities that are currently associated with multiple business lines or are general enough that they could be included in all business lines.

Additionally, industry revenues or costs associated with the RECONS stemming-from effects component were also identified and described. The work activity classification system serves two purposes:

1. To organize and arrange the USACE CW federal work activities in a manner that is easily identifiable to RECONS users.

2. To create a mapping structure whereby USACE work activities map directly to one or multiple IMPLAN sectors.

Figure 1 provides an overview of the RECONS approach. This method, also known as a "bill-ofgoods" or "second-round" approach (Alward 2009), seeks to disaggregate expenditures into key component activities, where appropriate, so that these activities can be mapped separately to the corresponding industry in IMPLAN for estimation of the multiplier effects. 


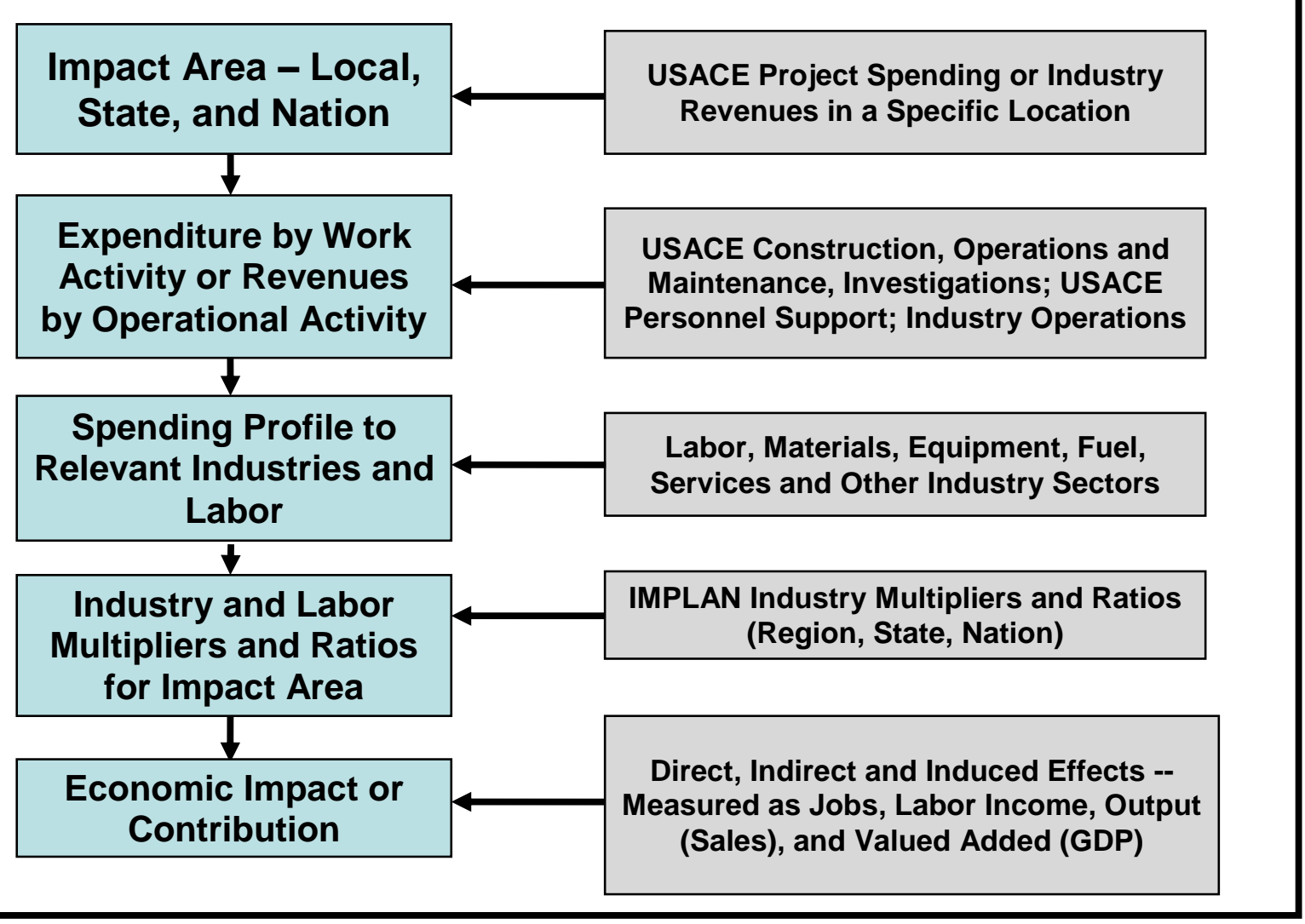

Figure 1.Flow Diagram of USACE Business Line Expenditures

\section{Illustration of the RECONS Model- Navigation Program}

This section will illustrate how a port impact study can be done in RECONS using Corps Navigation program as an example.

\subsection{Identify Spending Associated with Navigation Program}

In order to estimate the full economic impact of Corps Navigation, project expenditures were bridged into key component activities so that these activities can be mapped separately to the corresponding industry in IMPLAN. The complexity of the spending profiles depends on the type of work activity. For instance, a large infrastructure construction project would have several items within a spending profile, while a contract to provide security services at a facility may have only one item. For example, major expenditure elements of a navigation project may be described by the following spending profile (Table 1):

- Labor and administrative cost by the government

- Material (e.g., steel, concrete, glass)

- Architectural and engineering costs/subcontracting

- Transportation and/or fuel expense

- Capital equipment fee

- Disposal fees

- Survey costs 
Table 1. Sample spending profiles for hopper dredge and matching IMPLAN sectors

\begin{tabular}{|c|c|c|c|}
\hline Spending Category & $\begin{array}{l}\text { Total Project } \\
\text { Cost }(\%)\end{array}$ & IMPLAN Sector(s) & $\begin{array}{l}\text { Spending Profile by } \\
\text { IMPLAN Sector } \\
(\%)\end{array}$ \\
\hline Labor & 39.0 & Labor Response Coefficients & 39.0 \\
\hline \multirow{2}{*}{ Fuel } & \multirow{2}{*}{28.0} & 319 Wholesale Trade & 5.3 \\
\hline & & 115 Petroleum Refining & 22.7 \\
\hline \multirow{4}{*}{$\begin{array}{l}\text { Consumable Operating } \\
\text { Expenses (non-fuel) }\end{array}$} & \multirow{4}{*}{16.5} & 319 Wholesale Trade & 1.6 \\
\hline & & 329 Retail - General Merchandise & 2.3 \\
\hline & & Multiple Manufacturing & 11.6 \\
\hline & & 335 Truck Transportation & 1.0 \\
\hline Repairs \& Equipment & 16.5 & Ship Building and Repair & 16.5 \\
\hline Total & 100.0 & & 100.0 \\
\hline
\end{tabular}

In addition to direct federal spending, the RECONS port module estimates the economic contribution of cargo shipments within ports for various types of cargo (for example, dry bulk, automobiles, containers, etc.). This includes various port industries, such as port services, fuel services, cargo handling and packing, supplies and warehousing and storage services. Inland modes of transportation are also provided in the RECONS module, including rail, air, barge, pipeline, and short and long-distance trucking. Port kit provides the default expenditures for the port service and inland transportation per ton of cargo shipped, while the inland modal shares are provided by the Freight Analysis Framework (FAF).

The process of estimating stemming from effects from coastal and Great Lakes ports is depicted in Figure 2. The various aspects to estimate the stemming from effects of the port industries based on a modified version of Port Kit consist of the following, each of which is further described below:

1. Port locations and impact areas

2. Mapping of RIMSII industries to IMPLAN industries; extracting relevant industry economic multipliers derived from IMPLAN

3. Port default expenditures by sector for cargo

4. Identify cargo tonnage

5. Modal shares and distance for inland movements 


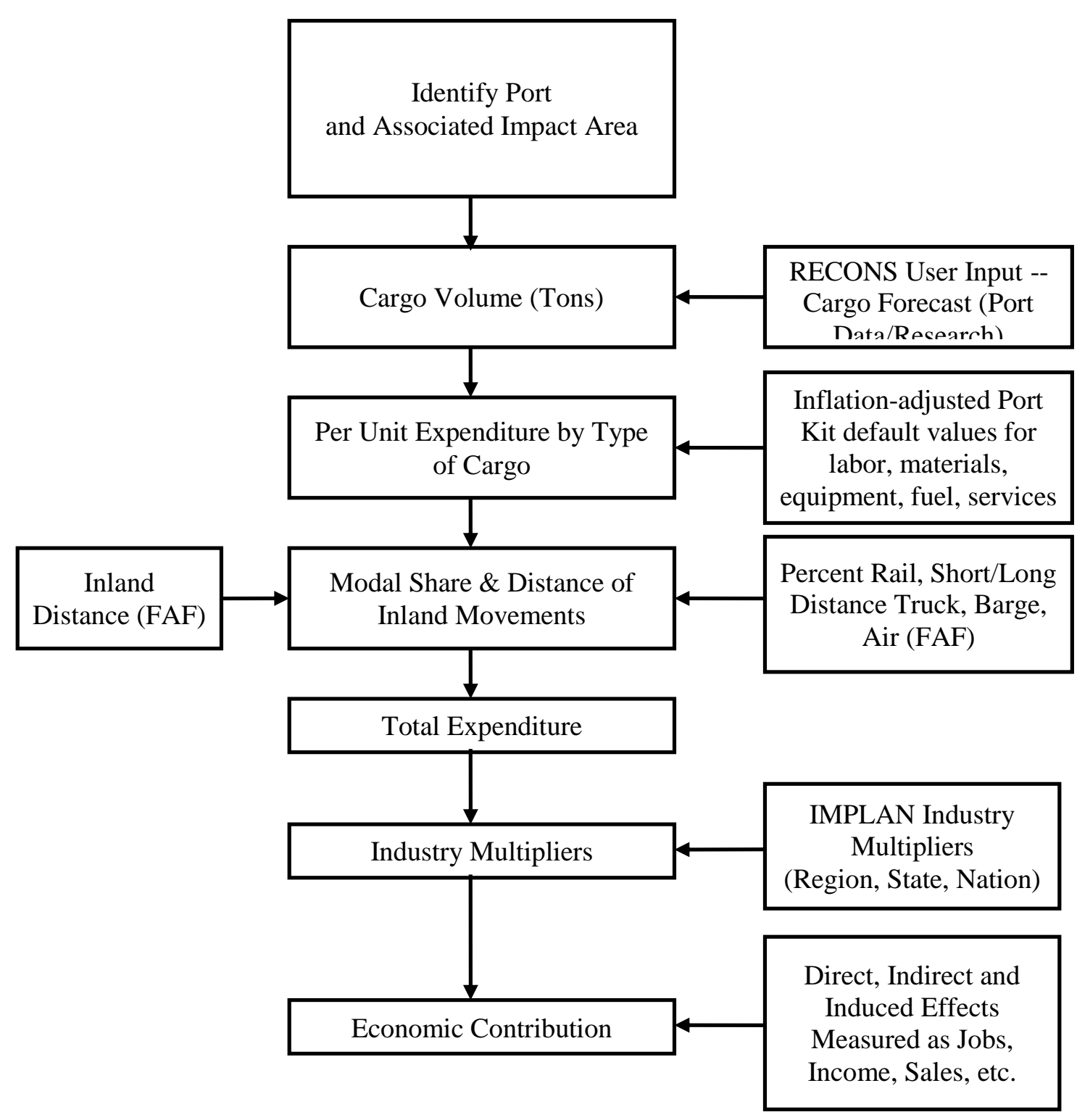

Figure 2. Flow Diagram of Ports Industries Stemming From Effects

\subsection{Regional economic Impact Models}

Regional economic models were first created in IMPLAN for all study areas where the Corps spending occurred. The extent to which an effect is captured within the study area is represented by regional purchase coefficients obtained from the IMPLAN model. This parameter is based on trade flow data for each industry sector, where the trade flows model is a doubly-constrained gravity model that uses county level to estimate how the demands of goods and services are captured in the region (Lindall et al. 2005). For retail and wholesale trade sales, the parameter would include local capture of just the margin, for labor/household sector, the parameter would adjust for commuting of labor resident from outside the study area. All of the multipliers and association economic ratios were then imported to RECONS with three levels of study areas identified for each project location for this study are local, state, and the U.S. as a whole. 


\subsection{Carbon Emission Impacts.}

The Corps is also moving forward on controlling and reducing the carbon footprint of its activities. This includes having better information concerning how alternative practices and sectors of the economy effected by their budgetary spending impact on greenhouse gas emissions. To assist in this pursuit, the initial RECONS model was enhanced in 2012 to enable the Corps to estimate and evaluate the carbon emissions produced as a result of its activities to maintain various ports.

Data on $\mathrm{CO} 2$ intensities for different sectors of the economy were incorporated into model along with IMPLAN produced LPC's and multipliers to determine direct and secondary emissions. $\mathrm{CO} 2$ intensities are the total carbon emissions divided by a measure of output (i.e., gross output in real dollars). Data on direct energy-related $\mathrm{CO} 2$ emissions of each industry, the Government and Households is provided by the USEIA and USEPA. Multiplying the CO2 intensity for different sectors by the output produced by Corps spending to maintain ports provides an estimate of carbon emissions. The total carbon emissions produced includes both the direct energy-related and process emissions generated in the sector, and the indirect energy- related emissions associated with the production of the inputs that the sector acquires. Since data shows that the $\mathrm{CO} 2$ emissions for different sectors varies considerably over time the information on carbon intensities will updated at the same time the IMPLAN data used in the RECONS is updated.

\subsection{Demonstration of RECONS Functions and Capabilities}

Area of interest (port) is first selected from a drop down menu (Figure 3). Once a port is selected the information for that port is shown including USACE project identification number, states and the economic impact area. In this case the counties comprising the Chicago Metropolitan Statistical District are analyzed through the functional economic area, labor market approach (Figure 4). Functional economic areas based on labor markets are derived from data on commute flows. Users are able to view a street, satellite and hybrid maps (street and satellite) of the economic impact area. Future versions of RECONS will provide detailed economic and demographic information of impact areas.

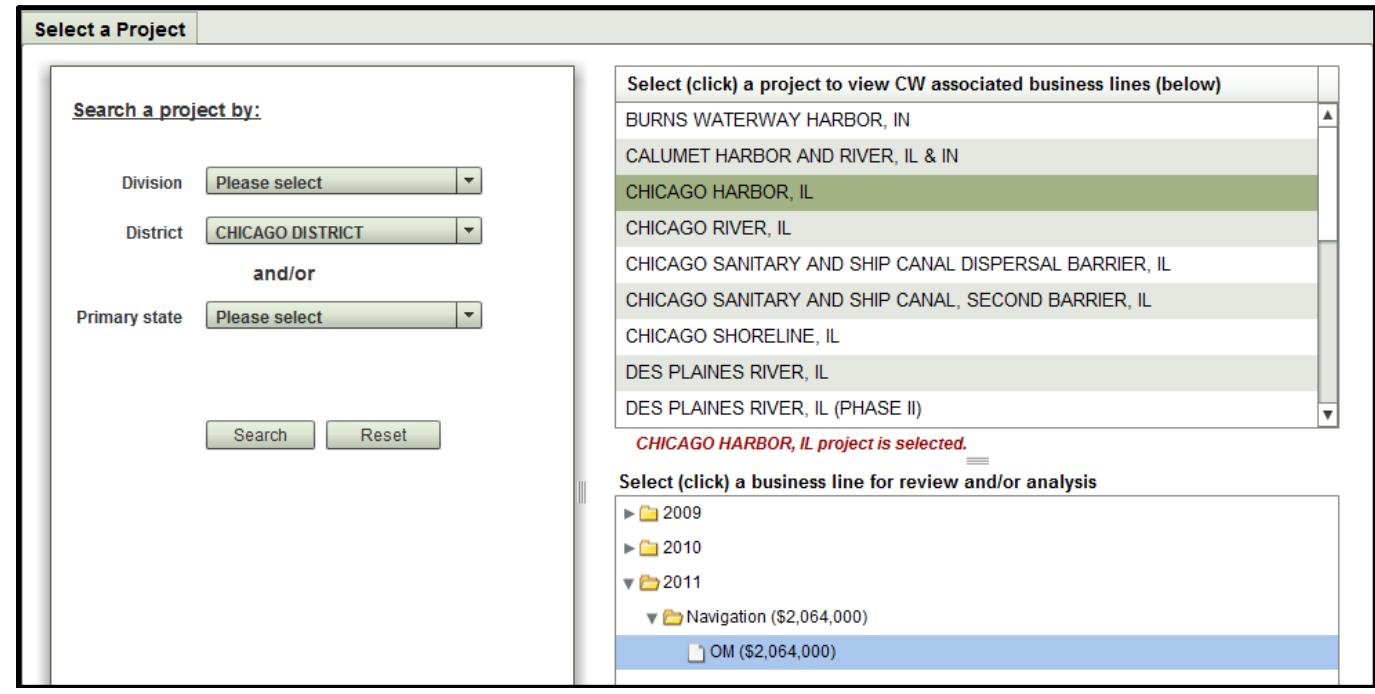

Figure 3. Screen for selecting business-lines and projects for analysis 


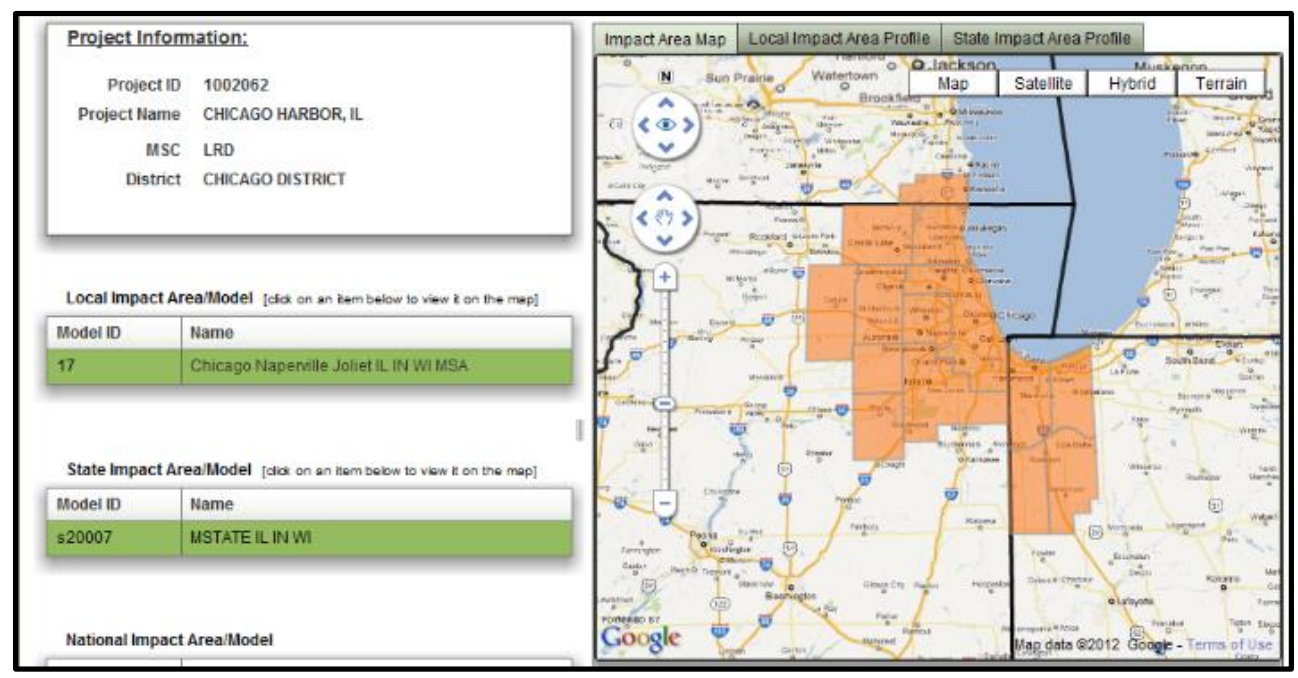

Figure 4. Economic impact region used for the analysis

Users are next shown the USACE budgeted expenditures (\$2 064 000) associated with the maintenance and operation of that port (Figure 5) during that year. These expenditures are disaggregated into a series of categories that are linked IMPLAN sectors. Users can edit the amount allocated to different categories and also change the total expenditures. In this way, the model can be used to simulate changes in total budget and allocation across line items.

\begin{tabular}{|c|c|c|c|c|}
\hline \multicolumn{2}{|r|}{ Review the percentage and amounts, and change them where desired } & $100.0 \%$ & \multicolumn{2}{|l|}{$\$ 2,064,000$} \\
\hline Industry & Expenditure Item/Category & Percentage $(\%)^{*}$ & Spending Amount (\$) ** & \\
\hline 115 & Petroleum Refining & 7.0 & $\$ 144,480$ & $\Delta$ \\
\hline 171 & Metals and Steel Materials & 2.4 & $\$ 49,536$ & \\
\hline 198 & Textiles, Lubricants, and Metal Valves and Parts (Dredging) & 2.4 & $\$ 49,536$ & \\
\hline 201 & Pipeline Dredge Equipment and Repairs & 5.9 & $\$ 121,776$ & \\
\hline 26 & Aggregate Materials & 2.3 & $\$ 47,472$ & \\
\hline 290 & Hopper Equipment and Repairs & 1.9 & $\$ 39,216$ & \\
\hline 36 & Construction of Other New Nonresidential Structures & 12.7 & $\$ 262,128$ & \\
\hline 365 & Industrial and Machinery Equipment Rental and Leasing & 5.8 & $\$ 119,712$ & \\
\hline 375 & Planning, Environmental, Engineering and Design Studies and Services & 4.0 & $\$ 82,560$ & \\
\hline 386 & USACE Overhead & 7.5 & $\$ 154,800$ & \\
\hline 39 & Repair and Maintenance Construction Activities & 4.6 & $\$ 94,944$ & \\
\hline 417 & Industrial Machinery and Equipment Repair and Maintenance & 11.8 & $\$ 243,552$ & $\nabla$ \\
\hline
\end{tabular}

Figure 5. Screen to review and edit the expenditure profiles

RECONS also (Figure 6) provides the user with national, state and local purchase coefficients for each of the shipping related expenditure categories. These are measures the portion of revenues that accrue to the region as final demand. It is the share of revenue initially injected into a local economy after subtracting the cost of related imports. If a high percentage of these revenues leak out in the form of purchased of imported goods there is high leakage and low capture. Users of RECONS that have other information that can better estimate these purchase rates will then have an option of modifying them here. 


\begin{tabular}{|c|c|c|c|c|}
\hline \multicolumn{5}{|c|}{ Review Local Purchase Coefficients and change them where desired } \\
\hline Industry & Spending Item/Category & Local LPC \%* & State LPC \%** & Nation LPC \% *** \\
\hline 115 & Petroleum Refining & 72 & 72 & 81 \\
\hline 171 & Metals and Steel Materials & 57 & 58 & 90 \\
\hline 198 & Textiles, Lubricants, and Metal Valves and Parts (Dredging) & 41 & 44 & 74 \\
\hline 201 & Pipeline Dredge Equipment and Repairs & 31 & 46 & 100 \\
\hline 26 & Aggregate Materials & 74 & 81 & 97 \\
\hline 290 & Hopper Equipment and Repairs & 4 & 8 & 99 \\
\hline 36 & Construction of Other New Nonresidential Structures & 99 & 99 & 100 \\
\hline 365 & Industrial and Machinery Equipment Rental and Leasing & 99 & 99 & 100 \\
\hline 375 & Planning, Environmental, Engineering and Design Studies and Services & 59 & 73 & 100 \\
\hline 386 & USACE Overhead & 97 & 97 & 100 \\
\hline 39 & Repair and Maintenance Construction Activities & 99 & 99 & 100 \\
\hline 417 & Industrial Machinery and Equipment Repair and Maintenance & 96 & 96 & 100. \\
\hline
\end{tabular}

Figure 6. Screen to review and adjust the local purchase coefficients

Using the estimate of captured revenues and multipliers extracted from IMPLAN, RECONS than produces overall summary of the estimate of both direct and total jobs, labor income and GRP produced by the USACE's spending on this port (Figure 7). Of the $\$ 2$ million project spending, about 83 percent ( $\$ 1.7$ million of the direct output in the study area out of the total $\$ 2$ million expenditures) was captured by the region's economy. Slightly higher capture rate for the state's economy as about 90 percent of the spending captured and with the even higher direct spending being captured at the national level. With multiplier effects, this project spending contributed $\$ 3.3$ million in sales effects, and supported about 25 jobs in the local region. These are compared to the $\$ 5.5$ million in total sales effects and 37 jobs to the nation's economy. The differences between impacts on the local economy and the nation economy illustrate how the nature of the spending and the size of the economy will affect the economic effects captured in the region. For goods and services that are not produced locally, most of the economic impacts will leak out of the region and will only be captured at the larger economic scale where the final demands can be satisfied.

\begin{tabular}{|c|c|c|c|c|c|c|c|c|}
\hline \multicolumn{2}{|c|}{ Economic Impact Results } & Overall summary & \multicolumn{2}{|c|}{$\begin{array}{l}\text { Local summary } \\
\text { by industry sector }\end{array}$} & $\begin{array}{l}\text { State summary } \\
\text { by industry sector }\end{array}$ & \multicolumn{2}{|c|}{$\begin{array}{l}\text { National summary } \\
\text { by industry sector }\end{array}$} & $\begin{array}{l}\text { Carbon } \\
\text { Emissions }\end{array}$ \\
\hline Region & $\begin{array}{l}\text { Local } \\
\text { Capture }\end{array}$ & $\begin{array}{c}\text { Direct } \\
\text { Jobs }\end{array}$ & $\begin{array}{c}\text { Direct } \\
\text { Labor Income }\end{array}$ & $\begin{array}{l}\text { Direct } \\
\text { GRP }\end{array}$ & $\begin{array}{l}\text { Total } \\
\text { Output }\end{array}$ & $\begin{array}{l}\text { Total } \\
\text { Jobs }\end{array}$ & $\begin{array}{c}\text { Total } \\
\text { Labor Income }\end{array}$ & $\begin{array}{l}\text { Total } \\
\text { GRP }\end{array}$ \\
\hline Local & $\$ 1,691,500$ & 14.91 & $\$ 931,365$ & $\$ 1,130,245$ & $\$ 3,346,137$ & 25.14 & $\$ 1,483,655$ & $\$ 2,082,668$ \\
\hline State & $\$ 1,804,922$ & 15.70 & $\$ 1,010,614$ & $\$ 1,223,873$ & $\$ 3,513,164$ & 27.79 & $\$ 1,566,718$ & $\$ 2,182,251$ \\
\hline National & $\$ 2,012,877$ & 16.47 & $\$ 1,065,025$ & $\$ 1,303,334$ & $\$ 5,498,921$ & 37.13 & $\$ 2,115,711$ & $\$ 3,099,805$ \\
\hline
\end{tabular}

Figure 7. Economic impact results at the local, state and national levels

Subtracting direct from the totals leaves the indirect and induced effects. The total economic impacts of the USACE's spending on navigation is the sum of direct, indirect and induced effects within the defined economic impact area, in this case the Chicago MSA. RECONS also provides a more detailed description of economic impacts by various sectors of the local economy. Figures 8 shows economic measures in selected industry sectors for this study area. 


\begin{tabular}{|c|c|c|c|c|c|c|c|c|}
\hline \multicolumn{2}{|c|}{ Economic Impact Results } & \multirow{2}{*}{$\begin{array}{c}\text { Overall summary } \\
\text { Industry Name }\end{array}$} & \multirow[b]{2}{*}{$\begin{array}{l}\text { Spending } \\
\text { Amount }\end{array}$} & $\begin{array}{l}\text { te summary } \\
\text { dustry sector }\end{array}$ & \multicolumn{2}{|c|}{$\begin{array}{l}\text { National summary } \\
\text { by industry sector }\end{array}$} & \multicolumn{2}{|l|}{$\begin{array}{l}\text { Carbon } \\
\text { Emissions }\end{array}$} \\
\hline Industry & & & & Output & Jobs & $\begin{array}{l}\text { Labor } \\
\text { Income }\end{array}$ & GRP & \\
\hline 365 & Commercial and indus & ial machinery and equipment rental and le... & $\$ 119,712$ & $\$ 118,695$ & 0.30 & $\$ 29,658$ & $\$ 55,293$ & $\mathbf{\Delta}$ \\
\hline 375 & Environmental and oth & technical consulting services & $\$ 82,560$ & $\$ 48,796$ & 0.31 & $\$ 23,942$ & $\$ 29,250$ & \\
\hline 386 & Business support serv & & $\$ 154,800$ & $\$ 150,036$ & 1.46 & $\$ 75,242$ & $\$ 101,183$ & \\
\hline 39 & Maintenance and repai & construction of nonresidential structures & $\$ 94,944$ & $\$ 94,264$ & 0.73 & $\$ 56,099$ & $\$ 58,848$ & \\
\hline 417 & Commercial and indus & ial machinery and equipment repair and ... & $\$ 243,552$ & $\$ 234,391$ & 1.14 & $\$ 77,712$ & $\$ 152,382$ & \\
\hline 439 & *Employment and pay & II only (federal govt, non-military) & $\$ 315,792$ & $\$ 236,844$ & 1.69 & $\$ 208,503$ & $\$ 236,844$ & \\
\hline 5001 & Labor & & $\$ 295,152$ & $\$ 295,152$ & 6.93 & $\$ 295,152$ & $\$ 295,152$ & \\
\hline \multirow[t]{3}{*}{69} & All other food manufact & & $\$ 29,513$ & $\$ 13,839$ & 0.04 & $\$ 2,780$ & $\$ 3,583$ & \\
\hline & Secondary Impact & & & $\$ 1,654,637$ & 10.24 & $\$ 552,290$ & $\$ 952,423$ & \\
\hline & Total Impact & & $\$ 2,064,000$ & $\$ 3,346,137$ & 25.14 & $\$ 1,483,655$ & $\$ 2,082,668$ & $\nabla$ \\
\hline
\end{tabular}

Figure 8. Economic impact result for various sectors (24 sectors in total)

For greenhouse gas emissions, the model can also simultaneously estimate the total economic impacts (e.g., direct, indirect and induced) and the associated $\mathrm{CO} 2$ emissions with various levels of navigation related spending. This is accomplished by incorporating estimates of $\mathrm{CO} 2$ emissions produced when goods and services are produced, and rates when final goods and services are consumed along with IMPLAN LPCs and multipliers. Estimates of carbon emissions were acquired from the U.S. Environmental Protection Agency. They are measured in terms of tons of emissions per dollar of output. Figure 9 provides estimates of the carbon emissions produced by USACE's spending on navigation for the port of Chicago. Roughly 512 tons of $\mathrm{CO} 2$ were produced through the various economic activities associated with the $\$ 2$ million Corps spending on Chicago Port.

\begin{tabular}{|c|c|c|c|c|c|c|c|c|c|c|}
\hline \multicolumn{2}{|c|}{ Carbon Emission Estimates } & \multirow[t]{2}{*}{ Overall summary } & $\begin{array}{l}\text { summary } \\
\text { sttry sector }\end{array}$ & \multicolumn{2}{|c|}{$\begin{array}{l}\text { State summary } \\
\text { by industry sector }\end{array}$} & \multicolumn{2}{|c|}{$\begin{array}{l}\text { National summary } \\
\text { by industry sector }\end{array}$} & \multicolumn{3}{|c|}{$\begin{array}{l}\text { Carbon } \\
\text { Emissions }\end{array}$} \\
\hline Industry & Industry Name & & $\begin{array}{l}\text { Output } \\
\text { Direct }\end{array}$ & $\begin{array}{c}\text { Direct } \\
\text { Emissions } \\
\text { (Tons) }\end{array}$ & $\begin{array}{l}\text { Output } \\
\text { Indirect }\end{array}$ & $\begin{array}{c}\text { Indirect } \\
\text { Emissions: } \\
\text { Domestic } \\
\text { (Tons) }\end{array}$ & $\begin{array}{c}\text { Indirect } \\
\text { Emissions: } \\
\text { Imports } \\
\text { (Tons) }\end{array}$ & $\begin{array}{c}\text { Total } \\
\text { Indirect } \\
\text { Emissions } \\
\text { (Tons) }\end{array}$ & $\begin{array}{c}\text { Total } \\
\text { Direct and } \\
\text { Indirect } \\
\text { Emissions } \\
\text { (Tons) }\end{array}$ & \\
\hline 365 & \multicolumn{2}{|c|}{ Commercial and industrial machinery and equipment rental ... } & $\$ 119,616$ & 27.56 & $\$ 108,991$ & 8.21 & 1.40 & 9.61 & 37.17 & $\Delta$ \\
\hline 375 & \multicolumn{2}{|c|}{ Environmental and other technical consulting services } & $\$ 82,560$ & 0.72 & $\$ 54,033$ & 2.96 & 0.65 & 3.61 & 4.32 & \\
\hline 386 & \multicolumn{2}{|c|}{ Business support services } & $\$ 154,800$ & 2.48 & $\$ 89,350$ & 8.02 & 1.67 & 9.69 & 12.16 & \\
\hline 39 & \multicolumn{2}{|c|}{ Maintenance and repair construction of nonresidential struct... } & $\$ 94,944$ & 9.74 & $\$ 66,553$ & 11.53 & 3.70 & 15.23 & 24.97 & \\
\hline 417 & \multicolumn{2}{|c|}{ Commercial and industrial machinery and equipment repair ... } & $\$ 243,552$ & 2.37 & $\$ 128,051$ & 21.24 & 11.08 & 32.32 & 34.70 & \\
\hline 439 & \multicolumn{2}{|c|}{ * Employment and payroll only (federal govt, non-military) } & $\$ 315,792$ & 0.00 & $\$ 0$ & 0.00 & 0.00 & 0.00 & 0.00 & \\
\hline 69 & \multicolumn{2}{|c|}{ All other food manufacturing } & $\$ 25,992$ & 3.39 & $\$ 35,865$ & 9.58 & 2.53 & 12.11 & 15.50 & \\
\hline & \multicolumn{2}{|l|}{ Total } & $\$ 1,717,725$ & 253.93 & $\$ 1,110,964$ & 184.70 & 73.86 & 258.57 & 512.50 & \\
\hline
\end{tabular}

Figure 9. Direct, indirect and total carbon emissions produced by navigation expenditures

In addition to the various economic measures associated with direct Corps's Navigation spending, RECONS allows users to estimate the stemming from effects associated with commercial shipping through USACE maintained ports. Figure 10 shows the input screen on which users enter data about the amounts of different type of cargo shipped through a port annually. 


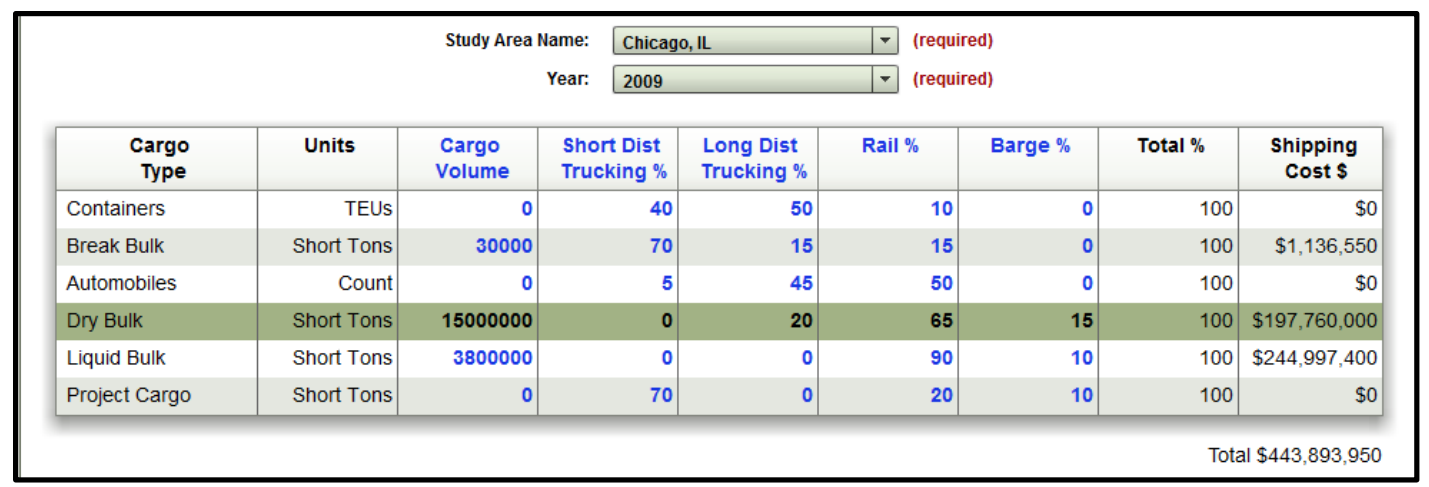

Figure 10. Screen to input cargo types and amounts

RECONS uses this input, along with cost profiles developed for different types of cargo, to estimate the total costs of shipping different amounts of various types of cargo, and allocate the total cost across various spending categories (Figure 11). LPCs associated with each of these spending categories are again reviewable and editable by the users. RECONS then produces tables at various levels (e.g., local, state, national) showing the direct and total economic impacts and carbon emissions associated with those volumes and types of cargo (Figures 12). The information can also be displayed by industry sectors (Figure 13).

\begin{tabular}{|c|c|c|c|c|c|}
\hline \multicolumn{6}{|c|}{ Review and Change Local Purchase Coefficients (if desired) } \\
\hline Industry & Spending Item/Category & Local LPC \% * & State LPC \% * & Nation LPC \% * & Total Cost(\$) \\
\hline 115 & Fuel & 70 & 70 & 79 & $\$ 47,161,200$ \\
\hline 319 & Supplies & 100 & 100 & 100 & $\$ 1,516,000$ \\
\hline 333 & Rail & 94 & 94 & 99 & $\$ 60,263,625$ \\
\hline 334 & Barge & 49 & 50 & 100 & $\$ 3,603,100$ \\
\hline 335 & Long Haul Truck & 93 & 93 & 98 & $\$ 83,915,685$ \\
\hline 335 & Short Haul Truck & 93 & 93 & 98 & $\$ 236,040$ \\
\hline 338 & Port Services & 100 & 100 & 100 & $\$ 125,991,400$ \\
\hline 340 & Warehousing & 100 & 100 & 100 & $\$ 94,997,000$ \\
\hline 387 & Security & 100 & 100 & 100 & $\$ 1,506,400$ \\
\hline 411 & Lodging & 100 & 100 & 100 & $\$ 24,703,500$ \\
\hline
\end{tabular}

Figure 11. Screen to review and edit local purchase coefficients for shipping expenditures

The total shipping costs associated with the total volume of cargos going through Chicago Port in 2009 were at $\$ 444$ million using this approach. Of the $\$ 444$ million shipping costs, almost $\$ 420$ million was captured by the region's economy and supported about 3400 direct jobs (Figure 12). With multiplier effects, these shipping costs contributed $\$ 806$ million in sales effects, and supported about 6000 jobs in the local region. Note that these numbers should not be directly compared with economic impacts estimated from the $\$ 2$ million Corps spending on operating and maintaining the port, as the latter only represents the portion of economic activities directly contributed from federal government spending, while the former represents a larger scale impact associated with all shipping expenditures accrue at the study area. 


\begin{tabular}{|l|c|c|c|c|c|c|c|c|c||}
\hline \multicolumn{2}{|l|}{ Economic Impact Results } & \multicolumn{2}{|c|}{ Overall Summary } & \multicolumn{2}{|c|}{$\begin{array}{c}\text { Local Summary } \\
\text { by Industry Sector }\end{array}$} & \multicolumn{2}{c|}{$\begin{array}{c}\text { State Summary } \\
\text { by Industry Sector }\end{array}$} & $\begin{array}{c}\text { National Summary } \\
\text { by Industry Sector }\end{array}$ & $\begin{array}{c}\text { Carbon } \\
\text { Emissions }\end{array}$ \\
\hline \multicolumn{1}{|c|}{ Region } & $\begin{array}{c}\text { Local } \\
\text { Capture }\end{array}$ & $\begin{array}{c}\text { Direct } \\
\text { Job }\end{array}$ & $\begin{array}{c}\text { Direct } \\
\text { Labor Income }\end{array}$ & $\begin{array}{c}\text { Direct } \\
\text { GRP }\end{array}$ & $\begin{array}{c}\text { Total } \\
\text { Output }\end{array}$ & $\begin{array}{c}\text { Total } \\
\text { Job }\end{array}$ & $\begin{array}{c}\text { Total } \\
\text { Labor Income }\end{array}$ & $\begin{array}{c}\text { Total } \\
\text { GRP }\end{array}$ \\
\hline Local & $\$ 418,826,458$ & $3,483.60$ & $\$ 199,144,468$ & $\$ 282,607,908$ & $\$ 805,918,992$ & $5,935.70$ & $\$ 328,615,684$ & $\$ 505,492,018$ \\
State & $\$ 418,866,340$ & $3,483.68$ & $\$ 199,149,975$ & $\$ 282,618,630$ & $\$ 795,483,745$ & $6,106.59$ & $\$ 327,074,818$ & $\$ 502,409,111$ \\
National & $\$ 432,011,048$ & $3,526.39$ & $\$ 201,870,946$ & $\$ 287,198,212$ & $\$ 1,074,667,818$ & $7,581,81$ & $\$ 398,485,646$ & $\$ 626,967,653$ \\
\hline
\end{tabular}

Figure 12. Local, state and national backward linked economic impacts of shipping

\begin{tabular}{|c|c|c|c|c|c|c|c|c|c|}
\hline \multicolumn{2}{|c|}{ Carbon Emission Estimates } & \multirow[t]{2}{*}{ Overall Summary } & $\begin{array}{l}\text { Local Summary } \\
\text { by Industry Sector }\end{array}$ & \multicolumn{2}{|c|}{$\begin{array}{l}\text { State Summary } \\
\text { by Industry Sector }\end{array}$} & \multicolumn{2}{|c|}{$\begin{array}{l}\text { National Summary } \\
\text { by Industry Sector }\end{array}$} & \multicolumn{2}{|c|}{$\begin{array}{c}\text { Carbon } \\
\text { Emissions }\end{array}$} \\
\hline Industry & Industry Name & & $\begin{array}{l}\text { Output } \\
\text { Direct }\end{array}$ & $\begin{array}{c}\text { Direct } \\
\text { Emissions } \\
\text { (Tons) }\end{array}$ & $\begin{array}{c}\text { Output } \\
\text { Indirect }\end{array}$ & $\begin{array}{c}\text { Indirect } \\
\text { Emissions: } \\
\text { Domestic } \\
\text { (Tons) }\end{array}$ & $\begin{array}{l}\text { Indirect } \\
\text { Emissions: } \\
\text { Imports } \\
\text { (Tons) }\end{array}$ & $\begin{array}{c}\text { Total } \\
\text { Indirect } \\
\text { Emissions } \\
\text { (Tons) }\end{array}$ & $\begin{array}{c}\text { Total } \\
\text { Direct and } \\
\text { Indirect } \\
\text { Emissions } \\
\text { (Tons) }\end{array}$ \\
\hline 115 & Petroleum refineries & & $\$ 37,466,87$ & $15,374.84$ & $\$ 27,401,40 ;$ & $2,242.07$ & $2,470.20$ & $4,712.27$ & $20,087.11$ \\
\hline 319 & Wholesale trade businesse & & $\$ 1,516,000$ & 150.38 & $\$ 830,062$ & 67.60 & 14.63 & 82.23 & 232.61 \\
\hline 333 & Transport by rail & & $\$ 59,819,26$ & $29,259.45$ & $\$ 39,629,711$ & $3,712.95$ & $1,013.24$ & $4,726.20$ & $33,985.64$ \\
\hline 334 & Transport by water & & $\$ 3,603,100$ & $12,476.74$ & $\$ 3,609,595$ & 444.40 & 105.80 & 550.20 & $13,026.94$ \\
\hline 335 & Transport by truck & & $\$ 82,407,50$ & $90,801.04$ & $\$ 61,141,49$. & $17,281.16$ & $2,641.00$ & $19,922.16$ & $110,723.20$ \\
\hline 338 & Scenic and sightseeing tran & tion and support activities $\mathrm{f...}$ & ... $\$ 125,991,4 \mid$ & $2,368.50$ & $\$ 20,480,891$ & $1,760.08$ & 433.95 & $2,194.03$ & $4,562.53$ \\
\hline 340 & Warehousing and storage & & $\$ 94,997,001$ & $97,281.61$ & $\$ 27,578,72$ & $2,416.84$ & 645.70 & $3,062.54$ & $100,344.16$ \\
\hline 387 & Investigation and security se & & $\$ 1,506,400$ & 12.94 & $\$ 707,071$ & 48.04 & 11.09 & 59.13 & 72.07 \\
\hline 411 & Hotels and motels, includin & no hotels & $\$ 24,703,501$ & $14,295.88$ & $\$ 15,258,95$ & 516.19 & 116.90 & 633.09 & $14,928.97$ \\
\hline & Total & & $\$ 432,011,0$ & $262,021.38$ & $\$ 196,637,9$ & $28,489.34$ & $7,452.51$ & $35,941.85$ & $297,963.23$ \\
\hline
\end{tabular}

Figure 13. Carbon emissions produced by shipping related expenditures

\section{Conclusions and Recommendations}

RECONS was initially developed to estimate the economic impacts of ARRA spending by the USACE. However, RECONS platform has and will continue to be enhanced to serve additional purpose with special focus on estimating and evaluating the economic impacts of the direct investment and operational spending of the Corps budget, as well as all the associated economic activities that are directly linked to Corps' infrastructure and program. This model provides a consistent means for estimating regional economic impacts associated with Corps' Civil Works program across the nation. These results provide a baseline for further analyses and improvements in future studies. We recommend three interrelated areas for future study.

\subsection{Institutionalizing the Economic Impact Analysis}

The spending and project type information gathered in this study can be used as a baseline for future analysis and refinement. This can be done by continuing to monitor the spending information and applying the price-adjusted spending (based on consumer price index) to new project type data. One example is to incorporate project type and spending profiles gathered from this study into existing modeling systems to estimate regional economic impacts of all economic activities directly associated with Corps program and other water resource infrastructure built by the Corps.

\subsection{Additional Options for Estimating the Stemming from Effects}

The example used in this paper illustrates the ability to estimate the direct economic impacts of Corps navigation budget and the stemming from different types and amounts of cargo.

Additional options are being added to include the use of the commodities being shipped instead 
of cargo types to estimate the stemming from effects associated with different types and amounts of commodities shipped to and from various ports. The navigation module will also be further enhanced to become a more general port economic impact assessment tool by adding the capability of estimating the economic impacts of cruise ships and recreational boating within the harbors maintained by the Corps.

\subsection{Trade-off Analysis for Greenhouse Gas Effects}

Recently RECONS has been improved to provide the capacity to estimate and track the carbon emissions impacts of Corps budgets. Although this enhancement provides baseline information for all the CO2 emissions linked to Corps' civil work spending, it does not address the net impacts of having, say, more goods shipped via waterways compared to other mode of transportations like rail and trucks. Additional analysis for the net effects for all infrastructures should be considered as an option for estimating impacts of Corps projects.

\section{Acknowledgments}

The authors wish to express our profound appreciation to our colleagues in the Corps for their input and support of this study, notable is Dr. David Moser for his leadership and technical oversight of this study. In addition, we would like to extend our appreciation to Drs. Lisa McDonald and Holly Bender of Louis and Berger Group for their technical support and expertise.

\section{References}

Alward, G., 2009. Using IMPLAN to Monitor Job Creation; Complying with the Reporting Requirements of the American Recovery and Reinvestment Act of 2009, [WWW] <URL: http://www.implan.com/> [Accessed 20 December 2009.]

Bichou, K., 2007. Review of Port Performance Approaches and a Supply Chain Framework to Port Performance Benchmarking. In: Mary Brooks and Kevin Culliname (eds.) Research in Transportation Economics. Devolution, Port Governance and Port Performance, (17): 567598.

Boske, L. and Cuttino, J., 2003. Measuring the economic and transportation impacts of maritimerelated trade, Maritime Economics and Logistics, vol. 5, issue 2, pp 133-157.

Bureau of Economic Analysis, 2010. Regional Input-Output Modeling System (RIMS II). [WWW] <URL: http://www.bea.gov/regional/rims/> [Accessed 17 February 2010.]

Bushnell, W. and Knight, K., 2010. Regional economic development (RED) procedures handbook. Technical report. Institute for Water Resources, US Army Corps of Engineers.

Chang, W.H., 2001. Variations in multipliers and related economic ratios for recreation and tourism impact analysis. PhD Dissertation. Michigan State University.

Chang, W.H., Jackson, R. S., 2003. Economic Impacts of Recreation Activities at Oregon Coastal and River Ports. Technical report, U.S. Army Engineer Research and Development Center, Vicksburg, MS. ERDC/EL TR-03-12.

Charney, A. H., and Leones, J., 1997. IMPLAN's induced effects identified through multiplier decomposition. Journal of Regional Science, 37(3): 503-517.

Chen, W., Chen C., Chen, F. and Liu, C., 2011. The impact of the Taipei Port Container Terminal on the Northern Region of Taiwan: a computable general equilibrium model, Journal of Marine Science and Technology, 19(2): 120-126.

Coto-Millán, P., Pesquera, M.A. and Castanedo Galán, J., 2010. A Methodological Discussion on Port Economic Impact Studies and Their Possible Applications to Policy Design. In: 
Coto-Millán, P., Pesquera, M.A. and Castanedo, J. Essays on Port Economics. Contributions to Economics, Physica-Verlag HD

Hamilton, G. L., Ramsussen, D. and Zeng, X., 2000. Rural inland waterways economic impactkit: User guide. Institute for Economic Advancement, University of Arkansas at LittleRock.

Haddad, E., Hewings, G., Perobelli, F., dos Santos and Raul, A., 2010. Regional Effects of Port Infrastructure: A Spatial CGE Application to Brazil, International Regional Science Review, 33(3): 239-263.

Hastings, S. E., and Brucker, S. M., 1993. An introduction to regional input-output analysis. In Otto, D.M., and Johnson, T.G. (Eds.), Microcomputer-based input-output modeling: Applications to economic development (pp. 1-27). Boulder: Westview Press, Inc.

Hewings, Geoffrey J. D., 1985. Regional input-output analysis. Beverly Hills, CA: Sage Publications, Inc.

Lindall, S., Olson, D., and Alward, G., 2005. Deriving multi-regional models using the IMPLAN national trade flows model. Paper prepared for the 2005 Mid-Continent Regional Science Association meeting, Arlington, VA.

Martin Associates, 2012. [WWW] <URL: http://www.martinassoc.net> [Accessed 27 June 2012.]

Miller, R. E. and Blair, P. D., 2009. Input-output analysis: Foundations and extensions, Second Edition. Cambridge University Press, New York.

Minnesota IMPLAN Group, 2009. IMPLAN Professional 3. Stillwater, MN: Minnesota IMPLAN Group, Inc.

Minnesota IMPLAN Group, 2000. IMPLAN professional software, analysis, and data guide. Stillwater, MN: Minnesota IMPLAN Group, Inc.

Olson, D., and Lindall, S., 1993. Micro IMPLAN user's guide version MI91-F. Stillwater, MN: Minnesota IMPLAN Group, Inc.

Pleeter, S., 1980. Methodologies of economic impact analysis: An overview. In Pleeter, S. (Ed.), Economic impact analysis: Methodology and applications, chapter 1 (pp. 7- 31). Boston: Maritinus Nijhoff Publishing.

Regional Dynamics, Inc., 2010. REDYN model. [WWW] <URL: http://www.regionaldynamics.com/> [Accessed 7 January 2010.]

Regional Economic Models, Inc., 2010. REMI model. [WWW] <URL: http://www.remi.com/> [Accessed 7 January 2010.]

Retzlaff, M., 2009. Economic Area Delineation - Identifying Areas for Economic Impact Analysis in the USDA-Forest Service, USDA Forest Service.

US Census Bureau, 2010. Metropolitan and Micro-politan Statistical Areas. [WWW] <URL: http://www.census.gov/population/www/metroareas/metroarea.html> [Accessed 15 March 2010.]

U.S. Water Resources Council, 1983. Economic and Environmental Principles and Guidelines for Water and Related Land Resources Implementation Studies

USACE, 2011. Regional Economic System (RECONS)- Methodology and User's Manual. US Army Corps of Engineers.

USACE, 2009. Economic Modeling for Estimating Jobs and other Economic Impacts of Corps of Engineers Stimulus Spending, Workshop in Phoenix, AZ, US Army Corps of Engineers.

USACE, 2005. Engineer Circular 1105-2-409, Planning in a Collaborative Environment, US Army Corps of Engineers. 
USACE, 2000.Engineer Regulation 1105-2-100, Planning Guidance Notebook, US Army Corps of Engineers.

USDA, 2003. Evaluating the Economic Significance of the USDA Forest Service Strategic Plan: Methods and Results for Programmatic Evaluations, Inventory and Monitoring Institute Report No. 6, USDA Forest Service.

Weisbrod, G., and Weisbrod, B., 1997. Measuring economic impact of projects and programs. Boston: Economic Development Research Group.

Wilson, J.S, Mann, C.L. and Otsuki, T., 2003. Trade facilitation and economic development: measuring the impact, Policy Research Working Paper Series 2988, The World Bank. 
Cutler, Harvey, Martin Shields, Daniele Tavani, Sammy Zahran, and John W van de Lindt

\title{
Computable General Equilibrium Models and Natural Disasters: A Note on Challenges and Possibilities
}

\begin{abstract}
Computable General Equilibrium (CGE) modeling is a quantitative methodology used to evaluate how a regional economy responds to changes in economic policy or other external factors. CGE models are particularly useful when the expected impacts of an external shock are complex and realized through multiple channels. While CGE models are typically used to estimate the impact of economic or policy shocks, we intend to broaden the use of CGE analysis to examine the economic impacts of natural disasters toward the development of NIST-CORE (the NIST Community Resilience Modeling Environment) at the Center for Risk-Based Community Resilience Planning at Colorado State University. In this short note, we highlight some of the key challenges associated with integrating a CGE model into NIST-CORE. These challenges involve: 1) data and accounting matrices; 2) model assumptions; 3 ) city selection and generalizability of model findings; and 4) interdisciplinary cooperation across engineering, social and economic sciences.
\end{abstract}

\section{Keywords}

Computable General Equilibrium Models, Resilience, Local Data, Static vs Dynamic, Generalizability, Interdisciplinary Research

\section{Background}

Computable General Equilibrium (CGE) modeling is a quantitative methodology used to evaluate how a regional economy responds to changes in economic policy or other external factors. CGE models are a preferred tool for regional impact analysis because they are founded in microeconomic theory, with model outcomes driven by the resource allocation decisions of utility maximizing households and profit maximizing firms. As compared to other kinds of economic analysis, CGE models are particularly useful when the expected impacts of an external shock are complex and realized through multiple channels. As a realistic portrayal of a regional economy, a CGE model can estimate the economic impact of external shocks that affect, among other things, household migration decisions, the location decisions of businesses, and industry productivity in a region. Moreover, a CGE model can estimate employment effects in different sectors, as well as the level and distribution of household incomes, to describe how segments of a regional economy are differentially impacted by external shocks.

Economic impact models can be an important disaster resiliency planning tool. In essence, the models allow communities to examine a variety of what-if scenarios in their planning and regulatory processes. For example, communities may be considering changes to their building codes that initially increase housing costs - harming the economy in the short-run - but result in structures that are more robust to storm damage. Alternatively, infrastructure planners may be considering undertaking investment in redundancy. Because the long-term resiliency of a place can be highly dependent on how it initially withstands a shock, economic impact models provide 
policy makers the ability to evaluate the costs and benefits under competing standards and policy interventions.

Figure 1 presents a schematic of a generic CGE model, showing interactions between economic agents - households, firms, and local government - that constitute a regional economy. Take for instance the box labeled households, representing all persons who live in a city in either single residential homes or multiple unit dwellings. The local labor supply comes directly from household groups - which can be differentiated by income - and is determined by the responsiveness of (potential) workers to changes in employment opportunities and wage payments. Labor supply can also change due to households migrating in or out of a city, depending on changes in relative economic conditions. The flow of income is represented by the arrows from firms and governments to households, including wage payments, capital and land income and transfer payments. Utility maximizing households then spend their income on goods, services, and housing that feedback to firms.

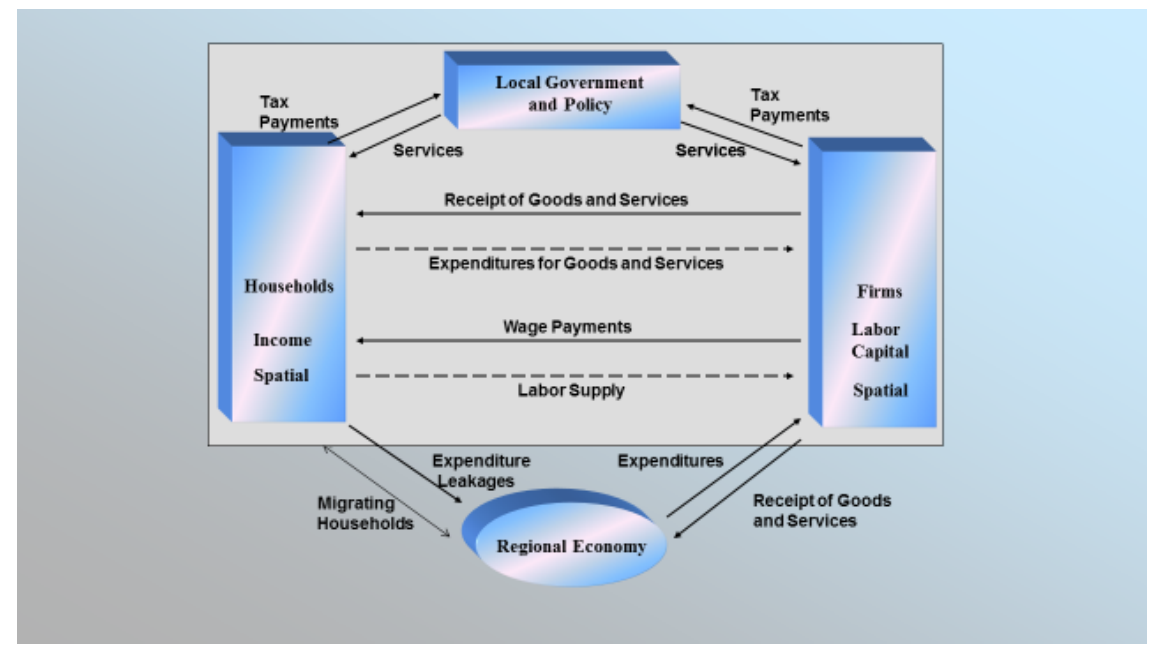

Figure 1. Flow Diagram of a Computable General Equilibrium Model

While CGE models are typically used to estimate the impact of economic or policy shocks, we intend to broaden the use of CGE analysis to examine the economic impacts of natural hazards such as hurricanes, earthquakes, floods and tornados, and to evaluate economic and engineering solutions to enhance the resiliency of local economies. These aims will be accomplished by incorporating a highly-detailed CGE model into NIST-CORE (the NIST Community Resilience Modeling Environment), under development at the Center for Risk-Based Community Resilience Planning at Colorado State University. In this short note, we highlight some of the key challenges associated with integrating a CGE model into a platform as complex as NIST-CORE. These challenges involve: 1) data and accounting matrices; 2) model assumptions; 3) city selection and generalizability of model findings; and 4) interdisciplinary cooperation across engineering, social and economic sciences.

\section{Research Needs and Challenges}

\subsection{Challenge of Data}

Regional economic resiliency is determined by the capacity of households, firms, organizations, and government agencies to resist and recover from the damages caused by hazard events. In 
applied modeling, characterizing the resiliency of a local economy is challenging, given the relatively poor spatial and temporal granularity of public data. Major data-related challenges facing CGE modeling efforts in the context of local natural disasters involve: 1) validly reproducing the structure of a regional economy; 2) integrating more subtle losses associated with temporary (or longer lasting) dislocations of households, injuries suffered by local populations, and how such losses are distributed across household groups; and 3) accounting for difficult-to-quantify community factors that appear to shape the recovery of a local economy.

In addressing the first challenge, it is important to first note that CGE models are founded on a Social Accounting Matrix (SAM), which characterizes the economic transactions between sources and recipients. Creating a sufficiently detailed SAM for smaller spatial units of analysis (e.g., cities, neighborhoods) is challenging because much of the underlying data are typically collected only at higher levels of aggregation (e.g. counties, states). In creating a local SAM from aggregate data, analysts rely on two primary local data sources, each with their own obstacles to overcome. The first source is the Quarterly Census of Employment and Wages (QCEW) from the US Bureau of Labor Statistics, which provides information on the number of workers employed and total wages paid for nearly every US business and organization that participates in the unemployment insurance program. Because QCEW provides address records for each firm, analysts can geocode them to develop spatial representations of regional economies. Although this data set is publicly collected and summarized at higher levels of spatial aggregation (counties and states), confidentiality requirements are significant, and vary across states, giving rise to substantial, but appropriate, bureaucratic challenges.

Data challenges also arise when modeling land markets, an important part of CGE models. In most states, property tax records are the best source of land data. Because these taxes are usually administered locally, model builders need to turn to individual county assessors' offices, presenting diverse challenges. Generally, assessor data describe each parcel of land in a county with respect to its use (residential or commercial), size, value (both land and structure), as well as property tax history. One important problem is that the quality and accessibility of assessor data vary substantially by locality, constraining the challenge of city selection (described in Section 4).

CGE models are described by a system of equations representing economic behavior, as well as the economic constraints faced by consumers, firms, and the government sector. Behavioral equations can be theoretically informed (the challenges of which we describe in Section 3) or anchored empirically by elasticities derived from econometric analyses. Consider for instance the problem of temporary household dislocation or out-migration following a disaster event. Household migration behavior is a key feature of regional CGE models (see Figure 1, bottom left hand corner). In the absence of sound theory, disaster elasticities of migration must be captured empirically with spatially and temporally resolved migration data. While the cohort component projection method, involving vital statistics, census data, and the demographic balancing equation, allows one to estimate change in local population attributable to net-migration, the decadal time-step and coarse spatial detail of the data render this method inadequate. Similarly, while Internal Revenue Service data on year-to-year address changes reported on individual tax returns capture the universe of annual filings, the data underreport segments of the population 
not required to file tax returns, such as the poor and elderly, who are often most affected by hazards.

The challenge is to find and uniquely leverage publicly available data to observe (infer) migration dynamics that unfold sub-regionally and by household type, with the aim to inform a regional CGE with empirically valid and disaster-specific elasticities that preferably operate by household group. Natality Birth Data from the National Vital Statistics System of the National Center for Health Statistics may represent a novel alternative to overcome data granularity problems. These micro-data contain demographic and socioeconomic information on birth mothers/fathers, timing of birth events, and information on maternal residence during pregnancy. With such data, one can possibly observe migration outcomes at the level detail necessary to inform a local CGE.

The third data challenge involves quantifying relevant community-level factors of community efficacy and social capital that have been argued to meaningfully impact economic recovery. The intuition here is that localities characterized by norms of trust and reciprocity can overcome coordination or collective action problems to engineer economic recovery. From a modeling perspective, the challenge is finding sufficient measures of such capacity. One idea is that community social capital is deposited or banked in non-profit organizations and voluntary associations. Such entities are present on the frontlines after a disaster, providing immediate and long-term assistance to affected households, and function as trusted conduits for the infusion of state and federal monies as well as charitable contributions from the general public. Perhaps, with data from the National Center for Charitable Statistics on nonprofit organizations of taxexempt status with $\$ 25000$ dollars in gross receipts that are required to file Form 990 with the IRS, one can populate a SAM with a non-profit sector that functions to buffer losses and speed recovery efforts.

\subsection{Challenge of Assumptions}

CGE models are comprehensive, data-heavy tools used to analyze the interacting economic behavior of many consumers, firms, the government sector, and the rest of the world (i.e., trading partners). Solving for an equilibrium in a CGE model amounts to numerically finding a vector of quantities (goods and services, labor, and so on) and prices (including real wages and rates of return on assets) that, given technological, behavioral and policy parameters: 1) match demand with supply in each sector; and 2) fulfills the accounting restrictions determined by the SAM describing the economy under consideration. By construction, the model is static: its solution provides a snapshot of an economy at a certain moment in time, but not the dynamic path followed by the economy to arrive at equilibrium.

As constructed, highly detailed CGE models are well-suited to address the resistance aspect of resilience: they can provide a detailed account of the entity of damages, as well as the potential benefits and costs of alternative policy scenarios. In a way, the comparison between an initial equilibrium without policy intervention and the equilibrium subsequent a certain policy regime (shock) can be interpreted as the comparison between two steady states of a dynamic economy. Yet, unless laws of motion governing the evolution over time of stocks and flows within the social accounting are specified, the model will be mute regarding the transition path from the initial equilibrium to the next equilibrium. This consideration points to a fundamental challenge of the approach. 
An example can be useful. Imagine a firm maximizing profits over one period, knowing its capital requirements, labor needs, land stock, and input prices over the period. The solution to this problem determines the supply of goods and services that the firm produces, as well as the firm's profits, for that period. Now imagine that the firm incorporates in its decision making the fact that its profits can be 1) reinvested in order to accumulate further capital stock, 2) buy more land, or 3) improve the efficiency of the existing technology, next period. The maximization program becomes inter-temporal and forward-looking. Such type of problems is typically solved through dynamic optimization methods that involve backward induction of current behavior given future choices. Similar reasoning can be applied to consumers - they can consume all of their income today, or they can save some of it for future consumption. Dynamic economic models acknowledge that an economy's private sector behaves in a forward-looking way, and that there is no reason to expect that the static decision rules obtained in the benchmark CGE model will conform with the dynamic solutions to the inter-temporal decision problems.

One question, then, is why would one not build dynamic CGE models from the outset? The answer is simple: maintaining a high level of disaggregation - which is the strength of the CGE approach - is both analytically and numerically intractable in a fully forward-looking economic model. Thus, the challenge is to calculate return times in a CGE model. There are two ways to address this fundamental challenge. A first, back-of-the-envelope approach, makes use of the relationship between the arrival rate of a natural disaster and the average waiting time for it to occur to linearly interpolate the return time over the length of time over which the economy recoups from the shock. In this case, any policy alternative that lowers return time can be seen as basically making the disruption from natural disasters less frequent. We will refer to this type of policy exercises as pseudo-dynamic. A second approach to address the return time question assigns agents with heuristic behavioral rules compatible with the static decision making rules (for instance, constant saving rates for consumers), and incorporates the evolution of stocks and flows in the social accounting. Accordingly, the system is explicitly dynamic, but not in a forward-looking way.

\subsection{Challenge of Generalizability}

In practice, CGE models are meant to realistically portray a specific, local economy. Because building thousands of community-specific CGE models is infeasible, our effort to integrate CGE models into NIST-CORE requires generalizability. This is a significant challenge, given that regional economies are heterogeneous. A fundamental thrust of this effort is building CGE models that match key details of a given local economy, but have the potential to generalize to other places. One possibility is developing models for a series of representative economies, which adequately characterize the fundamental economic relationships and conditions in any particular community, yet are flexible enough to be used across the country. While no representative communities have yet been identified, it is critical to have enough detail that epistemic uncertainties are reduced enough to provide an accurate outcome.

There are two fundamental approaches to address the generalizable nature of our work. First, a virtual city can be constructed which reflects fundamental economic relationships and conditions in any particular community yet are flexible enough to adjust to represent many regions or cities in the United States. As a few examples, these adjustment factors can focus on spatial characteristics of firms and households, the level of heterogeneity of economic production and 
demographic profile of local residents. It is important to recognize that the engineering aspect of the project that focuses on the built environment, transportation, telecommunication, energy and water and waste water management have to also create virtual models. These critical engineering components have to also have adjustment parameters to represent cities the size of New York down to towns in Oklahoma that were impacted by a tornado.

A second approach is to choose 7 to 10 representative cities that reflect the myriad of engineering and economic features that captures municipalities in the United States. A specific challenge of this approach is that collecting the engineering and economic data for different regions may encounter varying data restrictions that impact the quality of the regional model. However, having these multiple models would allow us to develop adjustment parameters for each of these cities/towns that can reflect with a greater degree of accuracy than the virtual city in terms of representing the many towns and cities in the United States. A possible compromise is to construct a virtual city and a specific city simultaneously and permit both approaches to enrich each other.

\subsection{Challenge of Interdisciplinary Research}

Effectively integrating inputs and outputs from myriad engineering and social science models with a CGE model requires considerable imagination. Engineering models provide predictions of how disaster events impact buildings, transportation networks, water, wastewater and energy infrastructures. The economic modeling challenge is translating these models' outputs into inputs for the CGE model. Further complicating this effort is adequately capturing both the spatial and temporal dimensions of the hazard.

Generally, engineering model outputs describing changes to infrastructure and buildings can be thought of as affecting a region's capital stock and technology. Both of these ideas are explicitly recognized in the production functions central to any CGE model. However, most CGE models tend to treat these factors fairly simply. One of our modeling challenges is enhancing the economic model to take advantage of the detailed data that comes out of engineering models. As noted above, economists face similar challenges when working with other social scientists. For example, two economies can be identical, yet have very different levels of social capital, which can subsequently impact recovery times. Building models that account for these differences requires establishing a new frontier in economic impact analysis.

\section{Acknowledgments}

The NIST Center of Excellence is funded through a cooperative agreement between the National Institute of Standards and Technology and Colorado State University. The content and views contained herein are solely those of the authors and do not necessarily represent the views of the NIST. 
Egli, Dane and Jared McKinney

\title{
Perspectives on the Economics of Resilience
}

\begin{abstract}
Investing in resilience is a national imperative and increasingly considered a basic business practice. In addition to mitigating disaster-related damage by introducing new flexibility, it increases productivity, revenue, reputation, and shareholder value. Investing in resilience before disaster strikes is the smart choice for individuals, companies, and governments alike. This paper offers perspectives on resilience related concerns.
\end{abstract}

\section{Keywords}

Economics, globalization, interconnectedness, resilience, supply chain

\section{Background}

The degree of interdependence across critical infrastructure sectors has been amplified by globalization, advanced technologies, and supply chain pressures. Our team at Johns Hopkins University Applied Physics Laboratory is studying - through modeling, analyses, and empirical research in places such as the Port of Baltimore and Austin, Texas - the measurable impact of disruptive events, such as Typhoon Haiyan of Figure 1, governance, and societal demands upon resilience ecosystems in bounded geographic areas.

Governments, communities, and individuals are not helpless in the face of natural disasters like Typhoon Haiyan, the category-5 super typhoon that struck the Philippines in November 2013, killing thousands and displacing hundreds of thousands. There are practical safeguards that can be designed within the multidisciplinary worlds of engineering, cyber-physical, and the social, behavioral and economic (SBE) sciences if we systematically identify the independent variables that contribute to critical infrastructure interdependencies, conduct analyses that support a generalizable model, and test these methods under simulated and real-world conditions. Drawing from the principles of collective action theory and computational analytics our studies are seeking to quantify the cost accounting and value proposition behind resilience by integrating economic factors into the research.

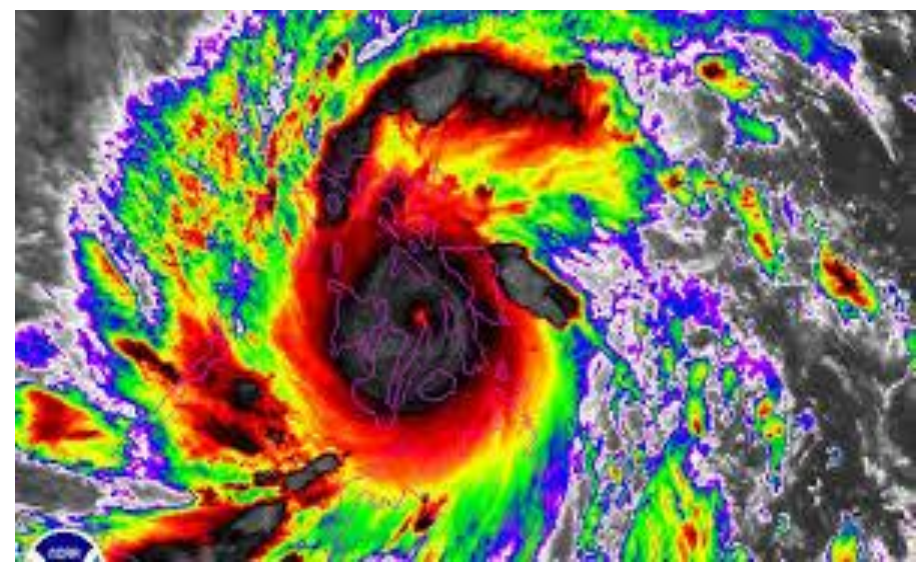

Figure 1. Typhoon Haiyan pictured in a NOAA satellite image taken November 8, 2013 


\section{Connected world, Globalization and Technology}

The degree of interdependence across critical infrastructure sectors has been amplified by globalization, advanced technologies, and supply chain pressures. Our team at Johns Hopkins University Applied Physics Laboratory is studying - through modeling, analyses, and empirical research in places such as the Port of Baltimore and Austin, Texas - the measurable impact of disruptive events, such as Typhoon Haiyan of Figure 1, governance, and societal demands upon resilience ecosystems in bounded geographic areas.

By creating a more connected world, globalization and technology have increased transparency and business efficiencies while simultaneously making systems more vulnerable. Businesses have more complex supply chains than ever before, allowing for greater speed and specialization. Further, outsourcing permits businesses to benefit from the competitive advantage of diverse countries and companies. Purchasing from a single source reduces costs. And just-intime delivery is reducing inventory and excess capacity. But these advances have also resulted in cascading impacts due to a global system with little room for error, in which a local disruption adversely impacts the entire supply-chain in distant locations. This connectedness amplifies the consequences of small local disruptive events as well as high-impact but low-probability "Black Swan" events. And the associated costs are high.

A groundbreaking 2005 study by Kevin Hendricks and Vinod Singhal analyzed the effects of 827 disruption events. The study found that over the course of three years, the average disruption reduced stock returns by up to an incredible $40 \%$. The result was a negative regardless of a disaster's cause (Hendricks and Singhal, 2005a). A follow-up study showed that disruptions increase share price volatility by $13.5 \%$, reduce operating income by $107 \%$, decrease sales growth by $7 \%$, and increase costs by $11 \%$ (Hendricks and Singhal, 2005b). A 2013 study by Accenture found that supply-chain disruptions reduce the share price of affected companies by $7 \%$ on average (World Economic Forum, 2013). Infrequent and unlikely disruptions thus canin a moment - destroy value created over a long period. As the study asserted (Hendricks and Singhal, 2005b, p. 3), "There is a direct relationship between efficiency and risk."

Supply-chain disruptions - of varying degrees of severity - are common. Seventy three percent of the respondents of The Business Continuity Institute's 2012 Annual Supply Chain Resilience Survey experienced at least one supply-chain disruption. Of these, nearly $40 \%$ occurred below the immediate tier-one supplier, showing the interconnectedness and complexity of modern business practices. Interestingly, information technology and telecommunications outages were the top sources of disruption, with severe weather taking a close second. The primary consequences of these disruptions are loss of productivity, increased cost of work, loss of revenue, and customer complaints.

Therefore globalization and supply-chain efficiencies - while among the great advances of the modern era - are only part of the value equation. Just as important is supply-chain resilience: the ability to withstand a crisis, absorb damage, recover quickly, and adapt to disruptive events. Resilience requires long-term planning and investment in redundancy, interoperability, and agility. Disruptions often cannot be predicted or controlled, but their negative impacts are 
incontrovertible. As Hendricks and Singhal (2005a, p. 51) conclude, "Investments in increasing reliability and responsiveness of supply chains could be viewed as buying insurance against the economic loss from disruptions." This is part of the adaptive learning process that resilience offers in response to the lessons of 9-11, active shooters, storms like Katrina and Sandy, as well as the current Ebola outbreak.

In addition to mitigating the risks and hazards of supply chain disruptions, resilience helps prepare businesses for future market slumps. According to Morgan Swink of the Neeley School of Business (Swink, 2012), "A firm's ability to weather economic downturns, deal with volatility and manage costs under shrinking demands depends in large part on the resiliency of its supply chains." According to research he conducted with Nancy Nix, companies with supply-chain flexibility and adaptability are better able to reduce expenses during a downturn, allowing them to outperform competitors and receive a substantially higher return on assets and equity. Our team at Johns Hopkins is working at operationalizing resilience in various geographic locations - including key maritime ports and economic megaregions of our nation-in order to establish a better interdisciplinary understanding of interconnected critical infrastructures in terms of physical, informational, and social phenomena.

\section{Investing in Resilience}

Resilience is "disaster agnostic," meaning it will favorably mitigate damage, to varying degrees, caused by earthquakes, terrorists, pandemics, and economic downturns. And though it may be difficult to quantify, after every disaster businesses that prepared ahead of time come out on top (Agrawal and Church, 2012). For example, an earthquake three years before the 2011 Japanese Fukushima tsunami helped prepare a semiconductor manufacturer to recover before its competitors because it had established a strategy to shift production to unaffected manufacturing plants (Marchese et al 2012). Maintaining critical operations in the face of disruptive events confers a measurable competitive advantage in the marketplace.

We know, from the emerging national policies and governance, that investing in resilience is a national imperative and increasingly considered a basic business practice. In addition to mitigating disaster-related damage by introducing new flexibility, it increases productivity, revenue, reputation, and shareholder value (USRP, 2012). Investing in resilience before disaster strikes is the smart choice for individuals, companies, and governments alike. What is the value proposition or return on investment? For individuals, it is an investment in adaptive safety and security. On the part of the government, it saves lives and property. For businesses, it protects the bottom line and sharpens their competitive advantage.

\section{References}

Agrawal M and C Church, "Resilience Return on Investment - An Impossible Argument?" Analytic Service, Inc., 2012. Available at http://tisp.org/index.cfm?pk=download\&pid=10261\&id=12606\%E2\%80\%8E.

Business Continuity Institute, 4th Annual Survey: Supply Chain Resilience, 2012. Available at http://www.zurich.com/internet/main/sitecollectiondocuments/reports/supply-chainresilience2012.pdf, Accessed on October 19, 2015.

Hendricks KB and V Singhal, 2005a, "An Empirical Analysis of the Effect of Supply Chain Disruptions on Long-Run Stock Price Performance and Equity Risk of the Firm," Production 
and Operations Management, vol. 14, no. 1 (Spring 2005): 35-52. Available at http://www.wilfridlaurieruniversity.ca/documents/17398/scm_glitches_and_shareholder_risk .pd, Accessed on October 19, 2015.

Hendricks KB and V Singhal, 2005b, "The Effect of Supply Chain Disruptions on Long-term Shareholder Value, Profitability, and Share Price Volatility," Supply Chain Magazine, 2005. Available at http://www.supplychainmagazine.fr/TOUTE-INFO/ETUDES/singhal-scmreport.pdf, Accessed on October 19, 2015.

Marchese K, S Paramasivam, and M Held, "Bouncing Back: Supply Chain Risk Management Lessons from Post-tsunami Japan,” Industry Week, 2012. Available at http://www.industryweek.com/global-economy/bouncing-back-supply-chain-riskmanagement-lessons-post-tsunami-japan, Accessed on October 19, 2015.

Swink, M. Weathering the Storm: How to Achieve Strategic Resilience Through Supply Chain Excellence, 2012. Fort Worth, TX: Neeley School of Business at TCU. Available at http://www.neeley.tcu.edu/News_and_Events/Press_Releases/Weathering_the_Storm_How _to_Achieve_Strategic_Resilience_Through_Supply_Chain_Excellence.aspx, Accessed on October 19, 2015.

U.S. Resilience Project (USRP), "Business Case for Supply Chain Security and Resilience," 2012. Available at http://www.usresilienceproject.org/workshop/participants/pdfs/USRP_Resources_Chapter_6 _030112.pdf.

World Economic Forum, Building Resilience in Supply Chains, 2013. Available at http://www3.weforum.org/docs/WEF_RRN_MO_BuildingResilienceSupplyChains_Report_ 2013.pdf, Accessed October 19, 2015. 
Rose, Adam

\section{Measuring Economic Resilience to Disasters}

\section{Abstract}

The purpose of this paper is to explain static and dynamic economic resilience in relation to disasters. This begins with a rigorous definition of concepts at the micro, meso, and macroeconomic levels. It is extended to an operational metric and discussion of its successful application to measuring resilience in case studies of simulated and actual events. We then discuss the formulation of resilience indices. We emphasize the importance of actionable variables that can lead to economic recovery. We also point out how to weight these variables in the overall index on the basis of studies of the effectiveness of individual resilience tactics.

\section{Keywords}

Economic resilience, operational metric, economic recovery, business management, resilience index, actionable variables

\section{Project background}

Over the past 10 years, researchers at the Center for Risk and Economic Analysis of Terrorism Events (CREATE), have addressed the following important questions relating to resilience:

- Is resilience a meaningful concept?

- Can resilience be rigorously defined?

- Can resilience be empirically measured?

- How effective has resilience been today?

- Can a meaningful resilience index be established?

The purpose of this paper is to explain how these questions, in the context of the economic domain, have been answered, modeled, and applied. We first define economic resilience in detail, including its various subtleties such as static vs. dynamic and inherent vs. adaptive resilience. We also discuss the role of resilience at the micro, meso, and macroeconomic levels. Next we present an operational metric that is relatively simple and straightforward, but has not been supplanted by more sophisticated definitions and metrics. We then discuss the application of the metric by CREATE researchers and others in measuring resilience in case studies of simulated and actual events. We then turn to the discussion of the recent flurry of activity on construction of resilience indices, pointing out that most of them are misguided because they simply view resilience as the flip-side of vulnerability. We emphasize the importance of actionable variables that can lead to recovery and how to weight these variables in the overall index.

\section{Defining Economic Resilience}

Resilience has four roles in the economics literature. Most generally, it is noted, typically in vague terms, as an attribute of the economy in studies of economic shocks (see, e.g., Dhawan and Jeske 2006). In ecological economics, it is a major focus of analysis as a key attribute necessary for sustainability (see, e.g., Folke 2006). Some initial attempts have been made to extend this research to the socioeconomic arena and have it overlap with the study of institutions 
(see, e.g., Levin 1998). In the disaster literature, it has been an important dimension of hazard economic loss estimation and terrorist consequence analysis (Rose 2009b). Following Rose (2004, 2009a) we provide specific definitions of Economic Resilience to disasters by linking it to the common essence of resilience definitions in other fields:

In general, Static Resilience refers to the ability of the system to maintain a high level of functioning when shocked. Static Economic Resilience is the: efficient use of remaining resources at a given point in time. It refers to the core economic concept of coping with resource scarcity, which is exacerbated under disaster conditions.

In general, Dynamic Resilience refers to the ability and speed of the system to recover. Dynamic Economic Resilience is: the efficient use of resources over time for investment in repair and reconstruction. Investment is a time-related phenomena - the act of setting aside resources that could potentially be used for current consumption in order to re-establish productivity for the future. Static Economic Resilience does not completely restore damaged capacity and is therefore not likely to lead to complete recovery.

Note that the definitions are couched in terms of function, typically measured in economics as the flow of goods and services, such as Gross Domestic Product (GDP) or broader measures of human well-being, as opposed to property damage. It is not the property (capital stock) that directly contributes to economic welfare but rather the flows that emanate from these stocks either for businesses or households. Two things should be kept in mind. First, while property damage takes place at a point in time, the reduced flow, often referred to on the production side as business interruption (BI), just begins at the time of the disaster but continues until the system has recovered or has attained a "new normal." Second, the recovery process, and hence the application of resilience, depends heavily on the behavior of economic decision-makers and on public policy. Of course, recovery is a multi-faceted activity. It is not as simple as, for example, rebuilding a school destroyed by an earthquake, hurricane, or armed attack. ${ }^{24}$

Ability implies a level of attainment will be achieved. Hence, the definitions of economic resilience are contextual -- the level of function has to be compared to the level that would have existed had the ability been absent. This means a reference point must be established. In the case of static economic resilience it refers to the worst case outcome. In the case of dynamic

\footnotetext{
${ }^{24}$ Research on resilience is split into two camps. About half of the researchers view resilience as any action that can reduce losses from disaster, ranging from pre-disaster mitigation to post-disaster recovery. Not surprisingly, this group is dominated by engineers, whose work is primarily in the area of mitigation (see, e.g., Bruneau et al. 2003, Haimes 2006). The other camp focuses on resilience following a disaster. Steps can be taken to enhance resilience, noting that it is very much a process, but such measures are usually not implemented until afterward (e.g., stockpiling of critical materials, development of emergency plans). Another aspect of the difference is that the former group typically measures resilience in terms of reduction in property damage, while the latter focuses on the reduction of the flow of goods and services stemming from the property stock. Recent events indicate that BI can be as large as or larger than property damage following a disaster. For example, a consortium of researchers utilizing a variety of methodologies, all found that the reduction in U.S. GDP following the World Trade Center attacks exceeded property damage by four-fold (Rose and Blomberg 2010). The BI associated with Hurricane Katrina began to exceed the property damage a few years ago, in part because New Orleans has not recovered according to most definitions. We focus on the second approach, noting, however, that much of our analysis is applicable to mitigation as well.
} 
resilience it refers to the normal recovery path. Further discussion of this oft-neglected point is provided below.

Another important distinction is between inherent and adaptive resilience. The former refers to aspects of resilience already built into the system, such as the availability of inventories, excess capacity, substitutability between inputs, and contingent contractual arrangements accessing suppliers of goods from outside the affected area (imports). Resilience capacity can be built up through these means and is then accessed after the disaster. Adaptive resilience arises out of improvisation under stress, such as Draconian conservation otherwise not thought possible (e.g., working many weeks without heat or air conditioning), changes in the way goods and services are produced, and new contracting arrangements that match customers who have lost their suppliers with suppliers who have lost their customers.

We analyze resilience pertaining to the economy at three levels:

- Microeconomic (individual business or household)

- Mesoeconomic (individual industry or market)

- Macroeconomic (combination of all economic entities, including their interactions)

Underlying each of the levels of analysis is an extensive body of economic principles, such as consumer and producer theory, the theory of markets, industrial organization, macroeconomic theory, and growth theory. Over the years these have been infused with the complexities of uncertainty, expectations, and bounded rationality that make them even more applicable to resilience to disasters.

At the micro-level, on the business supplier side, static economic resilience includes redundant systems, improved delivery logistics, and planning exercises. Several options also exist on the business customer side. Broadening the supply chain (see, e.g., Sheffi 2005) by expanding the range of suppliers in place or on a contingency basis is an increasingly popular option. Another is conservation of resources made all the more scarce by the disaster, such as automated controls to monitor the flow of water to reduce non-essential uses. Conservation is only minimally inherent because economists typically assume that resources are already being utilized most efficiently; thus, most resilient conservation options pertain to adaptive applications. All inputs (capital, labor, infrastructure services, and materials) can be conserved. The major obstacle is the necessity of the input in the production process. Other resilience tactics include input and import substitution, use of inventories and excess capacity, cross-training workers, relocation, and production recapture (working overtime and extra shifts when functionality is restored to make up lost production). Most of the same resilience tactics associated with businesses are applicable to government and household operations as well.

At the mesoeconomic level, resilience can bolster an industry or market and include, for instance, industry pooling of resources and information and innovative pricing mechanisms. What is often less appreciated is the inherent resilience of market prices that act as the "invisible hand" to guide resources to their best allocation in the aftermath of a disaster (see, e.g., Horwich 1995). Some pricing mechanisms have been established expressly to deal with such a situation, as in the case of non-interruptible service premia that enable customers to estimate the value of a continuous supply of electricity and to pay in advance for receiving priority service during an 
outage. The price mechanism is a relatively costless guide to redirecting goods and services. Price increases, to the extent that they do not reflect "gouging," serve a useful purpose of reflecting highest value use, even in the broader social setting. Moreover, if the reallocation violates principles of equity (fairness), the outcomes can be adjusted by income or material transfers to the needy. Of course, markets are likely to be damaged by a major disaster, in an analogous manner to buildings and humans. In this case, we have two alternatives for some or all of the economy: 1) substitute centralized decree or planning, though at a significantly higher cost of administration; 2) bolster the market, such as by improving information flows (e.g., the creation of a clearinghouse to match customers without suppliers to suppliers without customers).

At the macroeconomic level, resilience is very much influenced by interdependencies between sectors. Consequently, macroeconomic resilience is not only a function of resilience measures implemented by single businesses, but it is also determined by the actions taken by all individual companies and markets including their interaction. Examples of resilience options at the macrolevel would be economic diversity to buffer impacts on individual sectors or geographic proximity to economies not affected by a disaster in order to facilitate access to goods or aid. Others include fiscal (e.g., infrastructure spending to boost the affected economy) and monetary policy (e.g., keeping interest rates low to stimulate private sector reinvestment). The macro level overlaps with the popular focus on "community resilience" and represents a more holistic picture. However, economists have long appreciated the importance of microeconomic foundations of macroeconomic analysis for several reasons. First, the macroeconomy is composed of individual building blocks of producer and consumer behavior as underpinnings for macroeconomic considerations stemming from group interactions. Second, behavioral considerations are best addressed first at the most elemental level because of the prominence of individual motivations for survival and coping mechanisms in anticipation of and in response to disasters.

The previous examples relate primarily to Static Economic Resilience. Dynamic Economic Resilience is applicable at all three levels as well in terms of expediting the recovery process and enhancing its outcome. At the micro-level this can be promoted through rapid processing of insurance claims and arranging financing so as to facilitate repair and reconstruction (see also the NIST Economic Decision Guide by Gilbert, et al 2015). At the meso and macro-levels it includes hastening and improving the economic effectiveness of the recovery process by improving logistics and coordinating recovery across sectors. Cross-cutting all three levels is adapting to changing conditions by promoting flexibility and translating short-run practices into sustainable ones through a continuous learning process (see, e.g., Chang and Rose 2012, Zolli and Healy 2012, Rose 2015).

\section{An Operational Metric}

Following Rose (2004, 2009a), we provide an admittedly crude but operational metric of resilience. Direct Static Economic Resilience (DSER) refers to the level of the individual firm or industry (micro and meso-levels) and corresponds to what economists refer to as "partial equilibrium" analysis, or the operation of a business or household entity in and of itself. Total Static Economic Resilience (TSER) refers to the economy as a whole (macro level) and would ideally incorporate what is referred to as "general equilibrium" effects, which include all of the 
price and quantity interactions in the economy, macro-aggregate considerations, and the ramifications of fiscal, monetary and security policy.

An operational measure of $D S E R$ is the extent to which the estimated direct output reduction deviates from the likely maximum potential reduction given an external shock, such as the curtailment of some or all of a critical input. In essence, DSER is the percentage avoidance of the maximum economic disruption that a particular shock could bring about (see also Chang and Shinozuka 2004, who express their similar metric in absolute terms, but that limits comparisons).

A major measurement issue is what should be used as the maximum potential disruption. For ordinary disasters, a good starting point is a linear, or proportional, relationship, as, for example, between an input supply shortage and the direct disruption to the firm or industry. Note that while a linear reference point may appear to be arbitrary or a default choice, it does have an underlying rationale. A linear relationship connotes rigidity, the opposite of the "flexibility" connotation of static resilience defined in this paper. Analogously, the measure of TSER is the difference between a linear set of indirect effects, which implicitly omits resilience, and a nonlinear outcome, which incorporates the possibility of resilience.

We illustrate the application of the definition with the following case study by Rose et al. (2009), who estimated the national and regional economic impact of the September 11, 2001, terrorist attack on the World Trade Center. The researchers refined some available data indicating that more than 95 percent of the businesses and government offices operating in the WTC area survived by relocating; the vast majority to Mid-town Manhattan or across the river in Northern New Jersey. Had all of these firms gone out of business, the potential direct economic loss in terms of GDP would have been $\$ 43$ billion. However, relocation was not immediate, taking anywhere from a few days to as long as eight months for the vast majority of firms. Rose et al. (2009) calculated this loss in GDP at \$11 billion. They were then able to apply the resilience definition provided in this Section to estimate that the effectiveness of relocation as a resilience tactic in the aftermath of the $9 / 11$ attacks was 72 percent ( $\$ 43$ minus $\$ 11$, divided by $\$ 43$ ). This study highlights the importance of excess capacity as a resilience tactic. This more intensive use of resources is also the theme of the recovery in the current great recession in the U.S. and other countries, as employment recovery significantly lags behind the recovery of output. The experience of New York thus signals a significant change in approaches to disaster recovery, which has typically emphasized prompt rebuilding. Coupled with stronger requirements for mitigation, and hopefully some general accumulated wisdom, we are recovering less by reflex action and more by intelligent planning (see also Vale and Campanella 2005, Chang and Rose 2012).

For the most part, TSER refers to off-site considerations. These would include infrastructure interdependence, supply-chain interactions, community/institutional systems, and features of the economy of the entire region or nation, including the influence of fiscal and monetary policy. Clearly, Federal Reserve Bank policies of providing $\$ 100$ billion for interbank loans in the immediate aftermath of $9 / 11$ and keeping interest rates low for a much longer period greatly helped to reduce the potential losses of this disaster (Rose and Blomberg 2010). 
TSER pertains primarily to interdependencies that affect resilience. They apply to relationships up and down each individual industry supply chain (meso level) but also the integration of all these chains (macro-level). Even if two of these chains do not appear to be related, the fact that they utilize many of the same inputs means that they compete for their availability, and that affects their price. It also means each activity, or unit of analysis, effects macroeconomic variables, where the whole is not just the simple sum of the parts. Resilience can also stem from fiscal, monetary and security policies. The production interdependencies are referred to as simple multiplier effects, the price-quality relationships referred to as general equilibrium (GE) effects, and the aggregate relationships as macroeconomic effects. The size of TSER is influenced by the magnitude of the DSER but its proportion less so. A high DSER, will have a high TSER associated with it because of the high base value. But the basic/GE/macro multiplier is more dependent on the structure of the economy. More technologically advanced economies and more self-sufficient ones (and the former significantly affects the latter) have higher multipliers. This applies not only to the more obvious aspects of the technological relationships of factory production but also to less visible aspects of the economy such as the financial system. ${ }^{25}$

Our basic resilience metric can be applied to Direct Dynamic Economic Resilience (DDER) and Total Dynamic Economic Resilience (TDER) as well. The metric itself is unchanged (it is still expressed in terms of percentage losses avoided) but is influenced by a different set of factors than the static counterpart. The primary considerations relate to expediting investment in repair and reconstruction (see also Gilbert and Butry 2015). The reference base is normal recovery time in the presence of ordinary resilience activities or absence of resilience entirely (for the purists), which is not easy to measure precisely but can be approximated by historical averages adjusted for estimates of resilience that were put in place. Rules of thumb again provide insights, in that cutting recovery time in half will likely lead to a reduction of losses by an equal percentage. The complication comes from the likelihood of enhanced productivity associated with the new capital stock, which can be factored in to further offset losses and hence increase the resilience score. Likewise, the effect of repaired or new capital stock that makes a business, industry, or overall economy less vulnerable to future disasters can be factored into the metric as well.

\section{Measurement of Economic Resilience}

Several studies have examined economic resilience in actual disasters or with the use of simulation studies. The major pioneer is Tierney (1997), who surveyed businesses in the aftermath of the Northridge Earthquake and Midwest Floods. Rose and Lim (2002) translated

\footnotetext{
${ }^{25}$ Recall that the definition of resilience is contextual, i.e., resilience in comparison to a reference base of the absence of resilience, or, more specifically, the worst potential outcome from a given threat. This would best be modeled by a linear, or fixed-coefficient, production function at the micro and meso levels, and an input-output (IO) model, composed of such functions, at the macro level. Also, while DSER can be directly empirically measured (e.g., every firm is aware of the amount of electricity it purchases directly), TSER cannot be, primarily because of its complexity arising from the many rounds of interdependencies (the firm does not know how much electricity its direct and indirect suppliers and customers use). A formal modeling approach is needed. I-O is ideal for the establishment of the reference, or worse case, scenario (it does not allow for input or import substitution, conservation, or technological adaptation). In contrast, computable general equilibrium (CGE) models are able to incorporate several types of inherent resilience and can readily be modified to include adaptive ones (see, e.g., Rose and Liao 2005, Rose 2015). Macreconometric models are superior for capturing the resilience effects of monetary and fiscal policy.
} 
Tierney's findings into specific measures of resilience of the Los Angeles electricity system. They identified such factors as time-of-day-use, electricity "importance" (dependence), and production recapture as key to understanding why businesses that averaged an $\mathrm{X} \%$ reduction of electricity were able to continue operation at much less than an $\mathrm{X} \%$ reduction in their production goods and services. In fact, they found that these micro-level tactics resulted in a reduction of business interruption losses by more than 90 percent of baseline estimates, a level consistent with Tierney's survey responses.

Rose and Liao (2005) also used the Tierney survey responses relating to water service disruptions to evaluate two major types of resilience: conservation of scarce inputs and enhanced ability to substitute other inputs for water. Overall, the above resilience strategies only yielded a reduction of losses by a few percentage points, however. In this study macro impacts follow from micro impacts of resilience through various type of general equilibrium effects. The macro impacts of resilience doubled the micro-level impacts.

Other estimates of resilience have been less evidence-based, but are still prominent in the literature. Several resilience factors were incorporated by the author and colleagues into FEMA's loss estimation tool-HAZUS (FEMA, 2013), which is being adapted for use in many other countries. The Direct Economic Loss Module (DELM) includes factors for individual businesses making up lost production at a later date by working overtime or extra shifts after their utility lifelines had been restored or after building damage had been repaired. These "recapture factors" were based on a synthesis of the literature, and the indication is that these factors are very high (ranging between 50 and 98 percent for most sectors) for short periods. That is, customers are unlikely to cancel their orders for the output of disaster-sickened industries for short periods of time, because they have inventories on hand or long-standing supply-chain relationships. On the other hand, this type of resilience is likely to decline over time, and is likely to fall to zero after one year, if not after several months. The HAZUS Indirect Loss Module (IELM) includes such resilience factors as inventories, excess capacity, and the ability of increased imports and exports. However, there are no definitive estimates of the effectiveness of these resilience tactics for all cases, so it is necessary for the user to access primary or secondary data to specify this.

Several other simulation studies have been undertaken to estimate the effects of resilience on losses from disasters, using the metric presented in the previous section. Kajitani and Tatano (2009) used a survey to estimate the resilience of Japanese industries to various types of lifeline disruptions from disasters. Their findings are the most definitive to date on a broad spectrum of resilience tactics. Rose et al. (2007a, 2007b) estimated the resilience of the Los Angeles water and power systems to a 2 -week outage due to a terrorist attack. They found that resilience could be as high as 90 percent, primarily due to production recapture. Rose and Wei (2013) examined such resilience tactics as excess capacity, inventories, and export diversion to reduce potential losses from a 90-day shutdown of a major U.S. seaport complex. They also examined the effectiveness of major government policies such as accessing the Strategic Petroleum Reserve, but found it likely to be of limited help at the cost of considerable political capital. Overall, they found that the implementation of these resilience tactics could reduce GDP losses in the regional by more than 70 percent. 
Note, however, these results should be carefully applied to natural disasters. In the case of terrorism, a specific infrastructure provider is targeted, but the rest of the economy is unscathed. Hence, when the water or power is restored, firms can resume production immediately. This is not the case for natural disasters, which inflict widespread damage, so that factories need to be repaired in addition to having their lifelines restored. Thus, the context needs to be factored into the potential effectiveness of some resilience tactics, such as production recapture, inventories, or conservation, where the effectiveness of these tactics wane over time.

In addition, the simulation studies cited above are biased towards estimating resilience at its maximum effectiveness. This is not always the case due to the disarray accompanying most disasters, administrative obstacles, and personal failings. Moreover, Rose (2009a) has pointed out that resilience can be eroded during large disasters as inventories are depleted, Draconian conservation becomes onerous, and opportunities for production recapture decline as customers abandon their traditional suppliers unable to deliver.

Two other factors impinge on effectiveness. The first is cost, but it turns out that resilience tactics are relatively inexpensive, especially compared to mitigation measures such as structural reinforcement of buildings or building of levees. For instance, conservation more than pays for itself, input substitution requires a small penalty, the cost of inventories is just the carrying charge, emergency drills take relatively little time, production rescheduling only involves the payment of overtime wages. Still even small costs can be serious obstacles in poor countries. Secondly, resilience may have negative side-effects. In the rush to rebuild, requests are often made to suspend environmental and safety regulations. Such requests must be carefully considered in light of the ancillary damages that could occur.

Overall, more case studies are needed to contrast successes (e.g., recovery from SuperStorm Sandy) and failures (e.g., recovery to Hurricane Katrina). Best practice examples can be very helpful, especially at the small business and household levels, where expertise is limited. Crosscultural studies are enlightening as well in both broadening horizons and illustrating limits of resilient practices.

\section{Resilience Indices}

Recently, interest has shifted to identifying individual resilience indicators that can be aggregated into an overall index. This has emanated in part form he successful compilations of vulnerability indices (see, e.g., Cutter et al. 2003). Several well-intentioned examples of residence indices include Cutter et al. (2010) and Sherrieb et al. (2010). One major conclusion is that many of the components of resilience indicators to date are not in fact important to the resilience of individual businesses or the economy as a whole during the early stages of the recovery process. Specifically, resilience is not just the flip-side of vulnerability. For example, the Index derived by Cutter et al. (2010) includes housing capital, equitable incomes, employment, business size, and position access. Sub-component variables include percent employment, percent home ownership, business size, female labor force participation, and a proxy for single sector employment dependence. Hardly any of these indicators match those derived from a solid economic conceptual framework. Also, few have much to do with the operation of an individual firm or the economy as a whole. Percent employment is a good initial measure of excess capacity in the labor force from which to draw; however, it does not take into 
account the fact that disasters are able to draw additional labor from neighboring communities either through market signals (higher wages) or for altruistic motivations.

Another approach to measuring and evaluating resilience is the establishment of a resilience threshold. This is analogous to the poverty threshold measured by incomes of $\$ 1.25 /$ day per household. Some, for example, have proposed a resilience threshold of $\$ 5 /$ day. This is, however, a narrow and limited approach. First, it appears arbitrary because there is no basis for the dollar value. Second it does not help much in relation to the destruction of major assets, such as houses or businesses. Here, a better measure would be asset holdings or access to credit or other financial assistance. Third, it is weak from a pure personal standpoint. Aspects of connectedness to social support groups (families, neighborhood associations, religious or social organizations) should be included. Also important is access to social services and to information about recovery alternatives. Lastly, one would ideally proceed beyond the minimum that this threshold indicator implies to a functional relationship that tracks the degree of resilience attained by higher levels of income or assets. It would be valuable to determine whether the indicator is characterized by increasing and then diminishing returns.

A major reason to construct a resilience index is not only to study the recovery process, but also to improve it. This speaks to the importance of actionable variables. Several indicators included in prior resilience indices refer to background conditions and general trends that can hardly be improved in the near-term aftermath. Moreover, improvement of some of them is not necessarily consistent with other economic goals. For example, diversification of the economy may come at the cost of some economic activity. Other indicators need to be acknowledged as being immutable during the key period in which business take resilient actions. Examples include literacy rates, percent disabled, and percent minority population. More research is needed to replace these indicators with ones that really matter to economic resilience and that can be implemented in the short-run.

Finally, it is important to identify resilience that is inherent in the survival mechanisms of businesses and households from those that require government policy assistance. This way, future recovery efforts can better capitalize on existing capabilities and minimize duplication of government services. The focus of government can then be on facilitating this inherent resilience by removing obstacles to private enterprise, reducing wait times for assistance, and more effectively targeting its role.

Our analysis indicates that few resilience frameworks and no actual indices adequately focus on business operations in the aftermath of a disaster. We contend that business behavior, in relation to static and dynamic resilience, is the key to economic recovery, at least in the short-run. Thus, while many prior attempts at developing a resilience index are useful for long-run analyses (more than a year after the event), hardly any are useful for the short-run.

Following Rose and Krausmann (2013), we now outline the development of a short-run economic resilience index focusing on business behavior that is intended to help gauge recovery potential. The key issues are: 1) if and how to combine resilience actions at the micro, meso, and macro-levels and 2) how to weight the various components. Both of these considerations are applicable to household/community resilience as well. 
The first challenge is whether a single index can best reflect the features of resilience at various levels of the economic aggregation hierarchy. We suggest it is best to separate the three levels first, and then explore ways to combine them. At the microeconomic level, i.e., the level of individual companies and organizations, a plethora of actionable measures to increase economic resilience exists. Business resilience consists of resilience options on both the customer and supplier side. While the former relates to coping with disaster impacts on the delivery of inputs and making effective use of resources, the latter pertains to ways to guarantee the delivery of outputs to customers. Some of these options relate to static economic resilience by aiming at diminishing losses (excess capacity, input or import substitution, etc.), while others facilitate speedy business recovery (reduce operating impediments, management, etc.) and hence belong to the dynamic resilience category.

The second consideration is how to evaluate the relative contribution of each resilience tactic (each measured as a single indicator) to overlap resilience. This issue of "weighting" has been finessed in nearly all prior cases. For instance, weights can be derived empirically, e.g., using surveys, or, as a fall back, from a theoretical model of the indicator to be measured. An alternative way to assign weights is by consensus or relevance with respect to specific policy initiatives. We propose that the best way to develop weights is based on evidence of the relative effectiveness of each type of resilience tactic. The weights would then have to be adjusted for any likely differences in the context in which the index is to be applied, from the original case. There is no one-size-fits-all approach to deriving weights and the method of choice will depend on the particular problem at hand.

It is important to note that economics is only one part of the recovery from disasters. We are not suggesting economics is the only thing that matters in recovery, even just economic recovery. In addition to the importance of non-economic factors, we also need to consider the existence of market failure, where the interests of business are not necessarily consistent with the interests of the community as a whole. In our context, this is exemplified by the possibility that the dispersal of toxic waste or ordinary pollutants might be accelerated by more rapid recovery, partly because environmental concerns may be given lower priority. One approach is to go beyond ordinary market-based economic indicators, such as GDP, by utilizing broader measures of economic well-being including the value of environmental resources and the value of household services.

\section{Conclusion}

This paper has presented the answers to several important questions relating to economic resilience:

- Is resilience a meaningful concept? Yes it is, especially from an economic perspective.

- Can resilience be rigorously defined? Yes, though it is complex and has multiple dimensions.

- Can resilience be empirically measured? Yes, and an operational metric has been established and successfully applied in several contexts.

- How effective has resilience been today? It has been very effective, and moreover has been relatively low-cost and hence cost-effective. 
- Can a meaningful resilience index be established? Yes, if it has solid conceptual grounding, is based on actionable variables, and appropriate weights for individual indicators can be specified.

While it is desirable to reduce risk, this must be placed in the broader context of the several alternatives available. We can mitigate many threats and reduce vulnerability through various means. However, we can also reduce consequences via the Static and Dynamic Economic Resilience concepts discussed above. It is important to balance the picture among the most costeffective alternatives. It is also important to keep in mind that it is impossible to eliminate all threats and to minimize vulnerability completely. Resilience then becomes our next best line of defense against major disruptions.

\section{References}

Bruneau, M., S. Chang, R. Eguchi, G. Lee, T. O’Rourke, A. Reinhorn, M. Shinozuka, K. Tierney, W. Wallace, and D. von Winterfeldt, 2003, "A Framework to Quantitatively Assess and Enhance Seismic Resilience of Communities," Earthquake Spectra, 19(3), 733-52.

Chang, S. and A. Rose, 2012, "Economic Recovery to Disasters," International Journal of Mass Emergencies and Disasters, vol. 30, iss. 2, pp. 171-81.

Chang, S. and M. Shinozuka, 2004, "Measuring and Improving the Disaster Resilience of Communities," Earthquake Spectra, vol. 20, iss. 3, pp. 739-55.

Chang, S., A. Rose, and L. Johnson, 2011, National Research Council, "What is National Earthquake Resilience?” in National Earthquake Resilience: Research, Implementation, and Outreach, The National Academies Press, Washington, DC.

Cutter, S. et al., 2003, "Social Vulnerability to Environmental Hazards," Social Science Quarterly ,vol. 84, iss. 2, pp. 241-61.

Cutter, S. L., C. G. Burton, and C. T. Emrich, 2010, "Disaster Resilience Indicators for Benchmarking Baseline Conditions," Journal of Homeland Security and Emergency Management, vol. 7, Article 51.

Dhawan, R. and K. Jeske, 2006, "How Resilient is the Modern Economy to Energy Price Shocks?," Economic Review, Federal Reserve Bank of Atlanta, Third Quarter, pp. 21-32.

Federal Emergency Management Agency (FEMA), 2013, Multi-hazard Loss Estimation Methodology (HAZUS®MH MR4) http://www.fema.gov/library/viewRecord.do?id=3726

Gilbert, S., 2010, Disaster Resilience: A Guide to the Literature. NIST Special Publication 1117, Gaithersburg, MD: National Institute of Standards and Technology.

Gilbert, S., D. Butry, J. Helgeson, and R. Chapman, 2015, Community Resilience Economic Decision Guide for Buildings and Infrastructure Systems. NIST SP 1197, MD.

Haimes, Y. Y., 2006, "On the Definition of Vulnerabilities in Measuring Risks to Infrastructures," Risk Analysis, vol. 26, iss. 2, pp. 293-96.

Horwich, G., 1995, "Economic Lessons of the Kobe Earthquake," Economic Development and Cultural Change, vol. 48, iss. 3, pp. 521-42.

Kajitani, Y., and H. Tatano, 2009, "Estimation of Lifeline Resilience Factors based on Empirical Surveys of Japanese Industries," Earthquake Spectra, vol. 25, iss. 4, pp. 755-76.

Levin, S., 1998, "Resilience in Natural and Socioeconomic Systems," Environment and Development Economics, Special Issue on Resilience and Sustainability, 3(2), 221-35. 
Norris, F., S. Stevens, V. Pfefferbaum, K. Whyche, and R. Pfefferbaum, 2008, "Community Resilience as a Metaphor, Theory, Set of Capacities and Strategy for Disaster Readiness," American Journal of Community Psychology, vol. 41, pp. 127-50.

Rose, A. 2004. "Defining and Measuring Economic Resilience to Disasters," Disaster Prevention and Management, vol. 5, iss. 3, pp 307-14.

Rose, A., 2009a, Economic Resilience to Disasters. CARRI Research Report \#8. ORNL.

Rose, A., 2009b, "A Framework for Analyzing and Estimating the Total Economic Impacts of a Terrorist Attack and Natural Disaster," Journal of Homeland Security and Emergency Management, vol. 6, iss. 1, Article 6.

Rose, A., 2013, Defining and Measuring Societal Resilience from an Economic, Environmental and Personal Security Perspective, Background Paper for the United Nations Development Programme Human Development Report.

Rose, A., 2015, "Macroeconomic Consequences of Terrorist Attacks: Estimation for the Analysis of Policies and Rules," in C. Mansfield and V. K. Smith (eds.), Benefit Transfer for the Analysis of DHS Policies and Rules (pp. 172-201), Edward Elgar, Cheltenham, UK.

Rose, A. and S. B. Blomberg, 2010, "Total Economic Impacts of a Terrorist Attack: Insights from 9/11," Peace Economics, Peace Science and Public Policy, vol. 16, iss. 1, Article 2.

Rose, A. and E. Krausmann, 2013, "An Economic Framework for the Development of a Resilience Index for Business Recovery,” Int. J. Disaster Risk Reduction, vol.5, iss. 3, 73-83.

Rose, A. and S. Liao, 2005, "Modeling Resilience to Disasters: Computable General Equilibrium Analysis of a Water Service Disruption," Journal of Regional Science, 45 (1), 75-112.

Rose, A. and D. Lim, 2002, "Business Interruption Losses from Natural Hazards: Conceptual and Methodology Issues in the Case of the Northridge Earthquake," Environmental Hazards: Human and Social Dimensions, vol 4., iss. 2, pp. 1-14.

Rose, A. and D. Wei, 2013, "Estimating the Economic Consequences of a Port Shutdown: The Special Role of Resilience," Economic Systems Research, vol. 25, iss. 2, pp. 212-32.

Rose, A., G. Oladosu, and S. Liao, 2007a, "Business Interruption Impacts of a Terrorist Attack on the Electric Power System of Los Angeles: Customer Resilience to a Total Blackout," Risk Analysis, vol. 27, iss. 3, pp. 513-531.

Rose, A., G. Oladosu, S. Liao, 2007b, "Regional Economic Impacts of a Terrorist Attack on the Water System of Los Angeles: A Computable General Disequilibrium Analysis," in Richardson, H., Gordon, P., Moore, J., (eds.), The Economic Costs and Consequences of a Terrorist Attack, Edward Elgar Publishing Company, Cheltenham, UK.

Rose, A., G. Oladosu, B. Lee, and G. Beeler-Asay, 2009, "The Economic Impacts of the 2001 Terrorist Attacks on the World Trade Center: A Computable General Equilibrium Analysis," Peace Economics, Peace Science, and Public Policy, vol. 15, iss. 2, Article 4.

Sheffi, Y., 2005, The Resilient Enterprise, MIT Press, Cambridge, MA.

Sherrieb, K, F. Norris, and S. Galea. 2010. "Measuring Capacities for Community Resilience," Social Indicators Research, vol. 99, pp. 227-47.

Tierney, K., 1997, "Impacts of Recent Disasters on Businesses: The 1993 Midwest Floods and the 1994 Northridge Earthquake," in B. Jones (ed.), Economic Consequences of Earthquakes: Preparing for the Unexpected (pp. 189-222), NCEER, Buffalo, NY.

Vale, L. and T. Campanella. 2005. The Resilient City: How Modern Cities Recover from Disaster. New York: Oxford.

Zolli, A. and A. M. Healy, 2012, Resilience: Why Things Bounce Back, Free Press, NY. 
Seville, E., J.R. Stevenson, J. Vargo, C. Brown, and S. Giovinazzi

\title{
Resilience and Recovery: Business Behavior Following the Canterbury Earthquakes
}

\begin{abstract}
Within an economy, businesses, governments and community service providers are the actorson-the-ground that experience the direct and indirect impacts of infrastructure failures. They are the actors whose responses, decisions, and adaptive behaviors collectively shape the path of economic recovery and patterns of growth and decline. This brief report presents key findings from a study conducted with 541 public and private Canterbury regional organizations by Resilient Organizations as part of the Economics of Resilient Infrastructure (ERI) project in New Zealand. The study was conducted in the light of major disruptions in the aftermath of a complex earthquake sequence.
\end{abstract}

The research presented here found how organizations mitigated those disruptions and recovered their productive capacity. Highlighted are the ways in which they adapted to facilitate continued or even improved functioning and discovered the impact of organizations resilience on ability to meet customer demand, productivity and cash-flow.

\section{Keywords}

Christchurch earthquakes; infrastructure failure; business disruption; organizations; businesses; resilience; economic recovery

\section{Project background}

The Economics of Resilient Infrastructure (ERI) research project is funded by the New Zealand government to develop a new spatial decision support system for New Zealand. The system, referred to as 'Measuring the Economics of Resilient Infrastructure Tool' (MERIT), will be used to support government and infrastructure provider decision-making by enhancing their understanding of the societal value of resilience improvements.

MERIT consists of a suite of interlinked modules incorporating spatial features of a region and its infrastructure networks, economic activity, business behaviors, interdependencies, and policy options. These modules can be shocked using scenarios (e.g. volcanic eruption, significant single infrastructure outage) to understand the impacts of such disruptions.

This report summarizes a study of organizations affected by the 2010/2011 Canterbury earthquakes. In 2010 and 2011, the Canterbury region of New Zealand was affected by a series of destructive earthquakes. The two largest earthquake events on September $4^{\text {th }}, 2010$ (M7.1) and February 22 $2^{\text {nd }}, 2011$ (M6.3) were followed by thousands of aftershocks, some of which caused additional damage or exacerbated existing damage.

The earthquakes resulted in 185 deaths, extensive land, building and infrastructure damage from shaking and liquefaction (CCC, 2011; Giovinazzi et al., 2011; Eidinger, Tang, \& Rourke, 2010) 
and were the most expensive and socially disruptive disasters that New Zealand has ever experienced (Stevenson, 2014).

The study, based on a survey conducted in 2013, examined pre- and post-event behaviors that contributed to the recovery of organizations that were affected by the Canterbury Earthquake sequence and is being used to inform the business behaviors module for MERIT.

By examining how organizations mitigate, respond to, and recover from disruptions, this study contributes to our understanding of how business behaviors shape local and regional economic outcomes following a disruption. This information will be integrated into MERIT, so that appropriate organization-level event mitigation and post-event adaptation are testable model components.

\section{Survey Outcomes}

Between July and December 2013 ERI researchers sampled approximately 2170 organizations across Greater Christchurch. In total, 541 organizations responded to the survey (a response rate of about $25 \%$ ). The survey was extensive and this brief report only covers some of the key outcomes. Organizations were asked about their current situation and state of recovery, the results are seen in Figure 1.
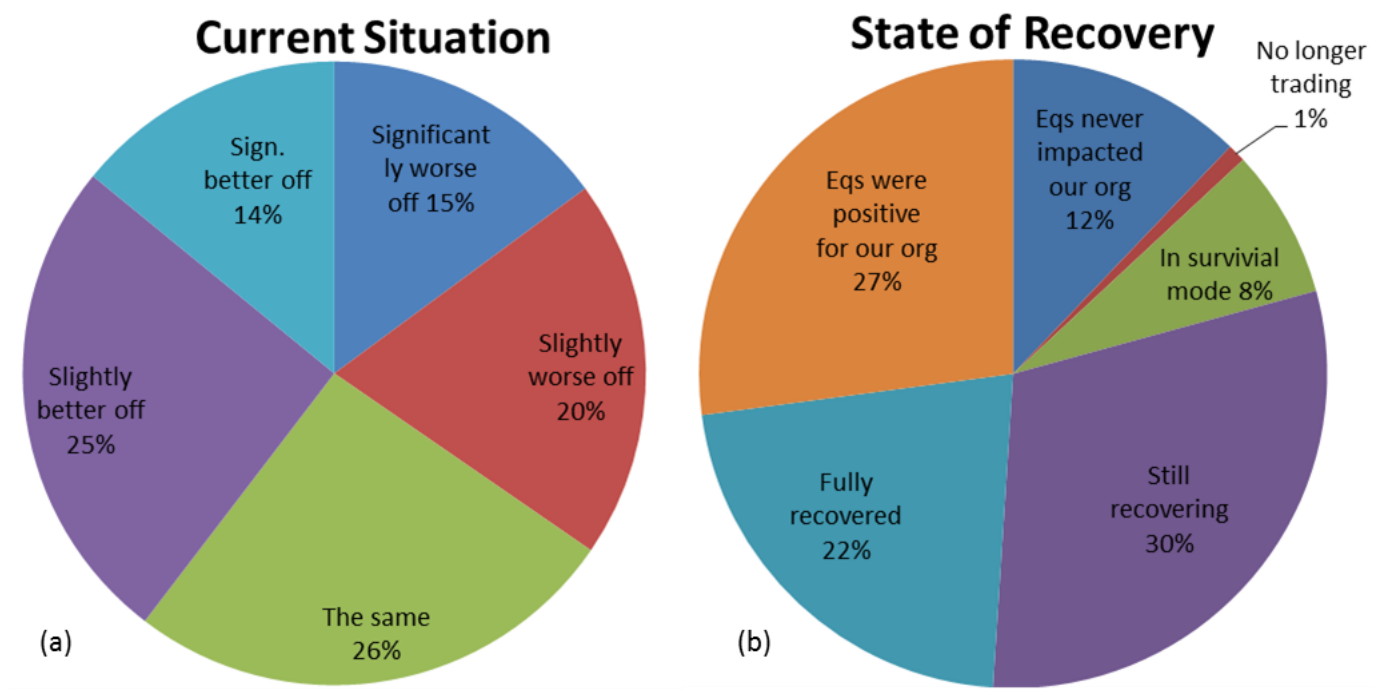

Figure 1. (a) Organizations' self-assessed situation at the time of surveying compared to before the earthquakes; (b) Organizations' state of recovery at the time of surveying.

We asked organizations about the degree to which they had been disrupted by different factors. These factors fall into four categories: 1) physical impacts to the organizations' stock or assets; 2) disruption to the organizations' external neighborhood or environment; 3) staff, market, and supply chain disruptions; and 4) lifeline utility supply disruptions.

Interestingly, even given the extensive levels of physical damage and disruption that organizations experienced, it was staff and market-based issues that organizations found to be most disruptive 
The single most disruptive factor for organizations was "customer issues." The survey allowed organizations to define customer issues for themselves, but it could include anything from delayed payments to customers relocating due to residential damage.

Issues regarding staff wellbeing were also especially disruptive for organizations. Common staff or human resourcing issues after the earthquake included: (1) difficulties finding qualified or suitable staff; (2) the additional burden of managing and supporting staff; and (3) reduced productivity due stress, being emotionally drained, and burnt out.

Organizations were also seriously disrupted due to damage to their buildings, buildings in their neighborhood, as well as people's perceptions that their buildings were unsafe.

Organizations that closed temporarily (after the February 2011 earthquake) were significantly more likely to experience reduced productivity compared to those who remained open immediately after the earthquake, and those that operated longer hours.

Loss of infrastructure services had a noticeable impact on productivity, regardless of length of closure. This was especially true for organizations that experienced water, sewage, electricity, phone, data, and road disruptions. These organizations were significantly more likely to experience reduced productivity compared to organizations that did not experience those disruptions. The greater the degree of infrastructure disruption the longer organizations were closed.

In addition to affecting their productive capacity, the earthquakes also caused shifts in demand for organizations' products and services (Figure 2).

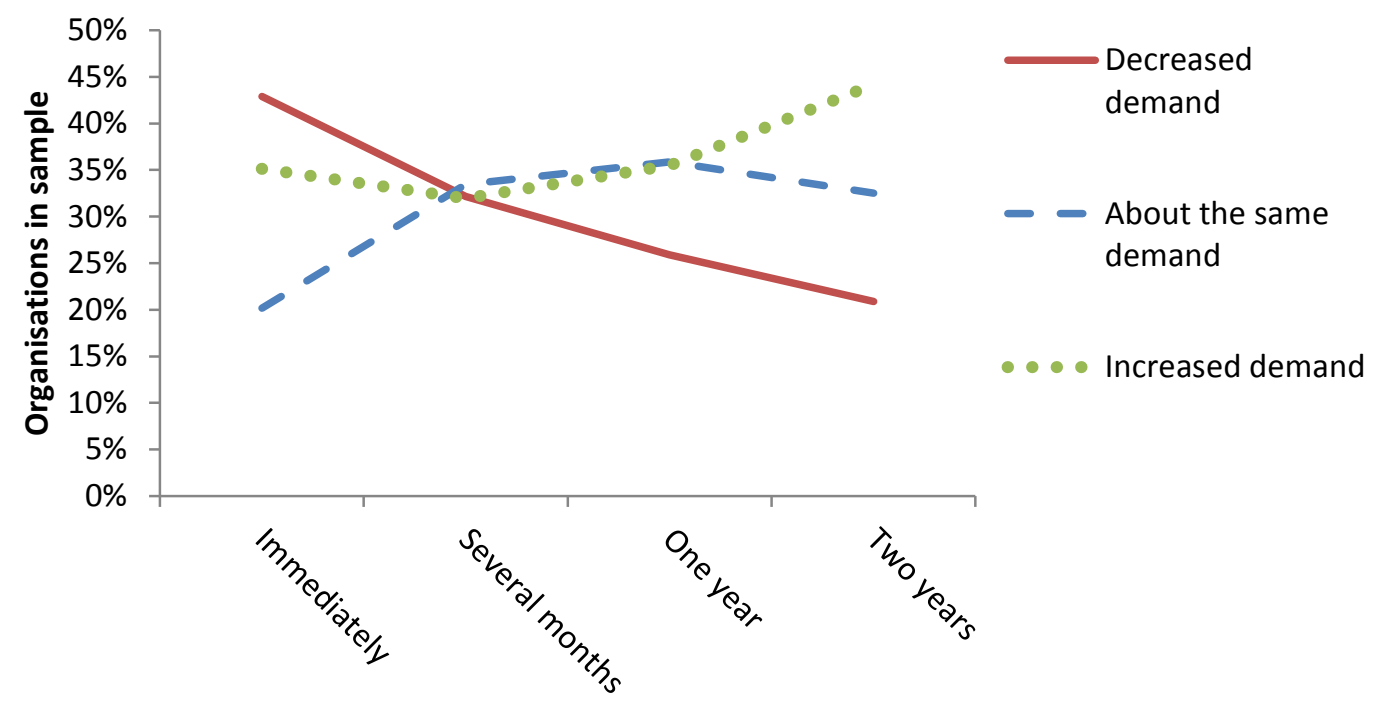

Amount of time after the September 2010 earthquake

Figure 2. Post-earthquake demand changes over time 


\section{Pathways to Resilience}

In this study we also examined the effect of organizational resilience on post-earthquake outcomes. Resilience describes an organization's ability to survive a crisis, and thrive in times of change and uncertainty (Resilient Organizations, 2014).

Resilience can be enacted in three phases. First, the organization can reduce the impact of a disruptive event by planning or mitigation. Second, after a disruption a resilient organization is able to recapture productivity relatively quicker. Third, a resilient organization is able to adapt to operate successfully in a disrupted environment.

The Resilient Organizations research program has identified 13 leading indicators of an organization's resilience, and developed assessment tools for evaluating how an organization performs against each indicator. These indicators are grouped into three overarching attributes an organization's leadership and culture, the networks it can draw on, and its change readiness (Figure 3). ${ }^{26}$

The results of the survey show that resilience is important. Organizations that scored highest against the 13 resilience indicators were better prepared, could function for longer with disrupted services, were more likely to be able to meet customer demand a year after the earthquakes, and had better cash flow and profitability.

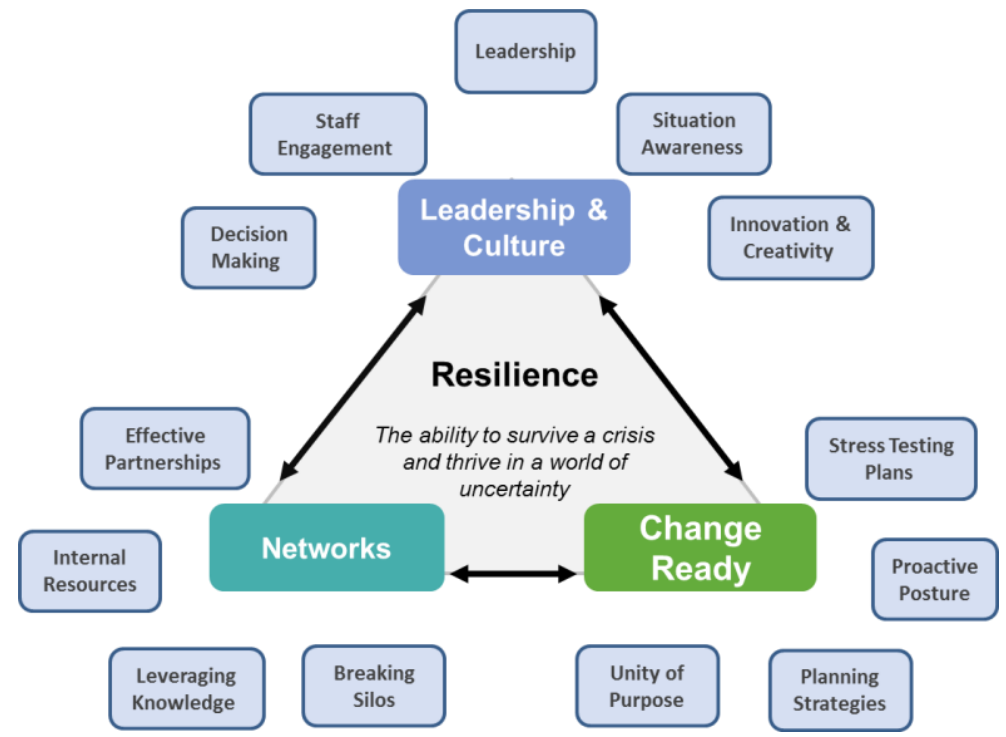

Figure 3. Leading indicators of organizational resilience (Resilient Organizations, 2014).

Some key pathways to resilience were identified in this study, including:

- Reducing impacts: Organizations can increase their ability to survive and thrive in a crisis by mitigating potential impacts through planning and by developing processes that enhance responsiveness and flexibility. Mitigation includes measures to reduce risks, such as

\footnotetext{
${ }^{26}$ For a definition of each of these indicators see: http://www.resorgs.org.nz/Content/what-is organizational$\underline{\text { resilience.html }}$
} 
building strengthening, having backup arrangements for when critical infrastructure services are disrupted, or taking out insurance. Relationships (with staff, customers and suppliers) were seen as the most important mitigation measures.

- Recapturing productivity: Many definitions of resilience refer to a system's capacity to retain or efficiently regain function following a disruption. According to Park, Cho, and Rose (2011, p.163), "One of the most prominent sources of resilience is the ability of businesses to reschedule, or recapture, lost production after the [disruptive] event." Following the Canterbury earthquakes, organizations employed a range of strategies to recapture productivity. One of the most common recapture strategies for organizations, and the most important, was also one of the simplest. More than $70 \%$ of organizations made more intensive use of staffing resources to recapture lost production. Other primary strategies included: more intensive use of existing resources, replaced or upgraded technology (especially by those most impacted), conservation of resources, and existing high levels of inventory.

- Adapting to new environments: Out of necessity, organizations across the region adapted significantly in order to reopen and recapture lost productivity. In some cases organizations altered their strategies and processes a number of times throughout the continuous and compounding disruptions. We found that nearly $30 \%$ of organizations entered new markets or served a new or expanded set of customers. Other relatively common adaptive strategies included restructuring (23\%), adopting new technologies (22\%), and making significant changes to operational processes $(20 \%)$ such as maintenance activities. Some organizations also opted to close unprofitable lines $(11.7 \%)$, add new lines of products or services $(10.7 \%)$, and provide new delivery channels for products and services $(8.3 \%)$. We also found that once an organization started adapting it tended to keep adapting This is something we call adaptive snowballing. Adaptive snowballing could also indicate a more general organizational posture of change readiness.

- Relative Resilience by Economic Sector: There are very different levels of resilience across different sectors of our economy. The sectors with the most resilient organizations include: Public Administration and Safety, Electricity, Gas, Water and Wastewater services, Education and Training, and the Information Media and Telecommunications sectors. Sectors with the lowest resilience include: Arts and recreation services, Agriculture, Forestry and Fishing, and the Retail Trade sectors. Resilience, regardless of sector, is a good indicator of the ability of organizations to recapture productivity.

\section{Conclusions}

It is natural when modeling the economy to think at an aggregated level, and yet much of the richness of the recovery process emerges at an organizational level. When trying to model how economies respond to disruptions it is important to understand how different economic actors' behaviors will modify the outcomes. Disasters inevitably create winners and losers, and this pattern evolves as recovery progresses.

Our research has found that overall organizations are recovering well from the Canterbury earthquakes. However, organizations have different capacities to respond and adapt to the challenges they face. Our challenge as part of the ERI project is to tease out the factors that 
support or inhibit different organizations to deal effectively with disruption, so that these factors can be incorporated into the MERIT suite of tools.

This report paints a high-level overview of some of the key findings from our preliminary analysis of the survey data. These findings include:

- Despite all of the physical damage, it was human / organizational issues, that were most disruptive for organizations including: customer-related issues, and managing staff wellbeing.

- Of all the infrastructure disruption organizations experienced, it was disruption on the roads they felt most keenly. Organizations experiencing infrastructure disruptions suffered reduced productivity and tended to close for longer.

- While we found that closure is associated with reduced productivity in the post-disaster period, interestingly, length of closure does not predict which organizations recover well and which do not.

- Supply chain resilience matters. Organizations whose suppliers were disrupted were significantly more likely to experience reduced productivity than organizations that did not face supplier issues.

- Organizations with a more resilient leadership and culture, that have strong networks, and that are change ready (as measured by the Resilient Organizations 13 resilience indicators) were better prepared, could function for longer with disrupted services and were more likely to meet customer demand a year after the earthquakes, and had better cashflow and profitability. Organizations with above average resilience were significantly more likely to maintain or improve productivity following the earthquakes.

- The earthquakes caused a dramatic reduction in resilience for many organizations in Greater Christchurch, but this reduction was temporary, showing the need to build and maintain the "stock" of resilience. Interestingly, Maori-focused organizations were more resilient and tended to recover better relative to their level of impact.

- Out of necessity, organizations adapted significantly; and once an organization started adapting, it tended to keep adapting - like an adaptive snowball. Of the adaptation strategies used to recover, more than $70 \%$ of organizations made more intensive use of their staffing resources to recapture lost production following the earthquakes. Nearly $30 \%$ entered new market sectors. Organizations that had engaged in some kind of relocation planning were more likely to move after the earthquakes. Organizations that experienced the greatest impact were also the ones most likely to take the opportunity to invest in new technologies.

This dataset, capturing the experiences of 541 organizations affected by the Canterbury earthquake sequence, is quite unique in the world of disaster research.

Our on-going analyses will advance the development of MERIT in two ways. First, the results will be used to develop causal networks demonstrating the relationships between organizational attributes, post-earthquake adaptive behaviors and recovery outcomes. These causal networks will be integrated into a larger systemic model of how a regional economy recovers from 
disruption. Second, the data will be examined at an aggregate level to explore interactions between different industry sectors and to help identify key leverage points to support economic recovery.

\section{References}

Christchurch City Council (CCC), (2011). Christchurch Earthquake Response: Liquefaction. Frequently Asked Questions. Christchurch, NZ. Retrieved from, http://canterburyearthquake.files.wordpress.com/2011/03/liquefaction-factsheet20110316.pdf

Eidinger, B. J., Tang, A., \& Rourke, T. O. (2010). Technical Council on Lifeline Earthquake Engineering (TCLEE) Report of the 4 September 2010 Mw 7.1 Canterbury (Darfield), New Zealand Earthquake, 1-49. Retrieved from

http://www.asce.org/uploadedFiles/Technical_Groups_and_Institutes/TCLEE/TCLEE\%20Preliminary\%2 02010\%20NZ\%20EQ\%20Report.pdf

Giovinazzi, S., Wilson, T., Davis, C., Bristow, D., Gallagher, M., Schofield, A.,...\& Tang, A. (2011). Lifelines Performance and Management Following the 22 February 2011 Christchurch Earthquake, New Zealand: Highlights of Resilience. Bulletin of the New Zealand Society for Earthquake Engineering, 44(4), 402-417.

NHRP. (2014). Economics of Resilient Infrastructure: Developing New Zealand's understanding of the economic impacts of infrastructure outages. Natural Hazards Research Platform. Retrieved from http://www.naturalhazards.org.nz/NHRP/Hazard-themes/SocietalResilience/Economics-of-Resilient-Infrastructure

Park, J. Y., Cho, J., \& Rose, A. (2010). Modeling a major source of economic resilience to disasters: recapturing lost production. Natural Hazards, 58(1), 63-182.

Resilient Organizations (2014) See URL www.resorgs.org.nz

Stevenson, J. R. (2014). Organizational Resilience after the Canterbury Earthquakes: A Contextual Approach. Ph.D. Thesis. University of Canterbury, Christchurch, NZ. 
Slaughter, E. Sarah

\title{
Economics of Investments for Resilient Communities: A Systems View
}

\begin{abstract}
In a systems view, a community is a set of people with shared values, norms and relationships that live in close proximity to each other in a specific place. The social system of a community has relationships with the other social systems in which it is nested, and also with the natural systems, both within that specific location and nested within the greater natural systems. Humans create built systems to provide critical services that enable civil society and commerce, and these built systems have relationships with both the social and natural, and they with it. Resilience is defined as the "persistence of systems and their ability to absorb change and disturbance and still maintain the same relationships among populations or state variables." Enhancing resilience entails developing the community's long-term capacity to accommodate changes by effectively leveraging all of the assets and resources associated with its systems, relationships, and states.
\end{abstract}

\section{Keywords}

Community, systems theory, economics, resilience, sustainability, investment

\section{Background}

A community can be defined as a collection of people that share a set of relationships, which include beliefs, rules, and resources. The people in a community live in fairly close proximity to each other and share the natural, social, and built systems in that location. A community can be seen as a locus of social and natural systems that are nested in larger systems, where a "system" is defined as a set of entities with interconnections that provide patterns of behavior over time (Meadows, 2008). Humans create built systems to provide critical services that enhance civil society and commerce (NRC, 2009).

Communities (and the larger social systems in which they are nested) establish a set of norms, conventions, and rules based on shared beliefs that guide the flows among the systems, including access to, distribution of, and control over resources. These rules are "may be formal or informal, overt or implicit, and are created to reduce uncertainty, to maintain continuity of social patterns and social order, and to [establish] forms of human interactions in more predictable ways" (Tyler and Moench, 2012, p. 315; Ostrom, 1990). Economic, political, and legal systems draw upon these social rules to create mechanisms for formal, explicit agreements among parties, for instance, to balance individual appropriation of benefits with the larger community interests.

Resilience, as defined by Holling in his seminal work, is defined as the "persistence of systems and their ability to absorb change and disturbance and still maintain the same relationships among populations or state variables" (Holling, 1973, p. 14). A system is "more resilient" when its flexibility allows it to accommodate changes over time while maintaining its relationships or state variables, including functionality. Within a system, resilience is provided through multiple feedback loops at different time and spatial scales with different mechanisms and redundancies that restore the system's relationships and state(s) (Meadows, 2008, p. 76). "Meta-resilience" is provided through a set of feedback loops that can restore or rebuild feedback loops, and an even 
higher level of resilience is provided through utilizing an intrinsic aspect of systems to selforganize, in which the feedback loops can learn to create, design, and evolve (op. cit.).

It should be noted that Holling defines stability in contrast to resilience, where stability is the "ability of a system to return to an equilibrium state after a temporary disturbance" (Holling, 1973). All systems, including social systems, are highly dynamic and often exhibit nonlinear behavior that may vary significantly over time and spatially. Because social, natural, and human systems are highly interdependent through their interrelationships, focusing on restoring a subsystem to a specific static state during endogenous or exogenous shocks (i.e., stability) may actually cause collapse and loss of the system (Quill, 2012).

\section{Building Community Resilience}

Building community resilience, therefore, can be seen as the practice of understanding the dynamics and interdependencies of the nested systems in a specific place at a particular time. The focus can be on utilizing specific leverage points to enhance the community's capacity and capability to accommodate perturbations and disturbances, and to persist in its purpose or role over time. Communities face multiple disturbances throughout their existence, including macro and micro-economic, social, political, and cultural shifts, as well as perturbations in the local, regional and global natural and built systems. As noted above, since a community's resilience relies upon the relationships among its systems, investments to build community resilience will consider the opportunities for enhancing the performance of all of the related social, natural, and built systems.

Communities continuously invest in (and withdraw from) its systems that affect resilience. Educating children, holding town meetings, and building roads that provide mobility and exchange are all investments in either the specific system or the relationships among the systems. Examples of withdrawals at the community level may include using a local water source to provide potable water and charging taxes and fees to support community operations, while withdrawals at the organizational or individual level may include resource extraction or harvesting crops. These flows are an inherent attribute of systems, and may be balanced to provide mutual benefit among the interdependent systems. However, imbalanced or excessive transfers (either in or out) can disrupt a community's systems. Withdrawals that permanently alter or degrade the local systems (such as mountaintop mining) seriously degrade a community's resilience and may imperil its continued existence.

The social rules that embody the community's values (and of its nested social systems) will change over time to reflect learning. The constant re-development of the social rules (and mechanisms) is critical to enhancing a community's resilience, particularly with respect to impacts that degrade the relationships or state variables within or among the community's systems. Interdependence among the community's systems may only be apparent over time, and the effects may not be proportional to the initiating action. In addition, the system impacts may be spatially unevenly distributed (such as at a distance from the initiating action), and may entail secondary and tertiary impacts that are discerned only after the development of additional knowledge, methodologies, or tools. For example, the addition of lead to automobile gasoline was seen to provide individual benefits (in the operation of the specific vehicle) but created 
serious and wide-ranging impacts across human and natural systems, and so the rules were changed to eliminate that additive from the fuel.

A small portion of the flows among the systems that affect a community's resilience can be measured in strictly economic terms. As noted earlier, the social rules that are embodied in the legal, political, and financial systems (and their mechanisms) represent a momentary manifestation of norms and conventions, which change over time to reflect the learning and evolution of the self-organizing community systems. This capacity to change over time can be a community's strongest form of resilience. Therefore, the economic valuation associated with a community's flows are both effected by and affect the relationships among the systems, and can explicitly accommodate new system structures and behaviors, as well as new social goals and rules, over time.

\section{Economics of Community Resilience}

Given that the economic system is a portion of the community's systems, the definition of the boundaries of this system is critical to understanding its relationship to the community as a whole, and to its resilience. Standard economic analysis focuses on the monetary expression of inflows (costs) and outflows (benefits) over a specific time period, and relative to current state of larger-scale economic systems.

Assessing the economic valuation of resilience investments depends upon the specific location and category of investor, as well as the expected (and unexpected) interdependence with other systems, as embodied in the rules and mechanisms at a particular point in time. Standard economic exchanges differentiate between categories of entities participating in the exchange. For example, when an entity borrows money, the borrowing fee (interest rate) is established by financial organizations relative to the larger regional, national, and international monetary markets. The location of the borrower (spatially, temporally, and within its nested systems) matters.

The economic exchanges associated with a community's systems occur over time and, depending upon the prevailing market system, can be associated with many of the community's formal flows. These economic exchanges, which can be seen to affect a community's resilience overall, can be traced through the dynamic interactions among the public, organizational, and household/individual economic exchanges within the community's social, natural, and built systems. For example, each U.S. city has an annual budget that predicts the cash outflows and inflows; this set of economic resources provides the wherewithal for the municipality to conduct its functions, including governance, emergency response, education, public works, and other activities. In the same way, the organizations within that community will have formal annual budget systems to achieve their functions, both within and outside the specific community. Households and individuals may or may not have formal budgets, but will similarly balance cash inflows and outflows and will likewise interact with systems at different scales and locations.

Each budget includes recurring expenditures (including personnel, operations, maintenance, and other costs), infrequent or nonrecurring expenditures (such as repairs) and capital investments. (An "investment" can be defined as a commitment of resources with the expectation that it provides benefits after a time delay.) While most attention on community resilience has focused 
on possible additional capital investments, the economic interventions to improve community resilience can draw upon the full set of economic and other resource flows within a community over time. For example, in 2014, the U.S. Gross Domestic Product was \$17.4 trillion, with personal consumption expenditures equaling \$12 trillion and private domestic investment equaling \$2.9 trillion (Bureau of Economic Analysis, 2014). These personal consumption and private investment expenditures could (and may already) contribute to overall national and community resilience through enhancing the relationships among community social, built, and natural systems.

Looking specifically at the public sector economic flows, total U.S. government expenditures for 2012 equaled over \$6.6 trillion, with federal expenditures of \$3.5 trillion (Executive Office of the President, 2014), and state and local expenditures of \$3.1 trillion (US Census, 2014a). ${ }^{27}$ Although two-thirds of the state and local direct expenditures go to current operations, with only $8 \%$ of state direct expenditures and $13 \%$ of local direct expenditures going to capital outlays (US Census, 2014a), the full $\$ 6.6$ trillion in U.S. government expenditures can be seen as a potential resource pool to improve community resilience.

Within the economic resources committed to build systems, the annual construction expenditures can be seen as a proxy for the capital investment category (since it includes nonrecurring expenditures such as repair and renovation as well as traditional capital investments), and across public and private economic sources. In 2014, the U.S. value of construction put in place was over $\$ 960$ billion, with approximately $37 \%$ in residential units and $63 \%$ ( $\$ 606$ billion) in nonresidential expenditures (US Census, 2014). Therefore, the annual construction expenditures of almost a trillion US dollars could be utilized to improve the capacity of the communities' built systems to more effectively accommodate change and retain their functionality - if the legal, economic, political, and regulatory systems embody the social rules focused on improving community resilience throughout the built systems.

Looking at the nonresidential sector, expenditures for buildings and infrastructure-related investments are each approximately $\$ 270$ billion (Table 1). In 2014, the majority of the annual value of construction put in place related to infrastructure came from public sources, and equaled over $\$ 160$ billion, and building-related public expenditures equaled approximately $\$ 100$ billion. Given the government responsibility for public safety and health, public nonresidential construction expenditures that could be directly utilized for the built systems to improve community resilience could equal over $\$ 260$ billion a year.

\footnotetext{
${ }^{27}$ The economic exchanges by public institutions are often easier to track and report than private organization and household/individual exchanges, and can reveal a proximate level of available financial resources to improve community resilience.
} 
Table 1: US Value of Construction Put in Place (2014): Nonresidential Expenditures in Millions of US Dollars

Type
BUILDINGS*
INFRASTRUCTURE**
Conservation and development
Manufacturing

TOTAL

\begin{tabular}{lrr}
\multicolumn{1}{c}{ Total } & Private & \multicolumn{1}{c}{ Public } \\
\cline { 3 - 4 }$\$ 264858$ & $\$ 164726$ & $\$ 99623$ \\
$\$ 278402$ & $\$ 117452$ & $\$ 160562$ \\
$\$ 7512$ & $\$ 0$ & $\$ 7360$ \\
$\$ 55336$ & $\$ 54795$ & $\$ 0$ \\
& & \\
$\$ 606105$ & $\$ 337335$ & $\$ 268769$ \\
& $56 \%$ & $44 \%$
\end{tabular}

Source: US Census, 2014.

Note: May not sum due to rounding.

*Buildings totals are the sum of the categories: Office, Commercial, Health care, Educational, Public safety, and Amusement and recreation.

**Infrastructure totals are the sum of the categories: Transportation, Power, Highway and street, Sewage and waste disposal, and Water supply.

The economic valuation of interventions to improve community resilience can include primary, secondary, and tertiary impacts on interdependent systems at multiple spatial and temporal scales. The measurable impacts may be monetary, quantitative (but not monetary), or qualitative (for instance, using nominal, ordinal, interval, or ratio scales). For example, the World Health Organization estimated that an additional annual expenditure of US\$11.3 billion for potable water and sanitary services (to meet the Millennium Development Goal 7) would provide direct benefits in the reduction in the disease burden and related lost time, with a benefit-to-cost ratio of between US\$3 and US\$34 for each US\$1 invested (WHO, 2004). Additional direct community benefits, such as increased education days for children and increased resource availability for productive work, are not included in the estimated economic benefits. Secondary and tertiary impacts from improved water and sanitary systems from improved health and well-being and increased commercial exchange, such as increased community engagement and effective governance, are likewise not included in these benefit-cost calculations, but play a critical role in the resilience of the communities to strengthen their relationships within the community as well as with other interdependent systems, and to improve their overall conditions.

In the same way in which economic (financial) investments in community resilience can provide non-economic community resilience benefits, non-economic interventions can provide significant economic benefits. For example, water conservation rules in Fort Worth, TX have significantly reduced water consumption, and increased the city's resilience to water shortages. In addition, the conservation measures have allowed the city to delay expanding its treatment facilities, with a savings of $\$ 20$ million a year in borrowing costs. The non-economic intervention has also provided economic benefits to the households/individuals, which would have experienced to a $10 \%$ increase in water rates if the expansion had been implemented (Walton, 2014). 


\section{Discussion}

Enhancing resilience entails developing the community's long-term capacity to accommodate changes by effectively leveraging all of the assets and resources associated with its systems, relationships, and states. Effective resilience interventions will require the development of new approaches, methodologies, and tools that seek to represent the interdependencies of community systems and that specifically incorporate the specific location and configuration for each community. Economic interventions may avoid large, irrevocable commitments that seek to stabilize a specific sub-system to prevent total system deterioration or collapse, and instead may employ adaptive management techniques that provide opportunities for learning and evolution.

\section{References}

Brugmann, J. (2012). "Financing the resilient city," Environment and Urbanization 24 (1) 215 232.

Executive Office of the President (2014). The Budget for Fiscal Year 2014: Table 3.1 Outlays by Superfunction and Function, Washington, DC, p. 59.

(https://www.whitehouse.gov/sites/default/files/omb/budget/fy2014/assets/hist.pdf)

Holling, C.S. (1973). "Resilience and stability of ecological systems," Annual Review of Ecological Systems 4.

Meadows, D.H. (2008) Thinking In Systems. Chelsea Green Publishing, VT.

National Research Council (2009). Sustainable Critical Infrastructure Systems: A Framework For Meeting $21^{\text {st }}$ Century Imperatives. National Academies Press, Washington, DC.

Ostrom, E. (1990). Governing the Commons: The Evolution of Institutions for Collective Action. Cambridge University Press, Cambridge, UK.

Quill, E. (2012). "When networks network: Systems display surprising behavior when they interact," Science News, Sept. 2012, p. 18-25 (https://www.sciencenews.org/article/whennetworks-network)

Tyler, S., Moench, M. (2012). “A framework for urban climate resilience," Climate \& Development 4 (4) 311-326.

U.S. Census (2014). 2012 Census of Governments: Finance-State and Local Government Summary Report. U.S. Census Bureau, Department of Commerce, Washington, DC, p. 8 (http://www2.census.gov/govs/local/summary_report.pdf)

U.S. Census (2014). "Value of Construction Put in Place," U.S. Census Bureau, Department of Commerce, Washington, DC. (https://www.census.gov/construction/c30/historical_data.html)

Walton, B. (2014). "Price of Water 2014: Up 6 Percent in 30 Major U.S. Cities; 33 Percent Rise Since 2010." Circle of Blue May 7, 2014 (http://www.circleofblue.org/waternews/2014/world/price-water-2014-6-percent-30-major-us-cities-33-percent-rise-since-2010/)

World Health Organization (2004). Evaluation of the costs and benefits of water and sanitation improvements at the global level. World Health Organization, Geneva, Switzerland (http://apps.who.int/iris/bitstream/10665/68568/1/WHO_SDE_WSH_04.04.pdf?ua=1) 


\section{Section IV. \\ Breakout Session Reports}


Co-Moderators: J. Fiksel and H. Kunreuther

\section{Outcomes of Breakout Session 1 on Resilience Planning and Deployment}

Keywords:

Community, economics, planning, deployment, resilience, return on investment, policy making, decision making, culture

\section{Moderators and Facilitators}

The moderators of this session are

- Joseph Fiksel, The Ohio State University, fiksel.2@ osu.edu

- Howard Kunreuther, University of Pennsylvania, Wharton, kunreuth@wharton.upenn.edu

The facilitators are

- Douglas Thomas, NIST, douglas.thomas@nist.gov

- Anand Kandaswamy, NIST, anand.kandaswamy@nist.gov

- Gerald E Galloway Jr., University of Maryland, gegallo@umd.edu

\section{Objective and Scope}

The Workshop on the Economics of Community Disaster Resilience is organized around three cross-cutting topics: (1) resilience planning and deployment, (2) dealing with uncertainty, and (3) economics of recovery. Perspectives on these topics are provided in the papers and presentations by the co-moderators.

The primary objective of the workshop was to determine whether specific disaster resilience investments are worthwhile and make a case for their acceptance and buy-in from decision makers. These are primary considerations since disaster-resilience projects must compete with non-disaster-resilience projects for funding.

Results from the breakout sessions offer NIST and the broader professional community relevant suggestions on knowledge gaps and research needs for quantifying costs, benefits and return on investment relating to the economics of community disaster resilience. Enhancing resilience in a cost effective manner requires collecting data and undertaking the relevant tradeoffs with respect to the expected benefits and costs of well-enforced standards, codes and other public policies for reducing future losses from disasters to buildings, infrastructure, networks and communities.

The NIST Community Resilience Planning Guide for Buildings and Infrastructure Systems (http://www.nist.gov/el/building_materials/resilience/guide.cfm) defines community resilience as the ability of a community to prepare for anticipated hazards, adapt to changing conditions, and withstand and recover rapidly from disruptions. This definition is contained in Presidential Policy Directive 21 (PPD-21) that states, "The term 'resilience' means the ability to prepare for and adapt to changing conditions and withstand and recover rapidly from disruptions." The participants recognize that resilience is a systems property, and community resilience is that of a system of systems. Additionally this definition makes robustness distinct from resilience, where system robustness is defined as its ability to function at a full or reduced level after disruptions. 
NIST is also developing an economic guide for community disaster resilience that is defined in terms of (1) losses as the negative economic value resulting from disasters including fatalities and injuries, property and content losses, business interruption and economic damage, and impacts on social and cultural institutions; (2) costs as the investments associated with disaster planning, prevention, mitigation, response and recovery; and (3) benefits as the reduction in losses and costs that result from the implementation of a mitigation plan.

Such analyses require addressing the following questions:

- What are the costs associated with disaster planning, mitigation and response for a community?

$\diamond \quad$ Which are the largest?

$\diamond \quad$ Which are the easiest to quantify?

$\diamond \quad$ Which are the hardest to quantify?

$\diamond \quad$ What's missing?

- What are the typical losses from disasters, either physical or economic, for a community?

$\diamond \quad$ Which are the largest?

$\diamond \quad$ Which are the easiest to quantify?

$\diamond \quad$ Which are the hardest to quantify?

$\diamond \quad$ What's missing?

- What kinds of metrics do communities need to make economic-based decisions?

$\diamond \quad$ Who would use this information?

$\diamond$ How would it be utilized?

$\diamond \quad$ When do communities need this information (how often would it need to be updated)?

$\diamond \quad$ What form would a tool need to take - software, website, guidance document, etc.? Would such a tool need to be developed, sanctioned, or approved by a specific entity/authority, such as, a government agency or a code/standards body?

Such analyses also require economic valuations for losses according to the following six categories: (1) people, (2) physical infrastructure, (3) the economy, (4) key governmental services, (5) social networks and systems, and (6) the environment. Users of the Economic Guide will benefit from including guidance on ways to compute total economic valuation for the six categories. For example EPA, USACE and ASME, among many others, offer guidance on valuation. Additionally, the economic valuation of resilience is necessary. How much do communities value resilience? What is the underlying value system that affects the outcome? Meeting these needs requires fundamental research programs to formalize and develop methods for economic valuation. There is a need to perform such analyses at different community levels and sizes.

Additionally, the following topics may be addressed:

- Uncertainty analysis and quantification that are unique to economic valuation

- Valuations related to recovery and its economics. Recent failures due to natural or human-caused events have highlighted a limitation that such systems are not explicitly designed for recovery. The engineering community is presented with the challenge of 
designing resilient systems for recovery by identifying desired levels of performance and examining the sequences of underlying events in the recovery process. Meeting such a challenge requires research programs to formalize and develop recovery in economic terms.

\section{Approach for Breakout Sessions}

The breakout sessions followed the keynotes that provided background information and motivation for the discussion. Each breakout session spanned three hours from start to finish according to the following segments:

1. Brainstorming to define scope, problems and challenges within the scope of this breakout theme and the other two themes as they relate to it (1 hour)

2. Selection and prioritization of challenges for developing their details during the third segment (1 hour)

3. Development of details of the selected challenges of at least five such challenges (1 hour)

\section{Best Practices}

Breakout participants commented on their views of desirable practices for community resilience, particularly with regard to the following economic issues in planning and deployment:

- The value of resilience initiatives should be evaluated on a day-to-day basis, rather than being justified based on hypothetical disaster scenarios.

- Community decisions about resilience investments must ensure transparency by clearly stating the underlying assumptions.

- Communities should strive for alignment of the "five Rs": risk, reward, role, resources, and responsibility.

- It is important to assess how costs and benefits (and indirect co-benefits) are distributed across different stakeholder groups, clarifying who pays and who reaps the rewards.

- Decision-making should explicitly account for the value of social and natural capital, including ecosystem services.

- Insurance can play a key role in encouraging community resilience by providing information on the risk that communities face from future disasters and encouraging adoption of loss reduction measures through premium reductions.

- Insurance needs to be complemented by other policy tools such as well enforced building codes and land use regulations that encourage wise development of the community

- We need to understand the higher costs associated with securing critical resources, such as safe drinking water, under extreme conditions.

- Federal agency decision-makers (e.g., FEMA) should consider local and community benefits to the extent possible.

- In addition to estimating risks, decision-makers should consider the public perception of risk and how risks are communicated to the key interested parties by community officials.

- Policy makers should consider how to address and mitigate moral hazards implicit in disaster mitigation schemes; e.g., if the government covers economic losses then citizens are less motivated to take preventive measures.

- There is a need for more explicit representation and involvement of stakeholder groups in resilience analysis to understand their values, objectives, and interpretation of resilience for their community. These stakeholder groups will vary across communities. 
- The use of resilience indicators is essential - a community needs to establish a baseline, measure progress, and evaluate the benefits of potential interventions in terms of both economic and non-monetary impacts.

- Resilience planning should be justified financially, with explicit consideration of the timing and location of investments and the expected benefits in both the short-run as over time.

- Beyond the immediate effects of disasters, it is important to address interdependencies in the social infrastructure, including cascading effects (e.g., impacts on employment).

- Infrastructure decision-makers should be protected from potential liabilities if they recommend going beyond the minimum level of compliance with existing codes and standards.

- Insurance efforts to promote resilience must strike a balance between efficiency and equity. For example there is a need to consider ways to deal with affordability so that one encourages those at risk who deserve special treatment to invest in loss-reduction measures.

\section{Key Challenges Identified}

The participants listed in SP A.3 discussed the objective and scope of this breakout session provided in Section 2. They produced the following list of five key challenges. All of these were considered high priority:

1. Tension between short-term returns and long term well-being

2. Inequitable distribution of costs and benefits among stakeholders

3. Lack of adequate collaboration between private and public sectors

4. Lack of motivation to build back better rather than merely recover

5. Presence of systematic biases and simplified decision rules hinder resilience efforts

The remaining sections expand on these challenges based on the deliberations at the session.

\subsection{Challenge. Tension between Short-Term Returns and Long-Term Well-Being}

\section{Description}

While some community stakeholders advocate initiatives for improving community resilience and long-term resilience, these often involve high upfront costs and must compete with shortterm budgetary demands that seem more pressing.

\section{$\underline{\text { Root Causes }}$}

- Additional costs of these initiatives are often transferred to citizens, e.g., homeowners

- There is generally a lack of political will to make choices that require large upfront expenditures

- Some consequences, such as social impacts, are not easy to measure objectively

\section{$\underline{\text { Recommendations }}$}

- Identify resilience improvements with low marginal cost and significant payback

- Highlight the short-term benefits of these measures and spread their costs over time

- Use scenarios to communicate the long-term consequences of neglecting resilience

- Create a culture of resilience by influencing social norms 
- Establish peer-to-peer dialogue among vulnerable communities

$\underline{\text { Action Plan }}$

- Present information in a way that is politically compelling; develop factual arguments about near-term economic benefits. For example, in coastal areas, sea-level rise is a documented trend that requires anticipatory actions to mitigate future losses.

- Spread the costs of resilient measures over time through long-term loans and highlight the short-term benefits from adopting these measures now.

- Develop expert analysis of broad economic trade-offs. An example is Swiss Re's work with Entergy on the economics of adaptation in the Gulf Coast region.

- Hold construction firms responsible for ensuring resilience; e.g., in Chile builders can be held liable for structural failures for a 10-year period.

- Get community stakeholders in involved in resilience planning; show relevance to community well-being. Post-disaster planning provides a window of opportunity.

- Develop community resilience conference events to encourage information sharing.

\begin{tabular}{|c|c|c|}
\hline No. & Stakeholders & Roles \\
\hline 1. & Community & - Citizen participation in resilience task forces \\
\hline 2. & Local government & $\begin{array}{l}\text { - Planning for resilience over long time horizon while } \\
\text { highlighting short-term benefits } \\
\text { - Assign specific responsibility to city planning director }\end{array}$ \\
\hline 3. & Federal government & $\begin{array}{l}\text { - Provide technical knowledge and strategic guidance } \\
\text { - Provide funding assistance for resilience enhancement }\end{array}$ \\
\hline 4. & Academia & $\begin{array}{l}\text { - Support local efforts with multidisciplinary expertise } \\
\text { - Help to organize regional or national conferences }\end{array}$ \\
\hline 5. & NGO & $\begin{array}{l}\text { - Support local efforts with subject matter expertise } \\
\text { - Assist in communicating importance of resilience awareness }\end{array}$ \\
\hline 6. & Private sector & $\begin{array}{l}\text { - Support local planning efforts with subject matter expertise } \\
\text { - Provide long-term loans to encourage investments in resiliency } \\
\text { - Provide in-kind assistance in recovery and adaptation }\end{array}$ \\
\hline 7. & Hardware needs & - N.A. \\
\hline 8. & Software needs & - Tools for comprehensive cost/benefit analysis \\
\hline
\end{tabular}

\subsection{Challenge 2. Inequitable Distribution of Costs and Benefits among Stakeholders}

Description

Those who provide financial support for resilience action may not be the ones who benefit; for example, government subsidized insurance and federal disasters assistance may support rebuilding of damaged homes; whereas those with foresight who invested in loss reduction measures are not rewarded with lower premiums for making their property more resilient with respect to natural disasters

$\underline{\text { Root Causes }}$

- Moral hazard by subsidizing those at risk 
- Myopia and hyperbolic discounting in evaluating benefits of measures over time

- Underestimation of likelihood and consequences of future disasters

- Disengagement of families concerned with economic survival

$\underline{\text { Recommendations }}$

- Motivate relevant stakeholder groups to come to the table

- Recognize the different values and objectives of stakeholders

- Designing strategies that are inclusive of all stakeholders

- Design policies to eliminate moral hazards

\section{$\underline{\text { Action Plan }}$}

- Provide accurate information on risks of future disasters

- Provide home improvement loans to encouraging investments in risk-reduction measures

- Risk-based insurance premium

- Reductions in insurance premiums for investing in loss reduction measures

- Means-tested vouchers for those deserving special treatment

\begin{tabular}{|l|l|l|}
\hline No. & Stakeholders & Roles \\
\hline 1. & Community & $\bullet$ Citizen involvement in policy development \\
\hline 2. & Local government & $\bullet$ Convening community conversations \\
\hline 3. & Federal government & $\bullet$ Development of national policies to correct inequities \\
\hline 4. & Academia & • Support dialogue through research and modeling \\
\hline 5. & NGO & • Assist in representing stakeholder interests \\
\hline 6. & Private sector & $\begin{array}{l}\text { - Insurance industry needs to provide accurate information on } \\
\text { risk through risk based premiums }\end{array}$ \\
\hline 7. & Hardware needs & • Financial institutions provide home improvement loans \\
\hline 8. & Software needs & $\bullet$ N.A. \\
\hline
\end{tabular}

\subsection{Challenge 3. Lack of Adequate Collaboration between Private and Public Sectors}

Description

Public efforts in resilience planning and post-disaster deployment are often disconnected from private sector business continuity activities, although companies often initiate ad hoc responses in disaster-stricken areas where they have operating facilities.

$\underline{\text { Root Causes }}$

- Public-private collaboration on resilience typically stops at the local level

- Geographically diversified enterprises may be unconcerned about local issues

- General tendency to look to public sector for assistance after a disaster

- Limited private and public financial support for mitigation measures prior to a disaster

\section{$\underline{\text { Recommendations }}$}

- Broaden mutual aid agreements among governments and industries (e.g., utilities) 
- Align business continuity plans with civic disaster plans

- Use advanced protocols for information sharing, leveraging private sector capabilities

- Coordinate insurance claims response with public sector programs

Action Plan

- Public sector low interest loans and grants for mitigation measures

- Permission by state regulators for insurers to charge premiums reflecting risk

- State and federal funds to provide protection to private insurers against catastrophic losses (e.g. National Flood Insurance Program, California Earthquake Authority)

\begin{tabular}{|l|l|l|}
\hline No. & Stakeholders & Roles \\
\hline 1. & Community & $\bullet$ N.A. \\
\hline 2. & Local government & $\bullet$ Actively seek out private sector engagement \\
\hline 3. & Federal government & $\begin{array}{l}\text { • Encourage private sector partners to engage locally } \\
\text { - Provide loans and grants for mitigation } \\
\bullet \text { Cover catastrophic losses to encourage private insurance }\end{array}$ \\
\hline 4. & Academia & - N.A. \\
\hline 5. & NGO & $\bullet$ N.A. \\
\hline 6. & Private sector & $\begin{array}{l}\text { - Adopt local engagement as a resilience principle } \\
\bullet\end{array}$ \\
\hline 7. & Hardware needs & - Advanced communication systems \\
\hline 8. & Software needs & $\bullet$ Tools for multi-party coordination in crisis response \\
\hline
\end{tabular}

\subsection{Challenge 4. Lack of Motivation to Build Back Better Rather than Merely Recover}

Description

Community response to disasters is typically focused on recovering as rapidly as possible and returning to normal, rather than considering what actions could be taken to invest in improved resilience as part of the recovery effort.

$\underline{\text { Root Causes }}$

- Fast tracking of public assistance encourages immediate requests, without reflection

- Outside organizations may not understand local issues such as construction styles

- The Stafford act may restore public facilities to pre-disaster position

- The status quo bias---maintain the past

- Lack of funds to make public facilities and infrastructure more resilient to disasters

$\underline{\text { Recommendations }}$

- Remove financial incentives to rebuild to the same standard

- Develop capabilities for community resilience planning

- Provide mitigation grants to improve public facilities and infrastructure

- Anticipate the need for rebuilding in establishment of reserves 


\section{Action Plan}

- Develop plans for making public facilities and infrastructure more resilient prior to a disaster

- Modify Stafford Act so that it does not provide funds to restore facilities to their predisaster condition but to improve facilities

- Require communities to purchase risk-based insurance to protect themselves against damage to public facilities and infrastructure and provide premium reductions for investing in loss-reduction measures

\begin{tabular}{|l|l|l|}
\hline No. & Stakeholders & Roles \\
\hline 1. & Community & $\bullet$ N.A. \\
\hline 2. & Local government & $\bullet$ Consideration of opportunities for better design \\
\hline 3. & Federal government & $\bullet$ Removal of incentives to rebuild immediately \\
\hline 4. & Academia & $\bullet$ Support trade-off analysis \\
\hline 5. & NGO & $\bullet$ Communicate importance of thoughtful planning \\
\hline 6. & Private sector & $\begin{array}{l}\bullet \text { Offer strategies and technologies for upgrading resilience } \\
\bullet \text { Provide insurance against damage to public facilities and } \\
\text { infrastructure }\end{array}$ \\
\hline 7. & Hardware needs & $\bullet$ N.A. \\
\hline 8. & Software needs & $\bullet$ Tools for alternative scenario comparison \\
\hline
\end{tabular}

\subsection{Challenge 5. Presence of Systematic Biases and Simplified Rules of Thumb Hinder Resilience Efforts}

Description

People's thinking is often guided by emotional reactions and simple rules of thumb that have been acquired by personal experience. Behavior patterns are guided by recent and salient outcomes with a focus on short term benefits and costs. As a result long-term consequences of ones actions are highly discounted or ignored.

\section{Root Causes}

- Availability bias leads one to focus on protection after suffering losses from a disaster

- Myopia prevents consideration of long-term consequences

- Prior to experiencing a disaster there is a tendency to view the event as below ones threshold level of concern

\section{Recommendations}

- Improve approaches for framing and communicating the problem (e.g., likelihood of 100year flood next year is ignored but framing the probability as greater than 1 in 5 chance of experiencing at least one flood in the next 25 years gets attention)

- Focus attention on consequences of worst case scenarios without adequate financial protection

- Develop short term incentives for undertaking protective measures now 


\section{$\underline{\text { Action Plan }}$}

- Community leaders provide salient examples of consequences of not undertaking protective measures now rather than waiting for a disaster to happen

- Well-enforced regulations and standards (e.g. building codes)

- Communities undertake preventive measures that reduce flood risk to gain premium reductions for residents through the community rating system (CRS) of the National Flood Insurance Program (NFIP).

\begin{tabular}{|c|c|c|}
\hline No. & Stakeholders & Roles \\
\hline 1. & Community & $\begin{array}{l}\text { - Citizen education to appreciate importance of resilience } \\
\text { - Invest in loss prevention measures to reduce homeowners } \\
\text { insurance premiums } \\
\text { - Enforce building codes and land use regulations }\end{array}$ \\
\hline 2. & Local government & - Improved communication methods and tools \\
\hline 3. & Federal government & - Credible reports and studies to emphasize need for action \\
\hline 4. & Academia & $\begin{array}{l}\text { - Improve understanding of systematic biases and simplified } \\
\text { rules of thumb }\end{array}$ \\
\hline 5. & $\mathrm{NGO}$ & - Support communication efforts \\
\hline 6. & Private sector & - N.A. \\
\hline 7. & Hardware needs & - N.A. \\
\hline 8. & Software needs & - N.A. \\
\hline
\end{tabular}


Co-Moderators: R. Prieto and R. Feigel

\section{Outcomes of Breakout Session 2 on Dealing with Uncertainty}

Keywords:

Community, economics, planning, resilience, return on investment, policy making, decision making, uncertainty

\section{Moderators and Facilitators}

The moderators of this session are

- Robert Prieto, Fluor, Bob.Prieto@fluor.com

- Richard Feigel, Hartford Steam Boiler, gene.feigel@gmail.com

The facilitators are

- David Butry, NIST, david.butry@ nist.gov

- Jennifer Helgeson, NIST, jennifer.helgeson@ nist.gov

- Richard Wright, University of Maryland, richard.n.wright@ verizon.net

\section{Objectives and Scope}

The Workshop on the Economics of Community Disaster Resilience was organized around three cross-cutting topics: (1) resilience planning and deployment, (2) dealing with uncertainty, and (3) economics of recovery. Perspectives on these topics are provided in the papers and presentations by the co-moderators.

The primary objective of the workshop was to determine whether disaster resilience investments are worthwhile and make an argument to get buy in from decision makers. These are primary considerations since disaster-resilience projects must compete with non-disaster-resilience projects for funding.

Results from the breakout sessions offer NIST and the broader professional community relevant suggestions on knowledge gaps and research needs for quantifying costs, benefits and return on investment relating to the economics of community disaster resilience. Enhancing resilience in a cost effective manner requires benefit-cost and tradeoff analyses for private sector standards, codes and public policies affecting buildings, infrastructure, networks and communities.

The draft NIST Community Resilience Planning Guide for Buildings and Infrastructure Systems defines community resilience as the ability of a community to prepare for anticipated hazards, adapt to changing conditions, and withstand and recover rapidly from disruptions. This definition is contained in Presidential Policy Directive 21 (PPD-21) that states, "The term 'resilience' means the ability to prepare for and adapt to changing conditions and withstand and recover rapidly from disruptions." The participants recognize that resilience is a systems property, and community resilience is that of a system of systems. Additionally this definition makes robustness distinct from resilience, where system robustness is defined as its ability to function at a full or reduced level after disruptions. 
NIST also is developing an economic guide for community disaster resilience. The economic guide focuses on expected value computations and addresses uncertainties affecting private sector standards, codes and public policies. Methods for modeling and using uncertainty quantification should be an integral part of the economic guide by considering the following: (1) Characterizing the uncertainties in (a) capital investments in terms of both their installation costs and timing, (b) losses both their magnitude and timing, (c) length of the planning horizon, and (d) discount rate; (2) Examining the sensitivities of the outcomes to variation in key parameters including the discount rate, and capital investment and loss scenarios; (3) Providing guidance on how to report results with uncertainties in the form of present value, benefit-to-cost ratio, internal rate of return, etc.; (4) Quantifying the probability that benefits will not be realized for a particular mitigation strategy; and other considerations. Additionally, the following questions and topics may be addressed:

- Of the costs and losses identified above, which are:

$\diamond$ Known

$\diamond \quad$ Uncertain, but well-characterized

$\diamond \quad$ Uncertain and ambiguous

$\diamond \quad$ Uncertain and poorly-defined

- What kinds of activities would allow us to better understand any unknown costs and losses?

- How risk-adverse are communities?

$\diamond \quad$ Examples?

- How should economic information be presented when uncertainty exists?

$\diamond$ How should uncertainty be presented to decision makers?

Additionally, the following topics may be addressed:

- Uncertainty analysis and quantification that are unique to economic valuation

- Uncertainty analysis and quantification related to recovery and its economics. Recent failures due to natural or human-caused events have highlighted a limitation that such systems are not explicitly designed for recovery. The engineering community is presented with the challenge of designing engineering systems for recovery that would lead to designing for resiliency. Recovery requirements should be identified for various service levels desired. Sequences of underlying events in recovery should account for recovery dependence relationships. Meeting such a challenge requires research programs to formalize and develop recovery in economic terms.

- Policy implications

\section{Approach for Breakout Sessions}

The breakout sessions followed the keynotes that provided background information and motivation for the discussion. Each breakout session spanned three hours from start to finish according to the following segments:

1. Brainstorming to define scope, problems and challenges within the scope of this breakout theme and the other two themes as they relate to it (1 hour)

2. Selection and prioritization of challenges for developing their details during the third segment (1 hour)

3. Development of details of the selected challenges of at least five such challenges (1 hour) 


\section{Best Practices}

Long range community plans addressing resilience

Comprehensive planning is a term used in the United States by land use planners to describe a process that determines community goals and aspirations in terms of community development. The outcome of comprehensive planning is the Comprehensive Plan, which dictates public policy in terms of transportation, utilities, land use, recreation, and housing. Comprehensive plans typically encompass large geographical areas, a broad range of topics, and cover a longterm time horizon. However, comprehensive plans generally do not address community resilience.

Performance-based standards for resilience

The decisions that determine the planning, design, construction, operation, maintenance, renovation and removal of the buildings and infrastructure systems of communities are guided and governed through regulations, standards and practices. Regulations, standards and practices generally are based on national standards developed by consensus procedures involving engineers and other professionals concerned with the built environment, owners, financial interests, product manufacturers, public officials, regulators and other stakeholders concerned with safety, health, and economic and social consequences. However, most regulations, standards and practices are prescriptive - describing the required properties of the system rather than performance-based - describing how the system should function when stressed. Performance-based standards will support innovations for resilience.

\section{Resilience for socially disadvantaged groups}

The resilience of social groups (such as families or neighborhoods) generally depends on their education and abilities, current income, savings, investments and insurance. Disadvantaged social groups are those lacking in these resources.

\section{Accounting for temporal uncertainties}

Temporal uncertainties include the frequencies and intensities of future hazards and the future resources such as human, social, produced, natural and financial capitals that will be available to provide robustness and resilience to the hazards. Current best practice generally assumes stationarity in definition of the frequency and intensity of future hazards - that is that the statistics of the known past will apply to the future. However observed changes in human behavior and in extremes of climate and weather indicate that stationarity is not a safe assumption. Additional temporal uncertainties apply to the characteristics of future human, social, produced, natural and financial capitals.

Financial products supporting resilience

Financial products supporting resilience include: savings, such as community "rainy day" funds; insurance; catastrophe bonds; and expectations of federal assistance following a disaster. It is in the interest of both private and public sectors to reduce dependence on federal assistance.

Streamlining permitting for resilience efforts

Permitting for a resilience upgrade for an infrastructure system may require approvals by federal, state and local regulators. Traditionally, regulators work in an uncoordinated and linear fashion - a project permitted by regulator A may be required to make a change by regulator $\mathrm{E}$, which 
invalidates A's permit, etc. The time required for obtaining all permits may make the project obsolete before it can be implemented. A number of pilot projects using current project information technology show that required qualities can be achieved in a timely and cost effective way when regulators work simultaneously and in a coordinated fashion.

\section{Strengthening community interests in resilience}

Public support is essential for community resilience measures and requires public understanding of hazards and resilience measures.

Strengthening community awareness of hazards and vulnerabilities

Public support is essential for community resilience measures and requires public understanding of hazards and resilience measures.

Insurance rating system for community resilience

Sales of insurance will be increased and costs for insurance of resilient facilities will be reduced by implementation of an insurance rating system for community resilience.

Bounding and prioritizing resilience value at risk

Planning, design, construction, operation and maintenance for resilience will benefit from improved knowledge of the resilience values at risk.

Determining interdependencies of community systems

Resilience is a system property, weak links must be identified and resilience investments focused on reducing the salient vulnerabilities rather than in making the already robust more robust.

\section{Key Challenges Identified}

The participants listed in SP A.3 discussed the objective and scope of this breakout session provided in Section 2. They produced the following list of key challenges (prioritized and sorted groups):

- High priority group (at least five)

- Challenge H1: Long range community plans addressing resilience.

- Challenge H2: Performance-based standards for resilience.

- Challenge H3: Resilience for socially disadvantaged groups.

- Challenge H4: Accounting for temporal uncertainties.

- Challenge H5: Financial products supporting resilience

- Medium priority group

- Challenge M1: Streamlining permitting for resilience efforts.

- Challenge M2: Strengthening community interests in resilience

- Challenge M3: Strengthening community awareness of hazards and vulnerabilities

- Low priority group

- Challenge L1: Insurance rating system for community resilience

- Challenge L2: Bounding and prioritizing resilience value at risk

- Challenge L3: Developing and normalizing resilience time objectives

- Challenge L4: Determining interdependencies of community systems. 
The remaining sections expand on the high priority challenges based on the deliberations at the session.

\subsection{Challenge 1. Long Range Community Plans Addressing Resilience}

Description

Long range community plan that incorporate resilience.

$\underline{\text { Root Causes }}$

1. Currently no related mandates (Policy, legislative, regulatory)

2. Inadequate guidance (e.g. not central) on how to go about the process.

3. Currently long range plans do not include recovery from extreme and hazardous events

4. System of systems perspective absent - Resilience is a system (and system of systems) property

$\underline{\text { Recommendations }}$

- Model legislation (in the absence of mandates) ; provide suggested guidelines for states and local communities to adopt (note need to make economic sense; economic modeling supporting the rationale reflected in these documents).

- Provide suggested guidelines for states \& local communities to adopt (economic modeling supporting the rationale reflected in these documents). Address roles of utilities and insurance industry.

- Part of the community and the mechanisms for getting money back into the community includes insurance providers. Incentive to be a first rebuilder. Roles of various utilities within the systems - part of the integrated community plan.

- Create an implementation structure that allows for emergency responses and gives a guide for decision-making. It should encourage post-disaster recovery that strives to be functional and high-performing.

- Research to enable communities to understand current guides and understand how these change post disaster.

$\underline{\text { Action Plan }}$

- Determine what economic data needs to be collected for recovery planning and analysis of related options. (Address transboundary, regional analysis)

- Establish baseline resilience levels. Identify core resilience strengths of communities.

- Develop enhanced forecasting tools that relate specifically to post-disaster (e.g. cost of scarce resources, displacement).

- Economic analysis for use of financial instruments/tools.

Roles (Community, Government, Academia, NGO, Private sector, Software/Hardware)

\begin{tabular}{|l|l|l|}
\hline No. & $\begin{array}{l}\text { Stakeholders (only } \\
\text { applicable ones }\end{array}$ & Roles \\
\hline 1. & Community & $\begin{array}{l}\text { - Participate in comprehensive planning including resilience } \\
\text { - Understand planned recovery objectives }\end{array}$ \\
\hline 2. & Local government & $\begin{array}{l}\text { - Update or create comprehensive plan including resilience } \\
\text { - Establish guides for post disaster expediting of permits and } \\
\text { approvals }\end{array}$ \\
\hline
\end{tabular}




\begin{tabular}{|l|l|l|}
\hline 3. & Federal government & $\begin{array}{l}\text { - Research and technical support for community comprehensive } \\
\text { planning including resilience } \\
\text { - Establish absolute and relative resilience metrics } \\
\text { - Develop template for required model legislation at state and } \\
\text { local level }\end{array}$ \\
\hline 4. & Academia & $\begin{array}{l}\text { - Education of future public administrators and built } \\
\text { environment professionals in community comprehensive } \\
\text { planning including resilience } \\
\text { - Research on planning issues. } \\
\text { - Recovery time modeling }\end{array}$ \\
\hline 5. & NGO & $\begin{array}{l}\text { American Planning Association and built environment } \\
\text { professional societies to provide model documents for } \\
\text { community comprehensive planning including resilience }\end{array}$ \\
\hline 6. & Private sector & $\begin{array}{l}\text { - Participate in community comprehensive planning including } \\
\text { resilience } \\
\text { - Communicate private sector response plans for incorporation } \\
\text { in community resilience plans } \\
\text { - Identify assumed community capacities and capabilities }\end{array}$ \\
\hline 7. & Hardware needs & $\begin{array}{l}\text { - To be determined } \\
\text { - Complexity modeling tools applied to post disaster setting } \\
\text { (non-deterministic systems modeling) } \\
\text { - Risk modeling with temporal uncertainty }\end{array}$ \\
\hline 8. & Software needs &
\end{tabular}

\subsection{Challenge 2. Performance-based Standards for Resilience}

Description

Performance-based standards for resilience.

$\underline{\text { Root Causes }}$

1. Most standards are prescriptive and often do not encourage innovation.

2. Often do not apply to resilience at all - beyond the standards' scope.

3. Most standards focus on output specification, not outcome-based.

4. Standards designed in silos; tend to be component-based (not systems-based); not enough focus on interdependencies.

\section{$\underline{\text { Recommendations }}$}

- Migrate to more life-cycle performance-based standards.

- Consider interdependencies within the relevant system(s).

- Help communities define their performance goals/regulations.

- Require review and revise in a cyclical manner; cycle should be issue-relevant.

- Look at cost effectiveness/costs and benefits (of recovery attributes, labor, logistics, construction means and methods, temporary relocation of businesses) for given plans. 


\section{Action Plan}

- Define specific actions that are practical and measurable

- Need a new set of tools. (e.g., How to confirm that a design meets the performance standards?)

- Estimate value creation of moving to performance-based systems. (considering and not considering extreme events)

Roles (Community, Government, Academia, NGO, Private sector, Software/Hardware)

\begin{tabular}{|c|c|c|}
\hline No. & $\begin{array}{l}\text { Stakeholders (only } \\
\text { applicable ones }\end{array}$ & Roles \\
\hline 1. & Community & $\begin{array}{l}\text { - Support adoption and enforcement of performance-based } \\
\text { standards for resilience }\end{array}$ \\
\hline 2. & Local government & - Adopt and enforce performance-based standards for resilience \\
\hline 3. & Federal government & $\begin{array}{l}\text { - Research and development for development, adoption and } \\
\text { enforcement of performance-based standards for resilience } \\
\text { - Adopt and enforce performance-based standards for resilience } \\
\text { for federal infrastructure. }\end{array}$ \\
\hline 4. & Academia & $\begin{array}{l}\text { - Education of future built environment professionals in the } \\
\text { understanding and application of performance-based standards } \\
\text { for resilience. } \\
\text { - Research to provide knowledge base for performance-based } \\
\text { standards for resilience }\end{array}$ \\
\hline 5. & NGO & - Development of performance-based standards for resilience. \\
\hline 6. & Private sector & $\begin{array}{l}\text { - Participate in the development and implementation of } \\
\text { performance-based standards for resilience }\end{array}$ \\
\hline 7. & Hardware needs & - To be determined \\
\hline 8. & Software needs & $\begin{array}{l}\text { - Performance assessment software for asset and systems level } \\
\text { applications }\end{array}$ \\
\hline
\end{tabular}

\subsection{Challenge 3. Resilience for Socially Disadvantaged Groups}

\section{Description}

The resilience of social groups (such as families and neighborhoods) generally depends on their education and abilities, current income, savings, investments and insurance, and access to education and employment. Disadvantaged social groups are those lacking in such resources. 


\section{$\underline{\text { Root Causes }}$}

Not all characteristics of disadvantaged groups or the stresses affecting their resilience are readily measurable, especially the societal impacts, which depend on value judgments.

- Disadvantaged social groups tend to be more vulnerable. (e.g. medically, financially/economically).

- Changes in land use/urbanization can be a hazard for disadvantaged groups. Urban, suburban, and rural settings face unique challenges.

\section{$\underline{\text { Recommendations }}$}

- Keeping communities together during immediate recovery.

- Research ways to identify/score/recognize vulnerable populations.

- Mechanism to communicate \& engage with disadvantaged groups.

\section{$\underline{\text { Action Plan }}$}

- Identify vulnerable socially disadvantaged groups as part of comprehensive community planning including resilience.

- Include measures supporting the resilience of these disadvantaged groups in the comprehensive community plan.

- Take timely actions reducing the vulnerability of these groups in advance of the occurrence of the identified hazards.

Roles (Community, Government, Academia, NGO, Private sector, Software/Hardware)

\begin{tabular}{|l|l|l|}
\hline No. & $\begin{array}{l}\text { Stakeholders (only } \\
\text { applicable ones }\end{array}$ & Roles \\
\hline 1. & Community & $\begin{array}{l}\text { - Support and participate in planning and actions to reduce } \\
\text { vulnerability of socially disadvantaged groups. }\end{array}$ \\
\hline 2. & Local government & $\begin{array}{l}\text { - Plan and implement actions to reduce vulnerability of socially } \\
\text { disadvantaged groups }\end{array}$ \\
\hline 3. & Federal government & $\begin{array}{l}\text { - Research on characterizing socially disadvantaged groups, } \\
\text { measures to strengthen their capabilities and measures to } \\
\text { reduce their vulnerabilities. } \\
\text { - Plan and implement actions to reduce vulnerability of socially } \\
\text { disadvantaged groups }\end{array}$ \\
\hline 4. & Academia & $\begin{array}{l}\text { - Education of members of socially disadvantaged groups and } \\
\text { the general public on measures to strengthen the capabilities } \\
\text { and reduce the vulnerability of socially disadvantaged groups. } \\
\text { - Research on measures to strengthen the capabilities and reduce } \\
\text { the vulnerability of socially disadvantaged groups }\end{array}$ \\
\hline 5. & NGO & $\begin{array}{l}\text { Development and implementation of best practices for } \\
\text { strengthening the capabilities and reducing the vulnerability of } \\
\text { socially disadvantaged groups }\end{array}$ \\
\hline
\end{tabular}




\begin{tabular}{|l|l|l|}
\hline 6. & Private sector & $\begin{array}{l}\text { - Support of and participation in measures to strengthen the } \\
\text { capabilities and reduce the vulnerability of socially } \\
\text { disadvantaged groups }\end{array}$ \\
\hline 7. & Hardware needs & To be determined \\
\hline 8. & Software needs & - Social vulnerability assessment tool \\
\hline
\end{tabular}

\subsection{Challenge 4. Accounting for Temporal Uncertainties}

\section{Description}

Temporal uncertainties include the frequencies and intensities of future hazards and the future resources such as human, social, produced, natural and financial capitals that will be available to provide robustness and resilience to the hazards. Current best practice generally assumes stationarity in definition of the frequency and intensity of future hazards - that is that the statistics of the known past will apply to the future. However observed changes in human behavior and in extremes of climate and weather indicate that stationarity is not a safe assumption. Additional temporal uncertainties apply to the characteristics of future human, social, produced, natural and financial capitals.

\section{$\underline{\text { Root Causes }}$}

- Changes in demographics of communities

- Degradation over time of the resilience of community infrastructure systems.

- Changes over time in the frequency and intensity of natural and man-made hazards.

\section{$\underline{\text { Recommendations }}$}

- Research to improve understanding of community demographics, degradation of resilience of existing infrastructure, and the frequencies and intensities of hazards that may impact communities

- Improved modeling of the resilience of communities to hazards.

Action Plan

- Explore the use of sensitivity analysis to account for changes (e.g., Monte Carlo with careful attention to assumed distributions; other simulation methods including scenario analysis)

Roles (Community, Government, Academia, NGO, Private sector, Software/Hardware)

\begin{tabular}{|l|l|l|}
\hline No. & $\begin{array}{l}\text { Stakeholders (only } \\
\text { applicable ones }\end{array}$ & Roles \\
\hline 1. & Community & $\begin{array}{l}\text { - Become aware of temporal uncertainties and supportive of } \\
\text { measures to address them. }\end{array}$ \\
\hline 2. & Local government & $\begin{array}{l}\text { - Address temporal uncertainties in the comprehensive } \\
\text { community plan including resilience. }\end{array}$ \\
\hline
\end{tabular}




\begin{tabular}{|c|c|c|}
\hline 3. & Federal government & $\begin{array}{l}\text { - Research to improve understanding of community } \\
\text { demographics, degradation of resilience of existing } \\
\text { infrastructure, and the frequencies and intensities of } \\
\text { hazards that may impact communities } \\
\text { - Address temporal uncertainties in the comprehensive plans } \\
\text { including resilience for federal facilities. }\end{array}$ \\
\hline 4. & Academia & $\begin{array}{l}\text { Education on and research to improve understanding of } \\
\text { community demographics, degradation of resilience of } \\
\text { existing infrastructure, and the frequencies and intensities } \\
\text { of hazards that may impact communities }\end{array}$ \\
\hline 5. & NGO & $\begin{array}{l}\text { - Address temporal uncertainties in their standards and } \\
\text { recommended practices }\end{array}$ \\
\hline 6. & Private sector & $\begin{array}{l}\text { - Address temporal uncertainties in their programs and facilities } \\
\text { and support development and implementation of } \\
\text { comprehensive community plans addressing temporal } \\
\text { uncertainties and resilience. }\end{array}$ \\
\hline 7. & Hardware needs & To be determined \\
\hline 8. & Software needs & $\begin{array}{l}\text { - Modified risk software that specifically considers temporal } \\
\text { uncertainty }\end{array}$ \\
\hline
\end{tabular}

\subsection{Challenge 5. Financial Products Supporting Resilience} Description

Financial products supporting resilience include: savings such as community "rainy day" funds; insurance; catastrophe bonds; and expectations of federal assistance following a disaster. It is in the interest of both private and public sectors to reduce dependence on federal assistance.

\section{$\underline{\text { Root Causes }}$}

1. A variety of disincentives create market distortions which retard rational financing of community resilience.

2. Incentives from insurers and federal government for resilience enhancing investments lacking

\section{$\underline{\text { Recommendations }}$}

- Investigate the disincentives that create the market distortions

- Engage insurance industry in a focused dialogue on resilience investments and premium reduction 


\section{Action Plan}

- Explore tools to spread risk across space/time, such as insurance and use of community catastrophe bonds

Roles (Community, Government, Academia, NGO, Private sector, Software/Hardware)

\begin{tabular}{|l|l|l|}
\hline No. & $\begin{array}{l}\text { Stakeholders (only } \\
\text { applicable ones }\end{array}$ & Roles \\
\hline 1. & Community & $\begin{array}{l}\text { - Understand and support community measures financing } \\
\text { resilience and implement such measures for personal } \\
\text { resources. }\end{array}$ \\
\hline 2. & Local government & $\begin{array}{l}\text { - Incorporate rational financing of resilience in community } \\
\text { budgeting and in the comprehensive community plan including } \\
\text { resilience. }\end{array}$ \\
\hline 3. & Federal government & $\begin{array}{l}\text { - Research to indentify and correct the market distortions } \\
\text { retarding the rational financing of community resilience. } \\
\text { Modify federal laws, regulations and programs to remove } \\
\text { market distortions retarding the rational financing of } \\
\text { community resilience. } \\
\text { - Create incentives for targeted resilience investments by private } \\
\text { sector that promote community resilience }\end{array}$ \\
\hline 4. & Academia & $\begin{array}{l}\text { Education and research supporting the rational financing of } \\
\text { community resilience. Economic modeling of resilience } \\
\text { investments }\end{array}$ \\
\hline 5. & NGO & $\begin{array}{l}\text { - Development and implementation of standards and practices } \\
\text { for the rational financing of community resilience. } \\
\text { - }\end{array}$ \\
\hline 6. & Hardware needs & $\begin{array}{l}\text { Support of the development and implementation of standards } \\
\text { and practices for the rational financing of community } \\
\text { resilience, and implementation of such practices in their own } \\
\text { enterprises. }\end{array}$ \\
\hline 8. & Software needs & $\begin{array}{l}\text { - Economic cost benefit models for resilience investments } \\
\text { highlighting such costs and benefits to differentiated } \\
\text { stakeholder groups }\end{array}$ \\
\hline
\end{tabular}


Co-Moderators: S. Chang and R. E. Chapman

\section{Outcomes of Breakout Session 3 on Economics of Recovery}

Keywords:

Community, economics, planning, deployment, resilience, recovery, return on investment, policy making, decision making

\section{Moderators and Facilitators}

The moderators of this session are

- Stephanie Chang, The University of British Columbia, stephanie.chang@ubc.ca

- Robert E. Chapman, NIST, robert.chapman@nist.gov

The facilitators are

- Stanley Gilbert, NIST, stanley.gilbert@ nist.gov

- David Webb, University of Maryland and NIST

- Bilal Ayyub, University of Maryland, ba@umd.edu

\section{Objectives and Scope}

The Workshop on the Economics of Community Disaster Resilience is organized around three cross-cutting topics: (1) resilience planning and deployment, (2) dealing with uncertainty, and (3) economics of recovery. Perspectives on these topics are provided in the papers and presentations by the co-moderators.

The primary objective of the workshop is to determine whether disaster resilience investments are worthwhile and make an argument to get buy in from decision makers. These are primary considerations since disaster-resilience projects must compete with non-disaster-resilience projects for funding.

Results from the breakout sessions will offer NIST and the broader professional community relevant suggestions on knowledge gaps and research needs for quantifying costs, benefits and return on investment relating to the economics of community disaster resilience.

The NIST Economic Decision Guide defines community resilience as the ability of a community to prepare for anticipated hazards, adapt to changing conditions, and withstand and recover rapidly from disruptions. This definition is contained in Presidential Policy Directive 21 (PPD21) that states, "The term 'resilience' means the ability to prepare for and adapt to changing conditions and withstand and recover rapidly from disruptions." Under this definition, resilience includes activities already conducted by communities, such as disaster preparedness, hazard mitigation, code adoption and enforcement, and emergency response. The participants recognize that resilience is a systems property, and community resilience is that of a system of systems. With that in mind, it is useful to distinguish between two types of economic resilience: static resilience and dynamic resilience. ${ }^{28}$ Static resilience is maintaining function, where the economic counterpart is utilizing remaining resources as efficiently as possible in order to maintain

${ }^{28}$ Following Rose (2009) and Rose and Krausmann (2013). 
function. Dynamic resilience refers to the ability and speed of recovery, where the economic counterpart pertains to investing wisely in repair and reconstruction.

Enhancing resilience in a cost effective manner requires benefit-cost and tradeoff analyses for developing codes, standards and public policies affecting buildings, infrastructure, networks and communities. These efforts should include recovery costs in their models and treatments. Recent failures due to natural or human-caused events have highlighted a limitation that such systems are not explicitly designed for recovery. The engineering community is presented with the challenge of designing engineering systems for recovery that would lead to designing for resiliency. Recovery requirements should be identified for various service levels desired. Sequences of underlying events in recovery should account for recovery dependence relationships. Meeting such a challenge requires research programs to formalize and develop recovery in economic terms. Such analyses require addressing the following questions:

- What are the economics of recovery?

- Why is there such a lack of understanding of the topic?

$\diamond \quad$ Why is it difficult to measure?

- For communities that have gone through disaster recovery

$\diamond \quad$ Provide examples of how/when recovery succeeded

$\diamond \quad$ Provide examples of how/when recovery failed

- What are the dependencies associated with recovery?

- Can we identify recovery tracks that are more favorable than others?

$\diamond \quad$ Can these tracks be incentivized?

$\diamond$ How can communities build business cases for these tracks?

Additionally, the following topics may be addressed:

- Uncertainty analysis and quantification that are unique to recovery

- Examining limitations, knowledge gaps and research needs as a result of not explicitly designing for recovery

- Financing recovery

- Policy implications

\section{Approach for Breakout Sessions}

The breakout sessions followed the keynotes that provided background information and motivation for the discussion. Each breakout session spanned three hours from start to finish according to the following segments:

1. Brainstorming to define scope, problems and challenges within the scope of this breakout theme and the other two themes as they relate to it (1 hour)

2. Selection and prioritization of challenges for developing their details during the third segment (1 hour)

3. Development of details of the selected challenges of at least five such challenges (1 hour)

\section{Best Practices}

A number of "best practices" were identified by the participants and are noted in Sections 5.1 through 5.4, below. 


\section{Key Challenges Identified}

The participants listed in Appendix A.3 discussed the objective and scope of this breakout session provided in Section 2. They produced the following list of key challenges (prioritized and sorted groups):

- High priority group

- Financing and incentives

- Build back better vs. build back quicker

- Compiling an economic resilience index

- Capacity of the community

- Medium priority group

- Availability of data

- Awareness

- Relationship between vulnerability and social capital

- How to make recovery orderly (business decisions vs. community decisions)

- Who pays? Federal, state, city, owner (moral hazard)

- Challenge of measuring indirect impacts

- Co-create solutions (bottom-up approach with all stakeholders)

- Multi-level decision making (scale)

- Low priority group

- Shortage of qualified individuals

- Usage of new technology

- Restrictive federal grant practices (make you whole - replace to original state)

- Inconsistent county assessor data (e.g., across states)

- Lack of "rainy day" fund

- How to measure recovery (metrics)?

- Heterogeneity of communities

- Geographic spillover

- How do you create a market for safer buildings?

The remaining sections expand on the high priority challenges based on the deliberations at the session.

\subsection{Challenge 1. Financing and Incentives}

Description

Financing and incentives were identified as a high priority challenge. In the pre-event context, there is a need for costs or benefits to motivate an owner/operator to make decisions to take certain actions that would reduce economic losses and facilitate economic recovery after a disaster. In the post-event context, there are many issues regarding who will pay for recovery and for mitigation investments to reduce future risk (see also Challenge H2: Build Back Better vs. Build Back Quicker). These issues present obstacles in the economics of recovery.

\section{$\underline{\text { Root Causes }}$}

Two major sources for this challenge are that: (1) costs of recovery can overwhelm communities, and (2) financing for recovery is often not available or not planned for. 


\section{$\underline{\text { Recommendations }}$}

With regard to incentives, several recommendations were made:

- Ensure that qualified individuals are utilized during reconstruction and recovery. Educate consumers to know what the best practices for resilience are; make this information available to consumers.

- Impose appropriate codes and standards.

- SAFETY Act provides important legal liability protections for providers of Qualified Anti-Terrorism Technologies: consider adopting SAFETY Act concepts for qualified construction experts.

- An important gap to address is the availability of affordable, resilient building materials.

- Another gap is that consumers do not know where to start.

- Rate of recovery is affected by federal procurement policies and the availability of liability professionals.

- Promote a better understanding of co-benefits among key private-sector stakeholders associated with disaster risk management decisions that have the potential to lower production costs, improve the health of workers, and contribute to general economic stability.

With regard to financing, recommendations and "best practices" included:

- Developing appropriate financial incentives.

- (Best practice) Pre-event financing by communities/owners themselves, e.g., guaranteed rate loans.

- (Best Practices) Tax-free savings accounts to build in pre-event resilience.

- (Best Practices) Insurance and catastrophe bonds.

$\underline{\text { Action Plan }}$

- Compare the costs of pre-event mitigation to post-event costs in order to provide evidence of mitigation savings.

- Use behavioral economics to overcome initial resistance to implementing resilience measures.

- Make existing grants contingent upon implementing more resilient practices.

\subsection{Challenge 2. Build Back Better vs. Build Back Quicker}

\section{Description}

Following a disaster, there is an inherent tension in the recovery process between "building back better" and "building back quicker." While reconstruction and recovery provide opportunities for resilience investments that can reduce future risk, taking advantage of these opportunities often involves (or is perceived to involve) delays in implementing immediate recovery measures.

\section{$\underline{\text { Root Causes }}$}

This challenge fundamentally involves tradeoffs between short-term needs and long-term benefits. Decision-makers such as elected officials or homeowners are myopic in this regard. They tend to deal with pressing, immediate concerns rather than imagining what could be. Furthermore, there is often a stigma associated with knowledge of risk conditions: people would prefer not to know about the risks they face so that they need not act on such knowledge. Following a disaster, people generally want to get on with their lives (i.e., get back to 
"normalcy"), and don't want to remain in limbo. Doing something quickly is perceived as being preferable to delay. There is often a scarcity of resources, which further exacerbates the tension between short-term needs and long-term benefits.

$\underline{\text { Recommendations }}$

Several "best practices" were identified that can help with this challenge:

- Conduct pre-planning for processes that will facilitate reconstruction and recovery activities as well as for appropriate building codes and standards.

- Provide consumers with information about how to rebuild better (people need to know what to ask for in the rebuilding process).

- Integrate community mitigation plans with community development plans, rather than have stand-alone mitigation.

- Give states and communities flexibility in how to utilize federal funds for improvements.

- Develop private sector engagement in mitigation planning and disaster recovery; e.g., involvement of Home Depot, Lowes, and other home improvement retailers in pre-event consumer education and post-event response and reconstruction.

- Have federal programs aligning better with markets; e.g., realistic funding amounts for elevating homes, being more agile with regard to setting limits.

There are important knowledge gaps that should be addressed, including knowledge of:

- How funding sources can be used effectively for mitigation

- Case studies on who did better (in recovery) and why; who did worse and why

- Who had robust plans before the event, who recovered quickly after the event, and who recovered better/improved

- Developing effective financing mechanisms

- Social science research on how to help people rebuild better

- How to change the dialogue to a bottom-up approach, that is, engaging homeowners so that they will want to undertake mitigation; e.g., through messaging strategies and incentives

- Bringing in the private sector (before a disaster) to help promote mitigation and market resilience; building private partnerships

- Understanding community leader motivations and how to encourage them to take a longterm view of pre- and post-disaster decision-making, including negative motivations (e.g., political risk)

- How to minimize delays (and costs) due to building back better

Action Plan

- Research knowledge gaps

- Implement best practices, including incorporation into NIST Planning Guide and Economic Decision Guide

- Acknowledge that action must come from the local level, but can be encouraged by state and federal governments

- Work with partners on developing information; e.g., American Planning Association (APA) for guidelines on integrating mitigation with community development plans 
- Work with partners in the private and not-for-profit sector; e.g., construction sector, National Association of Homebuilders, American Institute of Architects, post-disaster corps.

\subsection{Challenge 3. Compiling an Economic Resilience Index Description}

It is important to have measures of economic resilience that are systematically developed, conceptually sound, and empirically valid. An Economic Resilience Index would be useful for understanding the current state of resilience, for monitoring changes, and for assessing impacts of resilience investments. Creating such an index, however, entails numerous challenges.

An idealized version of such an Index would address factors at multiple scales: micro, meso, and macro. Recommendations are made below for each of these scales.

\section{$\underline{\text { Recommendations }}$}

Micro level:

- Should capture how the firm's production function is impacted.

- Should capture the effects of different resilience tactics, such as conserving inputs, substitution of inputs, building up of inventories, and business relocation.

- May require surveys to be conducted, if some of the data are not publically available.

- Should introduce the level of management.

- Should introduce a spatial component.

- Should consider the location of homes or businesses that are damaged.

- Should consider chronic stress.

- Should relate to pre-disaster vulnerability—hazard assessments conducted and mitigation measures put in place - as measured through a Vulnerability Index.

- Should consider natural capital; i.e., damage to the natural environment.

- Whether or not this is separate from social capital is debatable. Potentially should have a separate index for social capital.

- Should have separate indices for transportation, water, buildings, telecommunication, wastewater, etc., to consider if they have been damaged by the hazard event.

Meso level (industry or market):

- Should have an information clearinghouse to determine what supply chains have been lost.

- Should consider the working of price mechanisms to reallocate resources - some postdisaster price increases may be warranted, while others are not.

Macro level (economy-wide):

- Should consider the total community.

- Should account for importing of inputs to make up for local inputs lost.

- Should consider effects of federal policies, such as keeping interest rates low.

- Should consider fiscal policy.

- Should consider state policy.

- Should consider the distribution of the economic impacts across sectors, socio-economic groups, etc. 


\subsection{Challenge 4. Capacity of the Community}

\section{Description}

The capacity of the community comprises resources that contribute to resilience, independent of the type of disaster. These include human, financial, social, natural, built, political, and cultural capitals (Figure 1). Understanding how these different types of capital can be measured, how they are related, and how they influence communities' response and recovery to disasters remains an important challenge.

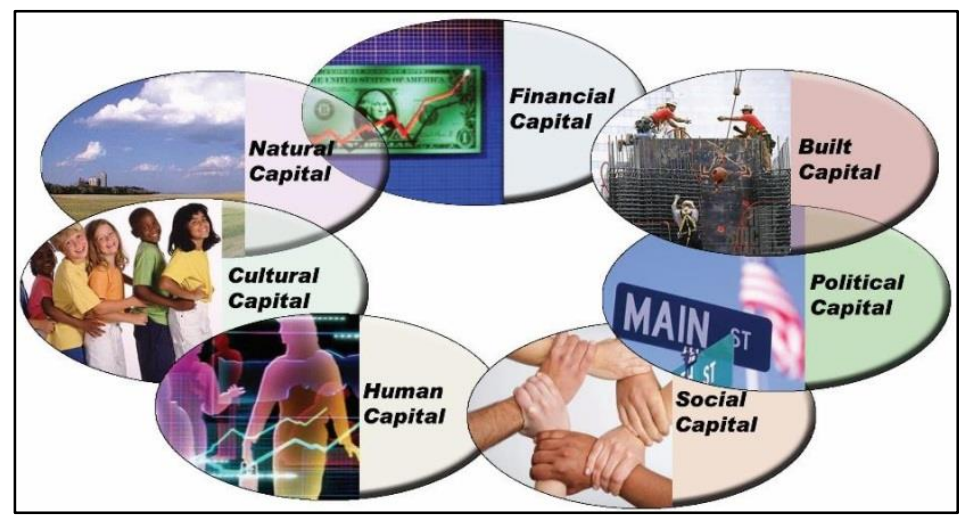

Figure 1. Community Capitals Framework (NIST 2015, adapted from Flora et al. 2008)

\section{$\underline{\text { Recommendations }}$}

Best practices:

- Community resilience assessment methodologies, e.g., CARRI, BRIC, CART, Rockefeller framework, etc.

- Inclusive feedback loop from communities.

- Identification of subsets of communities and how they are affected.

Knowledge gaps and research needs:

- How do you measure each of the community capitals? Some are better understood, with better-established methodologies, than others. One question is whether communities which have experienced repeated hazardous events are less resilient?

- How do the different capitals impact resilience?

- What are the key dependencies?

- What are the initial conditions? How do they change over time?

\section{$\underline{\text { Action Plan }}$}

- Map the community capitals to the nature of the shock and recovery. While these are to some extent shock-independent, they are not completely so, and they are expected to be heterogeneous across communities.

- Build on existing community assessment methodologies.

- Collect lessons learned from previous events. 


\section{Appendices}




\section{Appendix A. Participants}

A.1. Registrants

\begin{tabular}{|l|l|l|l|}
\hline First & Last & Role & Affiliation \\
\hline Bilal & Ayyub & Lead/Organizer/ Facilitator & University of Maryland \\
\hline Richard & Wright & Organizer/Facilitator & University of Maryland \\
\hline Gerald & Galloway & Organizer/Facilitator & University of Maryland \\
\hline Robert & Chapman & Organizer & NIST \\
\hline David & Butry & Organizer/Facilitator & NIST \\
\hline Stanley & Gilbert & Organizer/Facilitator & NIST \\
\hline Douglas & Thomas & Organizer/Facilitator & NIST \\
\hline Howard & Harary & Speaker & NIST \\
\hline Erica & Kuligowski & & NIST \\
\hline Terry & McAlister & & NIST \\
\hline Joseph & Fiksel & Moderator S1 & Ohio State University \\
\hline Stephanie & Chang & Moderator S3 & The University of British Columbia \\
\hline Richard & Feigel & Moderator S2 & HSB \& Former ASME president \\
\hline Eric & Berman & & FEMA Hazus \\
\hline Susan & Cutter & & University of South Carolina \\
\hline Wen-Huei & Chang & & USACE, IWR \\
\hline Jamie & Kruse & & East Carolina University \\
\hline Douglas & Bellomo & & FEMA \\
\hline Robert & Prieto & Moderator S2 & Fluor \\
\hline Howard & Kunreuther & Moderator S1 & University of Pennsylvania \\
\hline Matthew & Schaffer & & APL-JHU \\
\hline Christine & Morris & Speaker & City of Norfolk \\
\hline Michael & Kearney & & University of Maryland \\
\hline Michael & Beer & & University of Liverpool \\
\hline Konstantin & Zuev & & University of Liverpool \\
\hline Matteo & Broggi & & University of Liverpool \\
\hline
\end{tabular}




\begin{tabular}{|c|c|c|c|}
\hline Athanasios & Pantelous & & University of Liverpool \\
\hline Peter & Williams & & IBM Smarter Cities \\
\hline Saurabh & Mishra & & University of Maryland \\
\hline David & Webb & & University of Maryland \\
\hline Debra & Ballen & & Institute for Business and Home Safety \\
\hline Sue & Helper & Speaker & U.S. Department of Commerce \\
\hline Sarah & Slaughter & & Built Environment Coalition \\
\hline Rachel & Davidson & & University of Delaware \\
\hline Chris & Greer & & NIST \\
\hline Elizabeth & Asche & & DHS \\
\hline Jennifer & Helgeson & & NIST \\
\hline Gerald & Stedge & & Abt Conslting \\
\hline Bob & Zimmerman & & DHS HIS \\
\hline Andrew & Castaldi & & Swiss Re \\
\hline Jeremias & Alvarez & Replacement & RISE \\
\hline Nancy & McNabb & & NIST \\
\hline Tom & O'Rourke & & Cornell Univeristy \\
\hline John & van de Lindt & Lunch speaker & Colorado State Un. \\
\hline Harvey & Cutler & & Colorado State Un. \\
\hline Sammy & Zahran & & Colorado State Un. \\
\hline Daniele & Tavani & & Colorado State Un. \\
\hline Tony & Cheesebrough & & DHS \\
\hline John & Vargo & & University of Canterbury \\
\hline Roy & Emanuel & & APL-JHU \\
\hline Adam & Rose & Lunch speaker & USC \\
\hline Kathleen & Boyer & & FEMA-DHS \\
\hline Anand & Kandaswamy & & NIST \\
\hline Jane & Callen & & U.S. Department of Commerce \\
\hline Katerina & Oskarsson & & City of Norfolk \\
\hline
\end{tabular}



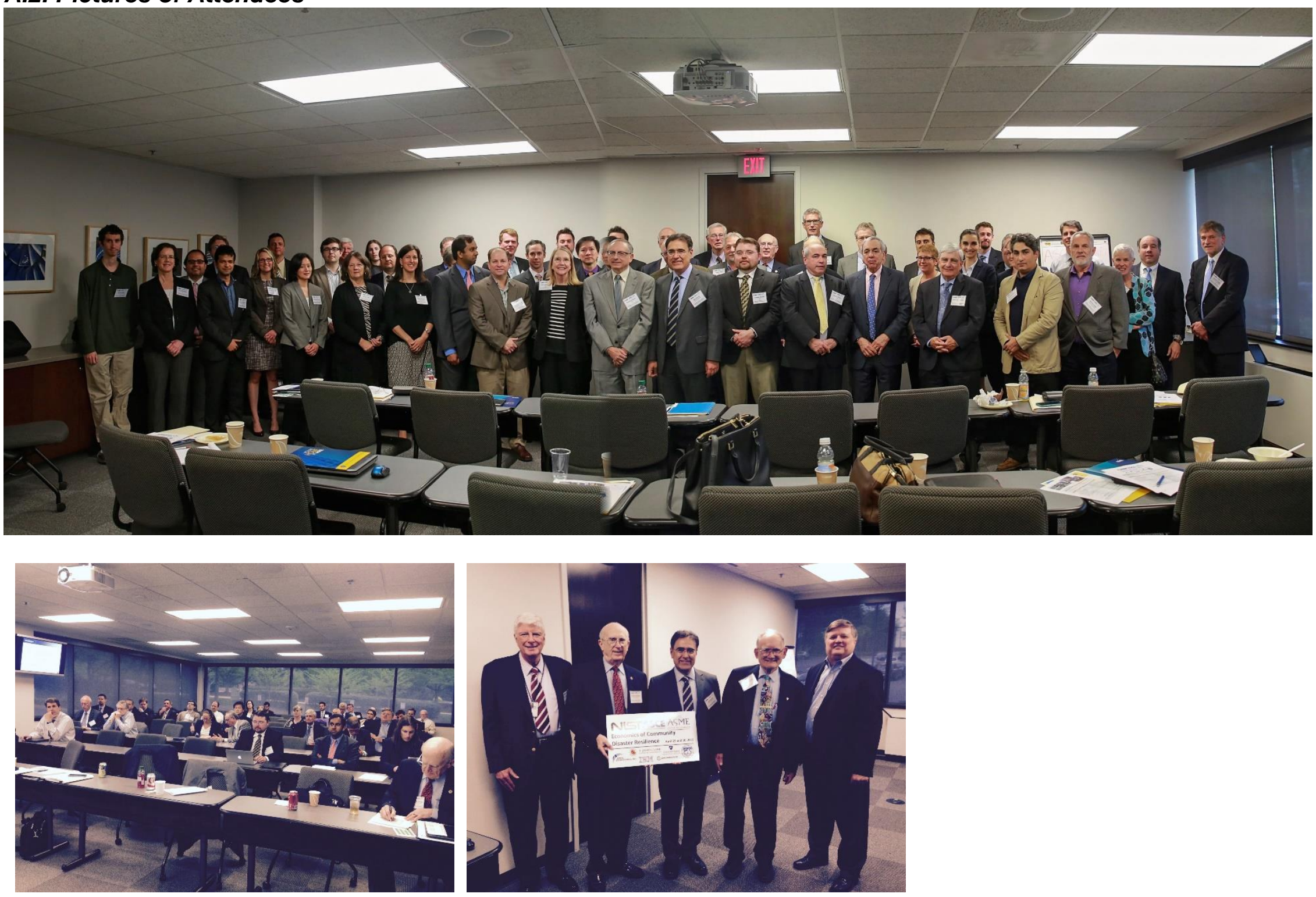


\section{A.3. Breakout Session Attendees}

\begin{tabular}{|c|c|c|c|c|}
\hline & \multicolumn{4}{|c|}{ Breakout Session 1. Resilience Planning and Deployment } \\
\hline & First Name & Last Name & Affiliation & email \\
\hline \multirow{2}{*}{$\begin{array}{l}\text { Co- } \\
\text { Moderators }\end{array}$} & Joseph & Fiksel & Ohio State University & fiksel.2@osu.edu \\
\hline & Howard & Kunreuther & University of Pennsylvania & kunreuth@wharton.upenn.edu \\
\hline \multirow{2}{*}{$\begin{array}{l}\text { Co- } \\
\text { Facilitators }\end{array}$} & Gerald & Galloway & University of Maryland & gegallo@umd.edu \\
\hline & Douglas & Thomas & NIST & douglas.thomas@nist.gov \\
\hline \multirow[t]{7}{*}{ Support } & Anand & Kandaswamy & NIST & anand.kandaswamy@nist.gov \\
\hline & Douglas & Bellomo & FEMA & Doug.Bellomo@fema.dhs.gov \\
\hline & Kathleen & Boyer & FEMA-DHS & Kathleen.Boyer@fema.dhs.gov \\
\hline & Wen-Huei & Chang & USACE, IWR & Wen-Huei.Chang@usace.army.mil \\
\hline & Rachel & Davidson & University of Delaware & rdavidso@udel.edu \\
\hline & Howard & Harary & NIST & howard.harary@nist.gov \\
\hline & Tom & O'Rourke & Cornell University & tdo1@cornell.edu \\
\hline \multirow{8}{*}{$\begin{array}{l}\text { Session } \\
\text { Members }\end{array}$} & Matthew & Schaffer & APL-JHU & Matthew.schaffer@jhuapl.edu \\
\hline & Sarah & Slaughter & Built Environment Coalition & sarah@builtenvironmentcoalition.org \\
\hline & Gerald & Stedge & Abt Conslting & Gerald_Stedge@abtassoc.com \\
\hline & John & van de Lindt & Colorado State Un. & jwv@engr.colostate.edu \\
\hline & Peter & Williams & IBM Smarter Cities & peter.r.williams@us.ibm.com \\
\hline & Sammy & Zahran & Colorado State Un. & sammy.zahran@colostate.edu \\
\hline & Mike & Kearney & University of Maryland & kearneym@umd.edu \\
\hline & Susan & Cutter & USC & SCUTTER@mailbox.sc.edu \\
\hline
\end{tabular}




\begin{tabular}{|c|c|c|c|c|}
\hline & \multicolumn{4}{|c|}{ Breakout Session 2. Dealing with Uncertainty } \\
\hline & First Name & Last Name & Affiliation & email \\
\hline \multirow{2}{*}{$\begin{array}{l}\text { Co- } \\
\text { Moderators }\end{array}$} & Richard & Feigel & HSB \& Former ASME president & gene.feigel@gmail.com \\
\hline & Robert & Prieto & Fluor & Bob.Prieto@fluor.com \\
\hline \multirow{2}{*}{$\begin{array}{l}\text { Co- } \\
\text { Facilitators } \\
\end{array}$} & David & Butry & NIST & david.butry@nist.gov \\
\hline & Richard & Wright & University of Maryland & richard.n.wright@verizon.net \\
\hline Support & Jennifer & Helgeson & NIST & Jennifer.helgeson@nist.gov \\
\hline \multirow{8}{*}{$\begin{array}{l}\text { Session } \\
\text { Members }\end{array}$} & Michael & Beer & University of Liverpool & M.Beer@liverpool.ac.uk \\
\hline & Matteo & Broggi & University of Liverpool & matteo.broggi@liverpool.ac.uk \\
\hline & Roy & Emanuel & APL-JHU & roy.emanuel@jhuapl.edu \\
\hline & Jamie & Kruse & East Carolina University & krusej@ecu.edu \\
\hline & Terry & McAlister & NIST & terri.mcallister@nist.gov \\
\hline & Nancy & McNabb & NIST & nancy.mcnabb@nist.gov \\
\hline & Daniele & Tavani & Colorado State Un. & daniele.tavani@colostate.edu \\
\hline & Konstantin & Zuev & University of Liverpool & zuev@liverpool.ac.uk \\
\hline
\end{tabular}




\begin{tabular}{|c|c|c|c|c|}
\hline & \multicolumn{4}{|c|}{ Breakout Session 3. Economics of Recovery } \\
\hline & First Name & Last Name & Affiliation & email \\
\hline $\begin{array}{l}\text { Co- } \\
\text { Moderators }\end{array}$ & Stephanie & Chang & The University of British Columbia & stephanie.chang@ubc.ca \\
\hline \multirow{3}{*}{$\begin{array}{l}\text { Co- } \\
\text { Facilitators }\end{array}$} & Bilal & Ayyub & University of Maryland & ba@umd.edu \\
\hline & Stanley & Gilbert & NIST & stanley.gilbert@nist.gov \\
\hline & David & Webb & University of Maryland & web29110@gmail.com \\
\hline \multirow{14}{*}{$\begin{array}{l}\text { Session } \\
\text { Members }\end{array}$} & Elizabeth & Asche & DHS & elizabeth.asche@hsi.dhs.gov \\
\hline & Debra & Ballen & Institute for Business and Home Safety & dballen@ibhs.org \\
\hline & Eric & Berman & FEMA Hazus & Eric.Berman@fema.dhs.gov \\
\hline & Andrew & Castaldi & Swiss Re & Andrew_Castaldi@swissre.com \\
\hline & Robert & Chapman & NIST & robert.chapman@nist.gov \\
\hline & Tony & Cheesebrough & GHS & tony.cheesebrough@hq.dhs.gov \\
\hline & Harvey & Cutler & Colorado State Un. & harvey.cutler@colostate.edu \\
\hline & Erica & Kuligowski & NIST & erica.kuligowski@nist.gov \\
\hline & Saurabh & Mishra & University of Maryland & SMishra2@imf.org \\
\hline & Athanasios & Pantelous & University of Liverpool & aap@liverpool.ac.uk \\
\hline & Adam & Rose & USC & adamzros@price.usc.edu \\
\hline & John & Vargo & University of Canterbury & john.vargo@resorgs.org.nz \\
\hline & Bob & Zimmerman & DHS HIS & robert.zimmerman@hsi.dhs.gov \\
\hline & Jeremias & Alvarez & PwC RISE & jeremias.alvarez@us.pwc.com \\
\hline
\end{tabular}




\section{Appendix B. Biographical Information on Some Participants}

\section{Elizabeth A. Asche}

Dr. Asche is a Senior Analyst at the Homeland Security Studies and Analysis Institute (HSSAI). In her current position, she provides economic expertise to variety of studies across the breadth of the Institute's engagements with the Department of Homeland Security, including Chemical Facility Anti-Terrorism Security (CFATS) with NPPD and the Community Rating System with FEMA. Dr. Asche's main research interests are the National Flood Insurance Program, Mitigation, and Community Resilience. More generally, her goal is to provide a bridge between academic studies and practical policy discussions by simplifying, clarifying, and appropriately discussing the results and implications of such studies. She has a $\mathrm{PhD}$ in economics and an undergraduate degree in environmental engineering.

\section{Bilal M. Ayyub}

Dr. Ayyub is the Director of the Center for Technology and Systems Management at the University of Maryland. He is a Professor of Civil and Environmental Engineering since 1983, Professor of Reliability Engineering since 1985, and Professor of Applied Mathematics and Scientific Computation since 2009. Presently, he is on sabbatical leave from the University of Maryland as a one-year visitor at the National Security Analysis Department of the Applied Physics Laboratory of the Johns Hopkins University, 2014-15. Previously he worked at the U.S. Naval Surface Warfare Center as a Consulting Professor on ONR-funded ASEE fellowships during 1993-94, 2000-01 and 2007-08. Dr. Ayyub's main research interests are risk, uncertainty and decision analysis, and systems engineering applied to civil, infrastructure, energy, defense and maritime fields. Dr. Ayyub is a fellow of ASCE, ASME, SRA and the Society of Naval Architects and Marine Engineers (SNAME). He is also IEEE senior member. Dr. Ayyub completed research and development projects for governmental and private entities. Dr. Ayyub is the recipient of awards from ASCE, ASNE, ASME, NAFIPS, the Department of the Army, and the Governor of the State of Maryland. Dr. Ayyub is the author and co-author of more than 600 publications including 8 textbooks and 14 edited books. His books include Risk Analysis in Engineering and Economics (2014 second ed.) and Uncertainty Modeling and Analysis in Engineering and the Sciences (with G. Klir, 2006). He is the editor-in-chief of the ASCE-ASME Journal of Risk and Uncertainty in Engineering Systems, serves on the ExCom of the Infrastructure Resilience Division of ASCE and the ExCom of the Committee of Adaptation to a Changing Climate of ASCE, and serves on the Board on Research and Technology Development of ASME. 


\section{Debra T. Ballen}

Ms. Ballen joined IBHS in 2008 as the general counsel and senior vice president of public policy. In this capacity, she is responsible for all of the Institute's legal matters and oversees a number of important public policy initiatives, including building codes, adaptation, community resilience, and economic incentives for mitigation. In addition, she serves as the organization's corporate secretary and manages member relations. Prior to her work with IBHS, Ms. Ballen was the executive vice president of public policy management for the American Insurance Association (AIA). She developed and implemented policy for AIA's priority federal and state public policy issues. She also serves on the Advisory Committee for the Natural Hazards Center at the University of Colorado and has participated

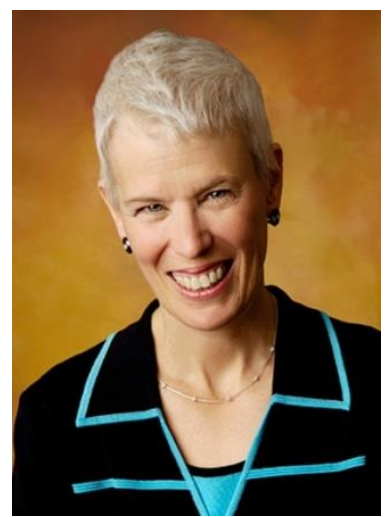
on the Organization for Economic Cooperation and Development (OECD) High Level Advisory Board on Financial Management of Large Scale Catastrophes. She is a frequent speaker about the broad benefits of mitigation and has testified before Congress and state legislatures on these matters. Ms. Ballen graduated with a juris doctorate degree from Harvard Law School and an A.B. degree from Princeton University. She also has received the CPCU designation.

\section{Michael Beer}

Dr. Beer is Professor of Uncertainty in Engineering and Director of the Institute for Risk \& Uncertainty in the University of Liverpool. He is also the Director of the EPSRC and ESRC Centre for Doctoral Training in Quantification and Management of Risk \& Uncertainty in Complex Systems \& Environments. Dr. Beer's research is focused on non-traditional uncertainty quantification and specifically on imprecise probabilities in engineering. Dr. Beer is a Feodor-Lynen Fellow of the Alexander von Humboldt-Foundation, Member of ASCE, ASME, ESRA, EASD, IACM, GACM. He is also Editor in Chief of the Encyclopedia of Earthquake Engineering (Springer), Associate

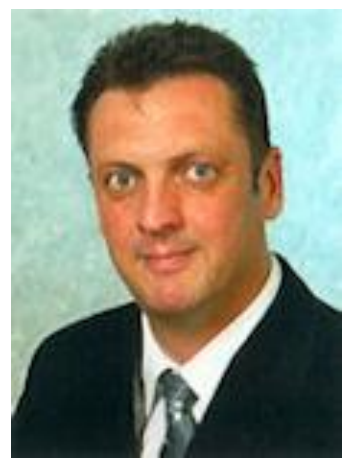
Editor of the ASCE-ASME Journal of Risk and Uncertainty in Engineering Systems, Associate Editor of the International Journal of Reliability and Safety as well as Member of eight Editorial Boards including Probabilistic Engineering Mechanics, Computers \& Structures, Structural Safety and Mechanical Systems and Signal Processing.

\section{Doug Bellomo}

Mr. Bellomo is a civil engineer with the Federal Emergency Management Agency (FEMA) in Washington, DC. He is currently the Director of the Risk Analysis Division within the Federal Insurance and Mitigation Administration at FEMA. Division responsibilities include flood hazard mapping as part of the National Flood Insurance Program, Natural Hazard Risk Assessment, Mitigation Planning, as well as implementing the National Dam Safety program. Mr. Bellomo is a professional engineer and holds a B.S. and M.S. in Civil Engineering. He has been working in the fields of flood hazard identification, risk management, and mitigation since 1993.

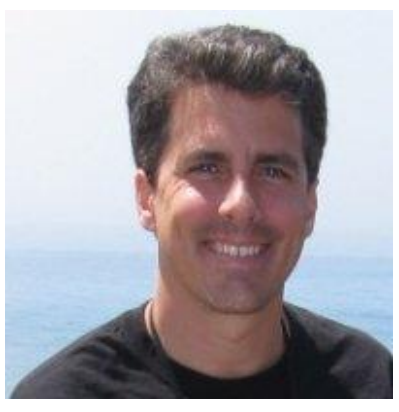


David T. Butry

Dr. Butry is an Economist in the Applied Economics Office of the Engineering Laboratory (EL) at the National Institute of Standards and Technology (NIST). Dr. Butry joined NIST in 2006. Currently, he is leading research in the areas of community disaster resilience and fire protection. His formal training is in the areas of applied microeconomics and econometrics, with specialization in the fields of natural resource economics, environmental economics, and spatial statistics (including the use of Geographic Information Systems). He is interested in the economics of natural and man-made disasters and with econometric issues relating to spatial autocorrelation and analysis, endogenous variables, and sample selfselection.

\section{Stephanie E. Chang}

Dr. Chang is a professor at the University of British Columbia, Canada, with the School of Community and Regional Planning (SCARP) and the Institute for Resources, Environment, and Sustainability (IRES). She has held a Canada Research Chair in Disaster Management and Urban Sustainability (Tier 2, 2004-2013). Dr. Chang has published extensively on the socioeconomic impact of natural disasters, modeling disaster losses, urban risk dynamics, critical infrastructure systems and interdependencies, economic evaluation of disaster mitigations, and disaster recovery. She has served on the U.S. National Research Council's Committee on Disaster Research in the Social Sciences and its Committee on Earthquake Resilience - Research, Implementation, and Outreach.

\section{Wen-Huei Chang}

Dr. Chang is a Senior Economist at the Institute for Water Resources, US Army Corps of Engineers. The Army Corps is one of the world's largest public engineering, design, and construction management agencies, and its civil works mission areas include navigation, flood risk management, hydropower, water supply, recreation, and environment. Dr. Chang serves as the Enterprise Technical Team Lead to direct programs and manage several nationally significant projects, and to conduct economic analysis for infrastructural recapitalization and budget allocation purposes. He also leads the USACE's Regional Economic System program, which is an agency wide certified modeling tool for estimating jobs, income, sales and other economic effects associated with Corps' Civil Works programs, and economic consequences from natural disaster or catastrophic events. In addition, Dr. Chang has extensive international work experiences, mostly on Integrated Water Resources Management projects in Southeast Asia working with local leaders/ government officials for planning and decision making processes. He also just spent three months in Beijing as a US Embassy Science Fellow to work on water resources issues and policies in China. 


\section{Robert E. Chapman}

Dr. Chapman is the Chief of the Applied Economics Office within the Engineering Laboratory at the National Institute of Standards and Technology (NIST). In his current position, he leads a group of economists that evaluate new technologies, processes, government programs, and codes and standards to determine efficient alternatives and to measure economic impacts. Dr. Chapman's main research interests are energy efficiency, sustainability, performance-based standards, and disaster resilience. Dr. Chapman is the recipient of awards from the U.S. Department of Commerce and ASTM International. Dr. Chapman is the author and coauthor of numerous publications, including: journal articles, conference proceedings, and technical reports.

\section{Tony Cheesebrough}

Mr. Cheesebrough is Chief Economist for the National Protection and Programs Directorate (NPPD) at the U.S. Department of Homeland Security (DHS) and Adjunct Professor at Carnegie Mellon University's Heinz College. As Chief Economist for NPPD, Tony is responsible for developing economic analyses that inform efforts to enhance critical infrastructure resilience, a framework for estimating the impact of cyber threats to the U.S. economy, and benefit-cost analyses required to support proposed regulations. He also teaches a graduate economics course in cost-benefit analysis at Carnegie Mellon University. Tony previously served as Director for Risk and Capability Analytics in the DHS Office of Policy and Deputy Assistant Director for Risk Analytics in the DHS Office of Risk Management and Analysis. Before joining DHS, Tony was a Senior Analyst at the U.S.

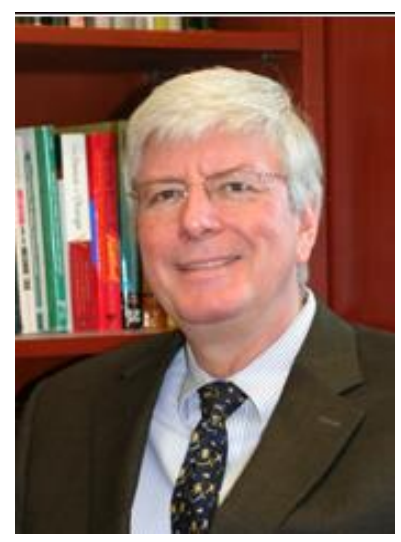
Government Accountability Office, a Presidential Management Fellow at the U.S. Office of Management and Budget, and also worked in the private sector as a management consultant. Tony is a member of the Society for Benefit Cost Analysis, the American Economic Association, the Economics of National Security Association, the Society for Risk Analysis, and the Institute for Operations Research and Management Science. He holds a Master's degree in Public Policy with a concentration in applied microeconomic analysis from Harvard University's Kennedy School of Government, as well as a B.A. in economics with the equivalent of a minor in mathematics from Swarthmore College. 


\section{Joseph Fiksel}

Dr. Fiksel is the Executive Director of Ohio State's Discovery Themes program on Sustainable and Resilient Economy. Previously he was cofounder and Executive Director of the Center for Resilience at Ohio State, and also served as special assistant for sustainability at U.S. EPA. $\mathrm{He}$ is an internationally recognized authority on supply chain sustainability and resilience, with over 25 years of research and consulting experience for multi-national companies, government agencies and industry consortia such as the World Business Council for Sustainable Development. A native of Montreal, Fiksel began his career at DuPont of Canada, and later served as Director of Decision

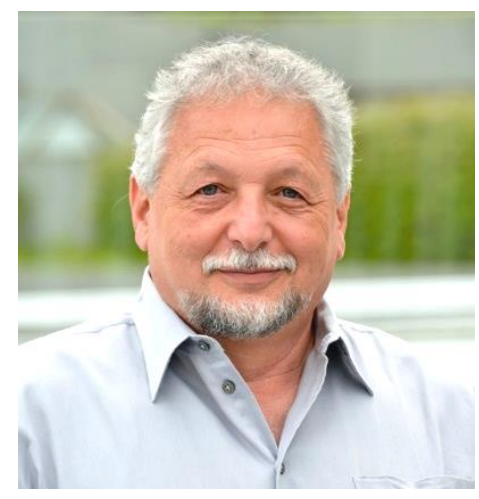
and Risk Management at Arthur D. Little, Inc. and Vice President for Life Cycle Management at Battelle. He holds a bachelor's degree from M.I.T., a doctorate from Stanford University, and an advanced degree from La Sorbonne. His most recent book is Design for Environment: A Guide to Sustainable Product Development, 2011.

\section{Gerald E. Galloway}

Dr. Galloway, PE is a Glenn L. Martin Institute Professor of Engineering, Department of Civil and Environmental Engineering and an Affiliate Professor, School of Public Policy, University of Maryland, College Park, Maryland, where his focus is on water resources policy, resilience, and disaster risk management. He also serves as a consultant to several international, federal, state and nongovernmental agencies and has been involved in water projects in the US, Europe, Asia and South America. He recently chaired a National Research Council (NRC) Study on Levees and the National Flood Insurance Program and is currently a member of the US National

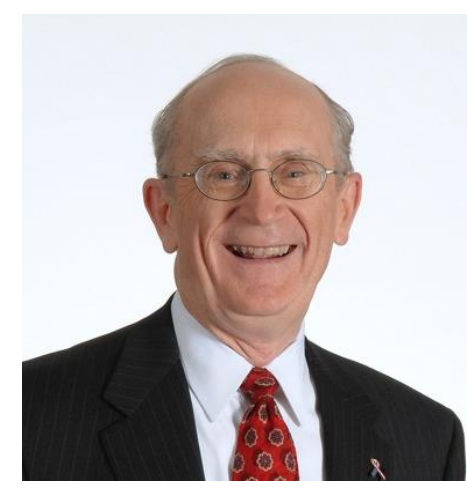
Academies' Risk, Resilience and Extreme Events Roundtable and the Louisiana Governor's Advisory Commission on Coastal Protection and Restoration. He is a member of the National Academy of Engineering and the National Academy of Public Administration. He served for 38 years in the US Army, retiring as a Brigadier General.

\section{Stanley Gilbert}

Dr. Gilbert is an economist for the Engineering Laboratory at the National Institute of Standards and Technology. His work is primarily on disaster resilience, and wildland fire. His work on fire has included empirically estimating how much people are willing to pay to avoid fire risk in the wildland-urban interface, and the value people place on fire sprinklers in the home. His work in disaster resilience has included a Guide to the Literature. He has also done work on construction and manufacturing labor supply. His is currently working on drafting the Economic Guide for community disaster resilience.

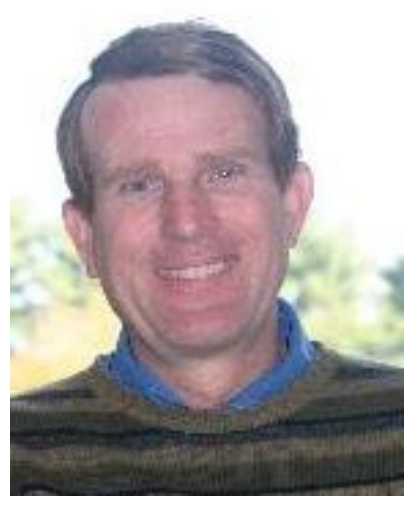




\section{Howard Harary}

Dr. Harary has been with the National Institute of Standards and Technology since 1985. Dr. Harary began his NIST career in the Precision Engineering Division of the Manufacturing Engineering Laboratory (MEL), working in the area of dimensional metrology. He was appointed Deputy Director of MEL in October 2004, and Acting MEL Director in August 2007. After the NIST re-alignment, he served as the Deputy Director for Manufacturing of the new NIST Engineering Laboratory. Dr. Harary is currently the Director of the Engineering Laboratory. Dr. Harary was awarded the Commerce Department Bronze Medal for his work in threedimensional measurement, and the NIST Edward Bennett Rosa Award for his collaboration with industry in re-establishing traceability for gear measurements. Dr. Harary currently serves on the visiting panel of the University of Maryland Mechanical Engineering Department, is the government liaison to the board of PDES, Inc., and is a member of the ASME Council on Standards and Certification.

\section{Susan Helper}

Dr. Helper is the Chief Economist of the U.S. Department of Commerce's Economics and Statistics Administration. Previously she served on the President's Council of Economic Advisors as a Senior Economist. Dr. Helper is on leave from the Weatherhead School of Management at Case Western Reserve University, where she is the Carlton Professor of Economics. She was formerly the chair of the Economics Department, and has been a visiting scholar at University of Oxford, the University of California (Berkeley), Harvard University and the Massachusetts Institute of Technology (MIT). Her research focuses on the globalization of supply chains, and on how U.S. manufacturing might be revitalized. Dr. Helper received her $\mathrm{PhD}$ in Economics from Harvard and her B.A. from Oberlin College in Economics, Government and Spanish. Dr. Helper lives with her

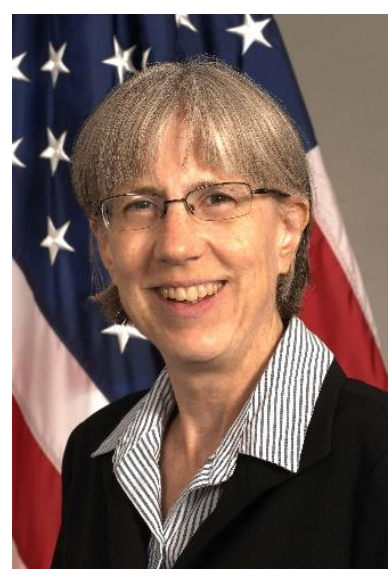
husband and three bicycles in Washington, DC. 


\section{Jamie Brown Kruse}

Dr. Jamie Kruse is recognized for her research in economics and decision making under uncertainty especially as it relates to natural hazards. She completed her doctoral work at University of Arizona under dissertation advisor, Vernon Smith (2002 Nobel Laureate). Dr. Kruse has published over fifty refereed journal articles in addition to proceedings, abstracts and reports. Her work has appeared in Econometrica, RAND Journal of Economics, Southern Economic Journal, Journal of Economic Behavior and Organization, Economic Inquiry, Natural Hazards Review, Journal of Wind Engineering and Industrial Aerodynamics, Environmetrics, Weather and Forecasting, Risk Analysis, Journal of Risk and Insurance and others. She has held faculty positions at the University of Colorado, Texas Tech University, East Carolina University and a visiting position at Eidgenossische Technische Hochschule (ETH) in Zurich, Switzerland. Her funded research has been supported by National Science Foundation, Department of Energy, National Institute of Standards and Technology, Federal Emergency Management Agency, Federal Deposit Insurance Corporation, Niagara Mohawk, State of Texas and the State of North Carolina. In 2010 she held the position of Chief Economist at NOAA. At the interagency level, she served as a member of the OSTP Subcommittee on Social, Behavioral and Economic Sciences, OSTP Subcommittee on Ocean Science and Technology. At East Carolina University, Dr. Kruse was inducted to the 2011 Women of Distinction. Since then she has been recognized by ECU's Division of Research and Graduate Studies with the Lifetime Achievement Award for Research and Creative Work and honored with the HCAS Distinguished Professorship.

\section{Howard C. Kunreuther}

Dr. Kunreuther is the James G. Dinan Professor of Decision Sciences and Business and Public Policy at the Wharton School, and co-director of the Wharton Risk Management and Decision Processes Center. Professor Kunreuther has a long-standing interest in ways that society can better manage low-probability, high-consequence events related to technological and natural hazards. He is a Fellow of the American Association for the Advancement of Science, and a Distinguished Fellow of the Society for Risk Analysis. Kunreuther currently serves on the National Academy of Science/National Research Council's

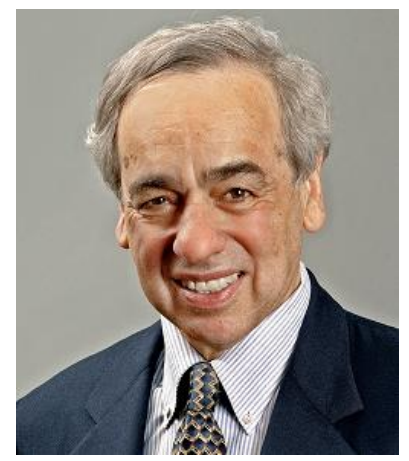
committees on Analysis of Costs and Benefits of Reforms to the National Flood Insurance Program and the Roundtable on Risk, Resilience, and Extreme Events. His books include Insurance and Behavioral Economics: Improving Decisions in the Most Misunderstood Industry" (with M. Pauly and S. McMorrow, 2013) and At War with the Weather (with E. Michel-Kerjan, 2011). 


\section{Christine R. Morris}

Ms. Morris is Chief Resilience Officer for the City of Norfolk. She began working for the City in March of 2013 as assistant to the City Manager. Prior to joining Team Norfolk, she served as Vice President of Initiatives for the Hampton Roads Community Foundation, which is the region's premier provider of philanthropic services including community impact through grants and scholarships, regional leadership through its focus on community needs and initiatives and personal philanthropy. Ms. Morris also served as Vice President of Training and Technical Assistance for EDTEC, Inc., a consulting firm specializing in organizational and community development projects. Her projects included assisting boards in

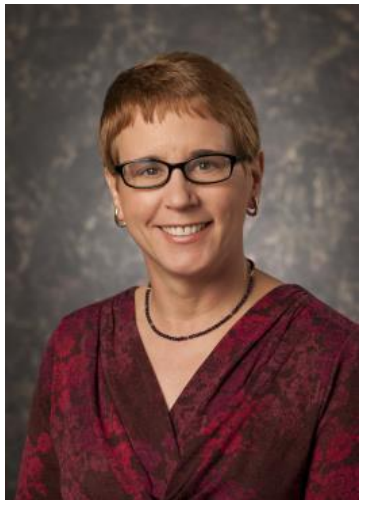
public housing developments organize and develop impactful programs. In all Ms. Morris has more than 25 years of experience helping nonprofits improve their management, board leadership, strategic planning and community relations. She holds a BA from the University of Pennsylvania and a Master's degree in International Affairs from George Washington University.

\section{Thomas O'Rourke}

Dr. O'Rourke is the Thomas R. Briggs Professor of Engineering, School of Civil and Environmental Engineering, Cornell University. He is a member of the the National Academy of Engineering, International Fellow of the Royal Academy of Engineering, Distinguished Member of ASCE, and AAAS Fellow. He is an Overseas Fellow, Churchill College, University of Cambridge, U.K., and was a Fulbright Senior Specialist with the Office of the Prime Minister and Cabinet, Wellington, NZ in 2007. He received his PhD and MSCE from the University of Illinois at Urbana-Chamapaign in 1973 and 1975, and BSCE from Cornell University in 1970. He authored or co-authored

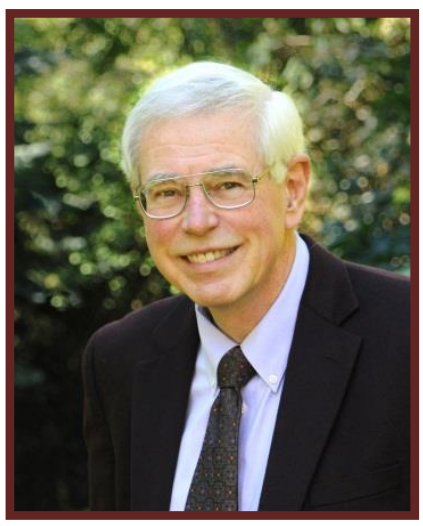
over 360 publications on geotechnical, underground, and earthquake engineering, and the impact of natural hazards and human threats on civil infrastructure. He served as consultant or advisor on more than 120 projects in 12 different countries. He was President of the Earthquake Engineering Research Institute [EERI] (2003-04) and Technical Director of the ATC Project for the NIST Research, Development and Implementation Roadmap for Earthquake Resilient Lifelines (2013-14). 


\section{Athanasios A. Pantelous}

Dr. Pantelous is Reader within the Department of Mathematical Sciences, University of Liverpool, UK. He has received two PhDs: in Statistics (Actuarial Science) from Athens University of Economics and Business (Athens, Greece) and in Stochastic Modelling and Control Theory (Engineering) from City University (London, UK). Dr. Pantelous is leading the research in the Institute for Financial and Actuarial Mathematics (IFAM) at the University of Liverpool as well as high-quality training in actuarial and financial mathematics through accredited UG/PGT level courses from the Institute and Faculty of Actuaries (IFoA) London UK, a big number of $\mathrm{PhD} /$ Post-Doc students, influential roles in professional

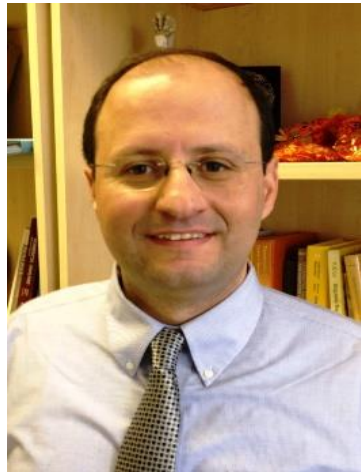
societies, service on editorial and advisory boards, as external advisor, expert and assessor for research councils, universities and industry. Dr. Pantelous co-leads, as its Deputy-Director and co-Principal Investigator, the EPSRC and ESRC Centre for Doctoral Training (CDT) in Quantification and Management of Risk \& Uncertainty in Complex Systems \& Environments. This research and training center has a total funding volume of \$31 million and involves 36 industrial and academic partners from around the globe. Dr. Pantelous is the author and coauthor of more than 120 publications in journals, conference proceedings, and reports.

\section{Adam Rose}

Dr. Rose is a Research Professor in the University of Southern California Sol Price School of Public Policy, and a faculty affiliate of USC's Center for Risk and Economic Analysis of Terrorism Events (CREATE). He has worked extensively on economic resilience at the levels of the individual business/household, sector/market and regional/national economies. He was the research team leader on the Multi-Hazard Mitigation Council report to the US Congress on the benefits of FEMA hazard mitigation grants, served on the NRC panel on Earthquake Resilience, and coordinated eight studies

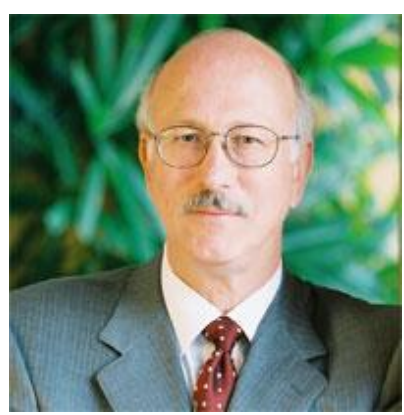
to arrive at a definitive estimate of the economic consequences of $9 / 11$. He is an advisor to the World Bank on co-benefits of disaster risk management and recently completed a report on disaster resilience for the United Nations Development Programme. He is the author of several books and 200 other publications. Professor Rose currently serves on the editorial boards of Environmental Hazards, Journal of Integrated Disaster Risk Management and International Journal of Disaster Risk Science. He has served as the American Economic Association Representative to the American Association for the Advancement of Science, as a member of the Board of Directors of the National Institute of Building Sciences Multi-Hazard Mitigation Council and of the Advisory Board of the Center for National Policy Resilience Forum. He is the recipient of a Woodrow Wilson Fellowship, East-West Center Fellowship, American Planning Association Outstanding Program Planning Honor Award, Applied Technology Council Outstanding Achievement Award, and Regional Economic Models Outstanding Economic Analysis Award. 


\section{Sarah Slaughter}

Dr. Slaughter is President and founder of the Built Environment Coalition, a research and education nonprofit (501c3) organization. She is also currently a Visiting Lecturer at MIT in the Department of Urban Studies and Planning, teaching and supervising research related to resilient communities. She was recently the Associate Director for Buildings and Infrastructure in the MIT Energy Initiative (MITEI), and co-founder and faculty head of the Sustainability Initiative in the MIT Sloan School of Management. Previously, Dr. Slaughter was founder and CEO of MOCA Systems, Inc., a construction program management company based on the construction simulation software system from her MIT research. Before MOCA, she was a professor in the Department of Civil and Environmental

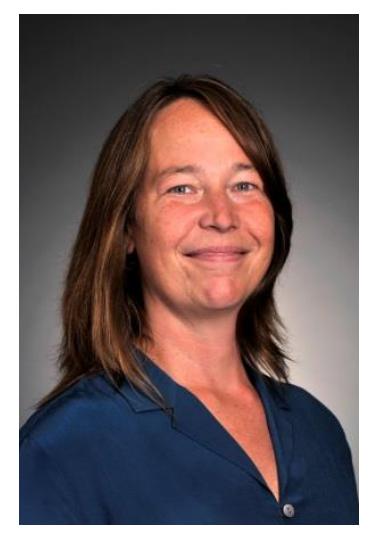
Engineering, and earlier, she was a professor of Civil and Environmental Engineering at Lehigh University and conducted research in the NSF Center for Advanced Technology for Large Structural Systems (ATLSS). Dr. Slaughter serves on the Green Building Advisory Committee for the US General Services Administration (GSA), and is currently a member of the National Academy of Construction, and an Associate Member of the National Academy of Sciences. She was previously on the National Research Council (NRC) Board on Infrastructure and the Constructed Environment (BICE), the National Academies DOD Standing Committee on Materials, Manufacturing, and Infrastructure, and the Vice Chair of the NRC Committee on Sustainable Critical Infrastructure Systems. She also served on the Massachusetts Sustainable Water Management Advisory Board, the Sustainability Committee in the International Facilities Management Association (IFMA), and several national advisory committees and editorial boards of professional publications. She currently serves on the Board of Directors for Retroficiency, Inc., and the Charles River Watershed Association.

\section{Gerald Stedge}

Dr. Stedge manages Abt Associates' Natural Resource Practice which provides natural resource economic and policy support to federal clients including the U.S. Army Corps of Engineers' Institute for Water Resources, the U.S. EPA's Office of Water, NOAA's Office for Coastal Management, and the Department of Homeland Security. Recently, Dr. Stedge led the development of the Corps of Engineers' National Flood Risk Characterization Tool and the EPA's Water Health and Economic Analysis Tool, both aimed at helping make infrastructure investment decisions to limit damages from disasters. He has received the Department of the Army Commander's Award for Public Service and has been named to the Army Corps of Engineers Institute for Water Resources Team of the Year twice. Dr. Stedge holds a Ph.D. from the Virginia Polytechnic Institute and State University. 


\section{Douglas Thomas}

Mr. Thomas is a research economist for the Engineering Laboratory's Applied Economics Office at the National Institute of Standards and Technology. Currently, his activities are focused in two areas of research: 1) smart manufacturing and construction and 2) disaster-resilient buildings, infrastructure, and communities. The first area includes examining spatial and temporal variations in the quality and quantity of industry activity in relation to the domestic and international economy. It utilizes industry data combined with various methods of analysis to understand production industries and their supply chains. Work in this area also examines microeconomic issues such as examining the life-cycle cost of buildings and building components in order to identify the most efficient products and practices. The second area of research involves examining issues related to natural and man-made disasters, including wildland and structure fires. His work in this area aims to reduce the cost and loss associated with these adverse events and has, more specifically, focused on understanding the occurrence and spatio-temporal patterns of fire incidents.

\section{John Vargo}

Dr. Vargo is a senior researcher and co-leader of the Resilient Organisations Research Programme based at the University of Canterbury. His interests focus on building organisational resilience in the face of systemic insecurity in a complex and interconnected world. The ResOrgs group (www.resorgs.org.nz) has been researching Organisational Resilience since 2004 and has been heavily involved in related research following the 2010-2011 series of devastating earthquakes that hit Christchurch, New Zealand. This research has looked at the impacts of the earthquakes on organisations and economic sectors and the application of the ResOrgs 13 indicator resilience model to systemic recovery. Other recent research projects have focused on the resilience of critical infrastructure organisations in Australia and New Zealand and the keystone role they play in the resilience of a community and a nation. John is the author and co-author of numerous publications, including: journal articles, conference proceedings, and technical reports (see resorgs.org.nz). His research interests are in organisational resilience, information security, risk management and strategic planning. Contact: john.vargo@ resorgs.org.nz. 


\section{Kateryna (Katya) Wowk}

Dr. Wowk is an expert in using multidisciplinary approaches to achieve sustainable management of human impacts on coastal and marine areas, with a focus on coastal hazards/disasters and resilience, integrating ecosystem services into decision-making to address threats related to climate change and the ocean, and marine resource management. Prior to her current position, Katya served as Senior Policy Official to the Assistant Secretary of Commerce for Conservation and Management, where she led NOAA and interagency efforts related to coastal resilience, Sandy Recovery, National Ocean Policy, and the National

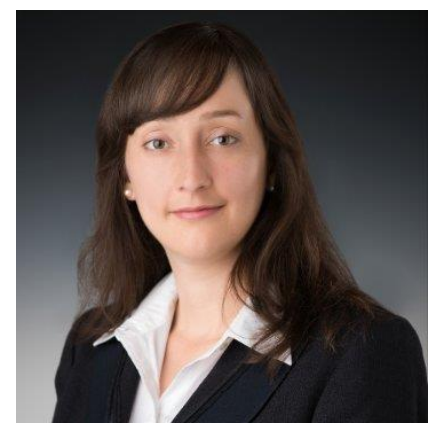
Drought Resilience Partnership. Katya holds a PhD in International Marine Policy from the University of Delaware and a Masters of Public Administration from Columbia University.

\section{Richard N. Wright}

Dr. Wright is a Research Professor of Civil and Environmental Engineering at the University of Maryland College Park, vice chair of ASCE's Committee on Adaptation to a Changing Climate, member of the ASCE Committee on Sustainability, and chair of its Sustainable Infrastructure Education Subcommittee. He is a Distinguished Member of ASCE and member of the National Academy of Engineering. He is retired as director of the Building and Fire Research Laboratory of the National Institute of Standards and Technology and as Professor of Civil Engineering at the University of Illinois at Urbana-Champaign. He has been president of the International Council for Research and Innovation in Building and Construction (CIB); and president of the Liaison Committee of International Civil Engineering Organizations. He received bachelor's and master's

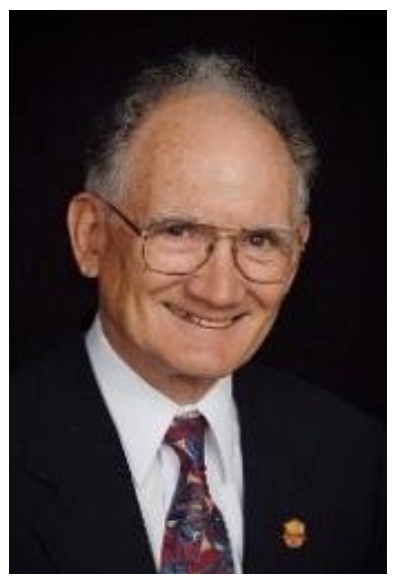
degrees from Syracuse University, and the Ph.D. from the University of Illinois at UrbanaChampaign, all in Civil Engineering. He has registered as a professional engineer in New York and a structural engineer in Illinois. 



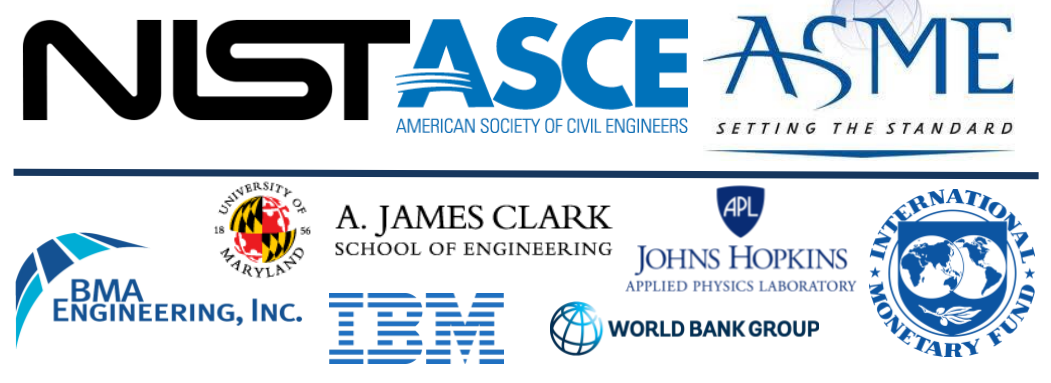

